\title{
Texture, Nonogram, and Convexity Priors in Binary Tomography
}

Author:

Judit SzÛ́CS
Supervisor:

Péter BALÁzS, Ph.D.

Doctoral School of Computer Science

Department of Image Processing and Computer Graphics

Faculty of Science and Informatics

University of Szeged, Hungary

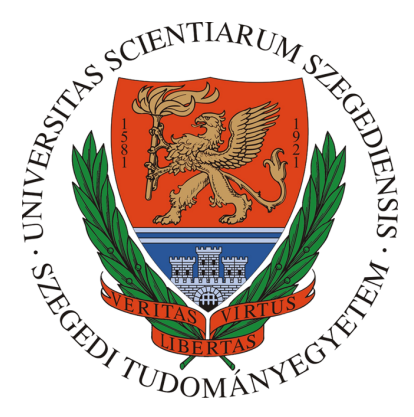

Szeged, 2021 



\section{Acknowledgements}

First of all, I would like to say a special thank you to my supervisor, Péter Balázs, who always supported me throughout the years of my PhD studies, even during hard times.

I would like to thank the following people for helping me in my research: Gábor Lékó, Péter Bodnár, László Varga, Rajmund Mokso, Sara Brunetti, Csaba Olasz, Gergely Pap, László Tóth, Laura Szakolczai, and Tamás Gémesi.

I would also like to thank Zsófia Beján-Gábriel for correcting this thesis from a linguistic point of view.

Last but not least, I would like to thank my family, especially my mother, my father, my grandmother, and my significant other for supporting me during my studies. Without their support, this PhD thesis would not have been possible.

Finally, I would like to thank the Doctoral School of Computer Science and the Department of Image Processing and Computer Graphics of the University of Szeged for providing me with a productive work environment.

This research presented in this thesis was supported by the following:

- NKFIH OTKA K112998 grant,

- ÚNKP-18-3 New National Excellence Program of the Ministry of Human Capacities,

- ÚNKP-19-3 New National Excellence Program of the Ministry for Innovation and Technology, Hungary,

- ÚNKP-20-4 New National Excellence Program of the Ministry for Innovation and Technology from the Source of the National Research, Development and Innovation Fund,

- The project "Integrated program for training new generation of scientists in the fields of computer science", no. EFOP-3.6.3-VEKOP16-2017-00002 (European Union and co-funded by the European Social Fund),

- Grant 20391-3/2018/FEKUSTRAT of the Ministry of Human Capacities, Hungary,

- Grant TUDFO/47138-1/2019-ITM of the Ministry for Innovation and Technology, Hungary.

Judit Szücs, January 2021. 



\section{Contents}

1.1 Problem Outline, Definitions . . . . . . . . . . . . . . . . 1

1.2 Reconstruction Algorithms . . . . . . . . . . . . . . . . . 4

1.2.1 Analytical Methods ... . . . . . . . . . . . 4

1.2.2 Algebraic Reconstruction Methods . . . . . . . . . . 5

Algebraic Reconstruction Technique . . . . . . . . 7

Simultaneous Iterative Reconstruction Technique . . . 7

Simultaneous Algebraic Reconstruction Technique . . . 8

1.3 Discrete Tomography . . . . . . . . . . . . . . . . . 8

1.3.1 Discrete Algebraic Reconstruction Technique . . . . . . 8

1.4 Binary Tomography . . . . . . . . . . . . . . . . . . . 10

1.4.1 Ryser's Algorithm . . . . . . . . . . . . . . . 10

1.4.2 Binary Reconstruction by Optimization . . . . . . . . 13

Simulated Annealing . . . . . . . . . . . . . 13

1.4.3 Quality Measurement in Binary Tomography . . . . . . 15

2 Binary Tomography with Local Binary Pattern Priors 17

2.1 Local Binary Patterns as Texture Descriptors . . . . . . . . . . 17

2.1.1 Local Binary Patterns (LBP) . . . . . . . . . . 18 
2.1.2 Fuzzy Local Binary Patterns (FLBP) . . . . . . . . . . . 18

2.1.3 Shift Local Binary Patterns (SLBP) . . . . . . . . . . . 20

2.1.4 Dominant Rotated Local Binary Patterns (DRLBP) . . . 21

2.2 Preliminary Studies . . . . . . . . . . . . . . . . . 21

2.3 Comparison of the LBP Variants . . . . . . . . . . . . . 27

2.4 Results . . . . . . . . . . . . . . . . . 28

2.4 .1 Experimental Setup . . . . . . . . . . . . . 28

2.4 .2 Synthetic Image Classes . . . . . . . . . . . . . 29

2.4.3 Software Phantom Images . . . . . . . . . . . . . . . . 33

2.4 .4 Real Images . . . . . . . . . . . . . . . . . . . . . . . 34

2.5 Conclusion . . . . . . . . . . . . . . . . . . . 39

3 Binary Tomography Based on Nonograms 4

3.1 Problem Outline . . . . . . . . . . . . . . . . . . . . . . . 41

3.2 Proposed Methods . . . . . . . . . . . . . . . . . . . 44

3.2.1 Constraint Satisfaction . . . . . . . . . . . . . . . . . 44

3.2.2 Variants of Simulated Annealing . . . . . . . . . . . . 45

The Basic Method . . . . . . . . . . . . . . . . . 45

Starting from a Precalculated Number of Object Pixels . $\quad 45$

Initialization with Ryser's Algorithm . . . . . . . . . . 46

SA with Curveball Algorithm . . . . . . . . . . . . . 46

3.3 Implementation Details . . . . . . . . . . . . . . . . . . . . 4 47

3.3.1 Deterministic Methods . . . . . . . . . . . . . 47

3.3.2 Stochastic Methods . . . . . . . . . . . . . . . 48

Local Update of the Strip Vectors . . . . . . . . . . . . . . . 48

3.4 Experimental Results . . . . . . . . . . . . . . . . . . . 4 49

3.4.1 Random Matrices of Different Densities . . . . . . . . 49

3.4 .2 Web Paint-by-Number . . . . . . . . . . 57

3.4 .3 TomoPhantom Images . . . . . . . . . . . . . 58

3.5 Conclusion . . . . . . . . . . . . . . 60

4 Global and Local Quadrant-Convexity 63

4.1 Global Quadrant-Convexity . . . . . . . . . . . . . . . . . . 64

4.1.1 Obtaining Enlacement Descriptors by Normalization . 66

4.1.2 Object Enlacement and Interlacement . . . . . . . . 68

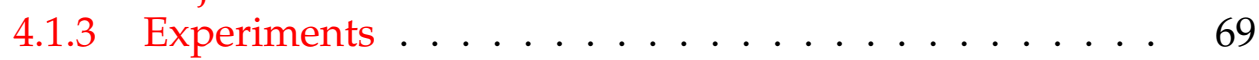

4.2 LQH for Image Classification . . . . . . . . . . . . . . . . . . . 72

4.2.1 Comparison of the LQH Variants . . . . . . . . . . 75

4.2.2 Experiment with the Retina Dataset . . . . . . . . . 79

4.2.3 Appropriate Window Size and Quantization Level . . . 84

4.3 LQH for Binary Image Reconstruction . . . . . . . . . . . . . . . . . 86

4.3 .1 Fast LQH Calculation . . . . . . . . . . . . . . 87

Dynamic Programming . . . . . . . . . . . . . . 87

Random Sampling . . . . . . . . . . . . . . . 90

Local Update . . . . . . . . . . . . . . . . . . . . . . . . 91

4.3 .2 Results ........................... 92 
4.4 Conclusions ........................... 95

5 Conclusions of the Thesis $\quad 97$

$\begin{array}{ll}\text { A Summary in English } & 99\end{array}$

A.1 Key Points of the Thesis . . . . . . . . . . . . . . 100

$\begin{array}{ll}\text { B Summary in Hungarian } & 103\end{array}$

B.1 Az eredmények tézisszerú összefoglalása . . . . . . . . . . . 104

$\begin{array}{ll}\text { C Publications of the Author } & 107\end{array}$

$\begin{array}{lr}\text { D Images } & 111\end{array}$

$\begin{array}{llr}\text { E Tables } & 125\end{array}$

Bibliography 



\section{List of Figures}

1.1 Sample images. . . . . . . . . . . . . . . . . 1

1.2 Parallel beam geometry. . . . . . . . . . . . . . . 2

1.3 A sample image and its projection $\left(\theta=20^{\circ}\right) \ldots \ldots \ldots \ldots$

1.4 Sample image (a) and its sinogram (b). . . . . . . . . . . 4

1.5 Sample for backprojection (a) and for filtered backprojection (b) of Fig. 1.4. . . . . . . . . . . . . . . . 5

1.6 Sample for binary image with parallel beams (a) and a projection value calculation $(\mathrm{b}) \ldots \ldots \ldots \ldots \ldots$. . . . . . . 6

1.7 Sample for ART (a), SIRT (b), and SART (c) reconstruction of

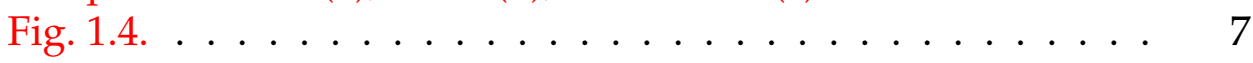

1.8 Sample for DART of Fig. 1.4. . . . . . . . . . . . . . . 9

1.9 Image representations with black and white pixels (a), with a lattice set (b), and with a binary matrix (c). . . . . . . . . 10

1.10 Example of switching component and elementary switching. . 12

1.11 Switching component graph. . . . . . . . . . . . . . 12

2.1 Different images with same horizontal and vertical projections. . . . . . . . . . . . . . . 17

2.2 Software phantom image classes. . . . . . . . . . . . . 22

2.3 Example of how the RME value changes by increasing the number of projections. . . . . . . . . . . . . . . . 26

2.4 Chessboard image (a) and its inversion (b) . . . . . . . . . 26

2.5 Sample SA results of the synthetic image classes. . . . . . . . 30

2.6 Sample result of Ryser's algorithm for Chessboard and Diagonal image classes. . . . . . . . . . . . . . . . . . . . . . 31

2.7 Frequency of occurrence of matrix $\mathbf{M}$ concerning increasing $\gamma$ weights for the Chessboard image class. . . . . . . . . . . .

2.8 Frequency of occurrence of matrix $\mathbf{M}^{\prime}$ concerning increasing $\gamma$ weights for the Diagonal image class. . . . . . . . . . . . . 32

2.9 Sample results of Fig. 2.2a. . . . . . . . . . . . . . . . . . 33

2.10 Real image classes I. [18]. . . . . . . . . . . . . . . . . . . 34

2.11 Sample results of Fig. 2.10c. . . . . . . . . . . . . . . . 36

2.12 Real image classes II. [35]. . . . . . . . . . . . . . . . . . 36

2.13 Sample results of Fig.2.12 . . . . . . . . . . . . . . 38

3.1 Instances of the BT (a, d, g), SCBT (b, e, h), and NonOGRAM (c, f, i) problems. Padding zero elements of the matrices LH and $\mathbf{L V}$ are not indicated. . . . . . . . . . . . . . 
3.2 Sample for uniqueness ( $c, f)$ and non-uniqueness $(a, d, b, e)$ of the SCBT problem. . . . . . . . . . . . . . . 44

3.3 Steps of the CurveballSA algorithm. . . . . . . . . . . . 46

3.4 Sample for a new strip appearing (a), two strips merging (b), and no change $(\mathrm{c}$ and $\mathrm{d}) . \ldots \ldots \ldots \ldots$

3.5 Images with $0 \%, 10 \%, \ldots, 100 \%$ randomly selected object pixels. . . . . . . . . . . . . . . . . . .

3.6 Mean pixel error (vertical axis) of the intlinprog (a) and the SA (b) methods for different image sizes (horizontal axis). . . . . .

3.7 Mean running time in seconds (vertical axis) of the intlinprog (a) BasicSA (b), FixpixelSA (c), RyserSA (d) and CurveballSA

(e) methods for different image sizes (horizontal axis). . . . . .

3.8 Mean final objective value (vertical axis) of the BasicSA (a), FixpixelSA (b), RyserSA (c) and CurveballSA (d) methods for different image sizes (horizontal axis). . . . . . . . . . . . .

3.9 Mean strip difference (vertical axis) of the BasicSA (a) and FixpixelSA (b) methods for different image sizes (horizontal axis).

3.10 Mean running time in seconds RyserSA (a) and CurveballSA (b) methods for different image sizes (horizontal axis). . . . . .

3.11 Mean final objective value (vertical axis) of the RyserSA (a) and CurveballSA (b) methods for different image sizes (horizontal axis). . . . . . . . . . . . . . . . .

3.12 Sample images from Web Paint-by-Number. . . . . . . . . . . . 57

3.13 TomoPhantom images taken from [94] . . . . . . . . . . . . .

3.14 Objective function values during the millions of iterations for Fig. 3.13a. . . . . . . . . . . . . . . 60

4.1 Non-Q-convex image. . . . . . . . . . . . . . . . . . 65

4.2 A $Q$-convex image (a) and a $Q$-concave image (b). . . . . . . . 66

4.3 Sample images with enlacement values. . . . . . . . . . . . . . 67

4.4 Enlacement landscapes of the last three images of Fig. 4.3 . . . 68

4.5 Sample images from [30], where $F$ and $G$ are represented by white and gray pixels, respectively. . . . . . . . . . . . .

4.6 Sample images from the CHASEDB1 (a) and DRIVE $(b)$ datasets. . . . . . . . . . . . . . . . . .

4.7 Retina images with moderate (above) and large (below) amounts of Speckle (a, d), Salt \& Pepper (b, e), and Gaussian (c, f) noise.

4.8 Samples from the HRF dataset. . . . . . . . . . . . . .

4.9 Precision-recall curves obtained for classifying healthy and diseased cases of the HRF images. . . . . . . . . . . . . . 72

4.10 Local $Q$-concavity histograms. . . . . . . . . . . . . . . . . 74

4.11 A globally non- $Q$-convex shape that is locally $Q$-convex in each window position (e.g. with window size $5 \times 5$ ). . . . . . . 74

4.12 TomoPhantom images taken from [94]. . . . . . . . . . . . 75

4.13 Software phantom image classes. . . . . . . . . . . . . . 77

4.14 Real image classes I.[18]. . . . . . . . . . . . . . . . . . 77

4.15 Sample image (a) and its contribution matrix (b). . . . . . . . . 81

4.16 Illustration of calculating DP1 part $(w=2) \ldots \ldots 87$ 
4.17 Illustration of calculating DP2 part $(w=2) \ldots \ldots \ldots$

4.18 Illustration of the dynamic programming process when calculating $\mathrm{LQH}$ values. . . . . . . . . . . . . . . . . . . 88

4.19 Sample for dynamic programming version. . . . . . . . . . . 89

4.20 Running time (in seconds) of the original and the DP approaches for different windows sizes of Fig. 4.14i. . . . . . . . . . . . .

4.21 Contents of the LQH bins for $q=10$ and window size $5 \times 5$ of Fig. 4.13c, with different amounts of pixels examined. . . . . .

4.22 Sample local update $(u=3, q=10) . \ldots \ldots \ldots$

4.23 Terms of the cost function (vertical axis) in the case of Fig. 4.13b, with image size $128 \times 128$, window size $7 \times 7, \xi=5000$, and $\gamma=0.6$ regarding the number of iterations (horizontal axis). .

4.24 Results of SA and Ryser's algorithm in the case of Fig. 4.13b for image size $128 \times 128$, window size $7 \times 7, \xi=5000$ and $\gamma=0.6$.

D.1 Synthetic image classes. . . . . . . . . . . . . . . . . 111

D.2 Software phantom image classes. . . . . . . . . . . . . . . 112

D.3 Real image classes I. [18]. . . . . . . . . . . . . . . . . . . 113

D.3 Real image classes I. [18]. . . . . . . . . . . . . . . . . 114

D.4 Real image classes II. [35]. . . . . . . . . . . . . . . . . . . . 115

D.5 Mean pixel error (vertical axis) of the intlinprog (a) and the SA (b) methods for different image sizes (horizontal axis). . . . . .

D.6 Mean running time in seconds (vertical axis) of the intlinprog (a) and BasicSA (b) methods for different image sizes (horizontal axis). . . . . . . . . . . . . . . . . .

D.6 Mean running time in seconds (vertical axis) of the FixpixelSA (c) and RyserSA (d) methods for different image sizes (horizontal axis). . . . . . . . . . . . . . . . . . .

D.6 Mean running time in seconds (vertical axis) of the CurveballSA (e) method for different image sizes (horizontal axis). .

D.7 Mean final objective value (vertical axis) of the BasicSA (a) and FixpixelSA (b) methods for different image sizes (horizontal

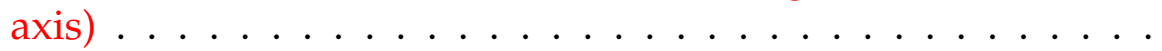

D.7 Mean final objective value (vertical axis) of the RyserSA (c) and CurveballSA (d) methods for different image sizes (horizontal axis) . . . . . . . . . . . . . . . .

D.8 Mean strip difference (vertical axis) of the BasicSA (a) and FixpixelSA (b) methods for different image sizes (horizontal axis). 122

D.9 Mean running time in seconds RyserSA (a) and CurveballSA (b) methods for different image sizes (horizontal axis). . . . . . 123

D.10 Mean final objective value (vertical axis) of the RyserSA (a) and CurveballSA (b) methods for different image sizes (horizontal axis). . . . . . . . . . . . . . . . 



\section{List of Tables}

2.1 RME values for the test images of Class 1 (Fig. 2.2a). . . . . . . 24

2.2 RME values for the test images of Class 2 (Fig. 2.2b). . . . . . . 24

2.3 RME values for the test images of Class 3 (Fig. 2.2c). . . . . . . 24

2.4 RME values for the test images of Class 4 (Fig. 2.2d). . . . . . . 25

2.5 RME values for the test images of Class 5 (Fig. 2.2e). . . . . . . 25

2.6 RME values for the test images of Class 6 (Fig. 2.2f). . . . . . . 25

2.7 Histogram values of matrices for different LBP variants. . . . . 27

2.8 Running times of different LBP variants in seconds. . . . . . . 27

2.9 Mean results of SA of the synthetic image classes for different $\gamma$ weights. . . . . . . . . . . . . . . 29

2.10 Mean results of SA of the software phantom image classes (Fig. 2.2) for different $\gamma$ weights. . . . . . . . . . . . . . . 34

2.11 Mean results of SA of Fig. 2.10 for different $\gamma$ weights. . . . . . 35

2.12 Numerical results of Fig. 2.11. . . . . . . . . . . . . . . . 36

2.13 Mean results of SA of Fig. 2.12 for different $\gamma$ weights. . . . . . 37

2.14 Numerical results of Fig. 2.13. . . . . . . . . . . . 39

3.1 Number of switching components for different matrix densities of size $n \times n \ldots \ldots \ldots \ldots \ldots \ldots$

3.2 Number of switching components (in percentages) preserving the number of horizontal (HSC) and vertical (VSC) as well as both horizontal and vertical (HVSC) strips for different matrix densities of size $n \times n$. . . . . . . . . . . . 51

3.3 Results of Web Paint-by-Number images. . . . . . . . . . . . . . . 58

3.4 Results of TomoPhantom images. . . . . . . . . . . . . . 59

4.1 Interlacement values of Fig. 4.5 . . . . . . . . . . . . 69

4.2 5NN classification accuracy (in percentage) of CHASEDB1 and DRIVE images for different types and levels of noise. . . . . . 71

4.3 Statistics of Euclidean distances for images of Fig. 4.12. . . . . 76

4.4 Statistics of mean interclass Euclidean distances for the two datasets. ........................... 78

4.5 Intraclass deviation of image classes of Fig. 4.13. . . . . . . . . 78

4.6 Intraclass deviation of image classes of Fig. 4.14. . . . . . . . . 79

4.7 Classification accuracy of retina images for $q=2$, in percentage. 82

4.8 Classification accuracy of retina images for $q=10$, in percentage. 83

4.9 PW values for Fig. 4.13 with different quantization levels (horizontal) and window sizes (vertical). . . . . . . . . . 85 
4.10 PW values for Fig. 4.14 with different quantization levels (horizontal) and window sizes (vertical). . . . . . . . . . . . . 85

4.11 Initial and final values corresponding to Fig. 4.23. . . . . . . 94

4.12 Sample SA results of Fig. 4.13. . . . . . . . . . . . . . . 95

4.13 Sample SA results of Fig. 4.14 . . . . . . . . . . . . . . . 95

A.1 Overview of thesis points in relation to the author's publications.101

B.1 A tézispontok és a szerző publikációinak kapcsolata. . . . . . . 105

E.1 Mean interclass Euclidean distances of image classes of Fig. 4.13.126

E.2 Mean interclass Euclidean distances of image classes of Fig. 4.14.127

E.2 Mean interclass Euclidean distances of image classes of Fig. 4.14.128 


\section{List of Abbreviations}
ARM Algebraic Reconstruction Method
ART Algebraic Reconstruction Technique
BT Binary Tomography
CT Computerized Tomography
DART Discrete Algebraic Reconstruction Technique
DP Dynamic Programming
DRLBP Dominant Rotated Local Binary Patterns
DT Discrete Tomography
FBP Filtered Backprojection
FLBP Fuzzy Local Binary Patterns
LBP Local Binary Patterns
LQH Local $Q$-concavity Histogram
RME Relative Mean Error
SA Simulated Annealing
SART Simultaneous Algebraic Reconstruction Technique
SCBT Strip Constrained Binary Tomography
SD Standard Deviation
SIRT Simultaneous Iterative Reconstruction Technique
SLBP Shift Local Binary Patterns
S\&P Salt \& Pepper noise 



\section{List of Symbols}

$m \times n$
$\mathbf{x} \in\{0,1\}^{m n}$
$\mathbf{X} \in\{0,1\}^{m \times n}$
$\mathbf{A} \in \mathbb{R}^{k \times m n}$
$a_{i j}$
$\mathbf{b} \in \mathbb{R}^{k}$
$H \in \mathbb{Z}^{m}$
$V \in \mathbb{Z}^{n}$
$C(\mathbf{X})$
$\|\mathbf{A x}-\mathbf{b}\|_{2}$
$\Phi(\mathbf{X}):\{0,1\}^{m n} \rightarrow \mathbb{R}$
$\gamma \geq 0$
$\mathbf{L H} \in \mathbb{Z}^{m \times n}$
$\mathbf{L V} \in \mathbb{Z}^{n \times m}$
$S H \in \mathbb{Z}^{m}$
$S V \in \mathbb{Z}^{n}$
$E_{p}$
$E_{\text {proj }}$
$E_{\text {strip }}$
$q$

size of the image

the unknown image of size $m \times n$ (in a row-by-row vector form)

the unknown image of size $m \times n$ (represented by a matrix)

matrix that describes the relationship between the $k$ different beams and the pixels

weight that represents how the $i^{\text {th }}$ beam affects the $j^{\text {th }}$ pixel

measured projection values

horizontal projections of the image

vertical projections of the image

cost function of the minimization problem

data fitting term (in the cost function)

regularization function

scaling constant

matrix that describes the length of each strip in the rows of the observed matrix

matrix that describes the length of each strip in the columns of the observed matrix

vector that contains the number of strips of the rows of the observed matrix

vector that contains the number of strips of the columns of the observed matrix

pixel error (defined in Eq. 2.18)

projection difference (defined in Eq. 2.17)

strip difference (defined in Eq. 3.9)

the number of quantization levels 



\section{Chapter 1}

\section{Preliminaries}

\subsection{Problem Outline, Definitions}

Computerized Tomography (CT) is an important imaging technique that is suitable for non-invasive visualisation of the interior of an object. It is widely used in many applications, for example, crystallography, materials science, medical science, the food industry, industrial non-destructive testing, etc. A few sample CT images are cited in Fig. 1.1.

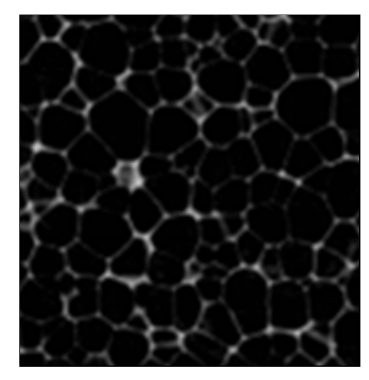

(a) Polyurethane foam [91].

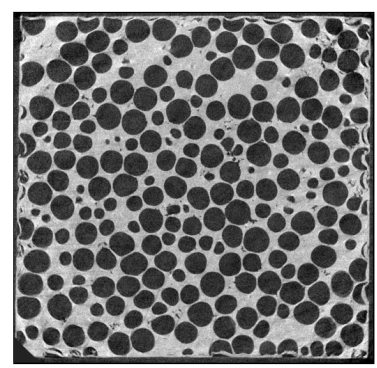

(d) Aluminium foam [4].

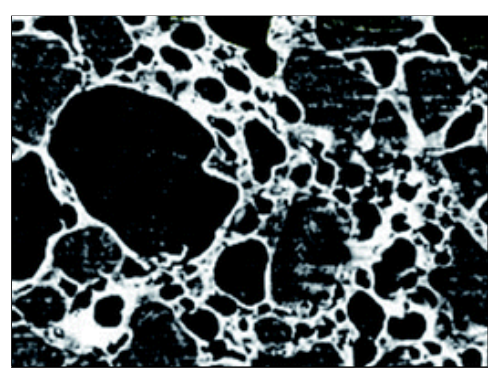

(b) Ice cream [42].

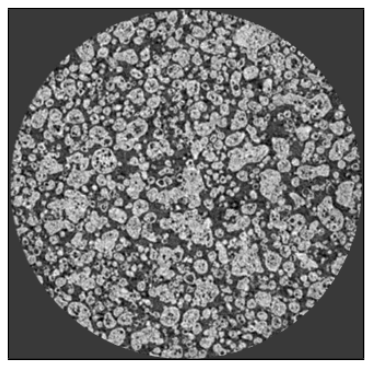

(e) Skim milk powder [28].

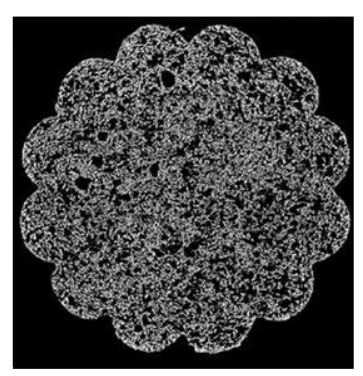

(c) Biscuit [102].

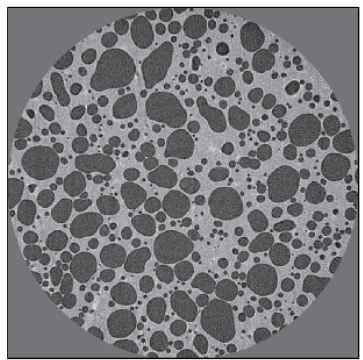

(f) Bread dough [5].

Figure 1.1: Sample images.

The basic aim of tomography is to reconstruct the description (or the model) of the source object from its slices. Slices are 2D cross-sectional images that are sectioned from the 3D object by a 2D plane. In mathematics, the density of the material of a $2 \mathrm{D}$ slice at a given $(x, y)$ point can be defined with a two-variable function $f(x, y)$. Due to the non-destructive restrictions, slices cannot be accessed directly, only secondary information is available about them. This information is usually the sum of the material densities in a given $2 \mathrm{D}$ slice along certain directions. Thus, instead of the function $f(x, y)$, only its 
integrals taken along given directions are known. The goal of the reconstruction is to produce the function $f(x, y)$ from its line integrals taken from given directions. The main properties of digital images are that their range and domain are both bounded and discrete, i.e. the values of $(x, y)$ and $f(x, y)$ are discrete.

In this study, we work with transmission tomography, meaning the radiation comes from outside of the examined object. During an experiment, the object to be examined stands between the source of the X-ray and the detectors, which measure the exiting intensity of radiation (Fig. 1.2). What actually appears on the detectors is the cast shadow of the object in X-rays.

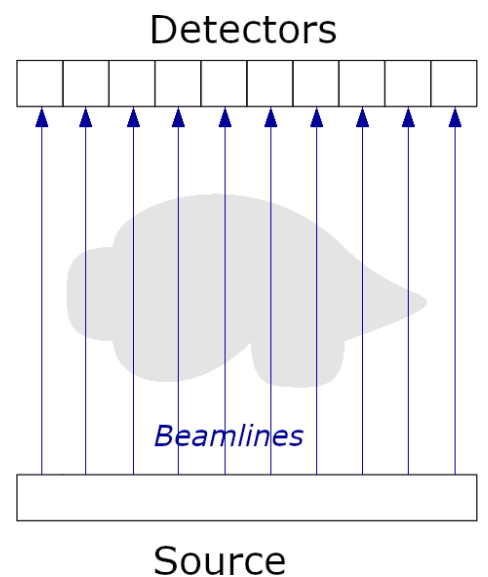

Figure 1.2: Parallel beam geometry.

When an X-ray beam passes through an object, its intensity decreases due to physical mechanisms, i.e. a part of it is absorbed, which is represented by the so-called linear absorption coefficient. Passing through different materials, the degree of absorption is different and is always specific to the given material. Based on the Beer-Lambert law known from physics, the measured exiting intensity $I$ can be calculated in the case of objects made of homogeneous material, by

$$
I=I_{0} \cdot e^{-\mu \Delta x}
$$

where $I_{0}$ is the starting intensity of the X-ray, $\Delta x$ is the thickness of the object and $\mu$ is the linear absorption coefficient of the object which the beam passes through. If there are several materials with different $\mu_{1}, \mu_{2}, \ldots, \mu_{n}$ absorption coefficients but the same $\Delta x$ thickness, Eq. 1.1 becomes

$$
I=I_{0} \cdot e^{-\sum_{i=1}^{n} \mu_{i} \Delta x}
$$

If $\Delta x$ decreases and an approximation of the continuous model is needed, then

$$
I=I_{0} \cdot e^{-\int_{0}^{d} \mu(x) d x},
$$

where $d$ is the distance between the source and the detector, $x$ is the distance of the given beam from the source, and $\mu(x)$ is the absorption coefficient in $x$. 
Log-normalization of Eq. 1.3 provides the projection of the given X-ray,

$$
-\ln \frac{I}{I_{0}}=\int_{0}^{d} \mu(x) d x .
$$

There are different projection geometries. In this thesis, we apply parallelbeam setting (Fig. 1.2).

Let $f(x, y)$ denote the absorption coefficient of the examined object in $(x, y) ; t$ and $s$ the axes of the coordinate-system obtained by rotating $x$ and $y$ axes by $\theta$; and $p(t, \theta)$ the line integral parallel to $s$ of $f(x, y)$, taken at a distance from $s$ to $t$. If $\theta$ is fixed, $p(t, \theta)$ values produce a function of $t$, which is called the projection of $f(x, y)$ of angle $\theta$. For all $\theta, p(t, \theta)$ is the Radon transform of $f(x, y)$ :

$$
[R f](t, \theta)=\int_{-\infty}^{\infty} f(t \cos \theta-s \sin \theta, t \sin \theta+s \cos \theta) d u .
$$

Figure 1.3 represents a two-variable function and its $p(t, 20)$ projection $\left(\theta=20^{\circ}\right)$.

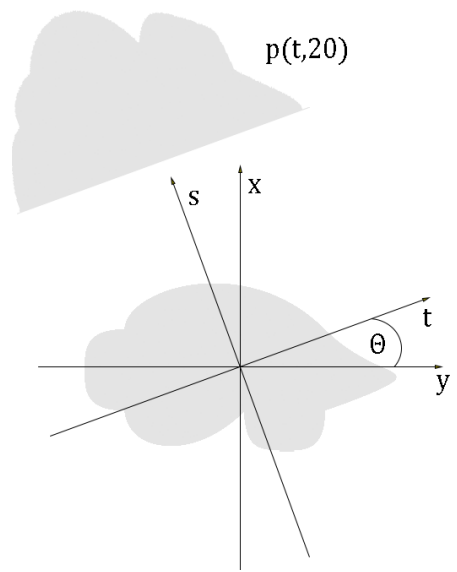

Figure 1.3: A sample image and its projection $\left(\theta=20^{\circ}\right)$.

In the case of transmission tomography and parallel-beam geometry, projection of any angle $\theta$ equals to $180^{\circ}+\theta$, therefore, examining projections between $0^{\circ}$ and $180^{\circ}$ is sufficient. A sinogram is a representation of $2 \mathrm{D}$ projections in a $2 \mathrm{D}$ coordinate system, where the projections can be placed one after other by ascending $\theta$ values on the vertical axis, and the grayscale values of the projections are plotted on the other axis. The size of the sinogram depends on the sampling density of the projections. Figure 1.4a represents a test image sized $256 \times 256$, and Fig. $1.4 \mathrm{~b}$ is its sinogram $\left(\theta=1^{\circ}, \ldots, 180^{\circ}\right)$. The projection angles are plotted on the horizontal axis, the distances on the vertical one. The image can be covered completely by $\lceil\sqrt{2} \cdot 256\rceil=362$ pieces of unit distance beamlines, i.e. the size of the sinogram is $362 \times 180$. 


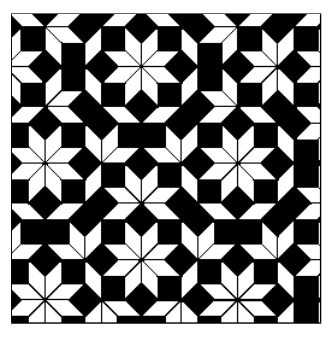

(a)

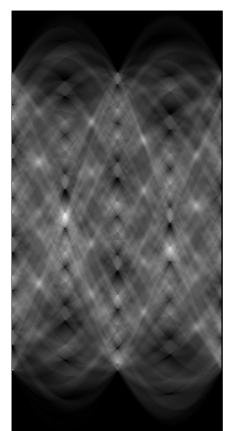

(b)

Figure 1.4: Sample image (a) and its sinogram (b).

The basic goal of image reconstruction is to create the original function, or its best approximation from the projections, i.e. to reconstruct an image from its sinogram.

\subsection{Reconstruction Algorithms}

The image to be reconstructed can be created with the help of several techniques; in this section, the most common ones are presented.

\subsubsection{Analytical Methods}

Analytical (or transformation-based) methods are used when only the projections are available without any prior knowledge. It is assumed that for each beamline, the pixels corresponding to the beam have the same role in creating the projection. The simplest method (which also forms the basis of the most commonly used reconstruction procedures) is called backprojection [48], as follows. First, each projection value is evenly backprojected from the appropriate direction. Then, the corresponding projected values for each pixel are summed. The result is called laminogram. The following observation can be made.

Theorem 1.1 (Fourier slice theorem) The 1D Fourier transform of a projection function corresponds to a line of the 2D Fourier transform of the original image, such that the line is parallel to the projection direction and passes through the origin of the Fourier transform.

As a consequence of the above theorem, the Radon transform uniquely determines the original image itself, and therefore, at least mathematically, the reconstruction problem is well-defined. However, in practice only the sinogram (i.e. a finite sampling of the Radon-transform) is accessible, which can turn the problem to be ill-posed. Nevertheless, the Fourier slice theorem directly provides a simple reconstruction technique called Fourier reconstruction method as follows. The 1D Fourier transforms of the projections define a line from the 2D Fourier transform of the function. If we take all projections between angles 0 and $\pi$, we can get all the points of the 2D Fourier transform 
of the original function. Finally, applying a 2D inverse Fourier transform, the original function can be obtained.

While Fourier reconstruction works well in theory, unfortunately some issues arise in practice (e.g. computational cost, discretization, interpolation, approximation errors, etc). Therefore, filtering can be used, i.e. in frequency space, the original projections are multiplied with an $\omega$ function and the inverse Fourier transform of their product are backprojected. This method is called filtered backprojection (FBP). Visually, according to the Fourier slice theorem, the 2D Fourier transform of the function $f(x, y)$ is obtained by fitting together the 1D Fourier transforms. Ideally, these 1D Fourier transforms would fill the entire frequency space if they were 'cake-shaped'. However, they are infinitely thin strip-shaped. Consequently, summarizing them causes the middle of the Fourier space (homogeneous regions) to be overrepresented, while the outer regions (edges) remain underrepresented. Therefore, a simple backprojection results in a blurred image. The essence of filtering is the mathematical reversal of image blurring. Hence, applying a suitable filter (e.g. Ram-Lak, Shepp-Logan, Cosine, Hamming, Hann, etc.) can result in an accurate representation of the examined object. According to the convolution theorem, the multiplication performed in the frequency space corresponds with the convolution performed in the image space. Therefore, technically speaking, filtering is usually the convolution of projection data with a suitable mask.

In Fig. 1.5a, a sample laminogram is shown for backprojecting the sinogram of Fig. 1.4, while in Fig. 1.5b, the FBP result with a Shepp-Logan mask is shown for the same sinogram. The difference is clearly visible, the result of the FBP is much more accurate in Fig. 1.5b than its counterpart.

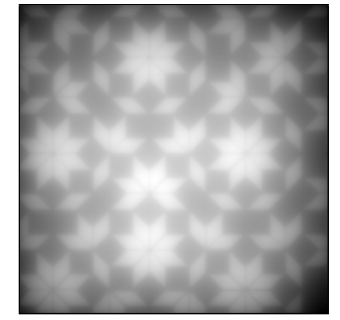

(a)

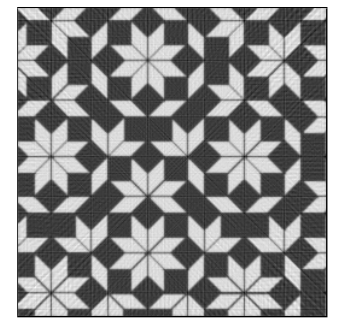

(b)

Figure 1.5: Sample for backprojection (a) and for filtered backprojection (b) of Fig. 1.4.

Analytical methods are fast and accurate, and therefore widely used in medical CT-scanners. However, they need several hundreds of equiangularly positioned projections to achieve reasonable image quality, meaning they are almost always useless when only few projections are available.

\subsubsection{Algebraic Reconstruction Methods}

The basis of algebraic reconstruction methods is that the reconstruction problem can be traced back to the problem of solving a system of equations. The 
values of $f(x, y)$ can be represented not only as a function but also as a matrix, since the intensity value is constant on a given pixel. The elements of the matrix (i.e. the pixels) represent the absorption coefficients of a given part of the object. Algebraic reconstruction methods describe the relationship between projections and pixels using equations, for an image size of $m \times n$ and $k$ piece of projection lines as follows:

- $\mathbf{x}=\left(x_{1}, x_{2}, \ldots, x_{m n}\right)$ denotes the unknown pixel values in vector form,

- $a_{i j}$ is the weight representing how the $i^{\text {th }}$ beam affects the $j^{\text {th }}$ pixel,

- $b_{1}, b_{2}, \ldots, b_{k}$ are the projection values measured along the beams.

In accordance with the above mentioned, the equation system becomes

$$
\begin{aligned}
a_{11} x_{1}+a_{12} x_{2}+a_{13} x_{3}+\cdots+a_{1 m n} x_{m n} & =b_{1} \\
a_{21} x_{1}+a_{22} x_{2}+a_{23} x_{3}+\cdots+a_{2 m n} x_{m n} & =b_{2} \\
\vdots & \\
a_{k 1} x_{1}+a_{k 2} x_{2}+a_{k 3} x_{3}+\cdots+a_{k m n} x_{m n} & =b_{k} .
\end{aligned}
$$

In shorter form:

$$
\mathbf{A x}=\mathbf{b},
$$

where the matrix $\mathbf{A} \in \mathbb{R}^{k \times m n}$ describes the relationship between the $k$ beams and the pixels $\left(a_{i j}\right.$ provides the length of the line segment of the $i^{\text {th }}$ projection ray in the $j^{\text {th }}$ pixel), while vector $\mathbf{b} \in \mathbb{R}^{k}$ contains the measured projection values, and $\mathbf{x} \in\{0,1\}^{m n}$ represents the unknown image of size $m \times n$, in a row-by-row vector form.

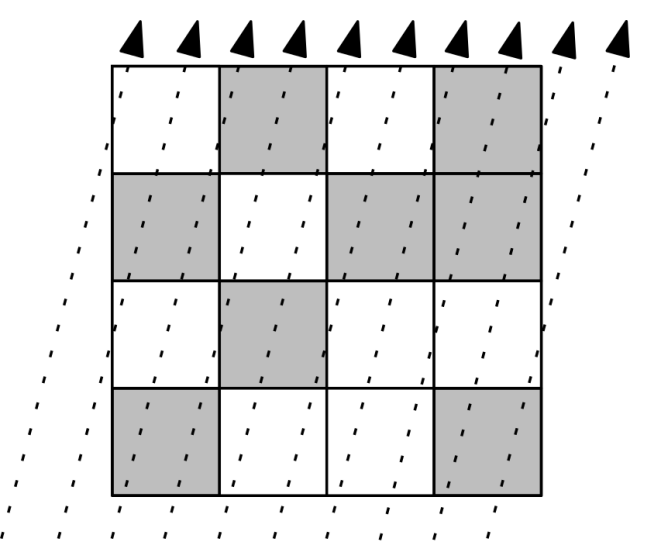

(a)

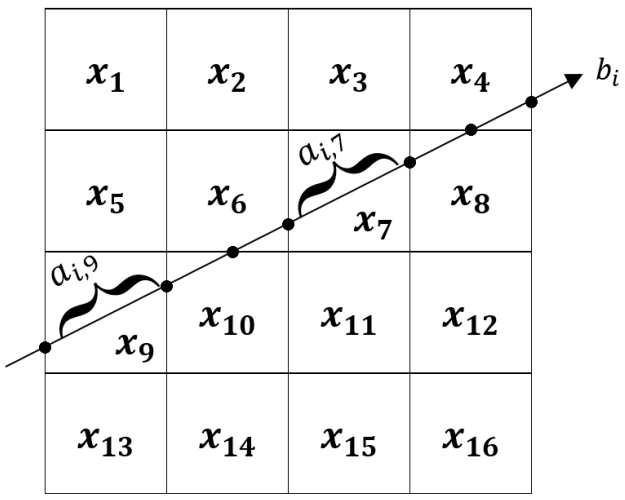

(b)

Figure 1.6: Sample for binary image with parallel beams (a) and a projection value calculation (b).

Figure 1.6a shows a binary image with parallel beams passing through it, while Fig. $1.6 \mathrm{~b}$ provides an example of a projection value calculation. The $i^{\text {th }}$ projection value $b_{i}$ is given by

$$
b_{i}=a_{i, 4} \cdot x_{4}+a_{i, 6} \cdot x_{6}+a_{i, 7} \cdot x_{7}+a_{i, 8} \cdot x_{8}+a_{i, 9} \cdot x_{9}+a_{i, 10} \cdot x_{10} .
$$


In theory, these types of equation systems can easily be solved by matrix algebraic methods. However, due to physical limitations in practice (e.g. scanner constraints, noisy projections, etc.) usually only an approximate solution is found. The difference of these methods lies in the diversity of the approximation method.

Remark 1.1 In the following, we will use $\mathbf{x}$, when we want to emphasize the vector representation of the image, otherwise we denote the image by $\mathbf{X}$.

\section{Algebraic Reconstruction Technique}

The basic iterative process is the Algebraic Reconstruction Technique - ART, or Kaczmarz's method [39]. It interprets the equation system 1.6 such that all equations describe a hyperplane in $k$-dimensional space. If the system of equations has a solution, the method converges - in a finite or infinite step to a solution $x^{*}$ that satisfies the equations of all hyperplanes. In one step of the iteration, the measured error is backprojected to the pixels affected by the given line along each projection line in the current image. It begins from an arbitrarily selected starting point and during each iteration, a perpendicular step is taken to another hyperplane. After there is no hyperplane for which the procedure has not been performed, it jumps to the next iteration. The speed of convergence depends on the angle enclosed by the hyperplanes, which is slow at small angles. In the case of an underdetermined system of equations, the procedure converges to the solution closest to the starting point. Therefore, correctly choosing the initial point and the next step is crucial. If the projections are too noisy, then the method may cycle around the intersections of the hyperplanes.

\section{Simultaneous Iterative Reconstruction Technique}

Simultaneous Iterative Reconstruction Technique (SIRT) is a least-squaresbased method for solving linear systems of equations with a positive definite matrix. It starts from the basic idea of ART, but backprojects the error of the system of equations on the variables in one iteration at the same time. SIRT usually converges slower than ART, but results in a smoother image.

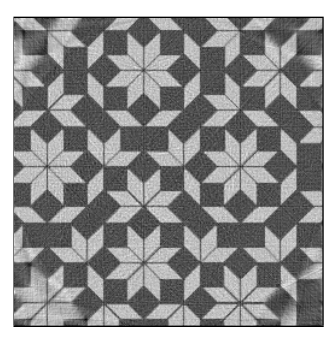

(a)

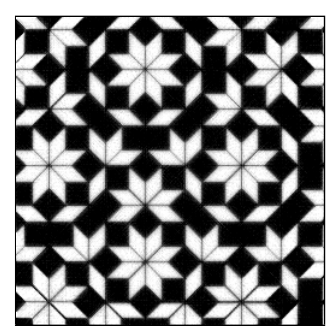

(b)

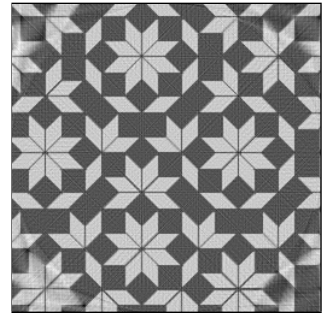

(c)

Figure 1.7: Sample for ART (a), SIRT (b), and SART (c) reconstruction of Fig. 1.4. 


\section{Simultaneous Algebraic Reconstruction Technique}

Simultaneous Algebraic Reconstruction Technique (SART) combines the features of basic ART and SIRT to provide a fast and high-quality image reconstruction algorithm [48]. The most important ideas of SART are the following. In order to eliminate errors arising from discretization, backprojection is performed not on a pixel basis, but by so-called bilinear interpolation, which is closer to continuous image representation. The backprojection of the errors is performed simultaneously, averaging on all beams belonging to the given direction - but not on all projection beams - by a Hamming window.

In Fig. 1.7, an example is shown for the results of ART (1.7a), SIRT (1.7b), and SART (1.7c) algorithms of Fig. 1.4 using the ASTRA Toolbox $[92,93]$.

Algebraic reconstruction techniques are more flexible than the analytical methods, so they can provide acceptable reconstructions, for instance, even when the projections are not equiangularly spaced. However, with few iterations or few projections, the quality of the reconstruction can be poor. Moreover, due to their iterative nature, they are slower than the analytical methods.

\subsection{Discrete Tomography}

Continuous reconstruction techniques (e.g. FBP or ART) usually require hundreds of projections to reach a good quality reconstruction. Conventional CT equipment can provide the sufficient number of projections, yet in some applications, it is not possible to create a large number of projections. Sometimes the test material is significantly damaged by the radiation when the projections are created, and obtaining several projections can be time-consuming and expensive as well. In some cases, one can assume that the object to be reconstructed consists of just a few known materials, i.e. only a few different grayscale intensity values that are known in advance can appear in the image representing the object. Such prior knowledge is available in a wide range of tomography applications: when performing X-ray tomography of industrial objects, the compositions in these objects (e.g. aluminium, plastic, air) are often known in advance [71, 75].

Discrete Tomography (DT) [43, 44, 45] is concerned with exactly such issues, aiming to make use of the above mentioned prior information. Thus, fewer projections could potentially be enough for a satisfactory reconstruction. Usually, the main focus in DT is on images for which the domain is a discrete set.

\subsubsection{Discrete Algebraic Reconstruction Technique}

Discrete Algebraic Reconstruction Technique (DART) [12] is based on the ART method, taking advantage of the properties of the discrete images: the 
range of the image function is finite and contains just a small number of elements. Its fundamental principle is that thresholding the result of an arbitrary continuous reconstruction method usually produces an approximately satisfactory result, even for discrete problems, except for some inaccuracies at the boundary of the object in the image. Therefore, after performing a continuous reconstruction and thresholding it, DART iteratively refines the boundary. The main steps of the method are as follows:

1. The initial reconstruction is performed with an arbitrary algebraic method (ARM - Algebraic Reconstruction Method).

2. The actual image $\left(\mathbf{x}_{a c t}\right)$ is thresholded in accordance with the known discrete values. Let $\mathbf{x}^{\prime}$ denote the actual discrete image.

3. Let $S$ denote the set of pixels of $\mathbf{x}^{\prime}$ that do not belong to the boundary.

4. A continuous image $\mathbf{x}^{\prime \prime}$ is created per the following. If the given pixel belongs to set $S$, then its value becomes the thresholded value, otherwise it is assigned the value of $\mathbf{x}_{a c t}$.

5. ART iteration is performed on image $\mathbf{x}^{\prime \prime}$, fixing the points belonging to set $S$.

6. $\mathbf{x}^{\prime \prime}$ is created by smoothing the boundary points.

7. If the stopping criterion is met, the method terminates after a final threshold. Otherwise, go to step 2 as $\mathbf{x}_{a c t}=\mathbf{x}^{\prime \prime}$.

The algorithm has several important parameters:

- which ARM is to be used,

- the number of iterations of the ARM,

- the number of inner iterations (when the boundary is searched),

- threshold parameter.

In Fig. 1.8, an example is shown for the DART algorithm, where the start image is the result of the SIRT algorithm (Fig. 1.7b), setting the number of ARM iterations to 10 and the number of inner iterations to 500, assuming a binary image.

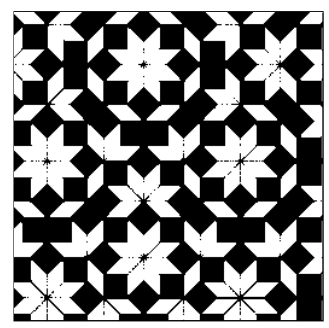

(a) Threshold image

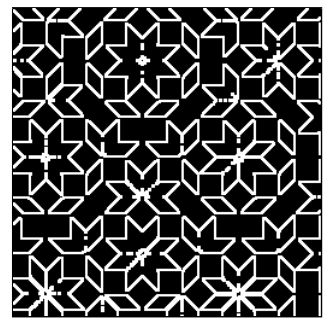

(b) Boundary of the image

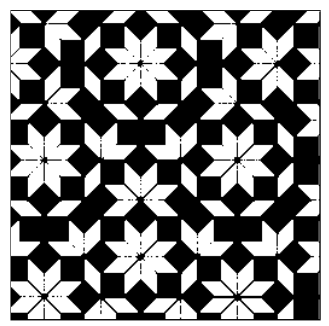

(c) Final result image

Figure 1.8: Sample for DART of Fig. 1.4. 
Due to the fact that it uses prior information about the image to be reconstructed, DART is effective if the number of gray levels is small (five or fewer), and it can also treat noisy projections.

\subsection{Binary Tomography}

Binary Tomography (BT) is a special case of DT, which can be utilized when the object to be reconstructed consists of a single material, yielding a corresponding image containing only $0 \mathrm{~s}$ and $1 \mathrm{~s}$ (representing the absence and presence of the material, respectively), where 1 stands for the object (black) pixels, and 0 for the background (white) pixels. The image can be represented in different ways: with black and white pixels (Fig. 1.9a), with a lattice set (a finite subset of $\mathbb{Z}^{2}$ ) (Fig. 1.9b), or with a binary matrix (Fig. 1.9c). Usually, the representation technique is chosen by convenience.

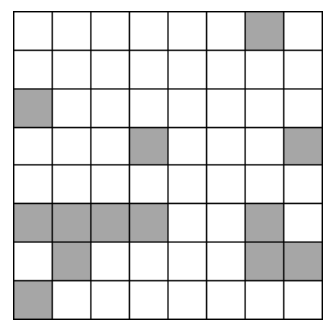

(a)

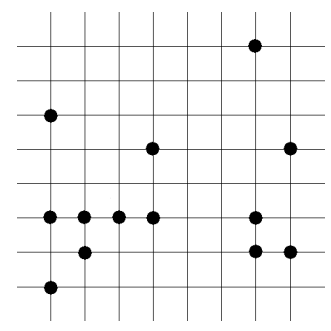

(b)

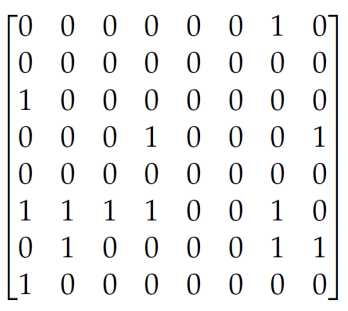

(c)

Figure 1.9: Image representations with black and white pixels (a), with a lattice set (b), and with a binary matrix (c).

Definition 1.1 The horizontal and vertical projections (also row and column sums) of the binary matrix $\mathbf{X}$ of size $m \times n$ are defined by the vectors $H(\mathbf{X})=\left(h_{1}, \ldots, h_{m}\right)$ and $V(\mathbf{X})=\left(v_{1}, \ldots, v_{n}\right)$, where

$$
h_{i}=\sum_{j=1}^{n} x_{i j} \quad(i=1, \ldots, m),
$$

and

$$
v_{j}=\sum_{i=1}^{m} x_{i j} \quad(j=1, \ldots, n) .
$$

The Binary Tomography problem can be defined as follows.

Problem. BINARY TOMOGRAPHY (BT)

Input: Two non-negative integer vectors $H \in \mathbb{Z}^{m}$ and $V \in \mathbb{Z}^{n}$.

Output: A binary matrix of size $m \times n$, if it exists, with row sum vector $H$ and column sum vector $V$.

\subsubsection{Ryser's Algorithm}

One of the earliest methods for solving a binary reconstruction problem is Ryser's algorithm [74], which creates a binary matrix based on the horizontal 
and the vertical projections of the source image. There are some necessary conditions that naturally have to be fulfilled $\left(H \in \mathbb{Z}^{m}, V \in \mathbb{Z}^{n}\right)$ :

$$
\begin{aligned}
& \sum_{i=1}^{m} h_{i}=\sum_{j=1}^{n} v_{j}, \\
& h_{i} \leq n(i=1, \ldots, m), \\
& v_{j} \leq m(j=1, \ldots, n) .
\end{aligned}
$$

Let $\mathbf{X}^{*} \in\{0,1\}^{m \times n}$ be the so-called canonical matrix, where

$$
x_{i j}^{*}=\left\{\begin{array}{ll}
1 & \text { if } j \leq h_{i} \\
0 & \text { if } j>h_{i}
\end{array} .\right.
$$

The steps of the algorithm are the following.

1. Let $\pi$ be a permutation that provides re-ordering for the elements of $V$ in a non-increasing way $\left(V^{\prime}=\left[v_{1}^{\prime} \geq v_{2}^{\prime} \geq \cdots \geq v_{n}^{\prime}\right]\right)$.

2. Create the corresponding $\mathbf{X}^{*}$ canonical matrix filled with 1 s from left to right, based on the row sums of $H$.

3. Let $V^{*}=V\left(\mathbf{X}^{*}\right)$.

4. For every $k=n, \ldots, 2$ :

- Let $\mathbf{B}$ be a submatrix of $\mathbf{X}^{*}$ containing the first $(k-1)$ columns of $\mathbf{X}^{*}$.

- If $v_{k}^{*}<v_{k}^{\prime}$ then shift $v_{k}^{\prime}-v_{k}^{*}$ pieces of 1 s from the $l^{\text {th }}$ column of $\mathbf{B}$ to the $k^{\text {th }}$ column in rows where there is 1 in the $l^{\text {th }}$ column and 0 in the $k^{\text {th }}$ column. Rightmost ones are shifted first.

- If there are multiple possibilities, then 1 s of the topmost rows are shifted.

- If there are less than $v_{k}^{\prime}-v_{k}^{*}$ number of $1 \mathrm{~s}$ in the $l^{\text {th }}$ column, then the remaining ones are shifted from columns $(l-1),(l-2)$, etc.

5. The columns of the reconstructed matrix are re-ordered using $\pi^{-1}$.

This algorithm runs in polynomial time, but usually does not result in a uniquely determined solution [74].

Definition 1.2 A switching component in a binary matrix $\mathbf{X} \in\{0,1\}^{m \times n}$ is a set of four positions $(i, j),\left(i^{\prime}, j\right),\left(i, j^{\prime}\right),\left(i^{\prime}, j^{\prime}\right)\left(1 \leq i, i^{\prime} \leq m, 1 \leq j, j^{\prime} \leq n\right)$, such that $x_{i j}=x_{i^{\prime} j^{\prime}}$ and $x_{i^{\prime} j}=x_{i j^{\prime}}=1-x_{i j}$.

In other words, the submatrices $\left(\begin{array}{ll}1 & 0 \\ 0 & 1\end{array}\right)$ and $\left(\begin{array}{ll}0 & 1 \\ 1 & 0\end{array}\right)$ of a binary matrix form a switching component.

Definition 1.3 An elementary switching is when the 1s of a switching component are changed to 0 s, and the 0 s to 1 s. 

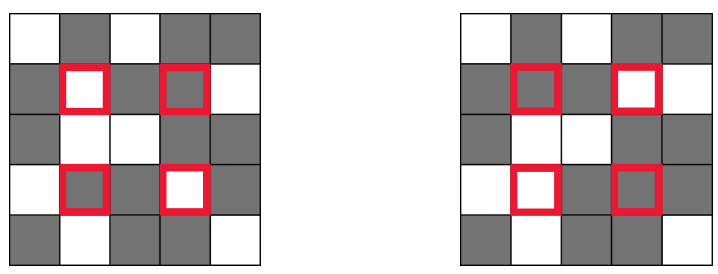

Figure 1.10: Example of switching component and elementary switching.

Fig. 1.10 provides an example of a switching component and an elementary switching (marked with red). Clearly, this operation does not affect the row and column sums. In his seminal work [74], Ryser made the following propositions.

Proposition 1.1 Binary Tomography problem can be solved in $\mathcal{O}(m n+n \cdot \log n)$ time.

Proposition 1.2 The presence of switching components is a sufficient and necessary condition for non-uniqueness of the solution. A binary matrix is unique in its given horizontal and vertical projections if and only if it does not contain any switching components.

Proposition 1.3 The application of elementary switching moves a solution into another solution.

Proposition 1.4 All the solutions of the same problem can be accessed from an arbitrary initial solution by applying a sequence of elementary switchings.

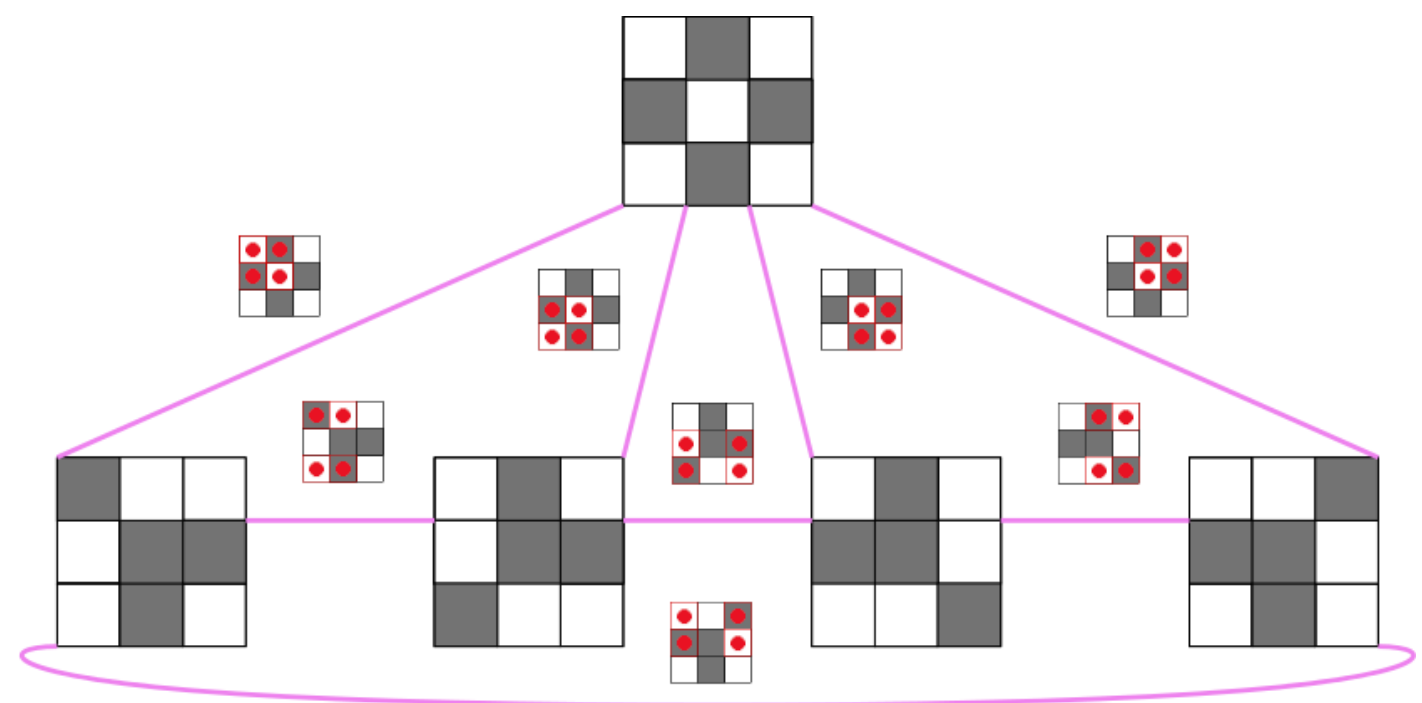

Figure 1.11: Switching component graph.

In Fig. 1.11, an example is shown for Propositions 1.3 and 1.4. The violet lines stand for the relations between the solutions that are available from each other, while the corresponding elementary switching is marked by red dots in the smaller images along the violet lines. It is clearly visible that all the solutions are available from each other applying elementary switchings. 


\subsubsection{Binary Reconstruction by Optimization}

The binary reconstruction can be traced back to the equation known from algebraic reconstruction (Eq. 1.7). To overcome the difficulties arising from underdeterminedness and inconsistency of Eq. 1.7, the binary reconstruction problem is commonly reformulated as a minimization problem

$$
C(\mathbf{X})=\|\mathbf{A x}-\mathbf{b}\|_{2}+\gamma \cdot \Phi(\mathbf{X}) \rightarrow \min ,
$$

where $\mathbf{x} \in\{0,1\}^{m n}$ represents the unknown image of size $m \times n$ in a row-byrow vector form; $\|\mathbf{A x}-\mathbf{b}\|_{2}$ ensures that the projections of the reconstructed image are close to the measured ones (data fitting term); and $\Phi(\mathbf{X}):\{0,1\}^{m n} \rightarrow \mathbb{R}$ is a regularization function expressing how image $\mathbf{x}$ fits with prior information (e.g. homogeneity, convexity, circularity, etc.). The smaller the value, the better the result. Finally, $\gamma \geq 0$ is a scaling constant. If it is established that the measured projection data is not trustworthy enough (e.g. due to noise), and that the prior information is trustworthy, then $\gamma$ is assigned higher value. In case the projection data is more reliable than the prior, $\gamma$ is assigned lower value.

Eq. 1.14 is a discrete global optimization problem, which is known to be NP-hard to solve. There are several methods to solve this optimization problem, but unfortunately, in this case, conventional gradient-based search algorithms can easily get stuck in a local optimum, as they only accept solutions of decreasing value during optimization. Hence, the use of metaheuristics (e.g. simulated annealing or a genetic algorithm) is needed.

\section{Simulated Annealing}

Simulated Annealing (SA) is a general stochastic heuristic for solving global optimization problems with suitable approximation in a large search space [50]. The search only runs on one thread. The method mimics the natural process of liquid metal behavior during continuous annealing: due to thermal noise, its energy sometimes increases, but when the temperature is properly controlled, it finally freezes in a crystal lattice with minimal energy. Using this theorem, an algorithm can be created, allowing a step to a higher objective function value in order to find the global minimum. The pseudocode of SA is provided in Alg. 1. 


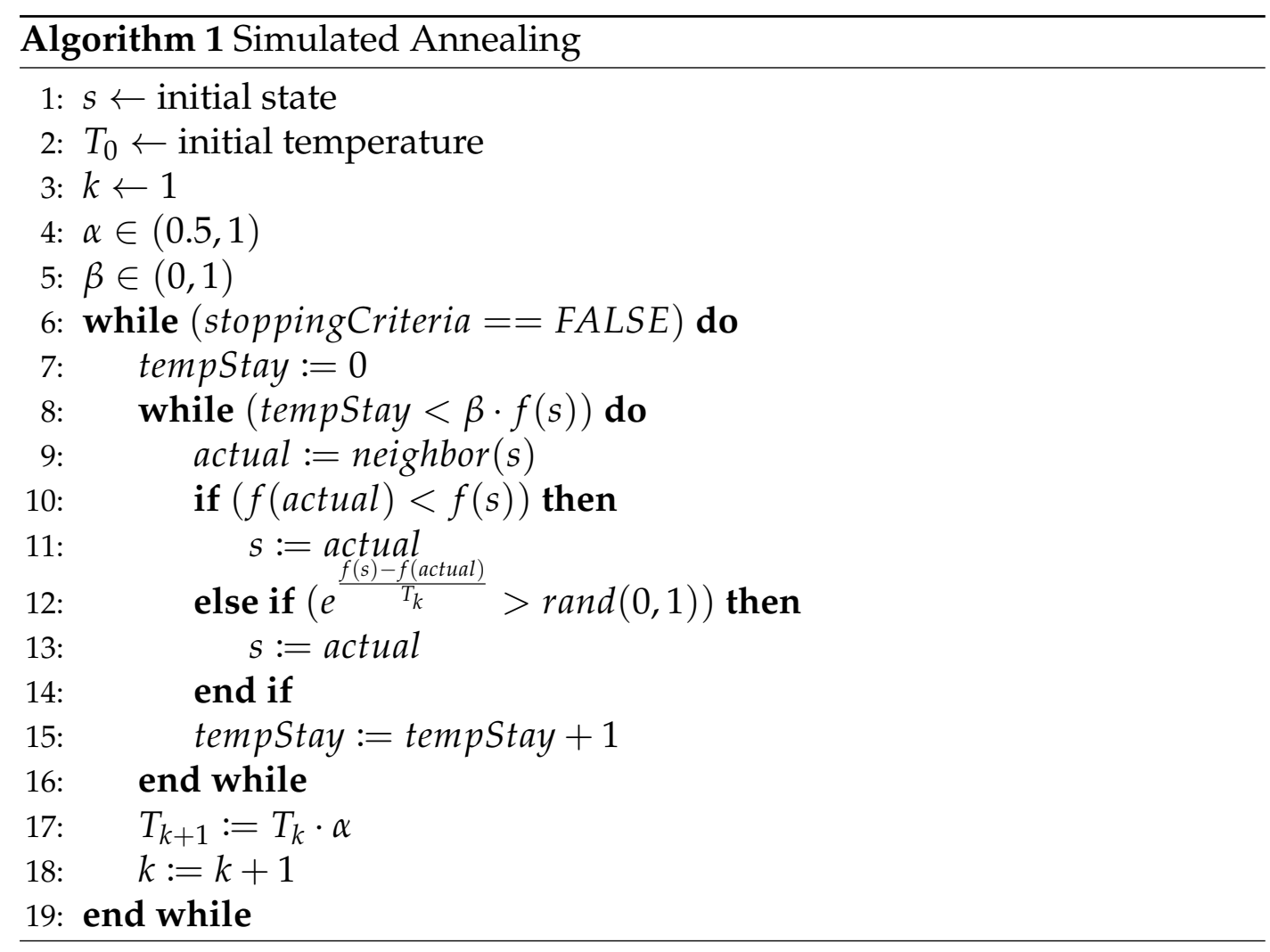

In general, the algorithm usually starts with a random solution in its variables (initial state $s$ ), and with a given initial temperature $T_{0}$, which is decreased by the cooling factor $\alpha$ during the iterations. The method runs until one of the stopping criteria is met, which depends on the specification of the problem. This can be, for example, to reach a number of iterations or a certain magnitude of temperature. Moving to a neighbor means selecting a solution from the feasible ones in the current iteration. The concept of 'neighbor' depends on the specification of question. In the case of binary images, it can be defined, for instance, by inverting a randomly selected pixel (easy coding, fast algorithm, but ignoring the 2D structure information) or changing a preselected geometrical attribution of an object (slow, but it allows for taking advantage of the structural property). The latter can be used when the image is interpreted as a set of geometrical objects (such as disjoint disks, for example), but not in our case (see [51]). In each iteration, the algorithm randomly selects a neighbor and evaluates whether to accept or deny it and keep the previous one. The decision between acceptance or denial depends on which one can keep the system at a lower energy level. If the objective function value assigned to the new proposal is not clearly better than the previous one, an exponential expression of these values is compared to a randomly generated number between 0 and 1 (see line 12 of Alg. 1). If this value is greater than the generated number, the new solution will be accepted, otherwise it is denied. It is necessary to accept a solution with worse value than the previous one for the function not to get stuck in a local optimum. The lower the temperature is, the less chance to adopt poor solutions. This way, approximating the global optimum is guaranteed. In some iterations, the 
temperature is not decreased: $\beta$ defines a maximum rate of the possibly denied proposals on the current temperature, while $k$ denotes the number of iterations. With a suitable cooling strategy, the method is proven to reach the global optimum. However, the algorithm has countless parameters, and fine-tuning them can be really challenging. There is no exact way to set the appropriate parameters $[46,70,77]$.

\subsubsection{Quality Measurement in Binary Tomography}

If the original image is known, a commonly calculated figure-of-merit for determining the quality of a reconstruction is the Relative Mean Error (RME) [52], specified by

$$
R M E=\frac{\sum_{i}\left|x_{i}^{o}-x_{i}^{r}\right|}{\sum_{i} x_{i}^{o}} \cdot 100 \%,
$$

where $x_{i}^{o}$ and $x_{i}^{r}$ stand for the $i^{\text {th }}$ pixel of the original and reconstructed image, respectively. RME value provides the ratio of the pixel difference between the original and the resulting image, and the number of object pixels of the original image. Note that RME can theoretically be even greater than $100 \%$. For instance, consider the identity matrix of size $10 \times 10$ as the original image, and its inverted version as the reconstruction. Then,

$$
R M E=\frac{100}{10} \cdot 100 \%=1000 \%
$$





\section{Chapter 2}

\section{Binary Tomography with Local Binary Pattern Priors}

Owing to the insufficient amount of available data, the binary reconstruction can be extremely underdetermined from two projections. An example for different images with the same horizontal and vertical projections is shown in Fig. 2.1.

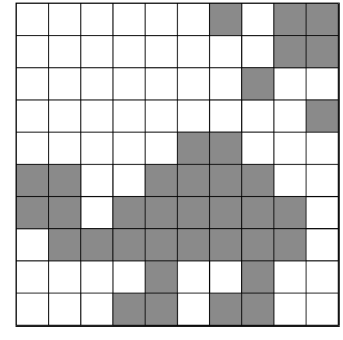

(a)

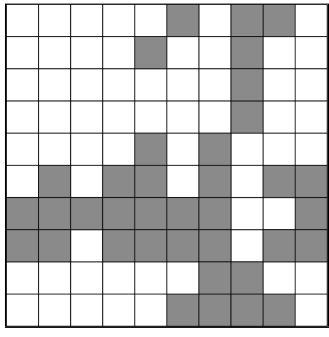

(b)

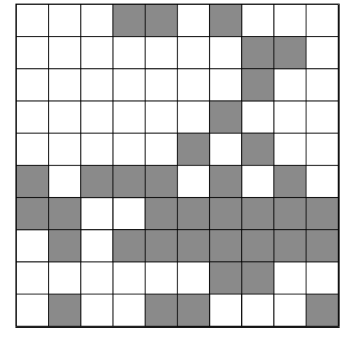

(c)

Figure 2.1: Different images with same horizontal and vertical projections.

One way to reduce the search space of feasible solutions is to exploit some prior knowledge of the image to be reconstructed. There is a wide array of literature regarding image reconstruction algorithms in BT using different kinds of geometrical or shape priors, depending on the application. There are, e.g. Works focusing on perimeter preserving regularization [58], shape orientation [56], convexity [22], pixel-based and geometric objects [51], gradient [57], convex-concave regularization [76], edge-preserving [59, 96], deep neural networks [38], local median [2], anatomic information [27], etc. In this chapter, the inherently insufficient amount of projection data is augmented by statistical image priors describing the approximate texture of the image to be reconstructed. The priors are extracted from sample images, ahead of the reconstruction.

\subsection{Local Binary Patterns as Texture Descriptors}

Local Binary Patterns (LBP) is a visual descriptor suitable for finding image patterns or repetitions, mostly used for classification in computer vision. In the most common implementations, it describes the relationship between the 
pixels and their 8-neighbors with an eight-digit binary code. Thus, there are 256 such binary codes, and as a result of an LBP process, we gain a 256dimensional feature vector ( $L B P$ histogram or $L B P$ vector) describing the normalized distribution of the binary codes in the image. The original LBP algorithm was published in 1996, in [67]. Since then, many variants of the basic LBP version have been developed and used, e.g. for image classification [54, 64, 68].

In order to explain different variants of LBP, consider the following grayscale matrix I,

$$
\mathbf{I}=\left[\begin{array}{lll}
p_{0} & p_{1} & p_{2} \\
p_{7} & p_{c} & p_{3} \\
p_{6} & p_{5} & p_{4}
\end{array}\right]=\left[\begin{array}{ccc}
200 & 0 & 255 \\
83 & 132 & 156 \\
132 & 10 & 130
\end{array}\right]
$$

where the center pixel is denoted by $p_{c}$ and its 8-neighbors by $p_{0}, p_{1}, \cdots, p_{7}$, in a clockwise manner from the top-left pixel.

\subsubsection{Local Binary Patterns (LBP)}

The basic LBP algorithm [67] examines the relation between the center pixel $p_{c}$ and its 8-neighbors $p_{0}, p_{1}, \cdots, p_{7}$ in a $3 \times 3$ window for each pixel, which thereafter describes it as a sequence of $0 \mathrm{~s}$ and 1s. This results in a binary code, which is converted to a decimal number. The resulted codes for all image pixels are aggregated in a 256-dimensional histogram representing the frequency of each possible pattern. The LBP value in the center pixel $p_{c}$ is defined as

$$
\operatorname{LBP}\left(p_{c}\right)=\sum_{i=0}^{N-1} d_{i} \cdot 2^{i},
$$

where $N$ is the number of the sampling points (in our example, $N=8$, since a $3 \times 3$ neighborhood is taken into account). The threshold function is

$$
d_{i}=\left\{\begin{array}{ll}
1 & \text { if } p_{i} \geq p_{c} \\
0 & \text { if } p_{i}<p_{c}
\end{array} .\right.
$$

Example 1. The LBP value of the center pixel $p_{c}$ of the matrix I defined in Eq. 2.1 is $\operatorname{LBP}\left(p_{c}\right)=1 \cdot 2^{0}+0 \cdot 2^{1}+1 \cdot 2^{2}+1 \cdot 2^{3}+0 \cdot 2^{4}+0 \cdot 2^{5}+1 \cdot 2^{6}+0$. $2^{7}=77$.

\subsubsection{Fuzzy Local Binary Patterns (FLBP)}

A soft extension of LBP is Soft LBP [1] or Fuzzy LBP (FLBP) [47], which integrates fuzzy logic into the basic LBP process. FLBP is robust and continuous with respect to the output, meaning minor changes in the input image only result in minor changes in the output. To improve the robustness of the basic LBP operator, the original threshold function is expanded by two fuzzy membership functions. Fuzzification allows FLBP to assign several (or even 
all) bins of the histogram to each pixel to some degree, not just a single one. While LBP is based on thresholding that makes it sensitive to noise, FLBP enables a more robust representation of image texture by fuzzifying the calculated LBP codes using fuzzy rules and membership functions. The fuzzy rules are:

- $R_{0}$ : The smaller $p_{i}$ is with respect to $p_{c}$, the greater the certainty that $d_{i}$ is 0 .

- $R_{1}$ : The larger $p_{i}$ is with respect to $p_{c}$, the greater the certainty that $d_{i}$ is 1 .

Based on these rules, the membership functions $f_{0, T}(i)$ and $f_{1, T}(i)$ $(i=1, \ldots, N)$ are defined as

$$
\begin{gathered}
f_{0, T}(i)= \begin{cases}0 & p_{i} \geq p_{c}+T \\
\frac{T-p_{i}+p_{c}}{2 \cdot T} & p_{c}-T<p_{i}<p_{c}+T, T \neq 0 \\
1 & p_{i} \leq p_{c}-T, T \neq 0 \\
1 & p_{i} \leq p_{c}, T=0\end{cases} \\
f_{1, T}(i)=1-f_{0, T}(i),
\end{gathered}
$$

where $T \in[0,255]$ represents a parameter that controls the degree of fuzziness. Once again, $N$ stands for the number of the sampling points. The contribution $C_{T}(L B P)$ of each LBP code in a single bin of the FLBP histogram is defined as

$$
C_{T}(L B P)=\prod_{i=0}^{N-1} f_{d_{i}, T}(i) .
$$

Therefore, the crisp thresholding of Eq. 2.2 is replaced with the softer membership functions of Eq. 2.4 and Eq. 2.5 resulting in each $3 \times 3$ neighborhood potentially contributing to more than one bin of the FLBP histogram. It is important to note that the total contribution of all neighbors to the bins equals 1.

Example 2. Consider again the center pixel $p_{c}$ of matrix I defined in Eq. 2.1 and let $T=10$. With this setting, some of the 8-neighbors yield a fixed value in the LBP code:

$$
p_{0}=1, p_{1}=0, p_{2}=1, p_{3}=1, p_{5}=0, p_{7}=0 \text {. }
$$

However, the membership functions of $p_{4}$ and $p_{6}$ are not crisp anymore. These are

- $f_{0, T}(4)=\frac{10-130+132}{2 \cdot 10}=0.6$,

- $f_{1, T}(4)=0.4$,

- $f_{0, T}(6)=\frac{10-132+132}{2 \cdot 10}=0.5$,

- $f_{1, T}(6)=0.5$. 
Thus, we have the following contributions

- for the LBP code 00001101: $C_{T}(13)=f_{0, T}(4) \cdot f_{0, T}(6)=0.6 \cdot 0.5=0.3$,

- for the LBP code 00011101: $C_{T}(29)=f_{1, T}(4) \cdot f_{0, T}(6)=0.4 \cdot 0.5=0.2$,

- for the LBP code 01001101: $C_{T}(77)=f_{0, T}(4) \cdot f_{1, T}(6)=0.6 \cdot 0.5=0.3$,

- for the LBP code 01011101: $C_{T}(93)=f_{1, T}(4) \cdot f_{1, T}(6)=0.4 \cdot 0.5=0.2$.

Therefore, the $13^{\text {th }}, 29^{\text {th }}, 77^{\text {th }}, 93^{\text {th }}$ bins get the nonzero values calculated above. Obviously, $C_{T}(13)+C_{T}(29)+C_{T}(77)+C_{T}(93)=0.3+0.2+0.3+$ $0.2=1$.

\subsubsection{Shift Local Binary Patterns (SLBP)}

The Shift Local Binary Patterns (SLBP) was introduced in [54] as a quick approximation of the computationally heavy FLBP. There, the authors described SLBP as generating a fixed number of local binary codes for each pixel position. An intensity limit $l$ is added to specify the shift interval $k$ :

$$
k \in[-l, l] \cap \mathbb{Z} \Rightarrow|k|=2 \cdot l+1 .
$$

When $k$ is modified, a new binary code is calculated and added to the histogram. The SLBP value of the center pixel with shift value $k$ is defined as

$$
\operatorname{SLBP}\left(p_{c}, k\right)=\sum_{i=0}^{N-1} d_{i} \cdot 2^{i}
$$

where

$$
d_{i}=\left\{\begin{array}{ll}
1 & p_{i} \geq p_{c}+k \\
0 & p_{i}<p_{c}+k
\end{array} .\right.
$$

Taking advantage of the fuzziness of the method, supposing high differences on the local $3 \times 3$ window, all the $|k|$ bins can have the same value, while in case of low contrast, the bins may present greater deviation. Finally, the histogram is divided by $|k|$.

Example 3. For $l=3, k \in[-3,3]$ and $|k|=7$, therefore 7 bins are taken into account. The SLBP value of the center pixel in the matrix I defined in Eq. 2.1 is

- for $k \in\{-3,-2\}: 1 \cdot 2^{0}+0 \cdot 2^{1}+1 \cdot 2^{2}+1 \cdot 2^{3}+1 \cdot 2^{4}+0 \cdot 2^{5}+1 \cdot 2^{6}+$ $0 \cdot 2^{7}=93$

- for $k \in\{-1,0\}: 1 \cdot 2^{0}+0 \cdot 2^{1}+1 \cdot 2^{2}+1 \cdot 2^{3}+0 \cdot 2^{4}+0 \cdot 2^{5}+1 \cdot 2^{6}+0$. $2^{7}=77$

- for $k \in\{1,2,3\}: 1 \cdot 2^{0}+0 \cdot 2^{1}+1 \cdot 2^{2}+1 \cdot 2^{3}+0 \cdot 2^{4}+0 \cdot 2^{5}+0 \cdot 2^{6}+0$. $2^{7}=13$.

Therefore, the $13^{\text {th }}$ bin gets $3 / 7$ value, the $77^{\text {th }}$ and the $93^{\text {th }}$ bins get $2 / 7$ value, and the contribution to all other bins are 0 . 


\subsubsection{Dominant Rotated Local Binary Patterns (DRLBP)}

Caused by the fixed arrangement of weights, the basic LBP is not invariant to rotations and viewpoint changes. Consequently, in [61] an extended LBP variant was proposed to ensure rotation-invariance. The main idea of the proposed method is that the weights are aligned in a circular manner, so the effects of image rotations can be traced by rotating the weights by the same (unknown) angle. The dominant direction is defined as the index of the neighboring pixel, whose difference from the central pixel is a maximum of:

$$
D=\underset{i \in\{0, \cdots, N-1\}}{\operatorname{argmax}}\left|p_{i}-p_{\mathcal{c}}\right|,
$$

which quantizes the dominant directions into $N$ discrete values. Hence, Eq. 2.2 becomes

$$
\operatorname{DRLBP}\left(p_{c}\right)=\sum_{i=0}^{N-1} d_{i} \cdot 2^{\bmod (i-D, N)},
$$

where the mod operator shifts the weights circularly with respect to the dominant direction, while the sequence of the weights remains the same. The shift results in a rotation invariance, as the weights depend exclusively on the neighborhood.

Example 4. The dominant direction in the position $p_{c}$ of matrix I defined in Eq. 2.1 is $D=1$, corresponding to the neighbor $p_{1}$ with the maximal difference $|0-132|$. Therefore, $\operatorname{DRLBP}\left(p_{c}\right)=0 \cdot 2^{0}+1 \cdot 2^{1}+1 \cdot 2^{2}+0 \cdot 2^{3}+0$. $2^{4}+1 \cdot 2^{5}+0 \cdot 2^{6}+1 \cdot 2^{7}=166$.

\subsection{Preliminary Studies}

In some preliminary studies, we used the basic LBP descriptor as follows. Assuming that the image to be reconstructed belongs to a given class, we first selected representatives of that class and calculated their LBP vectors. Then, in the reconstruction, we took two priors into account (the image is to be smooth, and must have a texture similar to the previously observed ones). Having two different priors, the formula of Eq. 1.14 became

$$
C(\mathbf{X})=\|\mathbf{A x}-\mathbf{b}\|_{2}+\gamma_{1} \cdot \Phi_{1}(\mathbf{X})+\gamma_{2} \cdot \Phi_{2}(\mathbf{X}) \rightarrow \min .
$$

$\Phi_{1}(\mathbf{X})$ measures the smoothness of the current solution by taking the sum of the convolution of each image pixel by a Gaussian-like kernel K Eq. 2.14. Formally,

$$
\Phi_{1}(\mathbf{X})=\sum_{i=3}^{m-2} \sum_{j=3}^{n-2}\left(\mathbf{K} * \mathbf{X}_{i, j}\right),
$$


where

$$
\mathbf{K}=\frac{1}{\sqrt{2 \pi}}\left(\begin{array}{ccccc}
0 & 0 & e^{-2} & 0 & 0 \\
0 & e^{-\sqrt{2}} & e^{-1} & e^{-\sqrt{2}} & 0 \\
e^{-2} & e^{-1} & 0 & e^{-1} & e^{-2} \\
0 & e^{-\sqrt{2}} & e^{-1} & e^{-\sqrt{2}} & 0 \\
0 & 0 & e^{-2} & 0 & 0
\end{array}\right)
$$

and $\mathbf{X}_{i, j}$ represents a $5 \times 5$ sized submatrix of $\mathbf{X}$ with center point $(i, j) . \Phi_{2}(\mathbf{X})$ provides the minimal Euclidean distance of the LBP vector of the current image compared to all representative LBP vectors. Formally,

$$
\Phi_{2}(\mathbf{X})=\min _{t}\left\{\left\|L B P(\mathbf{X})-L B P\left(\mathbf{X}_{t}\right)\right\|_{2}\right\}
$$

where $\mathbf{X}_{1}, \mathbf{X}_{2}, \ldots, \mathbf{X}_{t}$ are the $t$ sample images from the same class as $\mathbf{X}$, known a priori. Again, $\gamma_{1}$ and $\gamma_{2}$ are scaling weights.

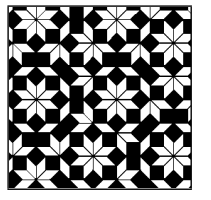

(a) Class 1

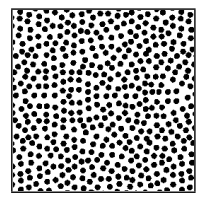

(b) Class 2

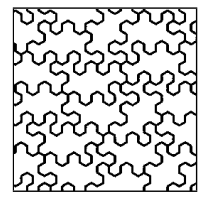

(c) Class 3

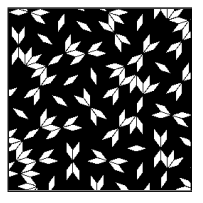

(d) Class 4

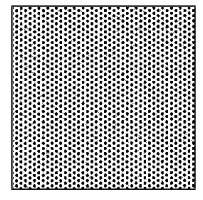

(e) Class 5

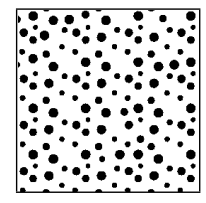

(f) Class 6

Figure 2.2: Software phantom image classes.

To test the efficiency of the method, we conducted experiments on software phantom images from 6 classes of various textures with SA (Alg. 1 in Section 1.4). Figure 2.2 (as well as Fig. D.2) exhibits the original image classes. The sizes of the images are diverse, the smallest one is $430 \times 300$, while the largest one is $1230 \times 1120$. Images in Class 1 (Fig. 2.2a) are formed by shapes with four possible orientations, resembling regular patterns. Class 4 (Fig. 2.2d) contains similar images but with larger empty areas between them to study whether the size of the objects affects the reconstruction quality. Classes 2 (Fig. 2.2b), 5 (Fig. 2.2e), and 6 (Fig. 2.2f) consist of images showing regular or less regular patterns of circular holes having equal or different sizes. Such images are typical in industrial non-destructive testing, where the aim is to detect air bubbles in homogeneous objects (e.g. cheese, chocolate, metal alloy products). Furthermore, by interchanging the foreground and background, the holes become small 'particles', providing structures similarly observed in electron-microscopic tomography of crystalline structures. Finally, images in Class 3 (Fig. 2.2c), or more precisely, their inverted versions, indicate thin walls between similar objects. These images may remind us of cross-sections of trabecular bones or metal/ plastic foams.

All parameters of the SA algorithm were set manually, in an empirical manner. Each time, the method started out with a random binary image. The stopping criteria of the algorithm were to reach 800000 iterations or to perform 50000 iterations without improving the optimal result. The initial temperature was set to $T_{1}=5800$, while the cooling schedule was controlled by $\alpha=0.99$. The SA algorithm was allowed to remain the same temperature 
for some iterations. In our case, this was fine-tuned by $\beta=0.035$. Selecting a neighbor meant randomly selecting and inverting some of the image pixels. We found that inverting a single pixel per iteration was unable to decrease the cost value significantly at the beginning. The number of pixels to be inverted $(l)$ in iteration $t$ depended on the cost value $f(s)$ in the previous iteration $(t-1)$. More precisely, $l=\frac{\beta}{2} \cdot f(s)$. We found that the best parameter values were $\gamma_{2}=0.5$ and $\gamma_{1} \in[0.03,0.06]$ (depending on the investigated image class).

To determine the quality of the reconstruction, RME (see Eq. 1.15) was used. The reconstructions were performed on random image patches of size $64 \times 64$ from each image class using 2,3,4, and 8 projections, assuming parallel beam geometry, with one pixel distance between the projection lines. The observed and the test dataset contained $150(t=150)$ and 10 images, respectively, from each image class. Due to the stochastic nature of SA, each reconstruction task was repeated 5 times, and the mean values of the results were utilized. The DART algorithm was used as a comparative study with the following parameters:

- ARM to be used: SIRT,

- the number of iterations of the ARM: 10,

- the number of inner iterations (when the boundary is searched): 500,

- threshold parameter: 0.5 .

The tests were performed on a QuadCore Intel Core i7-4770 processor, 3800 $\mathrm{MHz}$ with 8GB RAM. The algorithms were implemented in MATLAB.

Tables 2.1-2.6 show the RME values (in percentage) for the 10 test images of Fig. 2.2a-2.2f, respectively, for both DART and SA algorithms. The better RME values are highlighted. Based on the entries of these tables, we are able to deduce the following. Unfortunately, DART usually provided better results than $\mathrm{SA}$, but in some cases the differences were not significant. Interestingly, the results of Class 6 (Fig. 2.2f) with 2 and 8 projections were similar for both SA and DART, while with 3 or 4 projections DART usually outperformed SA. Moreover, with 8 projections, SA often provided better results or even perfect reconstructions ( $0 \% \mathrm{RME})$. 


\begin{tabular}{|c|c|c|c|c|c|c|c|c|}
\hline & \multicolumn{2}{|c|}{$\mathbf{2}$} & \multicolumn{2}{|c|}{$\mathbf{3}$} & \multicolumn{2}{|c|}{$\mathbf{4}$} & \multicolumn{2}{|c|}{$\mathbf{8}$} \\
& $\mathbf{S A}$ & $\mathbf{D A R T}$ & $\mathbf{S A}$ & DART & SA & DART & SA & DART \\
\hline $\mathbf{1}$ & 69.46 & 66.23 & 47.84 & 33.50 & 11.95 & 3.18 & 2.08 & 0.05 \\
\hline $\mathbf{2}$ & 61.49 & 65.59 & 62.50 & 65.03 & 17.64 & 0.56 & 0.50 & 0.12 \\
\hline $\mathbf{3}$ & 44.80 & 43.82 & 39.95 & 23.32 & 2.97 & 0.26 & 1.74 & 0.05 \\
\hline $\mathbf{4}$ & 75.60 & 72.97 & 44.21 & 36.46 & 7.96 & 2.41 & 2.58 & 0.50 \\
\hline $\mathbf{5}$ & 66.19 & 66.55 & 30.93 & 22.22 & 9.08 & 1.85 & 4.87 & 1.08 \\
\hline $\mathbf{6}$ & 90.62 & 106.50 & 58.85 & 37.69 & 15.32 & 0.80 & $\mathbf{0 . 0 0}$ & 0.08 \\
\hline $\mathbf{7}$ & 84.03 & 74.84 & 48.71 & 49.32 & 16.39 & 4.63 & 0.29 & 0.07 \\
\hline $\mathbf{8}$ & 65.90 & 71.00 & 45.81 & 29.83 & 19.10 & 0.95 & 0.24 & 0.12 \\
\hline $\mathbf{9}$ & 67.93 & 40.50 & 55.50 & 33.31 & 23.76 & 1.13 & 2.04 & 0.74 \\
\hline $\mathbf{1 0}$ & 91.08 & 71.84 & 44.07 & 26.24 & 10.38 & 9.58 & 8.06 & 0.20 \\
\hline
\end{tabular}

Table 2.1: RME values for the test images of Class 1 (Fig. 2.2a).

\begin{tabular}{|c|c|c|c|c|c|c|c|c|}
\hline & \multicolumn{2}{|c|}{$\mathbf{2}$} & \multicolumn{2}{|c|}{$\mathbf{3}$} & \multicolumn{2}{c|}{$\mathbf{4}$} & \multicolumn{2}{|c|}{$\mathbf{8}$} \\
& SA & DART & SA & DART & SA & DART & SA & DART \\
\hline $\mathbf{1}$ & 89.54 & 83.43 & 73.72 & 77.08 & 75.86 & 61.95 & 39.12 & 9.24 \\
\hline $\mathbf{2}$ & 78.13 & 71.33 & 59.96 & 63.12 & 65.19 & 55.50 & 44.73 & 11.45 \\
\hline $\mathbf{3}$ & 76.50 & 84.95 & 75.69 & 79.48 & 64.12 & 50.07 & 39.86 & 10.48 \\
\hline $\mathbf{4}$ & 73.78 & 77.10 & 63.87 & 57.15 & 69.12 & 51.10 & 49.80 & 11.65 \\
\hline $\mathbf{5}$ & 79.17 & 84.88 & 63.92 & 72.21 & 65.62 & 46.13 & 40.18 & 8.62 \\
\hline $\mathbf{6}$ & 76.91 & 71.61 & 72.25 & 57.74 & 56.96 & 46.14 & 40.07 & 10.41 \\
\hline $\mathbf{7}$ & 89.07 & 96.61 & 82.83 & 75.86 & 68.55 & 64.73 & 48.14 & 12.63 \\
\hline $\mathbf{8}$ & 87.08 & 87.93 & 68.98 & 62.28 & 69.69 & 62.66 & 61.81 & 11.16 \\
\hline $\mathbf{9}$ & 83.03 & 79.81 & 67.69 & 66.43 & 60.75 & 49.42 & 47.65 & 14.64 \\
\hline $\mathbf{1 0}$ & 66.33 & 64.86 & 58.19 & 48.89 & 59.03 & 45.42 & 48.93 & 7.96 \\
\hline
\end{tabular}

Table 2.2: RME values for the test images of Class 2 (Fig. 2.2b).

\begin{tabular}{|c|c|c|c|c|c|c|c|c|}
\hline & \multicolumn{2}{|c|}{$\mathbf{2}$} & \multicolumn{2}{c|}{$\mathbf{3}$} & \multicolumn{2}{|c|}{$\mathbf{4}$} & \multicolumn{2}{|c|}{$\mathbf{8}$} \\
\hline $\mathbf{1}$ & $\mathbf{2 A}$ & $\mathbf{D A R T}$ & $\mathbf{S A}$ & $\mathbf{D A R T}$ & $\mathbf{S A}$ & DART & SA & DART \\
\hline $\mathbf{2}$ & 30.60 & 31.83 & 18.45 & 18.54 & 19.16 & 10.62 & 4.90 & 0.50 \\
\hline $\mathbf{3}$ & 32.05 & 27.84 & 29.09 & 23.53 & 22.94 & 19.73 & 9.68 & 0.76 \\
\hline $\mathbf{4}$ & 31.95 & 29.35 & 28.39 & 25.01 & 24.13 & 22.81 & 11.10 & 0.60 \\
\hline $\mathbf{5}$ & 26.46 & 27.39 & 21.24 & 19.12 & 19.09 & 15.69 & 10.98 & 0.66 \\
\hline $\mathbf{6}$ & 29.69 & 24.80 & 15.59 & 21.33 & 16.33 & 14.18 & 5.74 & 0.53 \\
\hline $\mathbf{7}$ & 35.73 & 29.15 & 21.12 & 24.23 & 22.78 & 20.67 & 9.48 & 1.00 \\
\hline $\mathbf{8}$ & 32.09 & 24.29 & 29.72 & 22.79 & 24.63 & 16.17 & 11.04 & 1.38 \\
\hline $\mathbf{9}$ & 20.47 & 20.76 & 21.08 & 15.72 & 15.54 & 10.58 & 6.55 & 0.58 \\
\hline $\mathbf{1 0}$ & 22.55 & 20.02 & 10.12 & 7.65 & 8.52 & 2.53 & 3.18 & 0.11 \\
\hline
\end{tabular}

Table 2.3: RME values for the test images of Class 3 (Fig. 2.2c). 


\begin{tabular}{|c|c|c|c|c|c|c|c|c|}
\hline & \multicolumn{2}{|c|}{$\mathbf{2}$} & \multicolumn{2}{c|}{$\mathbf{3}$} & \multicolumn{2}{c|}{$\mathbf{4}$} & \multicolumn{2}{|c|}{$\mathbf{8}$} \\
& SA & DART & SA & DART & SA & DART & SA & DART \\
\hline $\mathbf{1}$ & 108.19 & 110.39 & 70.90 & 39.61 & 47.43 & 8.56 & 14.67 & 0.98 \\
\hline $\mathbf{2}$ & 132.45 & 121.33 & 67.46 & 72.74 & 50.87 & 27.44 & 23.61 & 5.47 \\
\hline $\mathbf{3}$ & 125.26 & 127.32 & 89.21 & 70.84 & 83.58 & 81.17 & 34.21 & 13.89 \\
\hline $\mathbf{4}$ & 122.39 & 95.52 & 89.01 & 72.05 & 73.00 & 50.34 & 26.87 & 7.87 \\
\hline $\mathbf{5}$ & 115.07 & 111.93 & 69.99 & 46.13 & 54.78 & 16.78 & 21.49 & 5.37 \\
\hline $\mathbf{6}$ & 141.32 & 126.45 & 78.28 & 113.81 & 65.29 & 32.11 & 29.87 & 6.02 \\
\hline $\mathbf{7}$ & 137.46 & 153.98 & 67.74 & 35.17 & 35.32 & 9.02 & 19.57 & 4.59 \\
\hline $\mathbf{8}$ & 140.45 & 117.80 & 60.58 & 67.01 & 48.18 & 24.32 & 25.35 & 8.39 \\
\hline $\mathbf{9}$ & 99.43 & 91.42 & 99.84 & 78.38 & 51.42 & 30.53 & 25.83 & 8.18 \\
\hline $\mathbf{1 0}$ & 154.45 & 96.93 & 121.17 & 86.04 & 67.02 & 25.31 & 22.55 & 4.14 \\
\hline
\end{tabular}

Table 2.4: RME values for the test images of Class 4 (Fig. 2.2d).

\begin{tabular}{|c|c|c|c|c|c|c|c|c|}
\hline & \multicolumn{2}{|c|}{$\mathbf{2}$} & \multicolumn{2}{|c|}{$\mathbf{3}$} & \multicolumn{2}{c|}{$\mathbf{4}$} & \multicolumn{2}{|c|}{$\mathbf{8}$} \\
& SA & DART & SA & DART & SA & DART & SA & DART \\
\hline $\mathbf{1}$ & 47.67 & 40.92 & 16.73 & 4.33 & 49.14 & 39.01 & 45.87 & 33.80 \\
\hline $\mathbf{2}$ & 45.40 & 41.11 & 12.88 & 4.43 & 42.51 & 39.26 & 43.04 & 31.87 \\
\hline $\mathbf{3}$ & 43.77 & 42.30 & 11.75 & 4.51 & 45.09 & 41.51 & 43.37 & 30.27 \\
\hline $\mathbf{4}$ & 47.54 & 44.04 & 13.32 & 4.19 & 48.20 & 40.07 & 48.90 & 32.93 \\
\hline $\mathbf{5}$ & 40.66 & 40.23 & 10.23 & 4.39 & 43.21 & 39.56 & 45.26 & 27.81 \\
\hline $\mathbf{6}$ & 41.89 & 44.05 & 12.38 & 4.05 & 46.90 & 39.44 & 46.13 & 32.21 \\
\hline $\mathbf{7}$ & 43.02 & 41.60 & 14.07 & 4.43 & 44.00 & 39.21 & 46.06 & 33.59 \\
\hline $\mathbf{8}$ & 47.23 & 43.24 & 15.30 & 5.10 & 47.60 & 44.60 & 51.48 & 36.07 \\
\hline $\mathbf{9}$ & 45.34 & 41.85 & 10.27 & 2.94 & 43.96 & 39.56 & 44.57 & 32.38 \\
\hline $\mathbf{1 0}$ & 43.87 & 42.58 & 9.86 & 3.30 & 41.83 & 38.39 & 44.55 & 32.44 \\
\hline
\end{tabular}

Table 2.5: RME values for the test images of Class 5 (Fig. 2.2e).

\begin{tabular}{|c|c|c|c|c|c|c|c|c|}
\hline & \multicolumn{2}{|c|}{$\mathbf{2}$} & \multicolumn{2}{|c|}{$\mathbf{3}$} & \multicolumn{2}{|c|}{$\mathbf{4}$} & \multicolumn{2}{|c|}{} \\
& SA & DART & SA & DART & SA & DART & SA & DART \\
\hline $\mathbf{1}$ & 24.41 & 22.50 & 14.39 & 1.59 & 14.14 & 0.41 & $\mathbf{0 . 0 0}$ & 0.03 \\
\hline $\mathbf{2}$ & 30.88 & 27.02 & 24.88 & 16.92 & 18.83 & 18.35 & $\mathbf{0 . 0 0}$ & 0.06 \\
\hline $\mathbf{3}$ & 27.93 & 24.74 & 19.98 & 17.27 & 20.74 & 20.81 & $\mathbf{0 . 0 0}$ & 0.09 \\
\hline $\mathbf{4}$ & 28.00 & 36.70 & 14.30 & 10.81 & 15.77 & 2.02 & 0.02 & 0.03 \\
\hline $\mathbf{5}$ & 24.88 & 17.73 & 14.05 & 7.23 & 13.70 & 3.67 & 2.29 & 1.08 \\
\hline $\mathbf{6}$ & 29.07 & 30.91 & 15.42 & 10.71 & 17.72 & 13.40 & 0.02 & 0.21 \\
\hline $\mathbf{7}$ & 27.52 & 35.45 & 20.64 & 2.18 & 15.74 & 0.92 & $\mathbf{0 . 0 0}$ & 0.12 \\
\hline $\mathbf{8}$ & 34.14 & 38.94 & 24.96 & 22.37 & 16.69 & 10.62 & 0.55 & 0.12 \\
\hline $\mathbf{9}$ & 27.51 & 34.06 & 18.32 & 9.52 & 19.43 & 4.13 & $\mathbf{0 . 0 0}$ & $\mathbf{0 . 0 0}$ \\
\hline $\mathbf{1 0}$ & 33.11 & 37.20 & 23.07 & 2.68 & 25.03 & 20.54 & $\mathbf{0 . 0 0}$ & 0.31 \\
\hline
\end{tabular}

Table 2.6: RME values for the test images of Class 6 (Fig. 2.2f). 
Figure 2.3 provides an example of how the RME value changes for the same test image (Nr. \#6 in Table 2.1) for a member of Class 1 (Fig. 2.2a) if the number of projections is increased. It clearly reveals that the trend is similar for the two approaches. Furthermore, it can be observed, that in this case SA provides better results for 8 projections, resulting in perfect reconstruction. When using 20 projections, both algorithms resulted in perfect reconstructions.

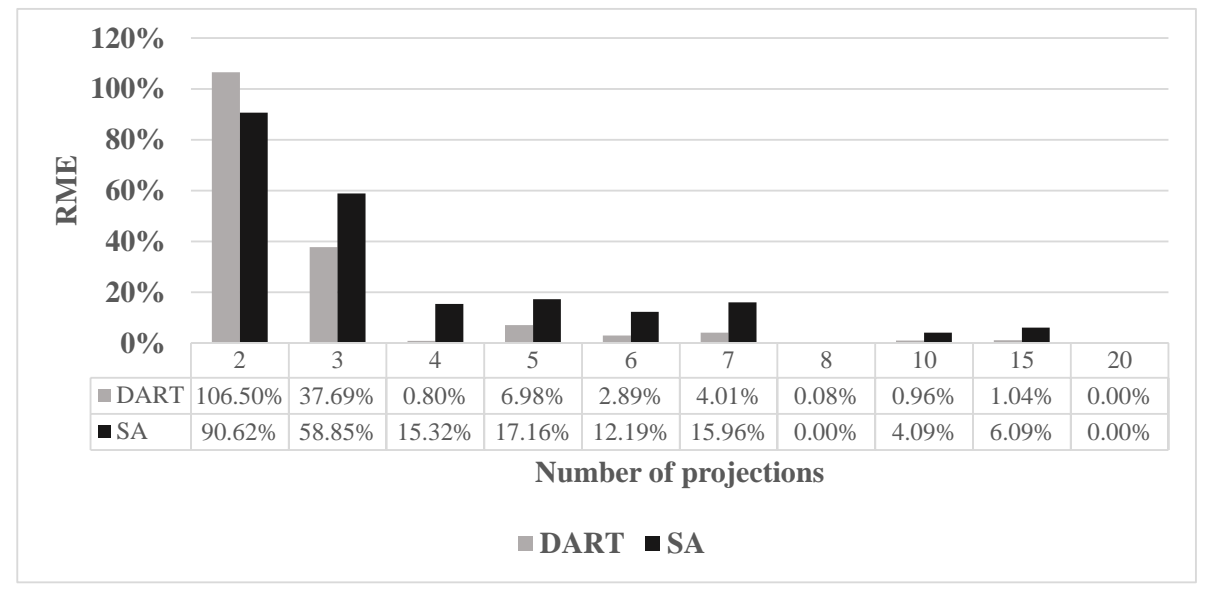

Figure 2.3: Example of how the RME value changes by increasing the number of projections.

Performing experimental analysis on software phantom images, we found the concept promising, especially in case of few available projections. However, we also deduced that in some cases, the expressive power of the standard LBP descriptor was not satisfactory. Fortunately, an advantage of this approach is that it can be improved by using other versions of LBP. Consequently, we decided to conduct experiments with the aforementioned LBP versions.

In addition, it became clear, that the RME error rate (see Eq. 1.15) is not appropriate for texture images as it is not always informative enough on its own. A clear example is the Chessboard image (Fig. 2.4a) and its inversion (Fig. 2.4b). Calculating the RME difference of these two images yields $200 \%$ $\mathrm{RME}$ - the theoretical maximum for this image - , although they represent the exact same texture and have the same horizontal and vertical projections.

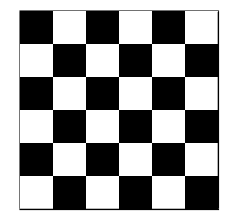

(a)

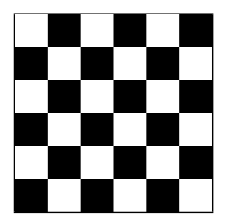

(b)

Figure 2.4: Chessboard image (a) and its inversion (b). 


\subsection{Comparison of the LBP Variants}

It is clear that the same LBP vector can belong to many different (binary) matrices, which may lead to an incorrect reconstruction [95]. To investigate this issue, we generated all the 512 binary matrices of size $3 \times 3$, and examined their LBP vectors. For LBP, FLBP, SLBP (with $l=3$ ), and DRLBP, we used MATLAB implementations of [53, 61, 103].

We found that in the case of LBP and DRLBP, the value is always the same (255) if the center pixel is 0. On the other hand, both SLBP and FLBP provided 511 different vectors, and only the full 0 s and full $1 \mathrm{~s}$ matrices had the same vectors.

\begin{tabular}{|c|c|c|c|c|c|c|}
\hline Matrix & \multicolumn{2}{|c|}{ LBP } & \multicolumn{2}{|c|}{ DRLBP } & \multicolumn{2}{|c|}{ SLBP } \\
\hline$\left[\begin{array}{lll}1 & 0 & 0\end{array}\right]$ & & & & & 0 & 0.2857 \\
\hline $\begin{array}{lll}0 & 0 & 0\end{array}$ & 255 & 1.0000 & 255 & 1.0000 & 65 & 0.1429 \\
\hline$\left[\begin{array}{lll}1 & 1 & 0\end{array}\right]$ & & & & & 255 & 0.5714 \\
\hline$\left[\begin{array}{lll}1 & 0 & 0\end{array}\right]$ & & & & & 0 & 0.2857 \\
\hline $\begin{array}{lll}0 & 0 & 1\end{array}$ & 255 & 1.0000 & 255 & 1.0000 & 17 & 0.1429 \\
\hline$\left[\begin{array}{lll}0 & 0 & 0\end{array}\right]$ & & & & & 255 & 0.5714 \\
\hline
\end{tabular}

Table 2.7: Histogram values of matrices for different LBP variants.

Table 2.7 represents an example. For the two different matrices, LBP and DRLBP provide the same values. More precisely, LBP and DRLBP provide nonzero values at the $255^{\text {th }}$ bin. In contrast, SLBP does not match for the two matrices: in the first case the $0^{t h}, 65^{t h}, 255^{\text {th }}$ are the nonzero bins, while in the second case, the $0^{\text {th }}, 17^{\text {th }}$, and $255^{\text {th }}$ bins are assigned nonzero values. Finally, owing to the fuzzy nature of FLBP, all the 256 bins have nonzero values for each of the 512 matrices, which is not reported here in detail. Therefore, we can deduce that the distinguishing power of SLBP and FLBP is greater than that of LBP or DRLBP. However, FLBP is extremely slow to compute compared to the other methods. Table 2.8 shows an example of the running times of the different variants of LBP, on the same random binary image of size $64 \times 64$ (see also [54] for a thorough comparison). Based on these observations, we opted to use SLBP in the subsequent investigations.

\begin{tabular}{|l|c|c|c|c|}
\hline Variant & LBP & DRLBP & SLBP & FLBP \\
\hline Running time (s) & 0.0040 & 0.0016 & 0.0028 & 1.6834 \\
\hline
\end{tabular}

Table 2.8: Running times of different LBP variants in seconds. 


\subsection{Results}

\subsubsection{Experimental Setup}

In the reconstruction formula (see Eq. 2.12), two priors were taken into account: the image must be smooth, and - at the same time - it must have a texture similar to the previously observed ones. Since SLBP is a more informative and more powerful texture descriptor than the basic LBP, we decided to omit the smoothness prior. Therefore, we turn back to the original cost function defined in Eq. 1.14,

$$
C(\mathbf{X})=\|\mathbf{A x}-\mathbf{b}\|_{2}+\gamma \cdot \Phi(\mathbf{X}) \rightarrow \min ,
$$

where $\Phi(\mathbf{X})$ provides the minimal Euclidean distance of the SLBP vector of the current image compared to all representative SLBP vectors of the sample images observed in advance. Formally,

$$
\Phi(\mathbf{X})=\min _{t}\left\{\left\|\operatorname{SLBP}(\mathbf{X})-\operatorname{SLBP}\left(\mathbf{X}_{t}\right)\right\|_{2}\right\}
$$

where $\mathbf{X}_{1}, \mathbf{X}_{2}, \ldots, \mathbf{X}_{t}$ are the $t$ sample images from the same class as $\mathbf{X}$, known a priori. In our settings, we observed 150 random patches of size $64 \times 64$ as the prior dataset, meaning $t=150$. We chose SLBP with $l=3$ because using 8-neighbors is the most popular version.

To optimize the cost function, we used Simulated Annealing again (Alg. 1 in Section 1.4). All parameters of the SA algorithm were set manually in an empirical manner, similarly to Section 2.2, except that the stopping criteria of the algorithm were to reach 800000 iterations or to perform 25000 iterations without improving the optimal result. We also found that the value of the scaling parameter $\gamma$ in the cost function had to be determined individually for each image class.

As mentioned previously, using RME (Eq. 1.15) to determine the quality of reconstruction can, in some cases, be misleading when dealing with texture images. Therefore, we present the two terms of the cost function, separately here, i.e. $\Phi(\mathbf{X})$ and also the 'projection difference'

$$
E_{\text {proj }}=\|\mathbf{A x}-\mathbf{b}\|_{2} .
$$

We also calculated 'pixel error', defined as

$$
E_{p}=\frac{\sum_{i j}\left|o_{i j}-r_{i j}\right|}{m \cdot n} \cdot 100 \%,
$$

where $O$ and $R$ are the original and the reconstructed image, respectively, and $m \times n$ is the size of the image. 


\subsubsection{Synthetic Image Classes}

As a first step, we generated synthetic images with simple textures of size $1024 \times 1024$ (Figs. 2.5a - 2.5d, and D.1). As prior information, we used the SLBP vectors of 150 randomly selected patches of size $64 \times 64$ from the same image classes. Then, we selected 10 random patches of size $64 \times 64$ from each class and attempted to reconstruct them from the horizontal and vertical projections complemented by the prior data using different $\gamma$ weights. Finally, we attempted to reconstruct the images using the prior information only (i.e. omitting the projection term), to emphasize the importance of both terms. Table 2.9 displays the mean results, where $C(\mathbf{X})_{\text {start }}$ and $C(\mathbf{X})_{\text {final }}$ stand for the initial and final objective function value, and $\Phi(\mathbf{X})_{\text {start }}, \Phi(\mathbf{X})_{\text {final }}$ represent the initial and the final minimal Euclidean distance from the SLBP vectors, respectively.

\begin{tabular}{|c|c|c|r|r|r|r|r|}
\hline & $E_{p}$ & RME & $C(\mathbf{X})_{\text {start }}$ & $C(\mathbf{X})_{\text {final }}$ & $E_{\text {proj }}$ & $\Phi(\mathbf{X})_{\text {start }}$ & $\Phi(\mathbf{X})_{\text {final }}$ \\
\hline \multicolumn{8}{|c|}{$\gamma=0$} \\
\hline Chessboard & 50 & 100 & 63.32 & 7.83 & 7.83 & 386.64 & 386.81 \\
\hline Diagonal & 50 & 100 & 62.75 & 7.20 & 7.20 & 272.49 & 271.82 \\
\hline Grid & 2 & 7 & 368.88 & 10.47 & 10.47 & 272.31 & 42.95 \\
\hline Line & 12 & 25 & 289.58 & 64.05 & 64.05 & 386.97 & 247.42 \\
\hline \multicolumn{8}{|c|}{$\gamma=1$} \\
\hline Chessboard & 50 & 101 & 449.49 & 326.11 & 6.36 & 387.23 & 319.75 \\
\hline Diagonal & 50 & 100 & 334.82 & 269.66 & 4.81 & 272.64 & 264.85 \\
\hline Grid & 0 & 0 & 639.60 & 3.05 & 1.77 & 272.76 & 1.28 \\
\hline Line & 0 & 0 & 675.58 & 4.22 & 2.09 & 386.96 & 2.13 \\
\hline \multicolumn{7}{|c|}{$\gamma=2$} \\
\hline Chessboard & 46 & 92 & 836.74 & 175.88 & 10.12 & 386.90 & 82.88 \\
\hline Diagonal & 48 & 96 & 611.32 & 176.57 & 8.92 & 272.75 & 83.82 \\
\hline Grid & 0 & 0 & 908.55 & 3.14 & 1.36 & 271.74 & 0.90 \\
\hline Line & 0 & 0 & 1065.56 & 5.57 & 2.19 & 387.16 & 1.69 \\
\hline \multicolumn{7}{|c|}{$\gamma=1$ without projection term } \\
\hline Chessboard & 43 & 86 & 386.82 & 45.32 & 12.20 & 386.82 & 45.32 \\
\hline Diagonal & 48 & 96 & 272.43 & 59.77 & 18.83 & 272.43 & 59.77 \\
\hline Grid & 38 & 152 & 272.88 & 67.49 & 269.08 & 272.88 & 67.49 \\
\hline Line & 52 & 103 & 386.86 & 39.42 & 296.52 & 386.86 & 39.42 \\
\hline
\end{tabular}

Table 2.9: Mean results of SA of the synthetic image classes for different $\gamma$ weights. 
Original images

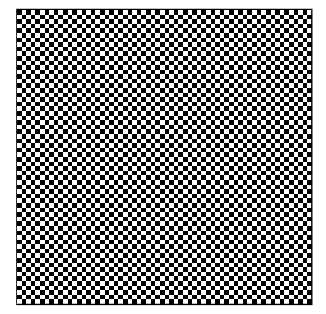

(a) Chessboard

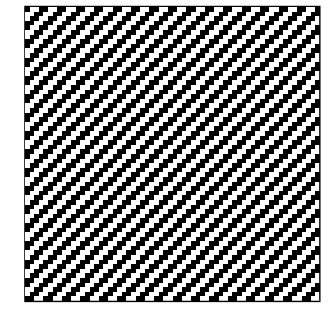

(b) Diagonal

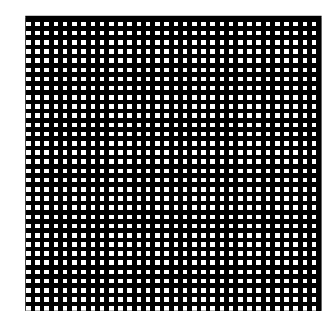

(c) Grid

$$
\gamma=0
$$

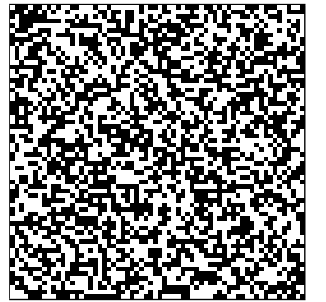

(e)

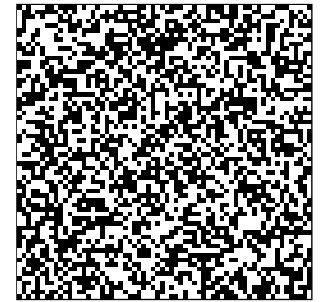

(f)

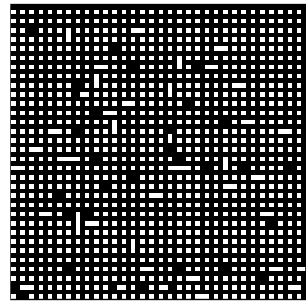

(g)

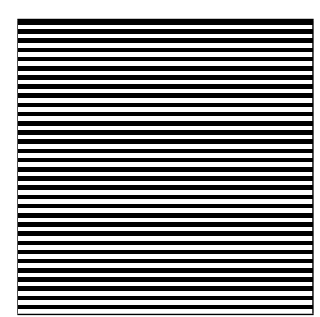

(d) Line

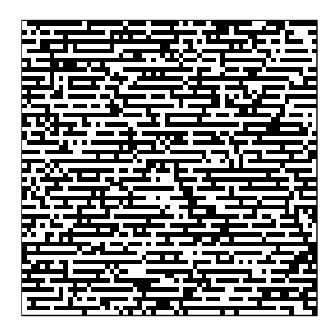

(h)

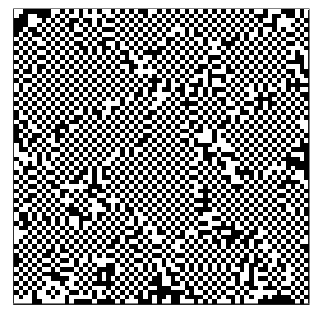

(i)

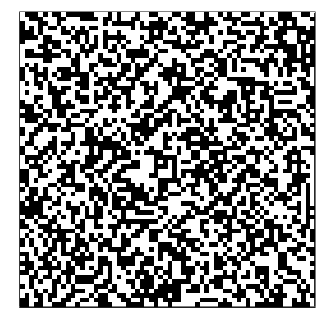

(j)

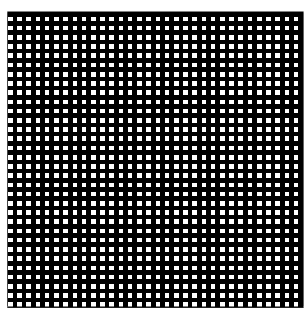

(k)

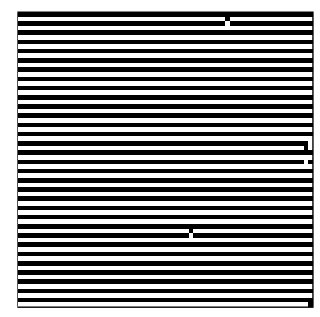

(l)

$$
\gamma=2
$$

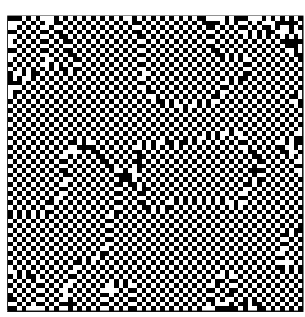

(m)

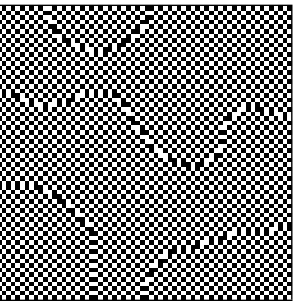

(q)

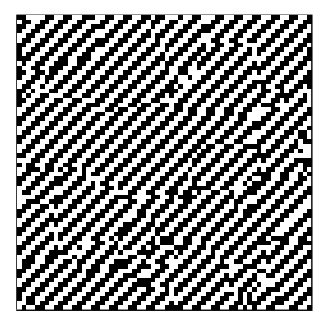

(n)

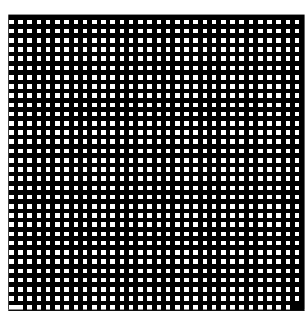

(o)

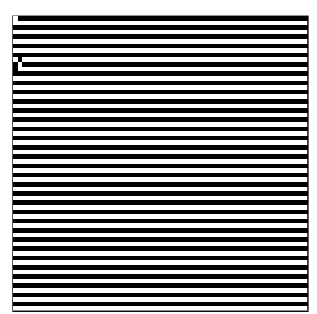

(p)

$$
\gamma=1 \text { without projection term }
$$

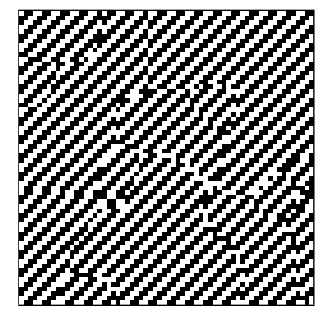

(r)

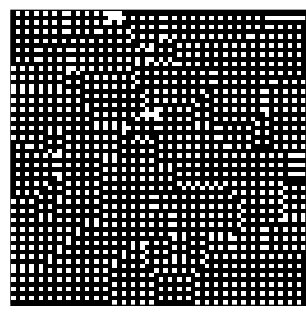

(s)

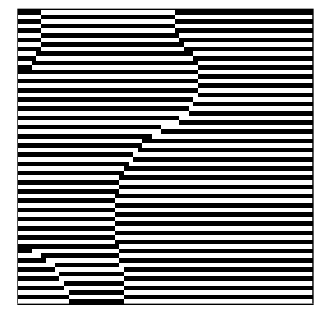

(t)

Figure 2.5: Sample SA results of the synthetic image classes. 
Figure 2.5 represents a sample SA result for each class as follows. Figures 2.5a - 2.5d provide examples from the original image classes; Figs. 2.5e - 2.5h supply sample SA results for $\gamma=0$; Figs. 2.5i - 2.51 lay out sample SA results for $\gamma=1$; Figs. 2.5m - 2.5p provide sample SA results for $\gamma=2$; and finally, Figs. $2.5 q-2.5 t$ deliver sample SA results for $\gamma=1$ by omitting the projection information. Based on these experiments, we can deduce the following. In the case of Line and Grid image classes, SA was able to reach $0 \% \mathrm{RME}$, and all the final values were satisfactory in case of $\gamma=1$ and $\gamma=2$. This is in accordance with the fact that these images are uniquely determined by their horizontal and vertical projections (as they do not contain switching components) [74]. Consequently, in these cases, DART and Ryser's algorithm provided exact reconstructions. Unfortunately, SA did not lead to perfect reconstruction in each case using only the projection term, but complementing it with the prior information could potentially improve the quality. In the case of the Chessboard and Diagonal image classes, by increasing the $\gamma$ weight of the SLBP term, the reconstructions could be forced to be more similar in texture to the observed patches. In contrast, DART was unable to reconstruct the images. It first created a grayscale image with 0.5 value at each pixel, and then thresholded it, resulting in a fully black or fully white image, depending on the threshold level. Ryser's algorithm was also unable to reconstruct them, resulting in images like Fig. 2.6.

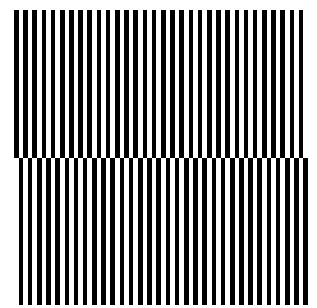

Figure 2.6: Sample result of Ryser's algorithm for Chessboard and Diagonal image classes.

To investigate the effect of increasing $\gamma$ in the case of the Chessboard image class, consider the matrix

$$
\mathbf{M}=\left[\begin{array}{ll}
1 & 0 \\
0 & 1
\end{array}\right]
$$

which codes a frequent pattern in this class. Let $F_{\mathbf{M}}$ denote the frequency of occurrence of matrix $\mathbf{M}$.

The original image contains submatrix M 1985 times. Based on experiments, we observe the following (Fig. 2.7). Increasing the $\gamma$ weight from 0 to 1 , there is no significant change in the frequency of occurrence of $M$ $\left(F_{\mathbf{M}} \in[200,400]\right)$. Then, somewhere between 1 and 1.05 , there is a big jump in frequency $\left(F_{\mathbf{M}} \approx 1400\right)$, as well as in between 1.1 and $1.15\left(F_{\mathbf{M}} \approx 1700\right)$. Above $1.15\left(F_{\mathbf{M}} \in[1700,1810]\right)$, again there is no significant improvement. 


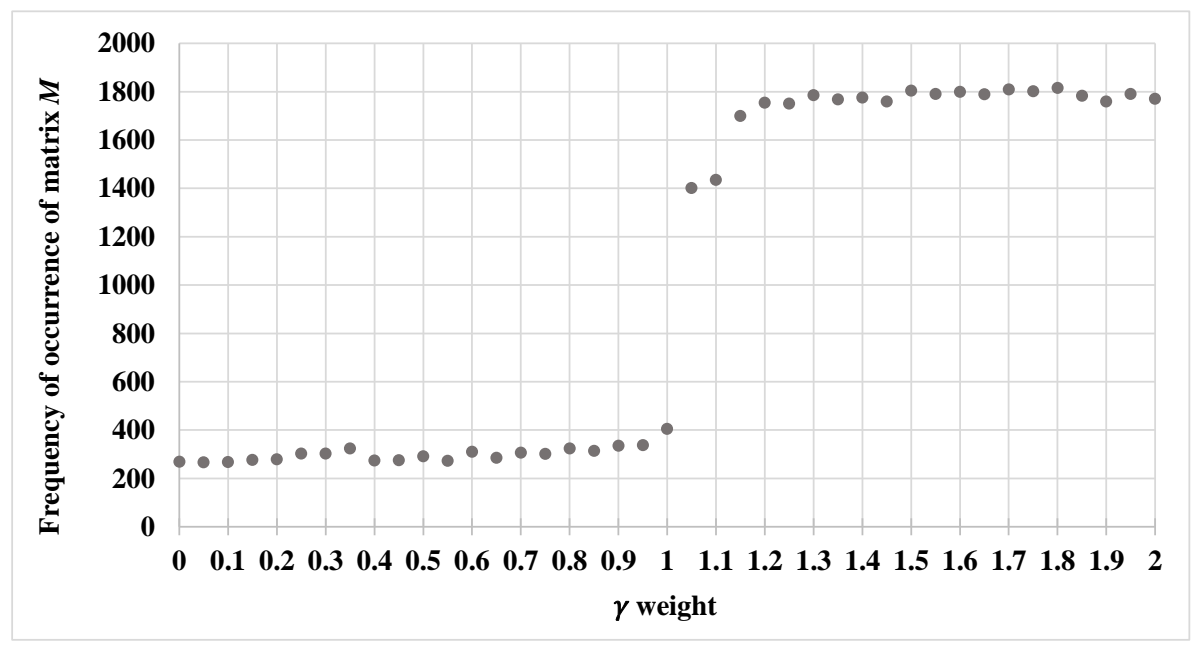

Figure 2.7: Frequency of occurrence of matrix $\mathbf{M}$ concerning increasing $\gamma$ weights for the Chessboard image class.

In addition, we can observe that Fig. 2.5e with $\gamma=0$ has no clear texture; however while increasing the $\gamma$ weight, the reconstructed images reveal more and more of the original Chessboard texture. Nevertheless, they may contain some noise-like curves due to the fact that during the run of the SA algorithm, poorer solutions can also be accepted in the iterations. Therefore, the algorithm may make local mistakes in the pattern, and this can be extended for the entire image.

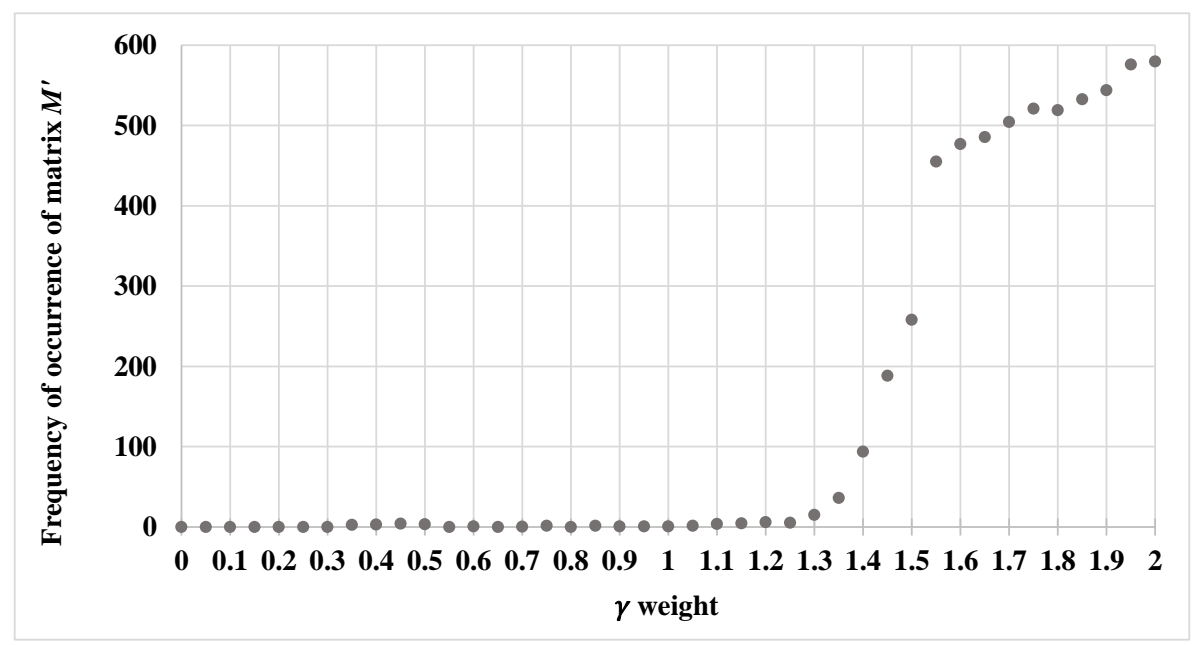

Figure 2.8: Frequency of occurrence of matrix $\mathbf{M}^{\prime}$ concerning increasing $\gamma$ weights for the Diagonal image class.

Similarly, in the case of the Diagonal image class, we calculated the frequency of occurrence of the matrix

$$
\mathbf{M}^{\prime}=\left[\begin{array}{llll}
1 & 1 & 0 & 0 \\
1 & 0 & 0 & 1 \\
0 & 0 & 1 & 1 \\
0 & 1 & 1 & 0
\end{array}\right]
$$


by increasing the $\gamma$ weight. Let $F_{\mathbf{M}^{\prime}}$ denote the frequency of occurrence of matrix $\mathbf{M}^{\prime}$.

The SA behaved similarly for the Diagonal image class, although it required higher $\gamma$ value to produce the appropriate texture. For the original image, $F_{\mathbf{M}^{\prime}}=930$, while for $\gamma \in[0,1.25] \quad F_{\mathbf{M}^{\prime}}<10$, and for $\gamma \in[1.3,1.4]$ $F_{\mathbf{M}^{\prime}} \in[10,100]$. There are a few jumps in frequency between $\gamma=1.4$ and $\gamma=1.6\left(F_{\mathbf{M}^{\prime}} \in[100,500]\right)$. Above $\gamma=1.6$, there is no significant improvement $\left(F_{\mathbf{M}^{\prime}} \in[500,600]\right)$.

\subsubsection{Software Phantom Images}

In the next experiment, we used software phantom images from 6 classes with distinct textures (Fig. 2.2 in Section 2.2). The sizes of the images vary, the smallest one being $430 \times 300$, while the largest one measures $1230 \times 1120$. We reconstructed 10-10 random image patches of size $64 \times 64$ from each class using increasing $\gamma$ weights, ultimately omitting the projection term. The mean results are presented in Table 2.10. Once again, $C(\mathbf{X})_{\text {start }}$ and $C(\mathbf{X})_{\text {final }}$ stand for the initial and final objective function value, and $\Phi(\mathbf{X})_{\text {start }}, \Phi(\mathbf{X})_{\text {final }}$ represent the initial and final minimal Euclidean distance from the SLBP vectors, respectively. Finally, $\Phi(\mathbf{X})_{\text {orig }}$ indicates the Euclidean distance between the SLBP vectors of the resulting and the original images. Note that an adequate reconstruction is not the one that corresponds to the minimal $\Phi(\mathbf{X})_{\text {final }}$, but whose $\Phi(\mathbf{X})_{\text {final }}$ value is close to $\Phi(\mathbf{X})_{\text {orig. }}$.

We can observe that increasing the $\gamma$ weight can greatly improve the numerical quality of the reconstruction (both $E_{\text {proj }}$ and $\Phi(\mathbf{X})$ can be decreased). Note that further incrementation of the $\gamma$ weight did not result in in additional enhancement. However, the visual results are not always satisfying, not even using DART or Ryser's algorithm (see an example in Fig. 2.9). The reason for this is, the small patterns of the original image classes do not have local regular textures, even though the original images follow some regularities in the global sense. Furthermore, using solely SLBP term provided poorer results than using both terms. Therefore, we can deduce that both terms are needed for an acceptable reconstruction.

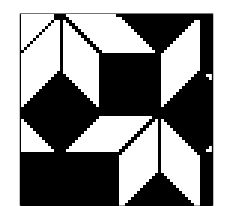

(a) Original image

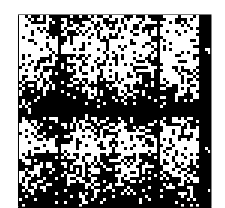

(b) SA

$(\gamma=0)$

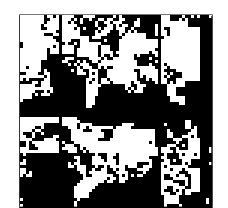

(c) SA

$(\gamma=1)$

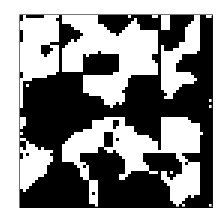

(d) SA $(\gamma=2)$

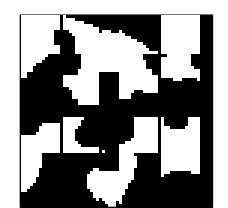

(e) DART

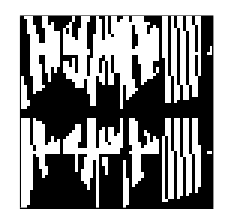

(f) Ryser's algorithm

Figure 2.9: Sample results of Fig. 2.2a. 


\begin{tabular}{|c|c|c|c|c|c|c|c|c|}
\hline & $E_{p}$ & RME & $\mathrm{C}(\mathbf{X})_{\text {start }}$ & $C(\mathbf{X})_{\text {final }}$ & $E_{\text {proj }}$ & $\Phi(\mathbf{X})_{\text {start }}$ & $\Phi(\mathbf{X})_{\text {final }}$ & $\Phi(\mathbf{X})_{\text {orig }}$ \\
\hline \multicolumn{9}{|c|}{$\gamma=0$} \\
\hline $2.2 \mathrm{a}$ & 28 & 67 & 240.84 & 8.59 & 8.59 & 257.02 & 177.34 & 197.11 \\
\hline $2.2 b$ & 40 & 62 & 207.04 & 11.84 & 11.84 & 213.00 & 199.36 & 211.27 \\
\hline $2.2 \mathrm{c}$ & 24 & 30 & 351.99 & 8.75 & 8.75 & 239.64 & 170.19 & 190.01 \\
\hline $2.2 \mathrm{~d}$ & 24 & 115 & 338.14 & 9.35 & 9.35 & 268.14 & 173.98 & 198.87 \\
\hline $2.2 \mathrm{e}$ & 26 & 34 & 324.85 & 21.95 & 21.95 & 160.53 & 96.67 & 106.06 \\
\hline $2.2 f$ & 25 & 31 & 344.40 & 9.28 & 9.28 & 303.73 & 200.89 & 214.67 \\
\hline \multicolumn{9}{|c|}{$\gamma=1$} \\
\hline $2.2 \mathrm{a}$ & 27 & 65 & 502.45 & 76.73 & 4.19 & 256.63 & 72.55 & 92.49 \\
\hline $2.2 b$ & 40 & 62 & 421.29 & 107.50 & 2.44 & 213.13 & 105.06 & 116.80 \\
\hline $2.2 \mathrm{c}$ & 23 & 29 & 593.07 & 55.15 & 4.83 & 239.39 & 50.32 & 68.07 \\
\hline $2.2 \mathrm{~d}$ & 24 & 114 & 609.27 & 56.85 & 5.55 & 268.09 & 51.30 & 80.41 \\
\hline $2.2 \mathrm{e}$ & 26 & 34 & 486.12 & 38.62 & 13.27 & 161.82 & 25.35 & 29.10 \\
\hline $2.2 f$ & 25 & 30 & 646.20 & 72.94 & 4.40 & 303.30 & 68.54 & 83.82 \\
\hline \multicolumn{9}{|c|}{$\gamma=2$} \\
\hline $2.2 \mathrm{a}$ & 27 & 64 & 759.18 & 34.17 & 7.94 & 256.95 & 13.11 & 30.72 \\
\hline $2.2 b$ & 40 & 62 & 629.39 & 29.98 & 5.06 & 212.93 & 12.46 & 20.30 \\
\hline $2.2 \mathrm{c}$ & 24 & 30 & 828.57 & 31.14 & 5.94 & 239.39 & 12.60 & 26.59 \\
\hline $2.2 \mathrm{~d}$ & 24 & 115 & 877.25 & 26.09 & 6.45 & 268.33 & 9.82 & 40.36 \\
\hline $2.2 \mathrm{e}$ & 25 & 33 & 649.98 & 42.41 & 13.60 & 162.24 & 14.40 & 18.41 \\
\hline $2.2 f$ & 24 & 30 & 949.43 & 16.93 & 8.28 & 303.31 & 4.33 & 18.55 \\
\hline \multicolumn{9}{|c|}{$\gamma=1$ without projection term } \\
\hline $2.2 a$ & 54 & 130 & 256.66 & 6.91 & 345.02 & 256.66 & 6.91 & 27.72 \\
\hline $2.2 b$ & 46 & 70 & 213.51 & 2.39 & 185.73 & 213.51 & 2.39 & 13.35 \\
\hline $2.2 c$ & 53 & 65 & 239.26 & 3.21 & 421.28 & 239.26 & 3.21 & 36.21 \\
\hline $2.2 d$ & 55 & 263 & 267.88 & 3.05 & 420.61 & 267.88 & 3.05 & 38.04 \\
\hline $2.2 \mathrm{e}$ & 39 & 50 & 162.32 & 3.06 & 189.03 & 162.32 & 3.06 & 15.34 \\
\hline $2.2 \mathrm{f}$ & 44 & 54 & 303.38 & 2.20 & 305.41 & 303.38 & 2.20 & 16.80 \\
\hline
\end{tabular}

Table 2.10: Mean results of SA of the software phantom image classes (Fig. 2.2) for different $\gamma$ weights.

\subsubsection{Real Images}

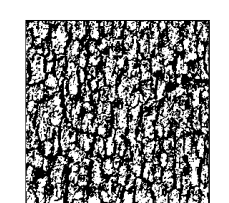

(a)

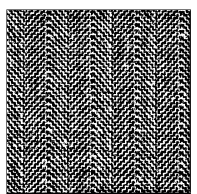

(g)

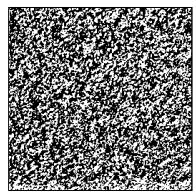

(b)

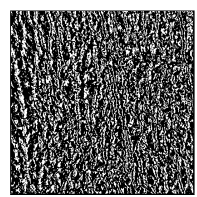

(h)

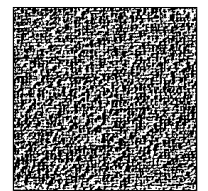

(c)

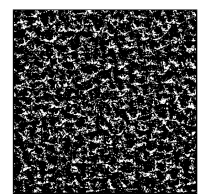

(i)

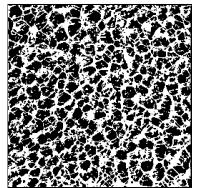

(d)

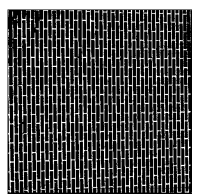

(j)

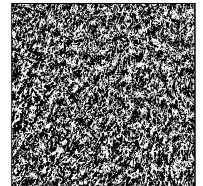

(e)

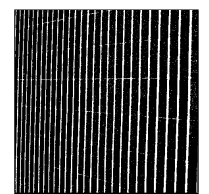

(k)

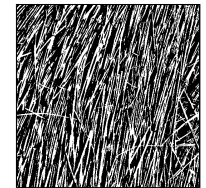

(f)

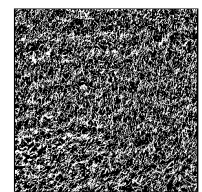

(l)

Figure 2.10: Real image classes I. [18]. 


\begin{tabular}{|c|c|c|c|c|c|c|c|c|}
\hline & $E_{p}$ & RME & $C(\mathbf{X})_{\text {start }}$ & $C(\mathbf{X})_{\text {final }}$ & $E_{\text {proj }}$ & $\Phi(\mathbf{X})_{\text {start }}$ & $\Phi(\mathbf{X})_{\text {final }}$ & $\Phi(\mathbf{X})_{\text {orig }}$ \\
\hline \multicolumn{9}{|c|}{$\gamma=0$} \\
\hline $2.10 \mathrm{a}$ & 44 & 99 & 405.26 & 48.06 & 48.06 & 627.62 & 594.75 & 710.41 \\
\hline $2.10 \mathrm{~b}$ & 48 & 102 & 274.05 & 11.19 & 11.18 & 450.06 & 432.81 & 480.72 \\
\hline $2.10 c$ & 42 & 95 & 437.33 & 12.69 & 12.69 & 628.55 & 569.06 & 617.28 \\
\hline $2.10 \mathrm{~d}$ & 44 & 103 & 401.15 & 22.91 & 22.91 & 710.81 & 687.11 & 763.28 \\
\hline $2.10 \mathrm{e}$ & 45 & 108 & 395.92 & 13.41 & 13.41 & 757.41 & 737.47 & 836.69 \\
\hline $2.10 \mathrm{f}$ & 41 & 120 & 556.91 & 39.39 & 39.39 & 855.29 & 843.58 & 976.07 \\
\hline $2.10 \mathrm{~g}$ & 37 & 88 & 574.99 & 18.26 & 18.26 & 935.23 & 764.41 & 813.04 \\
\hline $2.10 \mathrm{~h}$ & 40 & 125 & 588.29 & 26.67 & 26.67 & 821.56 & 801.51 & 882.76 \\
\hline $2.10 \mathrm{i}$ & 31 & 139 & 851.83 & 15.12 & 15.12 & 889.16 & 731.23 & 799.39 \\
\hline $2.10 \mathrm{j}$ & 11 & 42 & 1010.80 & 29.92 & 29.92 & 1107.01 & 269.86 & 334.75 \\
\hline $2.10 \mathrm{k}$ & 16 & 62 & 1006.56 & 59.90 & 59.90 & 950.97 & 238.12 & 406.89 \\
\hline 2.101 & 43 & 122 & 524.40 & 13.95 & 13.95 & 511.92 & 534.32 & 602.79 \\
\hline \multicolumn{9}{|c|}{$\gamma=1$} \\
\hline $2.10 \mathrm{a}$ & 43 & 96 & 1030.16 & 69.59 & 6.05 & 627.99 & 63.54 & 169.75 \\
\hline $2.10 \mathrm{~b}$ & 47 & 102 & 730.02 & 81.78 & 5.22 & 449.65 & 76.55 & 115.68 \\
\hline $2.10 c$ & 42 & 94 & 1076.42 & 80.19 & 6.32 & 628.00 & 73.86 & 111.48 \\
\hline $2.10 \mathrm{~d}$ & 44 & 102 & 1106.95 & 57.96 & 6.42 & 710.76 & 51.54 & 124.86 \\
\hline $2.10 \mathrm{e}$ & 44 & 106 & 1156.98 & 67.80 & 6.41 & 757.18 & 61.38 & 148.49 \\
\hline $2.10 \mathrm{f}$ & 40 & 116 & 1418.40 & 101.50 & 3.75 & 854.37 & 97.75 & 214.01 \\
\hline $2.10 \mathrm{~g}$ & 36 & 87 & 1519.82 & 44.46 & 6.24 & 936.73 & 38.22 & 83.61 \\
\hline $2.10 \mathrm{~h}$ & 41 & 126 & 1411.62 & 65.93 & 6.79 & 822.09 & 59.14 & 128.26 \\
\hline $2.10 \mathrm{i}$ & 31 & 138 & 1734.40 & 53.51 & 5.12 & 888.35 & 48.38 & 117.44 \\
\hline $2.10 \mathrm{j}$ & 12 & 46 & 2118.63 & 169.00 & 60.27 & 1105.65 & 108.73 & 173.85 \\
\hline $2.10 \mathrm{k}$ & 14 & 56 & 1948.58 & 54.52 & 25.41 & 948.66 & 29.12 & 197.78 \\
\hline 2.101 & 43 & 123 & 1034.66 & 83.88 & 5.04 & 512.17 & 78.85 & 148.22 \\
\hline \multicolumn{9}{|c|}{$\gamma=2$} \\
\hline $2.10 \mathrm{a}$ & 43 & 97 & 1656.68 & 51.16 & 6.63 & 627.43 & 22.26 & 130.28 \\
\hline $2.10 \mathrm{~b}$ & 47 & 102 & 1183.73 & 62.22 & 6.24 & 450.60 & 27.99 & 69.10 \\
\hline $2.10 \mathrm{c}$ & 42 & 96 & 1699.91 & 57.91 & 5.62 & 628.54 & 26.15 & 67.88 \\
\hline $2.10 \mathrm{~d}$ & 44 & 102 & 1824.67 & 47.20 & 6.65 & 711.71 & 20.27 & 96.14 \\
\hline $2.10 \mathrm{e}$ & 44 & 106 & 1906.63 & 59.56 & 6.80 & 756.43 & 26.38 & 118.29 \\
\hline $2.10 \mathrm{f}$ & 41 & 119 & 2267.28 & 72.50 & 5.84 & 854.74 & 33.32 & 165.11 \\
\hline $2.10 \mathrm{~g}$ & 36 & 86 & 2447.38 & 519.00 & 53.65 & 935.65 & 232.68 & 281.88 \\
\hline $2.10 \mathrm{~h}$ & 40 & 124 & 2241.40 & 49.46 & 5.89 & 822.78 & 21.78 & 92.56 \\
\hline $2.10 \mathrm{i}$ & 31 & 139 & 2623.95 & 24.39 & 6.09 & 889.11 & 9.15 & 81.97 \\
\hline $2.10 \mathrm{j}$ & 30 & 114 & 3220.56 & 1930.04 & 469.37 & 1106.50 & 730.33 & 798.40 \\
\hline $2.10 \mathrm{k}$ & 14 & 58 & 2889.86 & 71.95 & 40.40 & 945.98 & 15.78 & 197.78 \\
\hline 2.101 & 43 & 124 & 1543.74 & 55.93 & 5.84 & 510.23 & 25.04 & 101.92 \\
\hline
\end{tabular}

Table 2.11: Mean results of SA of Fig. 2.10 for different $\gamma$ weights.

As a next step, we conducted tests on real images of 12 different classes from the Brodatz texture database [18] (Figs. 2.10 and D.3). The size of the original images varied between $256 \times 256$ and $1230 \times 1120$. First, we attempted to reconstruct 10-10 random image patches of size $64 \times 64$ from each class. We were faced again with the fact that these image classes, as observed previously, do not have regular textures in this size; consequently, we went on 
to test image patches of size $128 \times 128$. The mean results are provided in Table 2.11.

Unfortunately, there are image classes (e.g. Figs. 2.10a, 2.10j, 2.101) that are hard to reconstruct due to the above mentioned issue. In contrast, there are classes that provided satisfactory results, e.g. see in Fig. 2.11 with Table 2.12. It can be observed, that increasing the $\gamma$ parameter again resulted better values. For $\gamma=2$ (Fig. 2.11d, row 4 in Table 2.12), the reconstruction is satisfying from a numerical and visual point of view as well. The resulting image does not have the exact same, but similar texture to the original one (Fig. 2.11a). In contrast, the outcome of using DART (Fig. 2.11e, row 5 in Table 2.12) or Ryser's algorithm (Fig. 2.11f, row 6 in Table 2.12) is not acceptable.

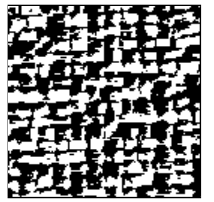

(a) Original image

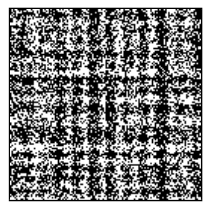

(b) SA

$(\gamma=0)$

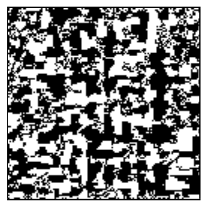

(c) SA

$(\gamma=1)$

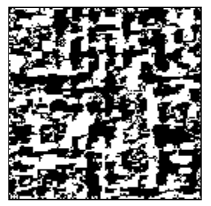

(d) SA

$(\gamma=2)$

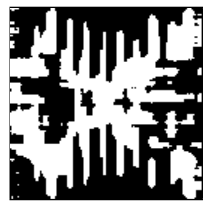

(e) DART

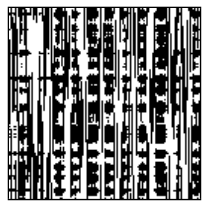

(f) Ryser's algorithm

Figure 2.11: Sample results of Fig. 2.10c.

\begin{tabular}{|l|c|c|r|r|r|r|r|r|}
\hline & $E_{p}$ & RME & $C(\mathbf{X})_{\text {start }}$ & $C(\mathbf{X})_{\text {final }}$ & $E_{\text {proj }}$ & $\Phi(\mathbf{X})_{\text {start }}$ & $\Phi(\mathbf{X})_{\text {final }}$ & $\Phi(\mathbf{X})_{\text {orig }}$ \\
\hline $2.11 \mathrm{~b}$ & 41 & 91 & 451.75 & 9.80 & 9.80 & 627.43 & 551.34 & 573.13 \\
\hline $2.11 \mathrm{c}$ & 41 & 90 & 1085.53 & 81.81 & 7.07 & 626.98 & 74.74 & 88.55 \\
\hline $2.11 \mathrm{~d}$ & 41 & 90 & 1706.57 & 56.93 & 5.10 & 627.44 & 25.91 & 40.12 \\
\hline $2.11 \mathrm{e}$ & 42 & 92 & - & - & 326.96 & - & - & 545.90 \\
\hline $2.11 \mathrm{f}$ & 41 & 90 & - & - & 0.00 & - & - & 406.06 \\
\hline
\end{tabular}

Table 2.12: Numerical results of Fig. 2.11.

Finally, tests were conducted on real images of various porous microstructures [35]. The original image classes (after applying image preprocessing methods) are presented in Fig. 2.12 (as well as in Fig. D.4). The size of the original images varied between $228 \times 228$ and $350 \times 350$. The SA algorithm was tested on 10-10 random image patches of size $64 \times 64$ from each class. The mean results are presented in Table 2.13.

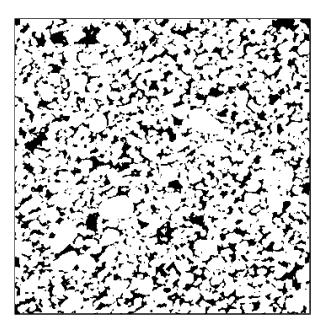

(a) Sandstone [63]

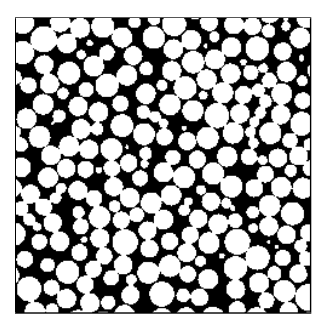

(b) Glass beads [49]

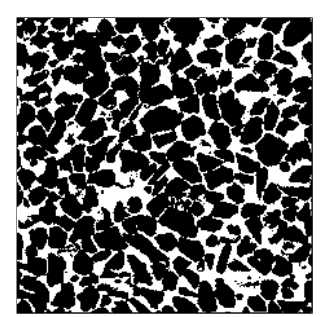

(c) Belgian fieldstone [24]

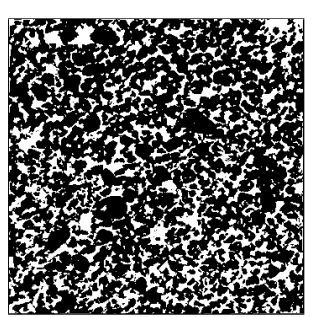

(d) Bentheimer networks [62]

Figure 2.12: Real image classes II. [35]. 
Once again, we can deduce that increasing the $\gamma$ weight to 2 resulted in better final objective function value, i.e. both $E_{\text {proj }}$ and $\Phi(\mathbf{X})$ were acceptable. In contrast, RME was still high, but $E_{p}$ was lower. The reconstruction did not become more accurate when $\gamma$ was assigned higher value than 2 or the projection term was omitted. We attempted to modify the size of the patches to $128 \times 128$. The results were similar to the images smaller in size.

\begin{tabular}{|l|c|c|r|r|r|r|r|r|}
\hline & $E_{p}$ & RME & $C(\mathbf{X})_{\text {start }}$ & $C(\mathbf{X})_{\text {final }}$ & $E_{\text {proj }}$ & $\Phi(\mathbf{X})_{\text {start }}$ & $\Phi(\mathbf{X})_{\text {final }}$ & $\Phi(\mathbf{X})_{\text {orig }}$ \\
\hline \multicolumn{8}{|c|}{$\gamma=0$} \\
\hline 2.12a & 30 & 38 & 320.76 & 8.33 & 8.34 & 200.63 & 164.21 & 191.62 \\
\hline $2.12 \mathrm{~b}$ & 40 & 67 & 192.69 & 11.05 & 11.05 & 229.71 & 210.80 & 226.24 \\
\hline 2.12c & 37 & 118 & 243.07 & 7.90 & 7.90 & 199.84 & 178.20 & 196.19 \\
\hline 2.12d & 38 & 119 & 230.03 & 8.18 & 8.18 & 157.19 & 155.44 & 188.42 \\
\hline \multicolumn{8}{|c|}{$\gamma=1$} \\
\hline 2.12a & 30 & 38 & 509.65 & 46.96 & 5.10 & 200.25 & 41.86 & 68.83 \\
\hline 2.12b & 40 & 67 & 419.59 & 123.17 & 3.15 & 228.97 & 120.03 & 135.16 \\
\hline 2.12c & 37 & 119 & 439.92 & 76.11 & 4.12 & 199.96 & 72.00 & 90.73 \\
\hline 2.12d & 38 & 121 & 382.92 & 70.15 & 4.18 & 156.67 & 65.96 & 102.18 \\
\hline \multicolumn{8}{|c|}{$\gamma=2$} \\
\hline 2.12a & 30 & 39 & 716.16 & 24.92 & 5.52 & 200.39 & 9.71 & 37.53 \\
\hline 2.12b & 40 & 66 & 650.97 & 23.04 & 4.97 & 229.34 & 9.03 & 21.78 \\
\hline 2.12c & 37 & 120 & 638.90 & 23.39 & 4.62 & 200.16 & 9.39 & 28.13 \\
\hline 2.12d & 37 & 117 & 540.71 & 35.55 & 4.74 & 156.53 & 15.40 & 50.37 \\
\hline
\end{tabular}

Table 2.13: Mean results of SA of Fig. 2.12 for different $\gamma$ weights.

The sample results are indicated for each class for SA with different $\gamma$ weights and for DART and Ryser's algorithm in Fig. 2.13 along with Table 2.14. It is clearly visible that for $\gamma=2$, SA outperformed the other methods from both a visual and numerical point of view, even though the reconstructed image does not fully resemble the structure of the original image. DART, by nature, prefers to create homogeneous areas, hence failing to resemble the original texture. RMEs are high in almost all cases. However, it has already been discussed that this figure-of-merit is not informative enough on its own. Taking a look at the $\Phi(\mathbf{X})_{\text {orig }}$ values we are convinced that the SA-based method performed better in solving the reconstruction. We must add that the SA-based method required 1-2 minutes for reconstructing an image, whereas DART and Ryser's algorithm provided the reconstruction in a few seconds. Seemingly, this is the price we pay for better image quality. 
Original images

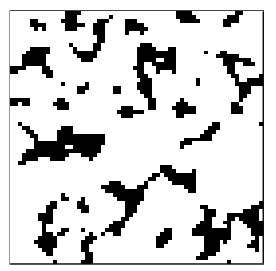

(a)

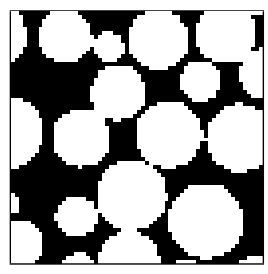

(b)

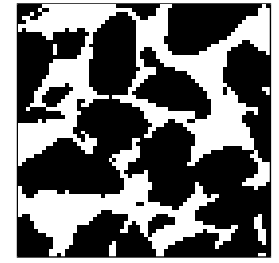

(c)

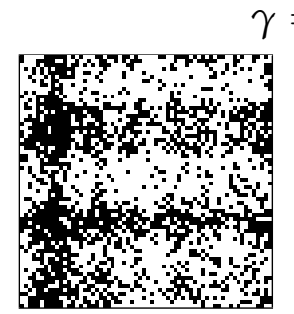

(f)

(e)

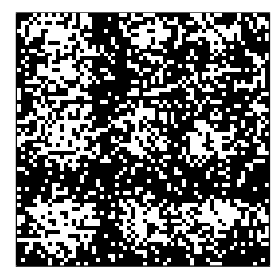

(g)

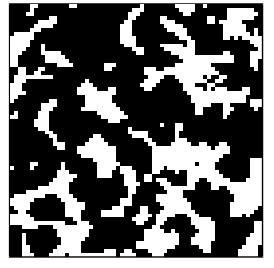

(d)

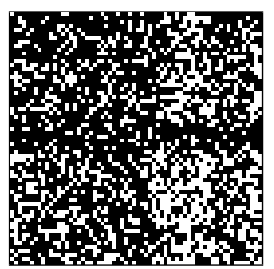

(h)

$\gamma=1$

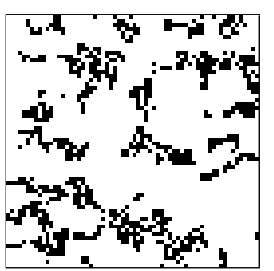

(i)

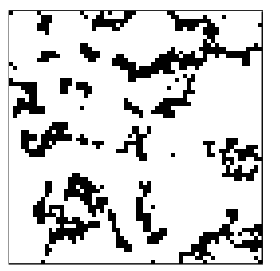

(m)

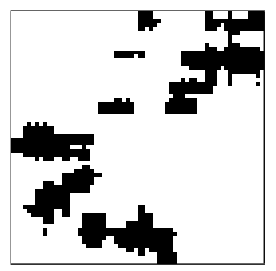

(q)

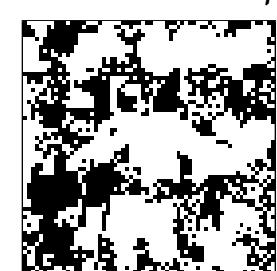

(j)

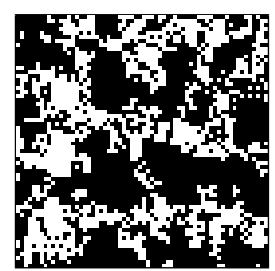

(k)

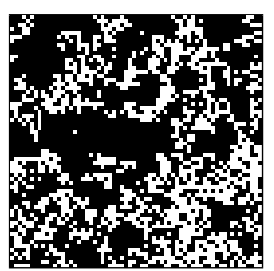

(1)

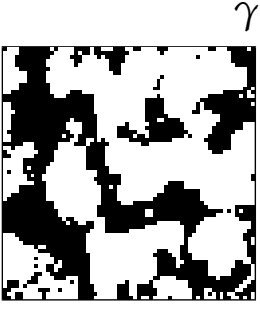

(n)

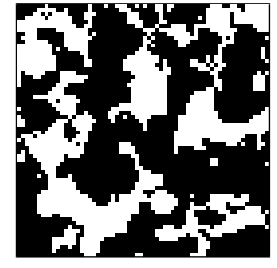

(o)

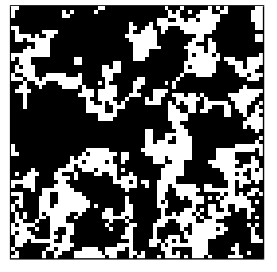

(p)

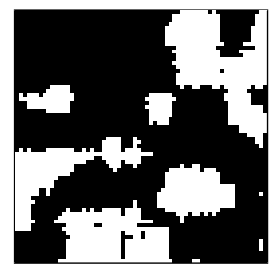

(t)

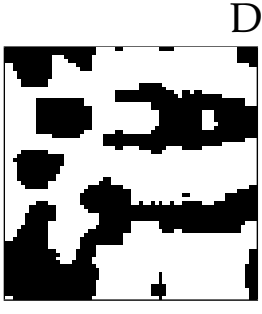

(r)

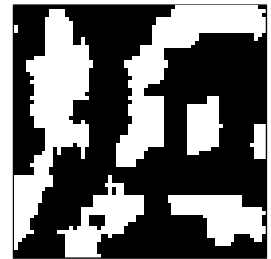

(s)

Ryser's algorithm

(1)

(u)

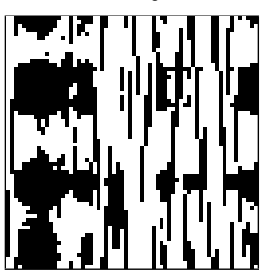

(v)

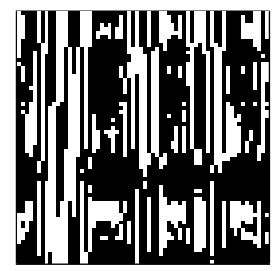

(w)

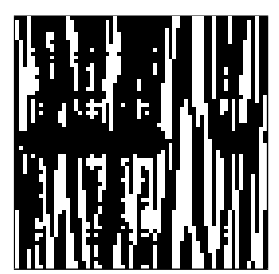

(x)

Figure 2.13: Sample results of Fig.2.12. 


\begin{tabular}{|l|r|r|r|r|r|r|r|r|r|}
\hline & $E_{p}$ & RME & $C(\mathbf{X})_{\text {start }}$ & $C(\mathbf{X})_{\text {final }}$ & $E_{\text {proj }}$ & $\Phi(\mathbf{X})_{\text {start }}$ & $\Phi(\mathbf{X})_{\text {final }}$ & $\Phi(\mathbf{X})_{\text {orig }}$ \\
\hline \multicolumn{8}{|c|}{$\gamma=0$} \\
\hline $2.13 \mathrm{e}$ & 28 & 35 & 343.76 & 9.70 & 9.70 & 201.89 & 182.30 & 197.34 \\
\hline $2.13 \mathrm{f}$ & 37 & 62 & 203.00 & 9.38 & 9.38 & 229.61 & 195.01 & 212.99 \\
\hline $2.13 \mathrm{~g}$ & 39 & 105 & 210.09 & 8.60 & 8.60 & 200.81 & 180.36 & 196.63 \\
\hline $2.13 \mathrm{~h}$ & 40 & 120 & 224.44 & 10.30 & 10.30 & 158.25 & 161.78 & 180.48 \\
\hline \multicolumn{8}{|c|}{$\gamma=1$} \\
\hline $2.13 \mathrm{i}$ & 30 & 37 & 535.76 & 28.58 & 2.83 & 201.23 & 25.75 & 38.46 \\
\hline $2.13 \mathrm{j}$ & 36 & 60 & 430.97 & 95.16 & 2.00 & 229.10 & 93.16 & 111.17 \\
\hline $2.13 \mathrm{k}$ & 39 & 104 & 402.52 & 84.76 & 1.41 & 200.36 & 83.34 & 100.08 \\
\hline $2.13 \mathrm{l}$ & 42 & 123 & 364.85 & 80.85 & 5.48 & 157.17 & 75.37 & 96.15 \\
\hline \multicolumn{7}{|c|}{$\gamma=2$} \\
\hline $2.13 \mathrm{~m}$ & 28 & 35 & 733.27 & 20.38 & 4.47 & 200.99 & 7.95 & 20.52 \\
\hline $2.13 \mathrm{n}$ & 34 & 57 & 671.01 & 27.83 & 7.35 & 230.08 & 10.24 & 24.99 \\
\hline $2.13 \mathrm{o}$ & 40 & 107 & 600.93 & 17.20 & 4.90 & 200.84 & 6.15 & 22.00 \\
\hline $2.13 \mathrm{p}$ & 38 & 111 & 517.23 & 37.49 & 5.66 & 156.42 & 15.91 & 33.60 \\
\hline \multicolumn{7}{|c|}{ DART } \\
\hline $2.13 \mathrm{q}$ & 29 & 36 & - & - & 22.14 & - & - & 79.29 \\
\hline $2.13 \mathrm{r}$ & 37 & 61 & - & - & 24.90 & - & - & 31.74 \\
\hline $2.13 \mathrm{~s}$ & 42 & 113 & - & - & 30.78 & - & - & 61.71 \\
\hline $2.13 \mathrm{t}$ & 41 & 120 & - & - & 23.91 & - & - & 108.46 \\
\hline \multicolumn{8}{|c|}{ Ryser's algorithm } \\
\hline $2.13 \mathrm{u}$ & 27 & 34 & - & - & 0.00 & - & - & 76.95 \\
\hline $2.13 \mathrm{v}$ & 35 & 58 & - & - & 0.00 & - & - & 126.41 \\
\hline $2.13 \mathrm{w}$ & 39 & 105 & - & - & 0.00 & - & - & 151.56 \\
\hline $2.13 \mathrm{x}$ & 40 & 119 & - & - & 0.00 & - & - & 111.61 \\
\hline
\end{tabular}

Table 2.14: Numerical results of Fig. 2.13.

\subsection{Conclusion}

In this chapter, we examined how texture information improves the quality of binary tomographic reconstruction using extremely few projections. We presented and compared different versions of Local Binary Patterns (LBP, FLBP, SLBP, DRLBP) and found that in our case, SLBP is the best choice. Integrating it into the reconstruction process, we solved the corresponding optimization problem by SA. We observed that the widely used RME is not suitable to describe reconstruction quality in our case. Therefore, for better comparison, we separated the two terms of the cost function (projection difference, $E_{\text {proj }}$ and $\Phi(\mathbf{X})$ ), and measured their initial and final values. Additionally, we also investigated pixel error $\left(E_{p}\right)$ to enable an all-encompassing analysis. We used DART and Ryser's algorithm as references.

We tested our idea on different datasets: first on synthetic images and software phantom images, and finally on real images. We found that SLBP as texture prior information can significantly improve the reconstruction quality, especially when only very few projections are available. Naturally, we cannot expect perfect reconstructions from merely two projections. Still, the improvement in quality when applying the method is indisputable. 
This chapter is based on papers [83, 85].

In this chapter, the author regards the following as her main contributions:

- analysis and comparison of the different LBP variants,

- definition of the proper objective function,

- definition of alternative quality measurements,

- implementation of the suggested methods,

- testing and comparing the methods,

- evaluation of the results. 


\section{Chapter 3}

\section{Binary Tomography Based on Nonograms}

Logic puzzles are very popular nowadays. One of them is the so-called Nonogram (also known as Japanese puzzle, Picross, and various other names), where the aim is either to fill in or leave blank the cells of an image grid according to the numbers at the side of the grid to reveal a hidden picture (see Figs 3.1c, 3.1f, and 3.1i). The numbers familiar from DT denote how many consecutive filled-in squares there are in the given rows or columns. These images are usually black and white, describing a binary image. Therefore, a Nonogram game can also be understood as a combinatorial problem, combining elements of logical reasoning with integer calculations. Inspired by Nonogram puzzles, in this chapter, we introduce a novel prior to describe the expected structure of the reconstructed image: the number of strips (consecutive 1s of maximal length) in each row and column.

\subsection{Problem Outline}

First, recall the basic problem of binary tomography, where the aim is to reconstruct a two-dimensional binary image from two projections. The image can be represented by a binary matrix, where 1 stands for the object (black) and 0 for the background (white) pixels, respectively. Furthermore, the horizontal and vertical projection of the image can be defined as the vector of the row and column sums of the image matrix. Therefore, formally, the following problem is investigated.

Problem. BINARY TOMOGRAPHY (BT)

Input: Two non-negative integer vectors $H \in \mathbb{Z}^{m}$ and $V \in \mathbb{Z}^{n}$.

Output: A binary matrix of size $m \times n$, if it exists, with row sum vector $H$ and column sum vector $V$.

This problem is known to be solvable in polynomial time, although usually not in a unique way [74]. It is also proven that the presence of switching components (Def. 1.2) ensures non-uniqueness of the solution. The above problem has a natural connection to the Nonogram puzzles. To formally describe this problem, we introduce the notion of strips, which are nonextendible (i.e. maximal) segments of black pixels of a row or column. 
Definition 3.1 Given a binary matrix $\mathbf{X}$ of size $m \times n$, a sequence of consecutive positions $\left(i, j_{s}\right),\left(i, j_{s+1}\right), \ldots,\left(i, j_{s+l-1}\right)$ (where $l$ is a positive integer, and $\left.1 \leq j_{s} \leq n\right)$ in the $i^{\text {th }}$ row $(1 \leq i \leq m)$ form a strip if $x_{i, j_{s}}=x_{i, j_{s+1}}=, \ldots,=x_{i, j_{s+l-1}}=1$, and $x_{i, j_{s}-1}=x_{i, j_{s}+l}=0$ (if the latter two positions exist). The length of the strip is provided by $l$. Strips of columns can be defined analogously.

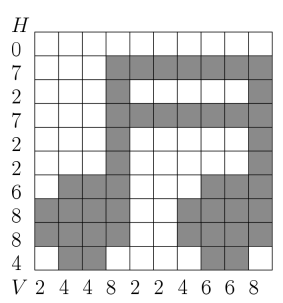

(a)

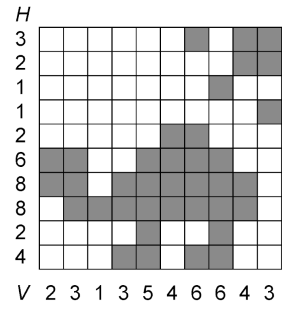

(d)

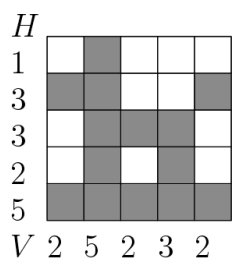

(g)

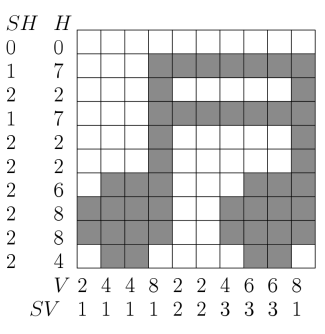

(b)

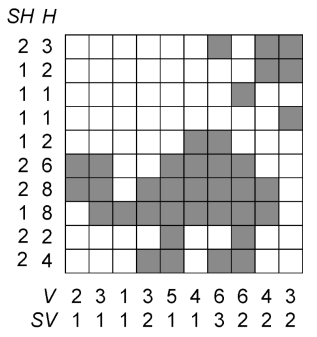

(e)

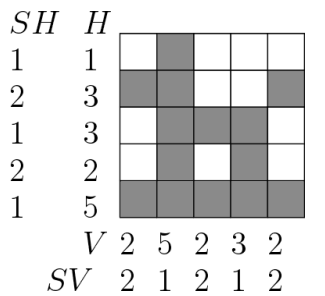

(h)

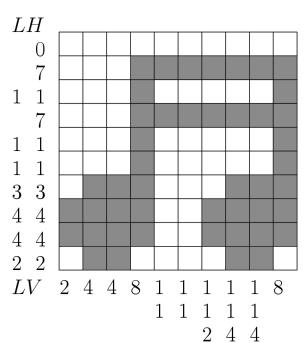

(c)

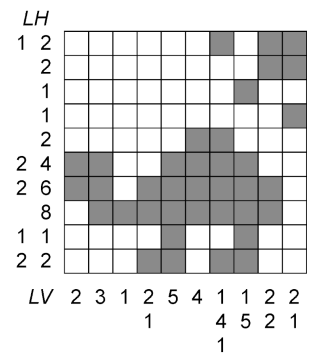

(f)

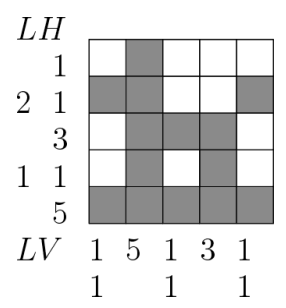

(i)

Figure 3.1: Instances of the BT $(\mathrm{a}, \mathrm{d}, \mathrm{g})$, SCBT $(\mathrm{b}, \mathrm{e}, \mathrm{h})$, and Nonogram $(c, f, i)$ problems. Padding zero elements of the matrices $\mathbf{L H}$ and $\mathbf{L V}$ are not indicated.

The length of each strip in the rows of matrix $\mathbf{X}$ can be encoded by an integer matrix LH of size $m \times n$, where $l h_{i j}$ is the length of the $j^{t h}$ strip from the left, in the $i^{\text {th }}$ row. Entries not used to indicate strips are set to 0. Similarly, a matrix LV of size $n \times m$ can describe the length of each strip in the columns of $\mathbf{X}$. The NONOGRAM problem can be defined as follows.

\section{Problem. NONOGRAM}

Input: Two non-negative integer matrices $\mathbf{L H}$ of size $m \times n$ and $\mathbf{L V}$ of size $n \times m$.

Output: A binary matrix of size $m \times n$, if it exists, each row and column having strips of length prescribed by $\mathbf{L H}$ and $\mathbf{L V}$, respectively. 
It is known from [90] that both NONOGRAM as well as checking whether its solution is unique are NP-complete problems. Thus, NONOGRAM is much harder to solve than BT, from both the viewpoints of existence and uniqueness. Further works on solvability and uniqueness of nonograms is published in $[3,10,11,14,69,97,101]$.

We define the following intermediate problem.

Problem. STRIP CONSTRAIned BINARY TOMOGRAPHY (SCBT)

Input: Four non-negative integer vectors $H \in \mathbb{Z}^{m}, V \in \mathbb{Z}^{n}, S H \in \mathbb{Z}^{m}$, and $S V \in \mathbb{Z}^{n}$.

Output: A binary matrix of size $m \times n$, if it exists, with row sum vector $H$, column sum vector $V$, and in each row and column having the number of strips prescribed by $S H$ and $S V$, respectively.

The above mentioned problems and their relations are presented in Fig. 3.1. The motive behind studying this problem comes from the fact that the $S H$ and $S V$ vectors can also carry texture-like information of the image, and such descriptors may reduce the ambiguity of the reconstruction, which was also presented in Chapter 2.

If the $S H$ and $S V$ vectors contain exclusively 1 values, then SCBT reduces to the problem of reconstructing so-called hv-convex images (where all the black pixels in each row and column must be consecutive). This latter problem is also NP-complete in general [98], thus, so is SCBT.

We have seen in Propositions 1.3 and 1.4 that for the BINARY TOMOGRAPHY problem (using only the horizontal and vertical projections), applying elementary switchings does not leave the set of possible solutions. In contrast, concerning the SCBT problem, we can make the following propositions.

Proposition 3.1 The solution of the SCBT problem is not always uniquely determined.

Proposition 3.2 For certain inputs, the SCBT problem can have several solutions, such that one cannot be transformed into the other by a sequence of elementary switchings in a way that all switching produces a matrix that is a solution of the same SCBT problem as well.

In addition, we can also make the following observation.

Proposition 3.3 For an arbitrary solution of a fixed instance of the SCBT problem, it holds that the number of pairs of adjacent 1 s in the $i^{\text {th }}$ row $(i=1, \ldots, m)$ is equal to $h_{i}-s h_{i}$, and the number of pairs of adjacent 1 s in the $j^{\text {th }}$ column $(j=1, \ldots, n)$ is equal to $v_{j}-s v_{j}$.

If there is only a single strip in the row or the column, Proposition 3.3 naturally holds, while 'cutting' a strip into two parts decreases the number of adjacent 1 s by 1 , and increases the number of strips by 1 . 


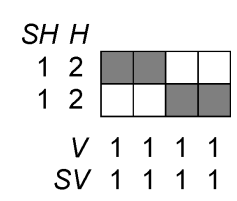

(a)

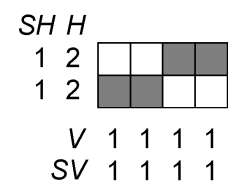

(d)

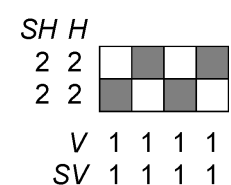

(b)

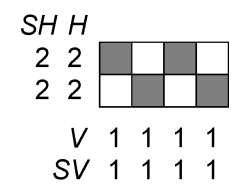

(e)

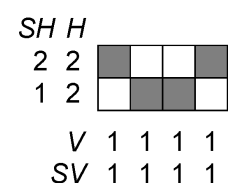

(c)

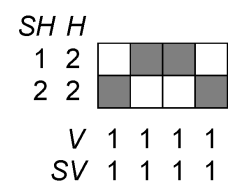

(f)

Figure 3.2: Sample for uniqueness (c, f) and non-uniqueness $(a, d, b, e)$ of the SCBT problem.

For an example of Proposition 3.1 and Proposition 3.2, see Fig. 3.2. Clearly, Figs. $3.2 \mathrm{a}$ and $3.2 \mathrm{~d}$, as well as Figs. 3.2b and 3.2e cannot be distinguished by their $H, V, S H$, and $S V$ vectors, therefore, the solution in this case is non-unique. Note also that an elementary switching cannot transform one solution into the other. Obviously, the existence of a switching component is necessary for non-uniqueness, but not always sufficient. Figures 3.2c and $3.2 \mathrm{f}$ are uniquely determined by their vectors, even though they contain switching components. It is clearly visible that the number of strips holds less information than the exact length of each strip, which is provided in case of the NONOGRAM.

\subsection{Proposed Methods}

\subsubsection{Constraint Satisfaction}

Consider the input instance $H \in \mathbb{Z}^{m}, S H \in \mathbb{Z}^{m}, V \in \mathbb{Z}^{n}$, and $S V \in \mathbb{Z}^{n}$ of the SCBT problem. The goal is to construct a binary matrix $\mathbf{X}$ of size $m \times n$ according to the given vectors. In line with [31], SCBT is formulated as a Constraint Satisfaction Problem.

Let $\mathbf{Y} \mathbf{H}^{m \times(n-1)}$ and $\mathbf{Y} \mathbf{V}^{(m-1) \times n}$ two unknown binary matrices indicate the locations of adjacent $1 \mathrm{~s}$ in the solution, i.e. the $\left[\begin{array}{ll}1 & 1\end{array}\right]$ and $\left[\begin{array}{l}1 \\ 1\end{array}\right]$ components of the solution image, respectively. The conditions of the model are as follows:

$$
\begin{aligned}
& \sum_{j=1}^{n} x_{i j}=h_{i} \quad(i=1, \ldots, m), \\
& \sum_{i=1}^{m} x_{i j}=v_{j} \quad(j=1, \ldots, n), \\
& \sum_{j=1}^{n-1} y h_{i j}=h_{i}-s h_{i} \quad(i=1, \ldots, m), \\
& \sum_{i=1}^{m-1} y v_{i j}=v_{j}-s v_{j} \quad(j=1, \ldots, n), \\
& y h_{i j} \leq x_{i j} \text { and } y h_{i j} \leq x_{i(j+1)} \quad(i=1, \ldots, m ; j=1, \ldots,(n-1)), \\
& y v_{i j} \leq x_{i j} \text { and } y v_{i j} \leq x_{(i+1) j} \quad(i=1, \ldots,(m-1) ; j=1, \ldots, n) .
\end{aligned}
$$


Equations 3.1 and 3.2 ensure that the reconstructed image complies with the given row and column sums, respectively, whereas the conditions of Eqs. 3.3 and 3.4 are to satisfy Proposition 3.3. Finally, Eq. 3.5 establishes the connection between the solution image and its components formed by the adjacent $1 \mathrm{~s}$ in rows. If $\left(x_{i j}, x_{i, j+1}\right) \in\{(0,0),(0,1),(1,0)\}$, then $y h_{i j}=0$ must hold up, indicating that the pair of positions $(i, j)$ and $(i, j+1)$ do not form a component of consecutive 1s. However, $y h_{i j}=1$ can hold up if both $x_{i j}$ and $x_{i, j+1}$ are equal to 1 . In fact, together with the constraints (Eqs. 3.1, 3.2, 3.3, and 3.4), $y h_{i j}=1$ is always true, whenever $x_{i j}=1$ and $x_{i, j+1}=1$ (meaning the condition is necessary and sufficient). The same relation is ensured for the consecutive 1s in columns, by condition 3.6.

\subsubsection{Variants of Simulated Annealing}

Although the mixed integer programming-based method always provides an exact solution, it is difficult to apply in practice, as the SCBT problem is NP-complete. Therefore, as an alternative approach, we reformulated it into an optimization problem, where the aim is to minimize

$$
C(\mathbf{X})=\left\|H-H^{\prime}\right\|_{2}+\left\|V-V^{\prime}\right\|_{2}+\left\|S H-S H^{\prime}\right\|_{2}+\left\|S V-S V^{\prime}\right\|_{2},
$$

where vectors $H, V, S H, S V$ are given as input; and $H^{\prime}, V^{\prime}, S H^{\prime}, S V^{\prime}$ are the corresponding vectors belonging to the current solution image $\mathbf{X}$. We suggest Simulated Annealing (SA) [50] again to solve the problem and propose here variants of different initialization and iteration strategies. The general framework of the algorithm is provided in Alg. 1 in Section 1.4.

\section{The Basic Method}

Each time, the basic method starts out with a random binary image; first, we take a full-zero image, then each pixel is set to 1 with 0.5 probability. Selecting a neighbor means randomly selecting and inverting a pixel. This method will be called BasicSA for short and will serve as the reference for further variants.

\section{Starting from a Precalculated Number of Object Pixels}

This approach takes advantage of the fact that the sum of the row sums (alternatively, the sum of the column sums) equals the total number of object pixels $N_{o p}$. Instead of starting out from completely random images, the algorithm selects $N_{o p}$ pixels from a uniform random distribution (without repetition), and sets them to 1 . The resulting image serves as the initial guess of SA. Selecting a neighbor again means, randomly selecting and inverting a pixel. We call this method FixpixelSA. 


\section{Initialization with Ryser's Algorithm}

We know from Prop. 1.1 that by omitting the $S H$ and $S V$ vectors (thus, relaxing SCBT to BT) the $H$ and $V$ vectors can be satisfied (if a solution exists) in $\mathcal{O}(m n+n \cdot \log n)$ time with Ryser's method [74]. Furthermore, Prop. 1.4 ensures that by applying elementary switchings, all the solutions of the BT problem can be reached. However, no efficient method is known to attain all of them. Therefore, checking all solutions of the BT whether they satisfy the vectors $S H$ and $S V$ does not seem feasible. Nevertheless, starting from an arbitrary solution of BT, and applying randomly selected elementary switchings to generate the new suggestions (the neighbor of the current state), we only have to focus on the $\left\|S H-S H^{\prime}\right\|_{2}+\left\|S V-S V^{\prime}\right\|_{2}$ term of the objective function as the remaining part is 0 . We call this method RyserSA.

\section{SA with Curveball Algorithm}

We can interpret the binary image matrices as presence-absence matrices. There are several methods to reorganize them without altering row and column totals. One of these approaches is the so-called Curveball algorithm, published in $[25,26,82]$. We can use this algorithm as follows (exemplified by Fig. 3.3 below).

$$
\left[\begin{array}{lllllll}
0 & 0 & 1 & 0 & 1 & 0 & 0 \\
0 & 1 & 1 & 0 & 0 & 1 & 0 \\
0 & 0 & 0 & 0 & 1 & 1 & 1 \\
0 & 1 & 0 & 1 & 0 & 0 & 1 \\
1 & 0 & 0 & 1 & 1 & 1 & 0 \\
1 & 1 & 1 & 0 & 0 & 1 & 1 \\
0 & 1 & 0 & 1 & 0 & 1 & 0
\end{array}\right]
$$

$$
\begin{gathered}
\text { list }_{1}=\left[\begin{array}{ll}
(2,2) & (2,3)
\end{array}\right] \\
\text { list }_{2}=\left[\begin{array}{lll}
(5,1) & (5,4) & (5,5)
\end{array}\right]
\end{gathered}
$$

(a) Image matrix with the chosen rows

(b) Indexes of the unique elements

$$
\left[\begin{array}{lllllll}
0 & 0 & 1 & 0 & 1 & 0 & 0 \\
0 & 1 & 0 & 0 & 1 & 1 & 0 \\
0 & 0 & 0 & 0 & 1 & 1 & 1 \\
0 & 1 & 0 & 1 & 0 & 0 & 1 \\
1 & 0 & 1 & 1 & 0 & 1 & 0 \\
1 & 1 & 1 & 0 & 0 & 1 & 1 \\
0 & 1 & 0 & 1 & 0 & 1 & 0
\end{array}\right]
$$

(c) Current solution after one switching

$$
\left[\begin{array}{lllllll}
0 & 0 & 1 & 0 & 1 & 0 & 0 \\
0 & 1 & 0 & 1 & 0 & 1 & 0 \\
0 & 0 & 0 & 0 & 1 & 1 & 1 \\
0 & 1 & 0 & 1 & 0 & 0 & 1 \\
1 & 0 & 1 & 0 & 1 & 1 & 0 \\
1 & 1 & 1 & 0 & 0 & 1 & 1 \\
0 & 1 & 0 & 1 & 0 & 1 & 0
\end{array}\right]
$$

(d) Final result

Figure 3.3: Steps of the CurveballSA algorithm. 
The initialization step is the same as used in the RyserSA method. Then, the algorithm randomly selects two rows from the current image matrix (Step 1, Fig. 3.3a), and collects the unique items - where a unique item is 1 in the observed row and 0 in the other one - from them (Step 2). This way, we are presented with two lists: the first containing the elements which are $1 \mathrm{~s}$ in the first row and 0s in the second row, and the second containing the elements which are $0 \mathrm{~s}$ in the first row and $1 \mathrm{~s}$ in the second row (Fig. 3.3b). The length of the shorter list is denoted by $l$ (in the example, $l=2$ ). In Step 3 the algorithm randomly chooses one element from each list (Fig. 3.3b, highlighted in red). Thus, the upper 1 and the lower 1 values of a switching component are defined. Next, the items of the switching components are inverted (Step 4, Fig. 3.3c). Finally, Steps $\mathbf{2 - 4}$ are iterated $k$ times, where $k \in\{0,1, \ldots, l\}$ is randomly selected in each iteration of SA (Fig. 3.3d). We call this method CurveballSA.

\subsection{Implementation Details}

\subsubsection{Deterministic Methods}

To implement the constraint satisfaction model, we used the intlinprog MATLAB built-in function, which is a mixed-integer linear programming solver. It finds the minimum of a problem specified by

$$
\min _{\mathbf{x}} \mathbf{f}^{T} \cdot \mathbf{x} \text { subject to }\left\{\begin{array}{l}
\mathbf{x}(\text { intcon }) \text { are integers } \\
\mathbf{A}_{\text {ineq }} \cdot \mathbf{x} \leq \mathbf{b}_{\text {ineq }} \\
\mathbf{A}_{\mathbf{e q}} \cdot \mathbf{x}=\mathbf{b}_{\mathbf{e q}} \\
\mathbf{l b} \leq \mathbf{x} \leq \mathbf{u b}
\end{array}\right.
$$

where

- $\mathbf{f}$ is the coefficient vector,

- intcon is the vector of integer constraints,

- $\mathbf{A}_{\text {ineq }}$ is the linear inequality constraint matrix,

- $\mathbf{b}_{\text {ineq }}$ is the linear inequality constraint vector,

- $\mathbf{A}_{\text {eq }}$ is the linear equality constraint matrix,

- $\mathbf{b}_{\mathbf{e q}}$ is the linear equality constraint vector,

- $\mathbf{l b}$ is the lower bound vector,

- $\mathbf{u b}$ is the upper bound vector. 
In order to use this solver, the unknown variables $(\mathbf{X}, \mathbf{Y H}, \mathbf{Y V})$ need to be reformulated in one matrix. Therefore, the conditions of the model become:

- $\mathbf{A}_{\text {eq }}$ contains the conditions of Eqs. 3.1, 3.2, 3.3, and 3.4,

- $\mathbf{b}_{\text {eq }}$ contains the vectors $[H, V, H-S H, V-S V]$,

- $\mathbf{A}_{\text {ineq }}$ contains the conditions of Eqs. 3.5 and 3.6 reformulated as $y h_{i j}-x_{i j} \leq 0 ; y h_{i j}-x_{i(j+1)} \leq 0(i=1 \ldots m ; j=1 \ldots(n-1))$ $y v_{i j}-x_{i j} \leq 0 ; y v_{i j}-x_{(i+1) j} \leq 0(i=1 \ldots(m-1) ; j=1 \ldots n)$,

- $\mathbf{b}_{\text {ineq }}$ contains only 0 values,

- all the unknowns are integers, thus intcon $=1,2 \ldots,(n m+(n-1) m+n(m-1))$,

- $\mathbf{l b}$ contains 0 values,

- $\mathbf{u b}$ contains 1 values,

- the optimization condition is $c(\mathbf{x})=1$, so vector $\mathbf{f}$ contains 1 values to the $n m^{\text {th }}$ index, and 0s after.

Since the number of unknowns are $(n m+(n-1) m+n(m-1))$, the size of vectors $\mathbf{u b}, \mathbf{l b}$, intcon, $\mathbf{f}$ are $(n m+(n-1) m+n(m-1))$. The size of matrix $\mathbf{A}_{\mathbf{e q}}$ is $(n m+(n-1) m+n(m-1)) \times(2 m+2 n)$, and the matrix $\mathbf{A}_{\text {ineq }}$ is of size $(n m+(n-1) m+n(m-1)) \times(4 n m-2 m-2 n)$. It is clear that the size of matrices and vectors increase significantly by increasing the size of the source image.

\subsubsection{Stochastic Methods}

The parameters of the SA algorithm were set manually, in an empirical manner. The stopping criteria were to reach 300000 iterations or to perform 3000 iterations without improving the solution. The initial temperature was set to $T_{1}=350$, while the cooling schedule was controlled by $\alpha=0.99$. The SA algorithm was allowed to remain the same temperature for some iterations, in this case, this was defined by $\beta=0.035$.

\section{Local Update of the Strip Vectors}

Since the objective function must be evaluated in each iteration, it is important to keep its processing time as low as possible. 


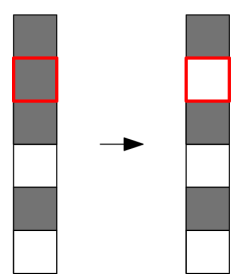

(a)

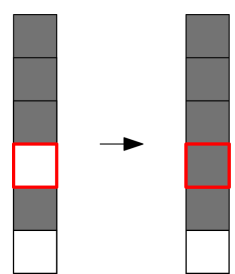

(b)

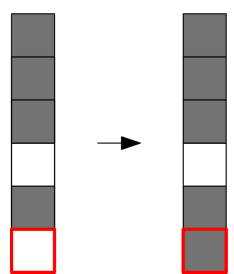

(c)

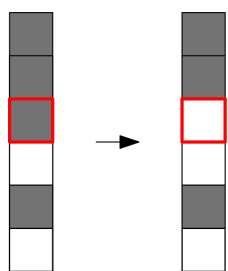

(d)

Figure 3.4: Sample for a new strip appearing (a), two strips merging (b), and no change (c and $d)$.

The key observation is that vectors $S H$ and $S V$ can be updated locally based on the following:

- If one object pixel is deleted from the interior of a strip, then one new strip appears (the old one breaks into two pieces), meaning the number of strips increases by 1. For example, there are two strips in Fig. 3.4a; deleting the marked object pixel will result in 3 strips.

- If one object pixel is added between two strips (that otherwise only have one non-object pixel in between), then the two strips are merging, hence the number of strips decreases by 1 . For instance, there are two strips in Fig. 3.4b; by adding an object pixel to the marked location, only one strip will remain.

- If one object pixel is added to a strip border, there is no change in the number of strips (Fig. 3.4c).

- If one object pixel is deleted from a strip border, there is no change in the number of strips (Fig. 3.4d).

- If a new single object pixel appears (with no neighboring object pixels), the number of strips increases by 1 . If a single object pixel is deleted (with no neighboring object pixels) then the number of strips decreases by 1 .

\subsection{Experimental Results}

The tests were performed on a QuadCore Intel Core i7-4770 processor, 3800 MHz with 8GB RAM. The algorithms were implemented in MATLAB.

\subsubsection{Random Matrices of Different Densities}

Initially, we used binary images of sizes $3 \times 3,4 \times 4, \ldots, 256 \times 256$, containing $0 \%, 10 \%, \ldots, 100 \%$ randomly selected object pixels (Fig. 3.5). 


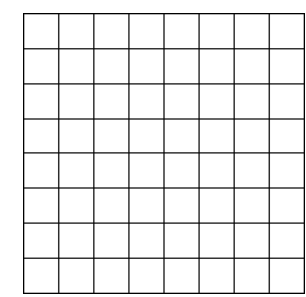

(a)

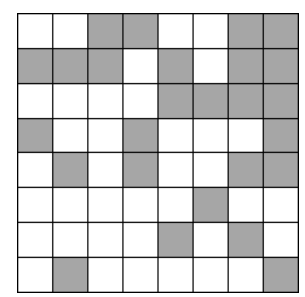

(e)

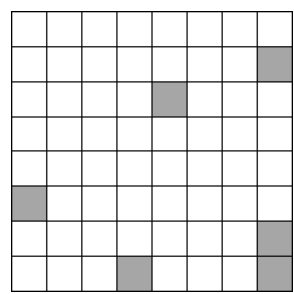

(b)

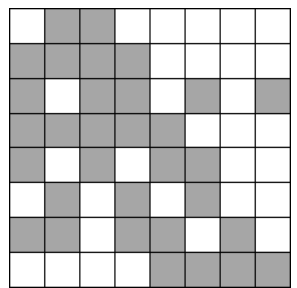

(f)

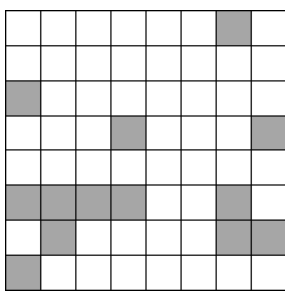

(c)

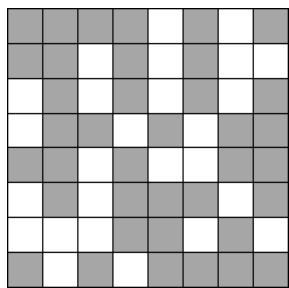

(g)

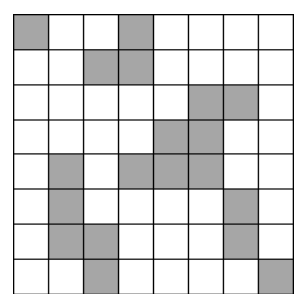

(d)

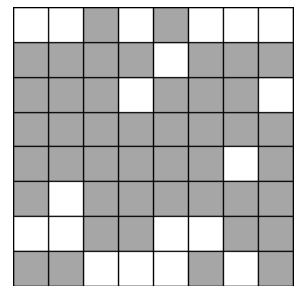

(h)

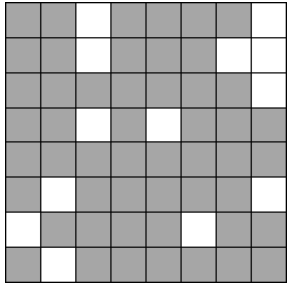

(i)

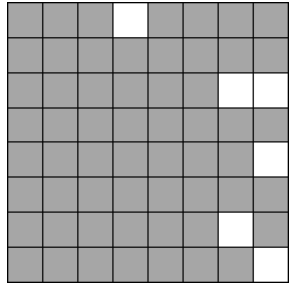

(j)

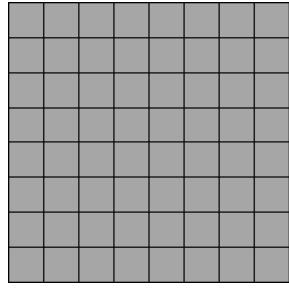

(k)

Figure 3.5: Images with $0 \%, 10 \%, \ldots, 100 \%$ randomly selected object pixels.

\begin{tabular}{|c|c|c|c|c|c|c|c|c|c|c|c|c|}
\hline$n$ & $S C$ & HSC & VSC & HVSC & $S C$ & HSC & VSC & HVSC & $S C$ & HSC & VSC & HVSC \\
\hline & \multicolumn{4}{|c|}{$10 \%$} & \multicolumn{4}{|c|}{$20 \%$} & \multicolumn{4}{|c|}{$30 \%$} \\
\hline 4 & 1 & 1 & 1 & 1 & 1 & 1 & 1 & 1 & 5 & 3 & 3 & 1 \\
\hline 8 & 10 & 6 & 8 & 4 & 40 & 13 & 15 & 4 & 68 & 19 & 19 & 5 \\
\hline 16 & 239 & 131 & 119 & 62 & 743 & 239 & 241 & 76 & 1267 & 313 & 307 & 76 \\
\hline 32 & 3938 & 2025 & 2038 & 1052 & 12690 & 3745 & 3778 & 1091 & 21728 & 4463 & 4423 & 918 \\
\hline 64 & 65667 & 31432 & 32984 & 15787 & 207916 & 57857 & 58971 & 16390 & 359789 & 68786 & 69106 & 13303 \\
\hline 128 & 67937 & 513042 & 515834 & 247982 & 379871 & 926908 & 917961 & 251358 & 5832027 & 1091199 & 1085942 & 202593 \\
\hline & \multicolumn{4}{|c|}{$40 \%$} & \multicolumn{4}{|c|}{$50 \%$} & \multicolumn{4}{|c|}{$60 \%$} \\
\hline 4 & 5 & 3 & 2 & 1 & 5 & 1 & 1 & 0 & 4 & 1 & 1 & 0 \\
\hline 8 & 99 & 24 & 28 & 7 & 100 & 20 & 20 & 3 & 96 & 17 & 19 & 4 \\
\hline 16 & 1732 & 307 & 309 & 51 & 1922 & 324 & 301 & 49 & 1598 & 251 & 280 & 44 \\
\hline 32 & 28251 & 4757 & 4577 & 758 & 30970 & 4693 & 4848 & 737 & 28543 & 4509 & 4487 & 707 \\
\hline 64 & 469149 & 74100 & 73206 & 11572 & 505018 & 74260 & 74449 & 10940 & 468847 & 71920 & 71964 & 10976 \\
\hline \multirow[t]{2}{*}{128} & 7602646 & 1164656 & 1158852 & 177741 & 8263580 & 1189276 & 1187353 & 170617 & 7613509 & 1149340 & 1147144 & 173335 \\
\hline & \multicolumn{4}{|c|}{$70 \%$} & \multicolumn{4}{|c|}{$80 \%$} & \multicolumn{4}{|c|}{$90 \%$} \\
\hline 4 & 4 & 1 & 1 & 0 & 1 & 0 & 0 & 0 & 0 & 0 & 0 & 0 \\
\hline 8 & 75 & 18 & 17 & 3 & 38 & 8 & 8 & 2 & 11 & 6 & 5 & 2 \\
\hline 16 & 1263 & 247 & 224 & 45 & 722 & 192 & 177 & 45 & 230 & 96 & 96 & 43 \\
\hline 32 & 21728 & 4058 & 4135 & 770 & 12626 & 3220 & 3331 & 862 & 3983 & 1897 & 1741 & 832 \\
\hline 64 & 358527 & 66559 & 66154 & 12304 & 208043 & 53608 & 55024 & 14184 & 65935 & 30739 & 30798 & 14163 \\
\hline 128 & 5829024 & 1065745 & 1061419 & 193750 & 3381691 & 890182 & 894164 & 235282 & 1069250 & 504757 & 493392 & 233465 \\
\hline
\end{tabular}

Table 3.1: Number of switching components for different matrix densities of size $n \times n$.

As a first observation, we calculated the number of switching components for different matrix densities of size $n \times n$. Table 3.1 displays the mean rounded results of 10 images. Concerning the original image, SC denotes the number of switching components, while HSC represents the number of switching 
components preserving the number of horizontal strips (VSC stands for the vertical ones). Finally, HVSC denotes the number of switching components preserving the number of both horizontal and vertical strips. In Table 3.2, we also present the percentages in which number of strips are preserved. It is clear that there are a large number of switching components for every image class, even for smaller sizes.

For the numerical evaluation of the quality of the reconstructed images, we used 'pixel error' again, that is

$$
E_{p}=\frac{\sum_{i j}\left|o_{i j}-r_{i j}\right|}{m \cdot n} \cdot 100 \%
$$

where $O$ and $R$ are the original and the reconstructed image, respectively, and $m \times n$ is the size of the image (as it was also defined in Eq. 2.18 in Section 2.4.1).

Remark 3.1 Pixel error differs from RME (Eq.1.15 in Section 1.4.3) in the normalizing factor only (in RME, it is the sum of the pixel values; whereas in pixel error, it is the size of the image). The reason we chose this error rate was to ensure a more accurate comparison between the images of different sizes.

\begin{tabular}{|r|r|r|r|r|r|r|r|r|r|}
\hline$n$ & HSC & VSC & HVSC & HSC & VSC & HVSC & HSC & VSC & HVSC \\
\hline \multicolumn{3}{|c|}{$10 \%$} \\
\hline 4 & $100 \%$ & $100 \%$ & $100 \%$ & $86 \%$ & $71 \%$ & $57 \%$ & $51 \%$ & $57 \%$ & $24 \%$ \\
\hline 8 & $57 \%$ & $75 \%$ & $40 \%$ & $32 \%$ & $36 \%$ & $10 \%$ & $28 \%$ & $27 \%$ & $8 \%$ \\
\hline 16 & $55 \%$ & $50 \%$ & $26 \%$ & $32 \%$ & $32 \%$ & $10 \%$ & $25 \%$ & $24 \%$ & $6 \%$ \\
\hline 32 & $51 \%$ & $52 \%$ & $27 \%$ & $30 \%$ & $30 \%$ & $9 \%$ & $21 \%$ & $20 \%$ & $4 \%$ \\
\hline 64 & $48 \%$ & $50 \%$ & $24 \%$ & $28 \%$ & $28 \%$ & $8 \%$ & $19 \%$ & $19 \%$ & $4 \%$ \\
\hline 128 & $48 \%$ & $48 \%$ & $23 \%$ & $27 \%$ & $27 \%$ & $7 \%$ & $19 \%$ & $19 \%$ & $3 \%$ \\
\hline \multicolumn{8}{|c|}{$40 \%$} & & \multicolumn{3}{|c|}{$50 \%$} & & \multicolumn{3}{|c|}{$60 \%$} \\
\hline 4 & $53 \%$ & $34 \%$ & $17 \%$ & $23 \%$ & $17 \%$ & $4 \%$ & $12 \%$ & $12 \%$ & $0 \%$ \\
\hline 8 & $24 \%$ & $28 \%$ & $7 \%$ & $20 \%$ & $20 \%$ & $3 \%$ & $18 \%$ & $20 \%$ & $4 \%$ \\
\hline 16 & $18 \%$ & $18 \%$ & $3 \%$ & $17 \%$ & $16 \%$ & $3 \%$ & $16 \%$ & $18 \%$ & $3 \%$ \\
\hline 32 & $17 \%$ & $16 \%$ & $3 \%$ & $15 \%$ & $16 \%$ & $2 \%$ & $16 \%$ & $16 \%$ & $2 \%$ \\
\hline 64 & $16 \%$ & $16 \%$ & $2 \%$ & $15 \%$ & $15 \%$ & $2 \%$ & $15 \%$ & $15 \%$ & $2 \%$ \\
\hline 128 & $15 \%$ & $15 \%$ & $2 \%$ & $14 \%$ & $14 \%$ & $2 \%$ & $15 \%$ & $15 \%$ & $2 \%$ \\
\hline \multicolumn{8}{|c|}{$70 \%$} & & \multicolumn{3}{|c|}{$80 \%$} & & & $90 \%$ & \\
\hline 4 & $14 \%$ & $20 \%$ & $6 \%$ & $14 \%$ & $14 \%$ & $0 \%$ & $25 \%$ & $0 \%$ & $0 \%$ \\
\hline 8 & $24 \%$ & $22 \%$ & $5 \%$ & $21 \%$ & $21 \%$ & $5 \%$ & $56 \%$ & $42 \%$ & $18 \%$ \\
\hline 16 & $20 \%$ & $18 \%$ & $4 \%$ & $27 \%$ & $24 \%$ & $6 \%$ & $42 \%$ & $42 \%$ & $19 \%$ \\
\hline 32 & $19 \%$ & $19 \%$ & $4 \%$ & $26 \%$ & $26 \%$ & $7 \%$ & $48 \%$ & $44 \%$ & $21 \%$ \\
\hline 64 & $19 \%$ & $18 \%$ & $3 \%$ & $26 \%$ & $26 \%$ & $7 \%$ & $47 \%$ & $47 \%$ & $21 \%$ \\
\hline 128 & $18 \%$ & $18 \%$ & $3 \%$ & $26 \%$ & $26 \%$ & $7 \%$ & $47 \%$ & $46 \%$ & $22 \%$ \\
\hline
\end{tabular}

Table 3.2: Number of switching components (in percentages) preserving the number of horizontal (HSC) and vertical (VSC) as well as both horizontal and vertical (HVSC) strips for different matrix densities of size $n \times n$. 
Remark 3.2 All following graphs are also presented in larger size in Appendix D.

Thereafter, we moved on to the SCBT problem and conducted experiments on 50-50 binary images of sizes $3 \times 3,4 \times 4, \ldots, 256 \times 256$, containing $0 \%, 10 \%, \ldots, 100 \%$ randomly selected object pixels (Fig. 3.5). The test set contained a total of $50 \cdot 254 \cdot 11=139700$ images.

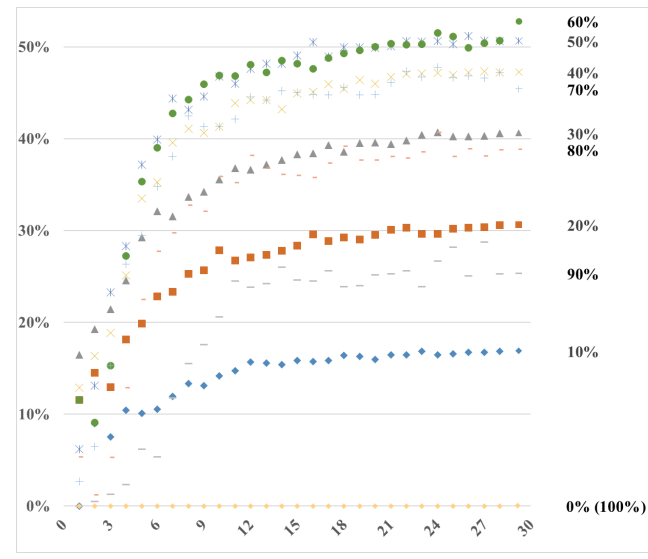

(a)

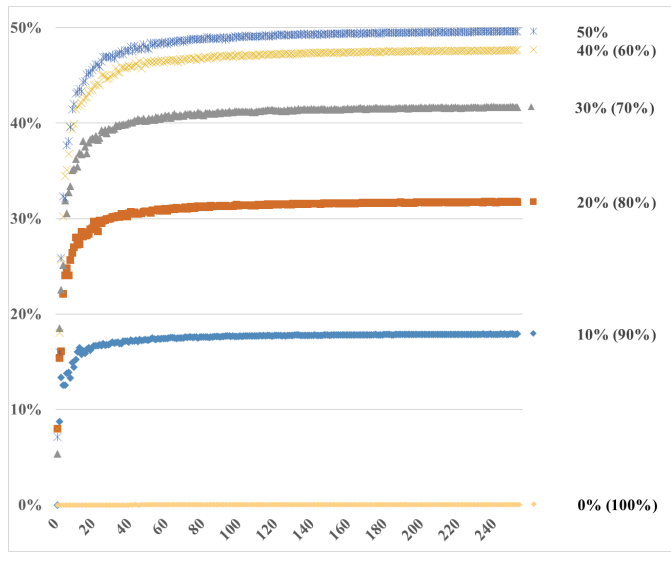

(b)

Figure 3.6: Mean pixel error (vertical axis) of the intlinprog (a) and the SA (b) methods for different image sizes (horizontal axis).

Fig. 3.6 (and Fig. D.5) indicates the pixel error of the methods for the different image classes. In the figures (and also in later figures), only the graphs of matrices with $0-50 \%$ object pixels are plotted for the SA variants. For $60-100 \%$ object pixel density, we achieved very similar curves, owing to the symmetrical nature of black and white pixels. Only one pixel error graph is plotted for the various SA approaches, since there is no significant difference between them. The closer the image is to the uniform random, the higher the pixel error is. This is relatively high even when the exact method (intlinprog) is applied. The reason for this is that a structure close to the uniform random one provides more freedom for switching components to occur (see also Tables 3.1 and 3.2), resulting in a highly ambiguous solution. Note that, due to the binary nature of the problem, if the density of a matrix is fixed, then for each misclassified object pixel a misclassified background pixel must exist, and vice versa. Therefore, the maximum pixel error of a binary matrix $\mathbf{X}$ of size $m \times n$ is

$$
2 \cdot \min \left\{\sum_{i, j} x_{i j}, m n-\sum_{i, j} x_{i j}\right\} .
$$

Furthermore, it can be observed that in case of $50 \%$ density, about $50 \%$ of the image pixels are misclassified, which is half of the theoretical bound. For $10 \%$ density, the classification error can reach up to about $18 \%$ (very close to the theoretical bound). This is in accordance with the observation reported in [99], where the author generated 5000 random nonograms of size $30 \times 30$ with $50 \%$ object pixels, and found that $97.5 \%$ of the puzzles had multiple solutions. As known, in SCBT a lesser amount of information is available in 
comparison with NONOGRAM, therefore, we highly suspect that the results of Fig. 3.6 follow from the non-uniquely determined solutions of the SCBT instances solved.

In $[10,11,14,69]$ the solvability and uniqueness of nonograms were also examined in detail, and it was deduced that the closer the density to $50 \%$, the harder it is to find a solution to the puzzle. One can also see in [99] that even for medium-sized puzzles, finding a solution and checking uniqueness is challenging with the automatic solvers.

Regarding the mean running time, we can observe that intlinprog needs an unreasonable amount of time to produce the solution (Figs. 3.7a and D.6a), even for small matrices, which is why only statistics for small matrices are presented. This is not surprising, as the problem is NP-complete. Thus, we can deduce that this approach is also not applicable in practice, since the pixel error and the running time are both high.

Remark 3.3 To relax the Constraint Satisfaction Problem, we attempted to replace the strict equalities of Eqs. 3.1-3.4 with inequalities. This way, the conditions of the relaxed model were similar to the original one, except the equality from Eq. 3.8 $\left(\mathbf{A}_{\mathbf{e q}} \cdot \mathbf{x}=\mathbf{b}_{\mathbf{e q}}\right)$ became inequality

$$
\mathbf{b}_{\mathrm{eq}}-d \leq \mathbf{A}_{\mathrm{eq}} \cdot \mathbf{x} \leq \mathbf{b}_{\mathrm{eq}}+d,
$$

where we first set $d=1$, and then $d=2$ in the next test. It turned out that the relaxed version of the model could not be applied in practice, too, since it required even higher running time than the original one.

In contrast, SA deals with the problem by searching for an image which may partially satisfy the conditions. Therefore, it works for larger images as well. Additionally, the fact that SA only seeks an approximate solution makes it more preferable in practical applications where the projections are noisy and the structure of the image is also only approximately known in advance. In the case of SA variants, only the running time of version using local update to calculate the number of strips (Section 3.3.2) is presented, since it turned out early that some variants would otherwise need hundreds of seconds to get results on the most difficult instances of this dataset. Indeed, the local update significantly decreased the running time. In case of BasicSA the running time increases excessively as the number of object pixels move farther away from $50 \%$. Since this method initiates from a uniform random matrix, more inversions are needed in these cases to reach a matrix with the proper density. FixpixelSA does not suffer from this drawback; it terminates much faster (and of course, it finds the solution in one iteration when the matrix density is $0 \%$ or $100 \%$ ). Finding a switching component in a matrix (RyserSA and CurveballSA) is a more costly operator than simply inverting one pixel (FixpixelSA and BasicSA). In the case of RyserSA (Figs. 3.7d and D.6d) and CurveballSA (Figs. 3.7e and D.6e) the algorithm often finds an optimal solution (with 0 objective function value) within less than 300000 iterations, and then it stops, whereas the other two approaches run 300000 iterations and terminate with a nonzero objective function value in many cases. 


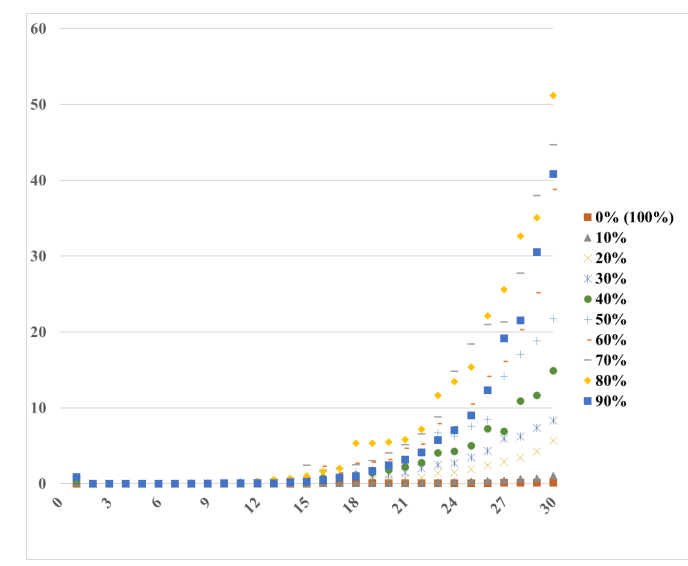

(a)

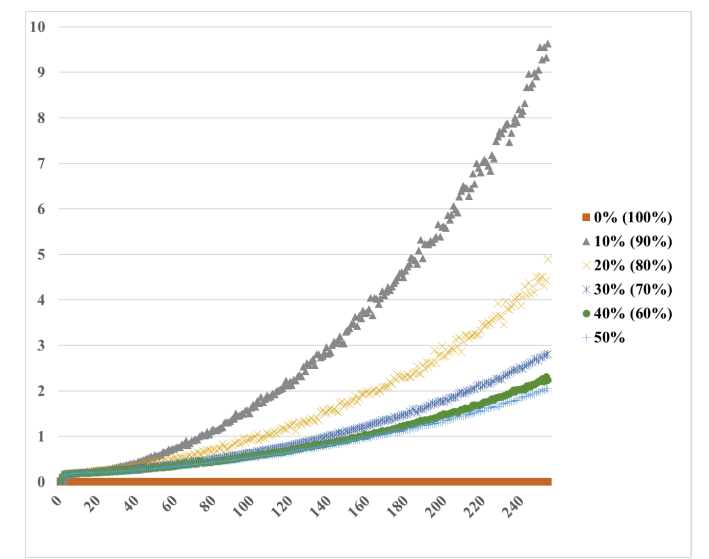

(c)

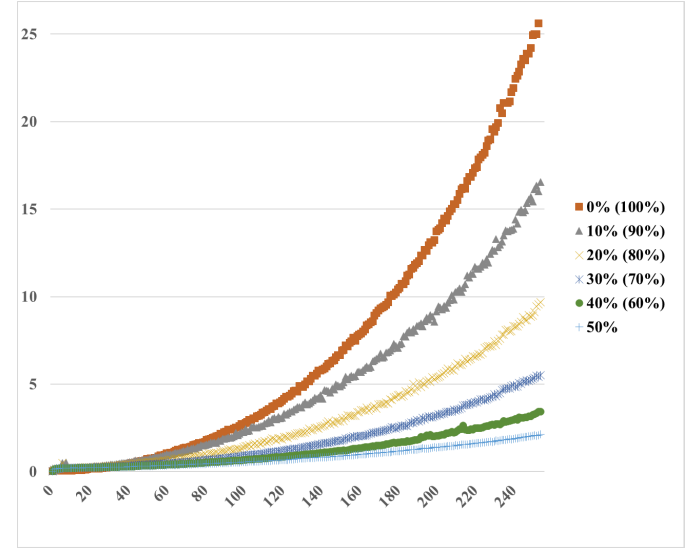

(b)

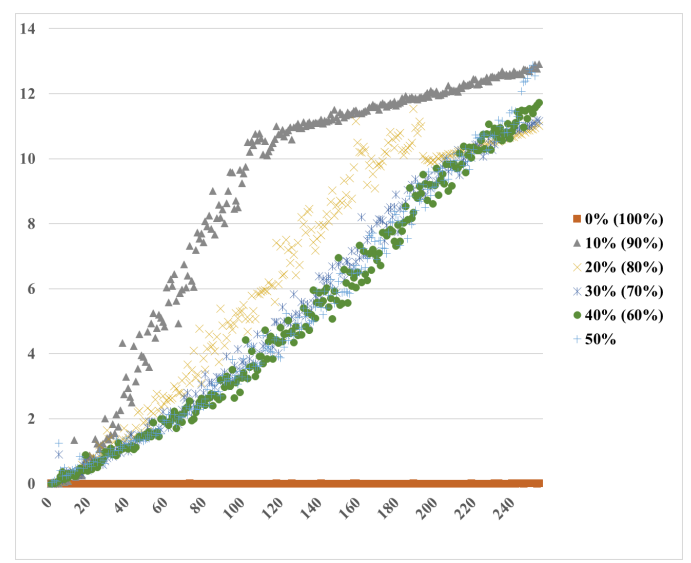

(d)

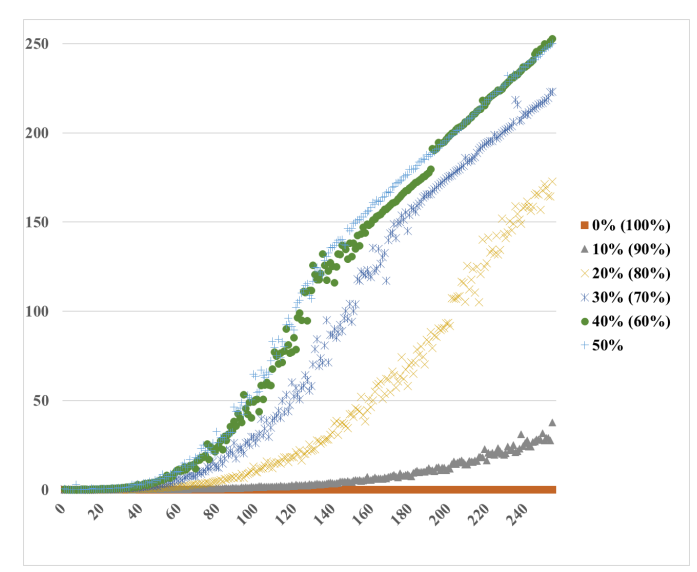

(e)

Figure 3.7: Mean running time in seconds (vertical axis) of the intlinprog (a) BasicSA (b), FixpixelSA (c), RyserSA (d) and CurveballSA (e) methods for different image sizes (horizontal axis).

For densities of $30 \%$ or more, the trend seems to be linear, much like in the case of smaller matrices with smaller densities. However, for $10 \%$ and $20 \%$ matrix density, we observe a drop in the slope of the graphs, at around size 
$120 \times 120$ and $180 \times 180$, respectively; the rest of the trend seems to remain linear. This drop is the consequence of the termination criterion of reaching 300000 iterations. It only takes effect for matrices of larger sizes yet, at the same time, small (10-20\%) densities. Otherwise, it is very likely that we reach 0 value of the objective function and can stop earlier. Clearly, CurveballSA performs much more switchings than RyserSA, meaning its execution time is higher (and would be even higher without the local update).

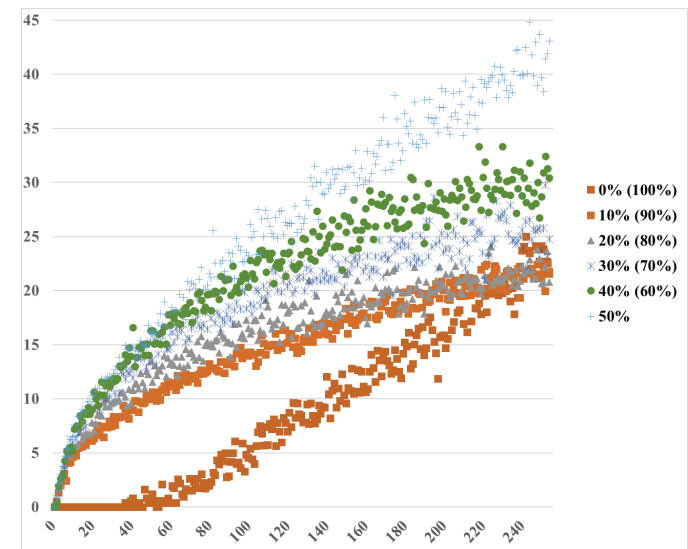

(a)

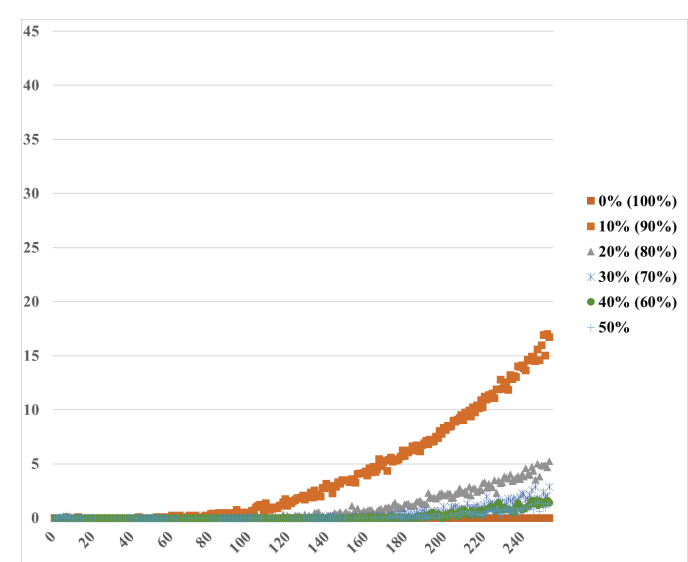

(c)

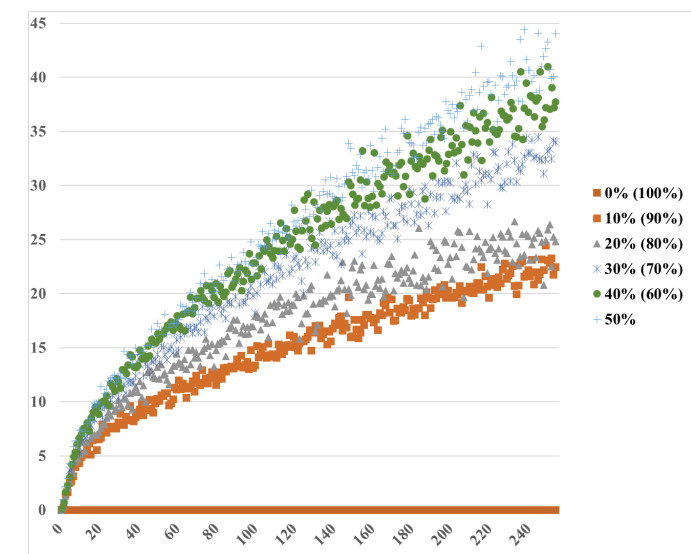

(b)

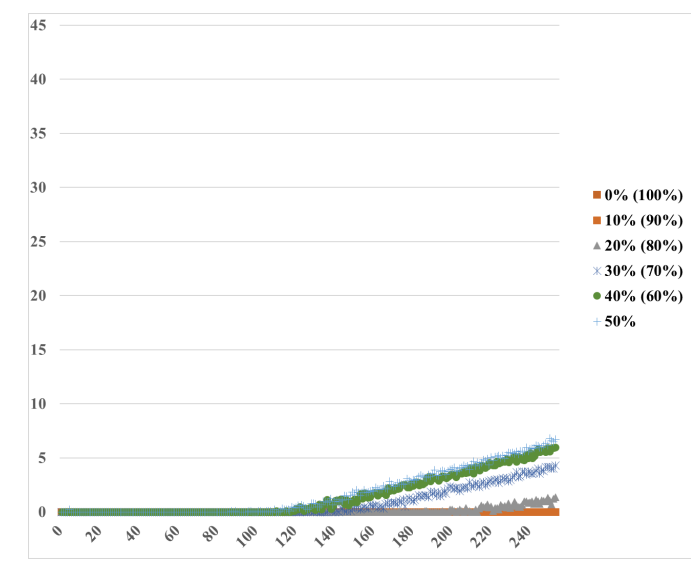

(d)

Figure 3.8: Mean final objective value (vertical axis) of the BasicSA (a), FixpixelSA (b), RyserSA (c) and CurveballSA (d) methods for different image sizes (horizontal axis).

Since pixel error does not hold enough information about the quality of the reconstruction, we also examined the final value of the objective function (Figs. 3.8 and D.7). We can see that BasicSA and FixpixelSA perform relatively similarly, and so do RyserSA and CurveballSA (except in the case of $10 \%$ density). Since the $\left\|H-H^{\prime}\right\|_{2}+\left\|V-V^{\prime}\right\|_{2}$ part of the objective function is always 0 during the run of the RyserSA and CurveballSA algorithms, we also present the 'strip difference' here for a more accurate comparison

$$
E_{\text {strip }}=\left\|S H-S H^{\prime}\right\|_{2}+\left\|S V-S V^{\prime}\right\|_{2} \text {, }
$$


for the BasicSA and FixpixelSA variants (Figs. 3.9 and D.8). $E_{\text {strip }}$ is a part of the objective function as well (Eq. 3.7). We can deduce that both RyserSA and CurveballSA outperform the other two methods. The graph belonging to RyserSA once again confirms the earlier observation that matrices of a larger size and $10-20 \%$ density are harder to reconstruct. In these cases, usually we cannot reach 0 value within the maximal 300000 iterations. One way to avoid this is to increase the maximal number of iterations permitted, which, on the other hand, also yields an increased running time.

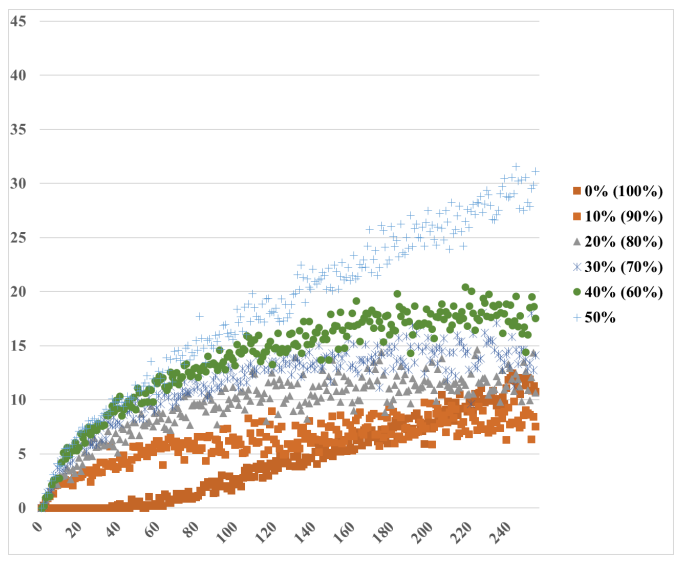

(a)

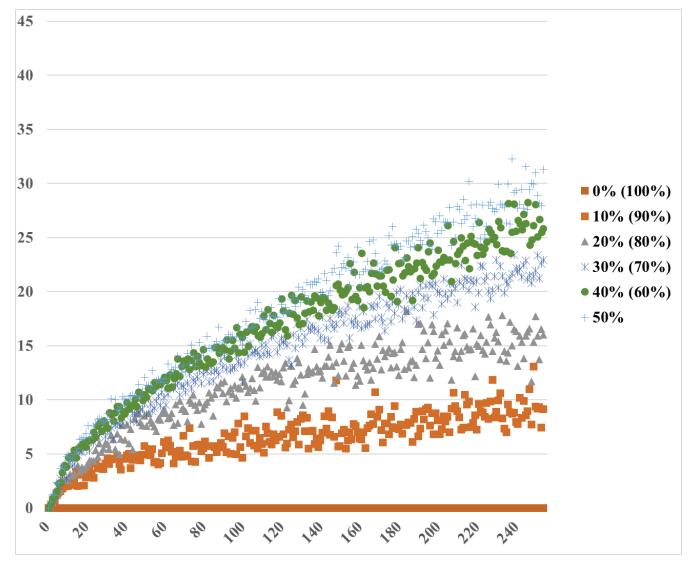

(b)

Figure 3.9: Mean strip difference (vertical axis) of the BasicSA

(a) and FixpixelSA (b) methods for different image sizes (horizontal axis).

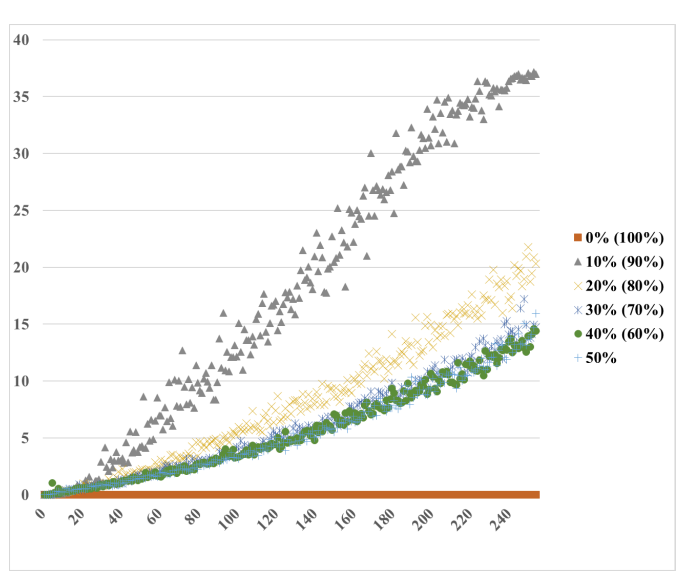

(a)

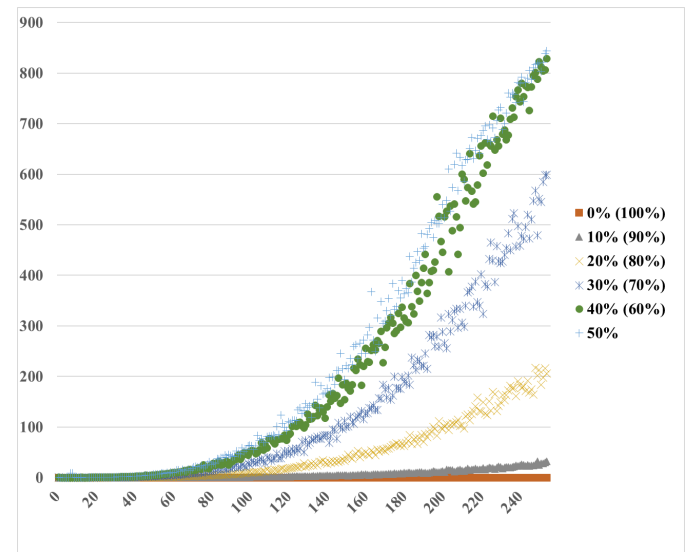

(b)

Figure 3.10: Mean running time in seconds RyserSA (a) and

CurveballSA (b) methods for different image sizes (horizontal axis).

In the next experiment, we used 10-10 binary images of sizes $3 \times 3,4 \times 4, \ldots, 256 \times 256$, containing $0 \%, 10 \%, \ldots, 100 \%$ randomly selected object pixels (Fig. 3.5), and letting the algorithm run a maximum of 1000000 iterations for RyserSA and CurveballSA methods. Again, CurveballSA 
performs a lot more switchings, making its execution time higher (Figs. 3.10 and D.9). Regarding the value of the objective function, from Fig. 3.11 (and Fig. D.10), it is clear that both methods perform similarly and they both ensure low objective function value (always less than 3; 0 in most cases), for all the examined images without breaks in the trend lines.

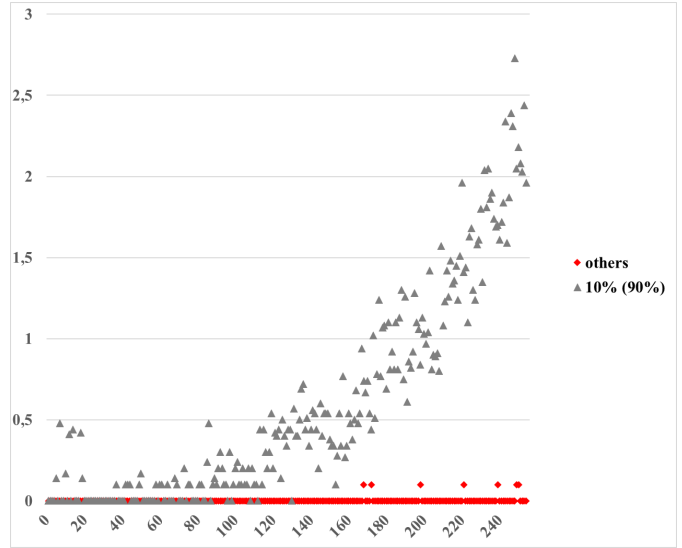

(a)

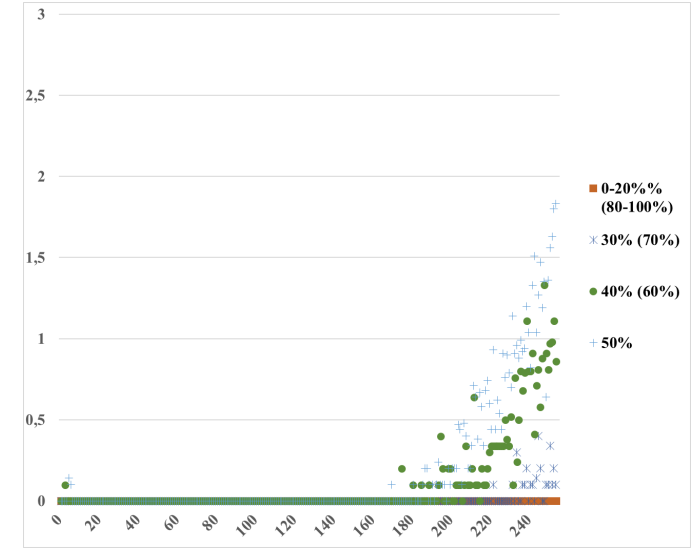

(b)

Figure 3.11: Mean final objective value (vertical axis) of the RyserSA (a) and CurveballSA (b) methods for different image sizes (horizontal axis).

\subsubsection{Web Paint-by-Number}

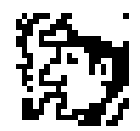

(a)

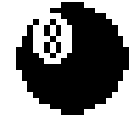

(b)

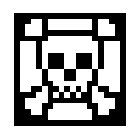

(c)

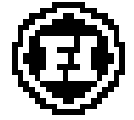

(d)

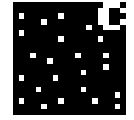

(e)

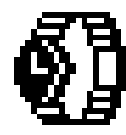

(f)

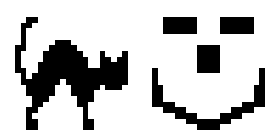

(h)

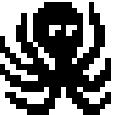

(i)

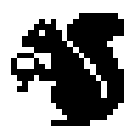

(j)

Figure 3.12: Sample images from Web Paint-by-Number.

The next test was conducted on images of size $20 \times 20$ from real Nonogram games (Fig. 3.12), downloaded from [100]. Based on the previous observation, the number of maximal iterations was increased to 1000000 . The mean results of 10 tests are cited in Table $3.3(C(\mathbf{X})$ denotes the final objective function value). It is clearly visible that in all cases the CurveballSA algorithm performed better, and RyserSA got more often stuck in local minima. It is also apparent that CurveballSA required higher running time. Unfortunately, though not surprisingly, the pixel error $\left(E_{p}\right)$ is high. This phenomenon is due to the high number of feasible solutions caused by the switching components present in the image. 


\begin{tabular}{|l|r|r|r|r|r|r|}
\hline & \multicolumn{3}{|c|}{ RyserSA } & \multicolumn{3}{c|}{ CurveballSA } \\
\hline Figure & Time $(\mathrm{s})$ & $E_{p}(\%)$ & $C(\mathbf{X})$ & Time $(\mathrm{s})$ & $E_{p}(\%)$ & $C(\mathbf{X})$ \\
\hline $3.12 \mathrm{a}$ & 3.61 & 39.65 & 0.51 & 1.53 & 39.70 & 0.00 \\
\hline $3.12 \mathrm{~b}$ & 1.11 & 18.00 & 6.09 & 147.70 & 10.60 & 1.78 \\
\hline $3.12 \mathrm{c}$ & 2.54 & 27.00 & 2.47 & 6.99 & 23.70 & 0.00 \\
\hline $3.12 \mathrm{~d}$ & 2.36 & 37.95 & 1.36 & 2.03 & 35.05 & 0.00 \\
\hline $3.12 \mathrm{e}$ & 1.36 & 12.15 & 0.00 & 0.15 & 11.60 & 0.00 \\
\hline $3.12 \mathrm{f}$ & 2.23 & 31.60 & 3.99 & 63.28 & 26.45 & 0.20 \\
\hline $3.12 \mathrm{~g}$ & 0.10 & 20.45 & 7.96 & 152.05 & 20.50 & 1.53 \\
\hline $3.12 \mathrm{~h}$ & 1.22 & 32.15 & 6.96 & 138.55 & 30.30 & 2.80 \\
\hline $3.12 \mathrm{i}$ & 3.21 & 36.60 & 0.93 & 1.70 & 37.30 & 0.00 \\
\hline $3.12 \mathrm{j}$ & 1.54 & 24.85 & 4.40 & 50.79 & 26.00 & 0.17 \\
\hline
\end{tabular}

Table 3.3: Results of Web Paint-by-Number images.

\subsubsection{TomoPhantom Images}

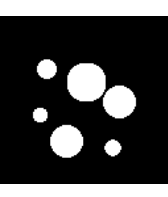

(a)

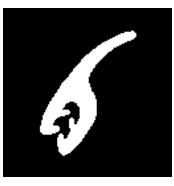

(g)

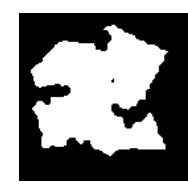

$(\mathrm{m})$

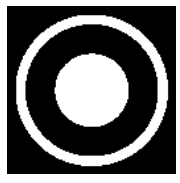

(b)

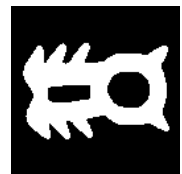

(h)

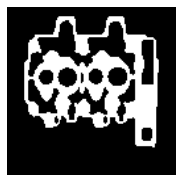

(n)

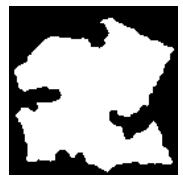

(s)

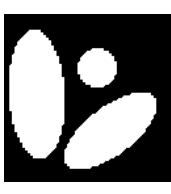

(c)

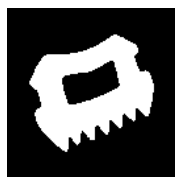

(i)

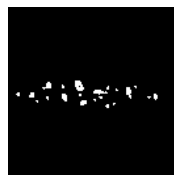

(o)

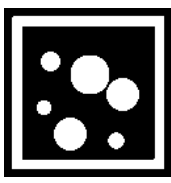

(t)

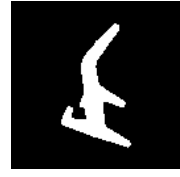

(d)

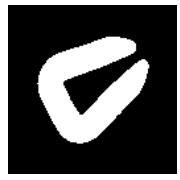

(j)

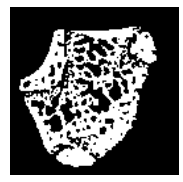

(p)

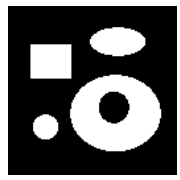

(u)

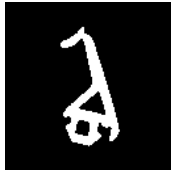

(e)

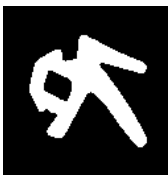

(k)

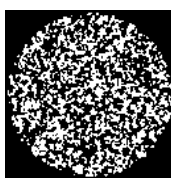

(q)

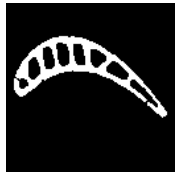

(v)

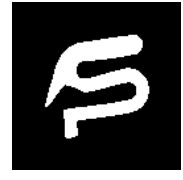

(f)

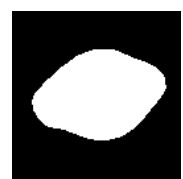

(1)

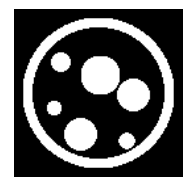

(r)

Figure 3.13: TomoPhantom images taken from [94].

The next experiment was conducted on 22 different binary images (TomoPhantoms) of size $128 \times 128$ from [94] (see Fig. 3.13). These images were also used in other papers to test the efficacy of binary tomographic reconstruction algorithms. Since the images were now more complex, the number of possible iterations was increased in this experiment. The new 
stopping criteria were to reach 3000000 iterations or to perform 6000 iterations without improving the solution. Table 3.4 shows the corresponding numerical evaluation (once again, $C(\mathbf{X})$ denotes the final objective function value). The CurveballSA algorithm performed much better, but, as seen previously, needed higher running time than RyserSA. There are some instances where the final objective values were the same for both methods. These correspond to the cases where both methods got stuck in local minima at the beginning, causing short running time but high objective function value of the CurveballSA algorithm.

\begin{tabular}{|l|r|r|r|r|r|r|}
\hline & \multicolumn{3}{|c|}{ RyserSA } & \multicolumn{3}{c|}{ CurveballSA } \\
\hline Figure & Time $(\mathrm{s})$ & $E_{p}(\%)$ & \multicolumn{1}{c|}{$C(\mathbf{X})$} & Time $(\mathrm{s})$ & $E_{p}(\%)$ & \multicolumn{1}{c|}{$\mathrm{X})$} \\
\hline $4.12 \mathrm{a}$ & 0.25 & 12.84 & 148.98 & 1161.94 & 12.61 & 45.33 \\
\hline $4.12 \mathrm{~b}$ & 0.37 & 30.33 & 222.88 & 6.30 & 30.34 & 222.91 \\
\hline $4.12 \mathrm{c}$ & 0.29 & 20.10 & 157.80 & 4.97 & 20.10 & 157.80 \\
\hline $4.12 \mathrm{~d}$ & 0.28 & 8.55 & 78.61 & 641.15 & 7.69 & 23.65 \\
\hline $4.12 \mathrm{e}$ & 0.35 & 8.26 & 66.81 & 134.24 & 8.32 & 57.55 \\
\hline $4.12 \mathrm{f}$ & 0.22 & 12.12 & 121.90 & 1103.57 & 11.60 & 34.49 \\
\hline $4.12 \mathrm{~g}$ & 0.24 & 13.07 & 147.28 & 767.81 & 10.80 & 39.36 \\
\hline $4.12 \mathrm{~h}$ & 0.21 & 11.96 & 99.05 & 1656.74 & 11.36 & 27.38 \\
\hline $4.12 \mathrm{i}$ & 0.23 & 17.61 & 118.90 & 4.89 & 17.61 & 118.90 \\
\hline $4.12 \mathrm{j}$ & 0.26 & 17.37 & 163.14 & 294.10 & 17.09 & 142.22 \\
\hline $4.12 \mathrm{k}$ & 0.26 & 18.21 & 154.63 & 129.50 & 18.24 & 144.50 \\
\hline $4.12 \mathrm{l}$ & 0.20 & 4.02 & 29.38 & 2284.37 & 3.71 & 19.10 \\
\hline $4.12 \mathrm{~m}$ & 0.19 & 11.76 & 81.44 & 3.55 & 11.76 & 81.45 \\
\hline $4.12 \mathrm{n}$ & 0.27 & 20.00 & 149.69 & 1065.55 & 20.47 & 37.00 \\
\hline $4.12 \mathrm{o}$ & 0.77 & 1.93 & 32.52 & 2427.76 & 1.82 & 2.20 \\
\hline $4.12 \mathrm{p}$ & 18.85 & 26.12 & 69.87 & 1017.08 & 25.98 & 24.22 \\
\hline $4.12 \mathrm{q}$ & 24.80 & 36.99 & 11.70 & 861.91 & 37.86 & 4.04 \\
\hline $4.12 \mathrm{r}$ & 0.44 & 33.37 & 298.19 & 2061.68 & 31.74 & 92.08 \\
\hline $4.12 \mathrm{~s}$ & 0.21 & 16.11 & 98.47 & 3.73 & 16.11 & 98.47 \\
\hline $4.12 \mathrm{t}$ & 0.25 & 12.83 & 149.23 & 1486.28 & 13.23 & 37.62 \\
\hline $4.12 \mathrm{u}$ & 0.29 & 23.08 & 179.36 & 6.70 & 23.08 & 179.35 \\
\hline $4.12 \mathrm{v}$ & 0.23 & 13.43 & 138.35 & 1276.23 & 11.51 & 28.68 \\
\hline
\end{tabular}

Table 3.4: Results of TomoPhantom images.

As a final observation, Fig. 3.14 indicates how the objective function value decreases during the iterations in the case of Fig. 3.13a if we allow the CurveballSA method to run as many as 100000000 iterations. The number of million iterations is provided on vertical axis and the actual objective values on the horizontal axis. Dots were only drawn when the value decreased in the corresponding iteration. After a large number of iterations, the decrease is much slower than in the beginning. In this example, the final objective value in the end is 31.70 (found in iteration 99166737 ). 


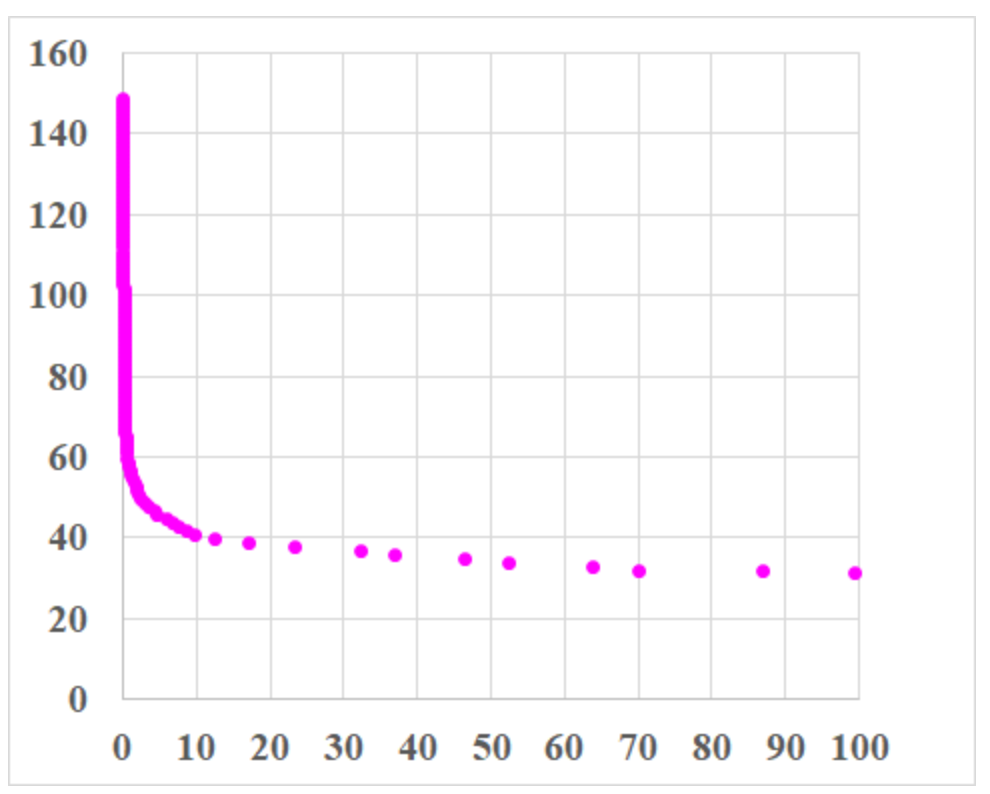

Figure 3.14: Objective function values during the millions of iterations for Fig. 3.13a.

\subsection{Conclusion}

Inspired by Nonogram puzzles, in this chapter, we defined the problem of reconstructing binary images from their horizontal and vertical projections and a texture-like prior, the number of strips per row and column.

First, we formulated the reconstruction as a Constraint Satisfaction Problem and solved it with a deterministic integer programming approach. Knowing that the problem is NP-hard, we also proposed a stochastic method based on Simulated Annealing to solve the issue.

For the evaluation, three different datasets were used: random images of different densities (Section 3.4.1); real Nonogram puzzles (Section 3.4.2); and so-called TomoPhantom images (Section 3.4.3). We found that the exact method is seldom applicable in practice, since it requires high running time even for small matrices, and cannot be used for larger matrices. In contrast, the stochastic approach is much more suitable for practical purposes, even though on occasion, it merely provides approximate solutions. The effectiveness of the SA method was influenced by several factors, among which initialization strategy is one of the key issues. Therefore, different initializing strategies were proposed as follows. BasicSA starts out with a completely random binary image, FixpixelSA begins with a random binary image with a fixed number of object points, RyserSA uses Ryser's algorithm to identify the initial solution and elementary switchings to refine it, and CurveballSA is based on the idea of the Curveball method. A local update of the number of strips in each iteration was also presented, which reduced the running time of the methods significantly. 
We found that although FixpixelSA is faster than the other methods, it does not yield the best results. RyserSA often finds a perfect solution, especially in case of dense and/or small matrices, but sometimes gets stuck in a local minimum. CurveballSA performs better for real images than RyserSA and is able to avoid getting stuck in local minima. Unfortunately, CurveballSA requires much higher running time.

We also found that the pixel error is high even if the objective function value is relatively small. This is due to the presence of switching components, which can yield many different solutions for the same input data. The reason for this is, a structure close to the uniform random one provides more freedom for switching components to occur, and the solution may be highly ambiguous. If a large portion of the pixels is fixed to belong to the foreground/background, this happens less often. This theory was also confirmed by the calculation of the number of switching components for different matrix densities of size $n \times n$. It turned out that there are, in fact, a large number of switching components for every image class, even for small sizes.

The results obtained in this chapter provide insight into binary tomographic reconstruction with structural priors.

This chapter is based on papers $[8,84,86]$.

In this chapter, the author regards the following as her main contributions:

- incorporating nonogram-based information into the reconstruction process and solving the problem with SA,

- definition of different SA strategies and fine-tuning its parameters,

- implementation of the suggested methods,

- testing and comparing the methods,

- evaluation of the results. 



\section{Chapter 4}

\section{Global and Local Quadrant-Convexity}

Shape representation is a relevant topic in digital image analysis, due to, for instance, object recognition and classification issues. Suitable approaches for handling these problems include designing new shape descriptors as well as measures for descriptors sensitive to distinguishing shapes, while also robust to noise. Some methods provide a unified approach that can be applied to determine a variety of shape measures, but more often they are specific to a single aspect of a shape.

Remark 4.1 Note that in image analysis as well as in this thesis, the technical term 'measure' is used as a synonym for figure-of-merit rather than referring to the measure concept of mathematical analysis. Therefore, shape measures often do not satisfy, for example, monotonicity.

Over the years, a variety of measures for descriptors based on convexity have been developed. Area-based measures form one popular category [17, 78, 79, 81], while boundary-based ones [104] are also frequently used. Other methods use simplification of the contour [55] or a probabilistic approach [72, 73] to solve the problem. Recently, measures based on directional (line) convexity have been defined and investigated, independently, in $[9,89]$ and in $[40,41]$, to use the degree of directional convexity as a shape prior in image reconstruction and segmentation. These methods cannot be extended easily to a two-dimensional convexity measure. A different approach is to employ the concept of so-called Quadrant-convexity ( $Q$-convexity for short) $[20,21]$, which is inherently two-dimensional. This way, an extension of the directional convexity was presented in [9], which uses quantitative information introduced in [19]. In [6, 7] a different 2D convexity measure was presented, which is based on the salient points [33, 34].

In this chapter, we investigate the measure presented in [19] in depth. The concept is based on the similar measure definition in the framework of fuzzy spatial relationships, seeing as this measure provides a quantitative representation of the object by the mean relative positions of its points. Therefore, the derived descriptors provide a model for studying the spatial relative position concepts concerning unary relationships (i.e. to a reference object) and binary relationships (i.e. between two objects) [60].

Spatial relations have been studied by many disciplines, including cognitive science, linguistics, geography, artificial intelligence (see Section 8 of [60] 
for a review of the related literature), and constitute an important part of the science currently available on image processing and understanding [15]. Two types of questions are raised when dealing with spatial relations: (1) given one reference object, define the region of space in which a relation to this reference is satisfied (to some degree); (2) given two objects, assess the degree to which a relation is satisfied. Concerning the latter, the relations can be categorized into directional (such as 'to the left'), distance (for example, 'far'), and topological (for instance, 'includes'). In particular, questions related to measuring complex spatial relations like enlacement, interlacement, and surrounding have been studied in $[29,30]$. The term enlacement between $F$ and $G$ indicates that object $G$ is somehow inside object $F$ (the reference). Given a direction, a straight line parallel to the direction intersects the object in a one-dimensional finite slice (possibly empty) called longitudinal cut. Roughly speaking, the directional enlacement of $G$ with regards to $F$ along an oriented line is defined by summing up the contributions of longitudinal cuts to count the number of triplet points in $F \times G \times F$, as $G$ is enlaced by $F$ if their points alternate in this order [30]. If we consider the unary relationship, given reference object $F$, the directional enlacement landscape of $F$ along an oriented line consists in quantifying the region of space that is enlaced by $F$ by longitudinal cuts. It is worth mentioning that objects can overlap only if the objects are concave or are constituted by multiple connected components; indeed, the condition of some form of convexity to deal with these spatial relationships has already been investigated in [16].

Here, we propose our Quadrant-concavity measure to tackle these issues directly in the two-dimensional space, i.e. to define a scalar shape descriptor based on spatial relative positions of points that permit a definition of enlacement and interlacement between two objects. This approach is supported by suitable examples. Specifically, we establish the application of our descriptor for enlacement landscape, i.e. treating the foreground as one object and the background as the other object. This enables dealing with classification problems, and the experiments perform well in the examined cases.

As many studies have revealed, histograms built on local features can provide much richer information on the geometry and structural properties of a shape than single scalar descriptors do (see e.g. the Histogram of Oriented Gradients [32], the Speeded Up Robust Features [13] or variants of the Local Binary Patterns [54]). Therefore, we also propose a novel local shape descriptor based on $Q$-convexity and present how it can improve the quality of the reconstruction in Binary Tomography.

\subsection{Global Quadrant-Convexity}

Consider a two-dimensional object $F$ represented by a non-empty lattice set, i.e. a finite subset of $\mathbb{Z}^{2}$, or equivalently, a function $f: \mathbb{Z}^{2} \rightarrow\{0,1\}$. Let $\mathcal{R}$ be the smallest discrete rectangle containing $F$ and suppose it is of size $m \times n$. Without loss of generality, we can assume that the bottom-left corner 
of $\mathcal{R}$ is in the origin $(0,0)$, i.e. $\mathcal{R}=\{0, \ldots, m-1\} \times\{0, \ldots, n-1\}$. Alternatively, $F$ can be viewed as a binary image, i.e. as a union of white unit squares (foreground pixels) corresponding to points of $F$, and $\mathcal{R} \backslash F$ being the union of black unit squares (background pixels). Figure 4.1 displays both representations.

Each position $(i, j)$ in rectangle $\mathcal{R}$, along with the horizontal and vertical directions, determines the following four quadrants:

$$
\begin{aligned}
& Z_{0}(i, j)=\{(l, k) \in \mathcal{R}: 0 \leq l \leq i, 0 \leq k \leq j\}, \\
& Z_{1}(i, j)=\{(l, k) \in \mathcal{R}: i \leq l \leq m-1,0 \leq k \leq j\}, \\
& Z_{2}(i, j)=\{(l, k) \in \mathcal{R}: i \leq l \leq m-1, j \leq k \leq n-1\}, \\
& Z_{3}(i, j)=\{(l, k) \in \mathcal{R}: 0 \leq l \leq i, j \leq k \leq n-1\} .
\end{aligned}
$$

Let us denote the number of object points (foreground pixels) of $F$ in $Z_{p}(i, j)$ by $n_{p}(i, j)$, for $p=0, \ldots, 3$, meaning

$$
n_{p}(i, j)=\left|Z_{p}^{w}(i, j) \cap F\right|(p=0, \ldots, 3) .
$$

Definition 4.1 Lattice set $F$ is Q-convex, if for each $(i, j)\left(n_{0}(i, j)>0 \wedge n_{1}(i, j)>\right.$ $\left.0 \wedge n_{2}(i, j)>0 \wedge n_{3}(i, j)>0\right)$ implies $(i, j) \in F$.

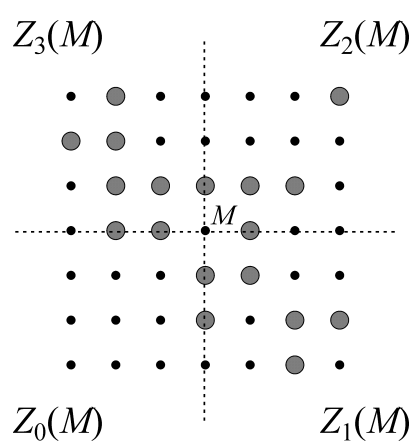

(a)

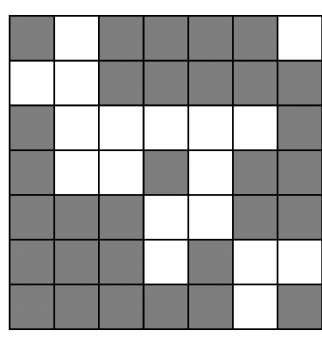

(b)

Figure 4.1: Non-Q-convex image.

If $F$ is not $Q$-convex, then a position $(i, j)$ exists, which violates the $Q$-convexity property, i.e. $n_{p}(i, j)>0$ for all $p=0, \ldots, 3$ and $(i, j) \notin F$. Note that if $F$ is not horizontally or vertically convex then it is not $Q$-convex. A lattice set that is not $Q$-convex is called $Q$-concave.

Figure 4.1 illustrates the above concepts: lattice set $F$, along with the four quadrants around point $M$ (Fig. 4.1a), and the corresponding binary image representation (Fig. 4.1b). $F$ is not $Q$-convex since $n_{p}(M)>0$ for all $p=$ $0, \ldots, 3$ and still $M \notin F$.

Figure 4.2 also illustrates the definition of $Q$-convexity. The four quadrants around point $(4,4)$ are: $Z_{0}(4,4)$ left-bottom, $Z_{1}(4,4)$ right-bottom, $Z_{2}(4,4)$ right-top, $Z_{3}(4,4)$ left-top. The lattice set of Fig. $4.2 \mathrm{~b}$ is $\mathrm{Q}$-concave (not $Q$-convex) because $(4,4) \notin F$ but $Z_{p}(4,4)$ contains object points, for all $p=0,1,2$, 3. In Fig. 4.2b, $n_{0}(4,4)=n_{1}(4,4)=n_{2}(4,4)=n_{3}(4,4)=24$. 


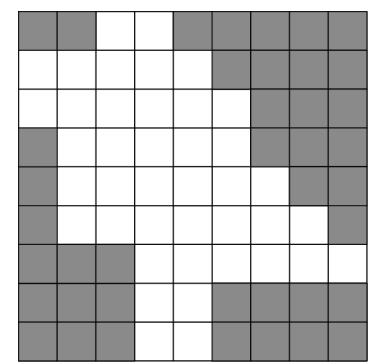

(a)

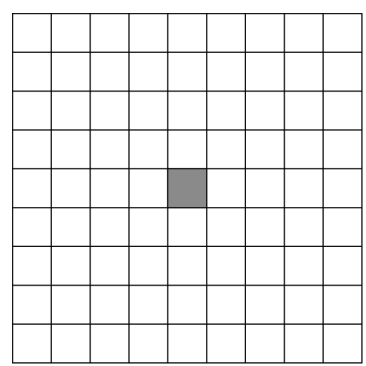

(b)

Figure 4.2: A $Q$-convex image (a) and a $Q$-concave image (b).

Let us note that Definition 4.1 is based on the relative positions of the object points: the quantification of the object points in the quadrants with respect to the considered point gives rise to a quantitative representation of $Q$-concavity.

We define the $Q$-concavity measure of $F$ as the sum of the contributions of non- $Q$-convexity for each point in $\mathcal{R}$. Formally,

$$
\varphi_{F}(i, j)=n_{0}(i, j) n_{1}(i, j) n_{2}(i, j) n_{3}(i, j)(1-f(i, j)),
$$

where $(i, j)$ is an arbitrary point of $\mathcal{R}$, and $f(i, j)=1$ if the point in position $(i, j)$ belongs to the object, otherwise $f(i, j)=0$. Moreover, let

$$
\varphi_{F}=\varphi_{F}(F)=\sum_{(i, j) \in \mathcal{R}} \varphi_{F}(i, j)
$$

For example, for the image in Fig. $4.2 b$, the only non-object point is $(4,4)$, thus, $\varphi_{F}=\varphi_{F}(4,4)=24 \cdot 24 \cdot 24 \cdot 24 \cdot 1=331776$.

Remark 4.2 If $f(i, j)=1$, then $\varphi_{F}(i, j)=0$. Moreover, if $f(i, j)=0$ and $n_{p}(i, j)=0$ exist, then $\varphi_{F}(i, j)=0$. Consequently, $F$ is $Q$-convex if and only if $\varphi_{F}=0$.

Remark 4.3 By definition, $\varphi$ is invariant by reflection and by point symmetry.

Remark 4.4 In [19], the authors established that Quadrant-concavity measure $\varphi$ extends directional convexity in [9].

\subsubsection{Obtaining Enlacement Descriptors by Normalization}

In order to measure the degree of $Q$-concavity, or equivalently the degree of landscape enlacement for a given object $F$, we normalize $\varphi$ so that it ranges in $[0,1]$ (fuzzy enlacement landscape). We propose two possible normalizations gained by normalizing each contribution. A global one is obtained as follows [29]:

$$
\mathcal{E}_{F}^{(1)}(i, j)=\frac{\varphi_{F}(i, j)}{\max _{\left(i^{\prime}, j^{\prime}\right) \in \mathcal{R}} \varphi_{F}\left(i^{\prime}, j^{\prime}\right)} .
$$

Second (local) one is based on [19]. There, the authors proved 
Proposition 4.1 Let $f(i, j)=0$, and $h_{i}^{F}$ and $v_{j}^{F}$ be the $i^{\text {th }}$ column and $j^{\text {th }}$ row sums, respectively. Then, $\varphi_{F}(i, j) \leq\left(\left(|F|+h_{i}^{F}+v_{j}^{F}\right) / 4\right)^{4}$.

As a consequence, we are able to normalize each contribution as

$$
\mathcal{E}_{F}^{(2)}(i, j)=\frac{\varphi_{F}(i, j)}{\left(\left(|F|+h_{i}^{F}+v_{j}^{F}\right) / 4\right)^{4}} .
$$

In order to obtain a normalization for the global enlacement for both Eqs. 4.4 and 4.5 , we sum up each single contribution and then divide by the number of nonzero contributions.

Definition 4.2 For a given binary image $F$, its global enlacement landscape $\mathcal{E}_{F}^{(\cdot)}$ is defined by

$$
\mathcal{E}_{F}^{(\cdot)}=\sum_{(i, j) \in \bar{F}} \frac{\mathcal{E}_{F}^{(\cdot)}(i, j)}{|\bar{F}|},
$$

where $\bar{F}$ denotes the subset of (landscape) points in $\mathcal{R} \backslash F$ for which the contribution is not 0 .

Figure 4.3 illustrates the values of the enlacement descriptors for four images. Figure $4.3 \mathrm{a}$ is $Q$-convex, meaning the descriptor gets 0 value. Figure $4.3 \mathrm{~b}$ receives a smaller $Q$-concavity value than Fig. 4.3c, since the background region inside of the object is deeper. In Fig. $4.3 \mathrm{~d}$ - where a thin black frame is added as a visual aid - part of the background is entirely enclosed by the object, therefore, this image receives a high enlacement value.

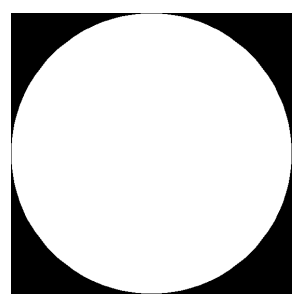

(a)

$\mathcal{E}_{F}^{(1)}=0$

$\mathcal{E}_{F}^{(2)}=0$

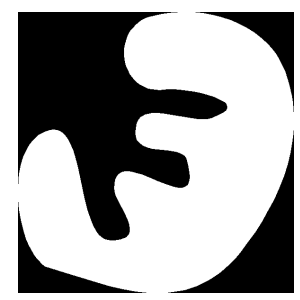

(b)

$\mathcal{E}_{F}^{(1)}=0.38225$

$\mathcal{E}_{F}^{(2)}=0.31707$

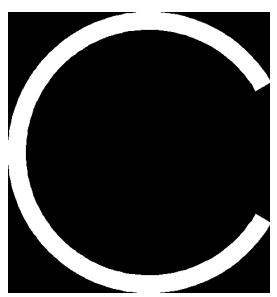

(c)

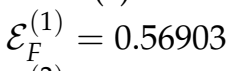

$\mathcal{E}_{F}^{(2)}=0.56773$

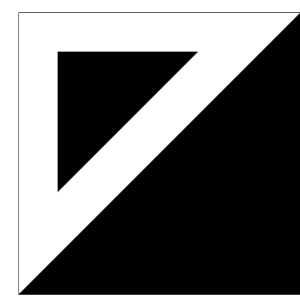

(d)

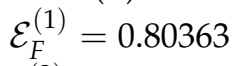

$\mathcal{E}_{F}^{(2)}=0.65960$

Figure 4.3: Sample images with enlacement values.

Figure 4.4 shows the contribution of each pixel according to Eq. 4.4: the grayscale levels correspond to the degrees of fuzzy enlacement for each pixel in the landscape. We can see that pixels inside the concavities are of lighter color (representing higher values) than pixels outside. Similar images can be provided according to Eq. 4.5. Naturally, in the case of Fig. 4.3a, the enlacement landscape is an entirely completely black image. Note that normalization plays a key role in Def. 4.2, as demonstrated in the experiments. 


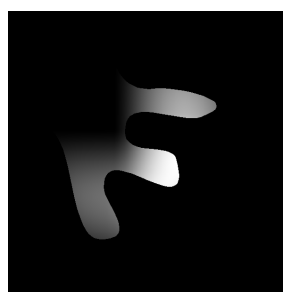

(a)

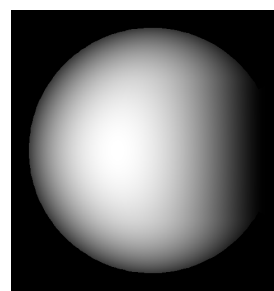

(b)

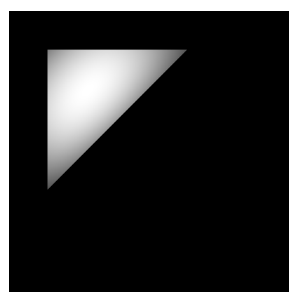

(c)

Figure 4.4: Enlacement landscapes of the last three images of Fig. 4.3.

\subsubsection{Object Enlacement and Interlacement}

Up to this point, we have defined shape measure $\varphi_{F}$ based on the concept of $Q$-convexity, which provides a quantitative measure for examining relationships with a reference object. Now, we modify this into a spatial relationship between two objects. Let $F$ and $G$ be two objects. The idea is to determine how many occurrences of points of $G$ are somehow between points of $F$. This is achieved by restricting the points in $\mathcal{R} \backslash F$, while also taking the points in $G$ into account. Therefore,

$$
\varphi_{F G}(i, j)=\left\{\begin{array}{ll}
\varphi_{F}(i, j) & \text { if }(i, j) \in G \\
0 & \text { otherwise }
\end{array} .\right.
$$

Note that if $G=\mathcal{R} \backslash F$, then trivially $\varphi_{F G}(i, j)=\varphi_{F}(i, j)$. The enlacement descriptors of $G$ by $F$ are thus

$$
\mathcal{E}_{F G}^{(1)}(i, j)=\frac{\varphi_{F G}(i, j)}{\max _{(i, j) \in G} \varphi_{F G}(i, j)},
$$

and

$$
\mathcal{E}_{F G}^{(2)}(i, j)=\frac{\varphi_{F G}(i, j)}{\left(\left(|F|+h_{i}^{F}+v_{j}^{F}\right) / 4\right)^{4}} .
$$

To clarify, note that, by definition, $\varphi_{F G}(i, j)=0$ if $(i, j) \notin \bar{F}$, thus the maximum of $\varphi_{F G}(i, j)$ in $G$ is equal to the maximum in $G \cap \bar{F}$.

Definition 4.3 Let $F$ and $G$ be two objects. The enlacement of $G$ by $F$ is

$$
\mathcal{E}_{F G}^{(\cdot)}=\sum_{(i, j) \in G} \frac{\mathcal{E}_{F G}^{(\cdot)}(i, j)}{|G \cap \bar{F}|} .
$$

Undoubtedly, the enlacement of two objects is an asymmetrical relation, so the enlacement of $G$ by $F$ and the enlacement of $F$ by $G$ provide different 'views'. Combining by their harmonic mean results in a symmetrical relation, which is the description of mutual enlacement (in other words, interlacement). 
Definition 4.4 Let $F$ and $G$ be two objects. The interlacement of $F$ and $G$ is

$$
\mathcal{I}_{F G}^{(\cdot)}=\frac{2 \mathcal{E}_{F G}^{(\cdot)} \mathcal{E}_{G F}^{(\cdot)}}{\mathcal{E}_{F G}^{(\cdot)}+\mathcal{E}_{G F}^{(\cdot)}},
$$

where $\mathcal{E}_{F G}^{(\cdot)}$ and $\mathcal{E}_{G F}^{(\cdot)}$ are the enlacement of $G$ by $F$ and the enlacement of $F$ by $G$, respectively.

Fig. 4.5 and Table 4.1 exhibit two sample images with their interlacement values.

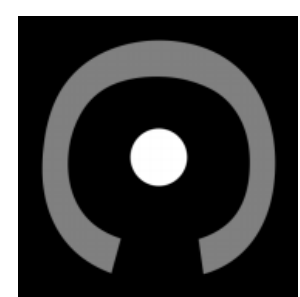

(a)

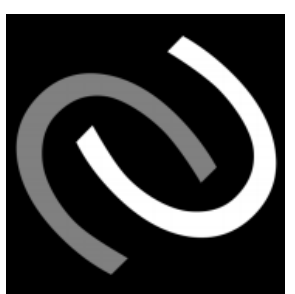

(b)

Figure 4.5: Sample images from [30], where $F$ and $G$ are represented by white and gray pixels, respectively.

\begin{tabular}{|c|c|c|c|c|c|c|}
\hline & $\mathcal{E}_{F G}^{(1)}$ & $\mathcal{E}_{G F}^{(1)}$ & $\mathcal{I}_{F G}^{(1)}$ & $\mathcal{E}_{F G}^{(2)}$ & $\mathcal{E}_{G F}^{(2)}$ & $\mathcal{I}_{F G}^{(2)}$ \\
\hline $4.5 \mathrm{a}$ & 0 & 0.93259 & 0 & 0 & 0.93332 & 0 \\
\hline $4.5 \mathrm{~b}$ & 0.54401 & 0.54914 & 0.54656 & 0.52357 & 0.52856 & 0.52605 \\
\hline
\end{tabular}

Table 4.1: Interlacement values of Fig. 4.5.

The measures can be implemented efficiently in linear time in the size of the image. By definition, $Z_{0}(l, k) \subseteq Z_{0}(i, j)$ if $l \leq i$ and $k \leq j$, and hence $n_{0}(l, k) \leq$ $n_{0}(i, j)$ with $l \leq i$ and $k \leq j$. Analogous relations hold for $Z_{1}, Z_{2}, Z_{3}$ and for $n_{1}, n_{2}, n_{3}$ accordingly. Exploiting this property and proceeding line by line, we are able to count the number of points in $F$ for $Z_{p}(i, j)$, for each $(i, j)$ in linear time, and store them in a matrix for any $p=\{0,1,2,3\}$. Then, $\varphi(i, j)$ can be computed in constant time for any $(i, j)$. Normalization is straightforward.

\subsubsection{Experiments}

In the following experiments, we used public datasets of fundus photographs of the retina for classification purposes. We opted to compare our descriptor with its counterpart in [30] since they model a similar idea based on a quantitative concept of convexity. The main difference is that we provide a fully 2D approach, whereas the directional enlacement landscape in [30] is onedimensional. The CHASEDB1 [37] dataset is composed of 20 binary images 
with centered optic disks, while the DRIVE [80] dataset contains 20 images, where the optic disk is shifted from the center (Fig. 4.6). The images are inverted for better visibility.

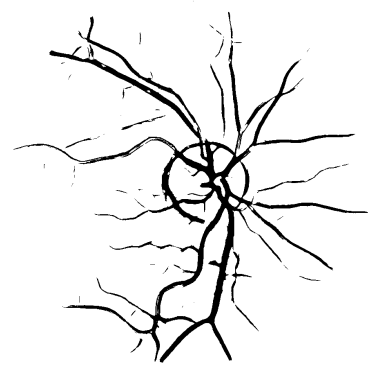

(a)

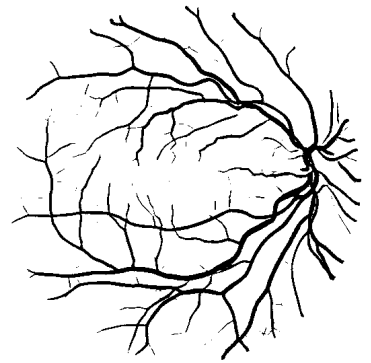

(b)

Figure 4.6: Sample images from the CHASEDB1 (a) and DRIVE (b) datasets.

Following the strategy of [30], we gradually added different types of random noise (which can also be interpreted as increasingly stronger segmentation errors) to size $1000 \times 1000$ images. Gaussian and Speckle noises were added with 10 increasing variances $\sigma^{2} \in[0,2]$, while Salt \& Pepper noise was added with 10 increasing amounts in $[0,0.1]$. A few sample images are cited in Fig. 4.7. The images are again inverted for better visibility.

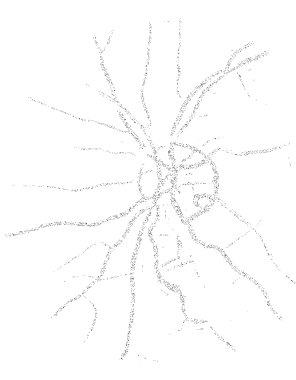

(a)

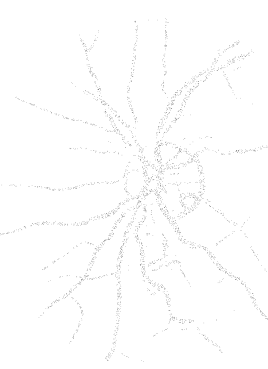

(d)

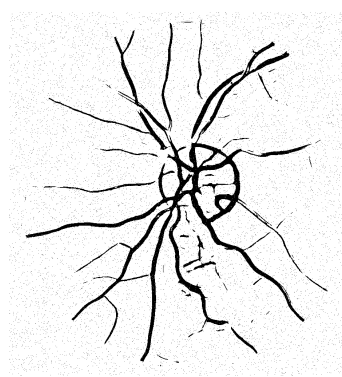

(b)

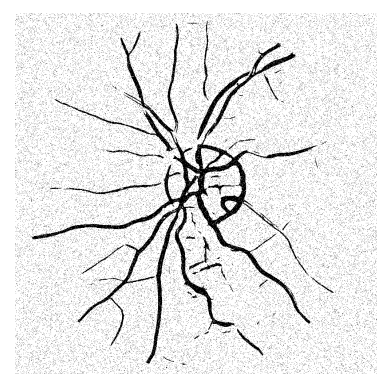

(e)

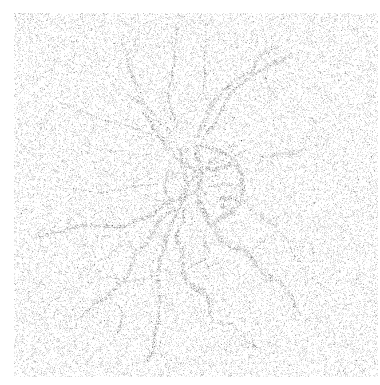

(c)

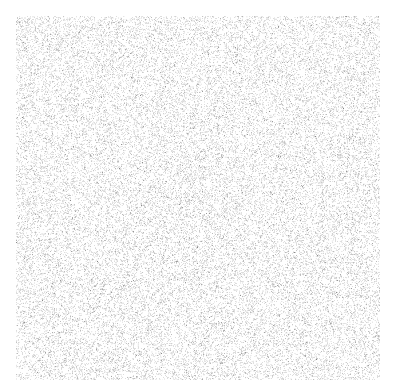

(f)

Figure 4.7: Retina images with moderate (above) and large (below) amounts of Speckle (a, d), Salt \& Pepper (b, e), and Gaussian (c, f) noise.

Then, we attempted to divide the images into two classes (CHASEDB1 and DRIVE) based on their interlacement values ( $F$ being the object and $G$ the 
background) by the 5-nearest neighbor classifier (5NN) with inverse Euclidean distance. For the implementation, we used the WEKA Toolbox [36] and leave-one-out cross-validation to evaluate accuracy. The results are presented in Table 4.2. In [30], the authors reported reaching an average accuracy of $97.75 \%, 99.25 \%$, and $98.75 \%$ for Speckle, Gaussian, and Salt \& Pepper noise, respectively, on the same dataset with 5NN. In comparison, $\mathcal{I}_{F G}^{(2)}$ demonstrates a substandard performance. Fortunately, the manner of normalization featured in Eq. 4.5 generally solves the problem; therefore the results using $\mathcal{I}_{F G}^{(1)}$ are just slightly worse in the case of Speckle and Salt \& Pepper noise. Gaussian noise is more challenging, even a moderate amount distorts the structures drastically (see Fig. 4.7), hence two-directional enlacement can no longer ensure trustworthy classification. Here, for a moderate amount of noise (Levels 3-6), $\mathcal{I}_{F G}^{(2)}$ is better. The reason could possibly be that, in these cases, $\mathcal{E}_{G F}^{(2)}$ can compensate the low classification accuracy supplied by $\mathcal{E}_{F G}^{(2)}$. Nevertheless, this is especially promising, since - being two-dimensional based - our descriptor only uses two directions (four quadrants), whereas that of [30] - being one-dimensional based - uses 180 directions, also taking more time to compute.

\begin{tabular}{|c|c|c|c|c|c|c|}
\hline & \multicolumn{2}{|c|}{ Speckle } & \multicolumn{2}{c|}{ Salt \& Pepper } & \multicolumn{2}{c|}{ Gaussian } \\
& $\mathcal{I}_{F G}^{(1)}$ & $\mathcal{I}_{F G}^{(2)}$ & $\mathcal{I}_{F G}^{(1)}$ & $\mathcal{I}_{F G}^{(2)}$ & $\mathcal{I}_{F G}^{(1)}$ & $\mathcal{I}_{F G}^{(2)}$ \\
\hline Level 1 & 92.5 & 57.5 & 92.5 & 87.5 & 92.5 & 57.5 \\
\hline Level 2 & 90.0 & 80.0 & 90.0 & 82.5 & 80.0 & 67.5 \\
\hline Level 3 & 92.5 & 60.0 & 92.5 & 90.0 & 70.0 & 95.0 \\
\hline Level 4 & 92.5 & 62.5 & 92.5 & 80.0 & 57.5 & 82.5 \\
\hline Level 5 & 95.0 & 85.0 & 92.5 & 87.5 & 55.0 & 65.0 \\
\hline Level 6 & 92.5 & 72.5 & 90.0 & 80.0 & 45.0 & 67.5 \\
\hline Level 7 & 92.5 & 50.0 & 92.5 & 85.0 & 70.0 & 52.5 \\
\hline Level 8 & 90.0 & 60.0 & 90.0 & 77.5 & 70.0 & 70.0 \\
\hline Level 9 & 90.0 & 62.5 & 87.5 & 80.0 & 57.5 & 40.0 \\
\hline Level 10 & 95.0 & 62.5 & 90.0 & 85.0 & 47.5 & 57.5 \\
\hline
\end{tabular}

Table 4.2: $5 \mathrm{NN}$ classification accuracy (in percentage) of CHASEDB1 and DRIVE images for different types and levels of noise.

For a more complex classification problem, we used the High-Resolution Fundus (HRF) dataset [66], composed of 45 images of fundus: 15 healthy, 15 with glaucoma symptoms, and 15 with diabetic retinopathy symptoms (Fig. 4.8). The images are again inverted for better visibility. Using the same classifier as before, we attempted to separate the 15 healthy images from the 30 diseased cases. Figure 4.9 indicates the precision-recall curves obtained for this classification problem by the two interlacement descriptors. In comparison, we also present the curve based on the interlacement descriptor introduced in [30]. The performance of $\mathcal{I}_{F G}^{(1)}$ seems to be poorer, in this instance. 
On the other hand, we observe that descriptor $\mathcal{I}_{F G}^{(2)}$ performs just as well as the one presented in [30] (or even slightly better). We stress again that our descriptor only uses two directions.

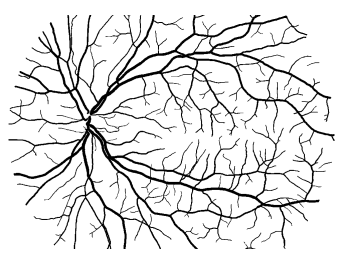

(a) Healthy case

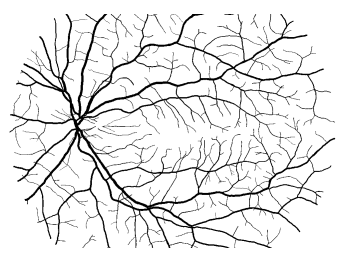

(b) Glaucoma

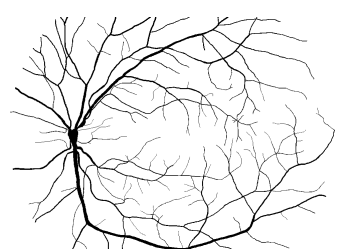

(c) Diabetic retinopathy

Figure 4.8: Samples from the HRF dataset.

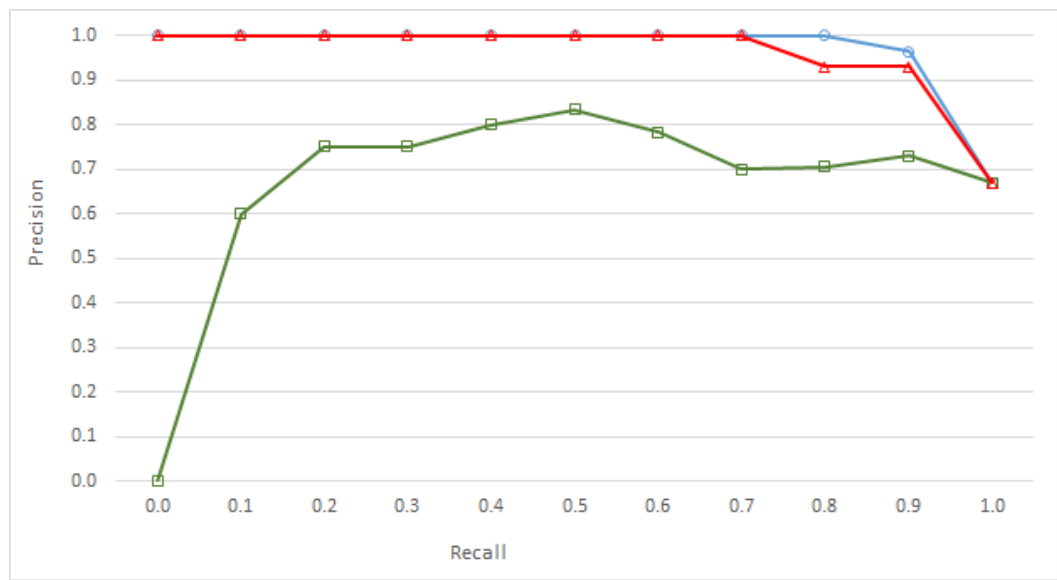

(a)

Green: $\mathcal{I}_{F G}^{(1)}$, Blue: $\mathcal{I}_{F G}^{(2)}$, Red: curve of [30]

Figure 4.9: Precision-recall curves obtained for classifying healthy and diseased cases of the HRF images.

\subsection{Local Quadrant-Concavity Histograms for Image Classification}

As many studies have revealed, histograms built on local features are able to provide much richer information on the geometry and structural properties of the shape than single scalar descriptors do (see e.g. the Histogram of Oriented Gradients [32], the Speeded Up Robust Features [13] or variants of the Local Binary Patterns [54]). Here, we extend the global $Q$-concavity measure to histograms collecting $Q$-concavity values calculated under all possible positions of an image window of predefined size.

The aim is refining Eqs. 4.2 and 4.3 to achieve a local and thus more informative measure of $Q$-concavity. To this end, consider a $(2 w+1) \times(2 w+1)$ window $\left(w \in \mathbb{Z}^{+}\right)$. The quadrants around $(i, j)$ restricted to this window size 
can then be defined as

$$
\begin{aligned}
& Z_{0}^{w}(i, j)=\{(l, k) \in \mathcal{R}:(i-w) \leq l \leq i,(j-w) \leq k \leq j\}, \\
& Z_{1}^{w}(i, j)=\{(l, k) \in \mathcal{R}: i \leq l \leq(i+w),(j-w) \leq k \leq j\}, \\
& Z_{2}^{w}(i, j)=\{(l, k) \in \mathcal{R}: i \leq l \leq(i+w), j \leq k \leq(j+w)\}, \\
& Z_{3}^{w}(i, j)=\{(l, k) \in \mathcal{R}:(i-w) \leq l \leq i, j \leq k \leq(j+w)\},
\end{aligned}
$$

where $\mathcal{R}=\{0, \ldots, m-1\} \times\{0, \ldots, n-1\}$ and $m \times n$ is the size of the image. The number of object points in $Z_{p}^{w}$ is

$$
n_{p}^{w}(i, j)=\left|Z_{p}^{w}(i, j) \cap F\right|(p=0, \ldots, 3),
$$

and the local $Q$-concavity contribution at point $(i, j)$ is

$$
\varphi_{F}^{w}(i, j)=n_{0}^{w}(i, j) n_{1}^{w}(i, j) n_{2}^{w}(i, j) n_{3}^{w}(i, j)(1-f(i, j)) .
$$

Finally, the local Q-concavity histogram of $F(\mathrm{LQH})$ is a mapping hist $_{F, w}: \mathbb{Z} \rightarrow \mathbb{Z}$, which can be defined in various ways. The first approach focuses on the background points in $\mathcal{R}$. In this case,

$$
\operatorname{hist}_{F, w, b g}(r)=\left|(i, j) \in \mathcal{R} \backslash F: \varphi_{F}^{w}(i, j)=r\right|,
$$

i.e. we take each background point, calculate its local $Q$-concavity value, and increase the value of the corresponding bin by 1 . Alternatively, we can take all points in $\mathcal{R}$ into account. Then,

$$
\operatorname{hist}_{F, w, \text { all }}(r)=\left|(i, j) \in \mathcal{R}: \varphi_{F}^{w}(i, j)=r\right| .
$$

A third approach focuses exclusively on the points that truly violate local $Q$-convexity (approach 'nonzero'). Then we get

$$
\operatorname{hist}_{F, w, n z}(r)=\left|(i, j) \in \mathcal{R}: \varphi_{F}^{w}(i, j)=r>0\right|,
$$

i.e. in this case, the 0 bin is omitted.

Remark 4.5 In practice, $L Q H$ can be calculated by omitting positions where the window does not fit into the image entirely. Another solution would be to use padding. As all frequently used padding techniques (zero-, replicate-, and mirrorpadding) may introduce novel patterns that are not present in the interior of the image, we prefer to omit the border positions of the image.

Let $F$ be an arbitrary binary image. Employing elementary combinatorics, the theoretical maximum of $\varphi_{F}^{w}(i, j)$ is $\left((w+1)^{2}-1\right)^{4}$. Moreover, $\varphi_{F}^{w}(i, j)$ is either equal to 0 or is a product of four positive integers from the interval $\left[1,(w+1)^{2}-1\right]$. Owing to the associative property of multiplication, using the formula of $k$-combinations with repetition, the upper bound on the possible number of the necessary bins is equal to

$$
\left(\begin{array}{c}
\left((w+1)^{2}-1\right)+4-1 \\
4
\end{array}\right)+1=\left(\begin{array}{c}
(w+1)^{2}+2 \\
4
\end{array}\right)+1
$$


Nevertheless, many of the bins are inherently empty, e.g. those having indices obtained by multiplying five or more primes.

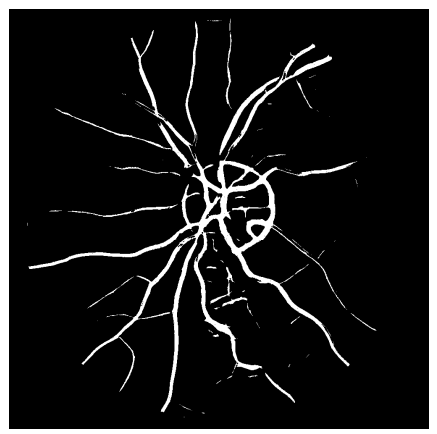

(a)

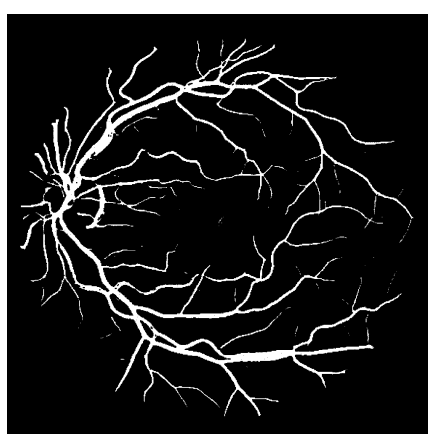

(c)

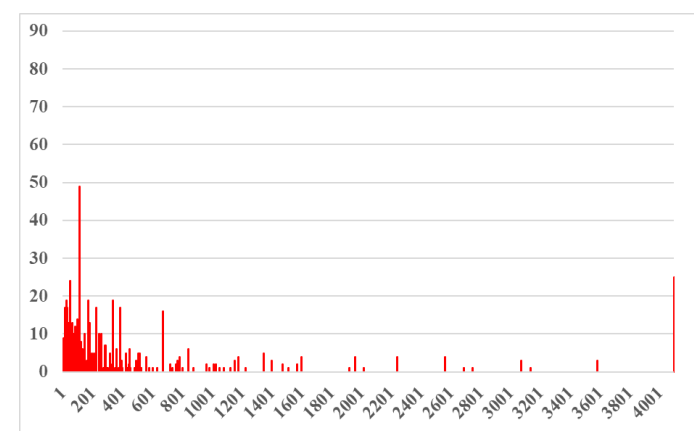

(b)

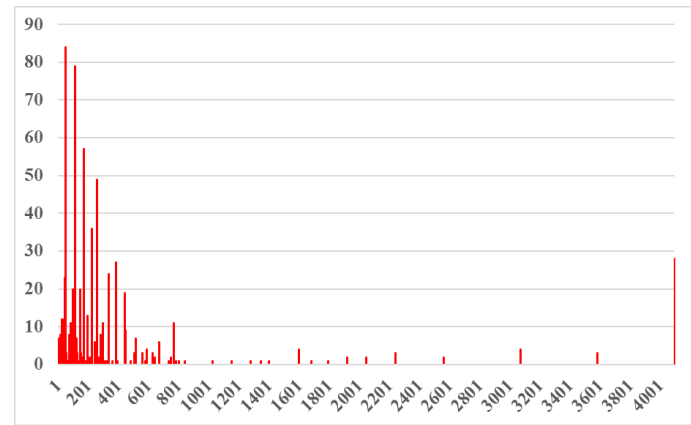

(d)

Figure 4.10: Local Q-concavity histograms.

Fig. 4.10 displays two binarized retina images of size $1000 \times 1000$ with their local $Q$-concavity histograms hist $_{F, 2, n z}$ processed for a $5 \times 5$ window. Since the maximum of $\varphi_{F}^{w}(i, j)$ is 4096 in this case, we allocated 4096 bins to store the values (keep in mind that the 0 bin is omitted in this variant). The histograms hist $_{F, 2, b g}$ and hist $t_{F, 2, \text { all }}$ look the same, except that in these cases, the 0 bin is also presented. For the image in Fig. 4.10a, the value of this bin in the case of hist $F, 2, b g$ and hist $F, 2$,all is 937885 and 991253 , respectively. Concerning the image of Fig. 4.10c, the value of the 0 bin in the case of hist $t_{F, 2, b g}$ and hist $_{F, 2, \text { all }}$ is 918465 and 991 167, respectively. Therefore, in these cases, the 0 bin generates a significant peak in the histograms, while all other bins become negligible.

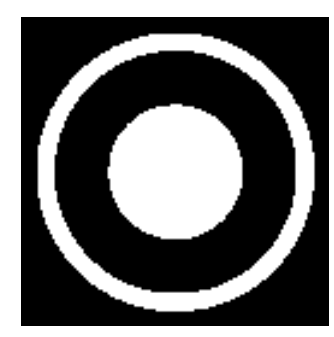

Figure 4.11: A globally non- $Q$-convex shape that is locally $Q$-convex in each window position

(e.g. with window size $5 \times 5$ ). 
In another instance, consider the image of Fig. 4.11 (of size $256 \times 256$ ), and let the window again be $5 \times 5$. In this case, all the bins excluding the 0 bin will have 0 value, regardless of the type of the calculated histogram. This reveals an interesting behavior of the descriptor: the shape seems to be locally $Q$-convex in each window position, even though it is clearly globally not $Q$-convex. For the sake of completeness, the value of the 0 bin for this image in the case of hist $F, 2, b g$ and hist $F, 2$,all is 43492 (the number of background points) and 63504 (the number of positions where the window fit into the image entirely), respectively. Naturally, for sufficiently large window sizes, the shape will neither be locally nor globally $Q$-convex.

\subsubsection{Comparison of the LQH Variants}

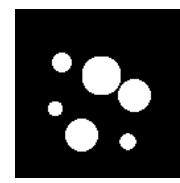

(a)

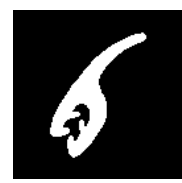

(g)

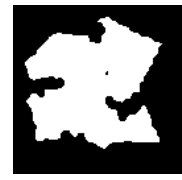

$(\mathrm{m})$

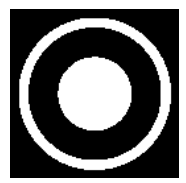

(b)

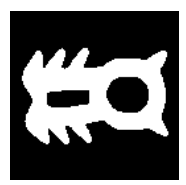

(h)

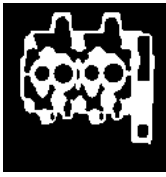

(n)

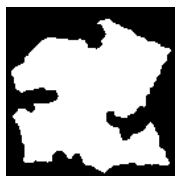

(s)

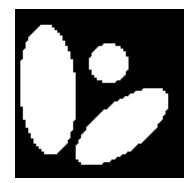

(c)

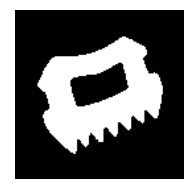

(i)

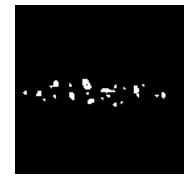

(o)

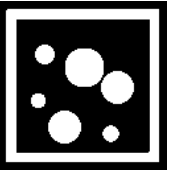

(t)

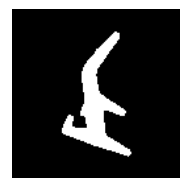

(d)

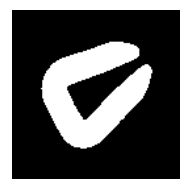

(j)

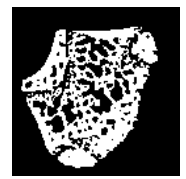

(p)

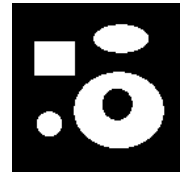

(u)

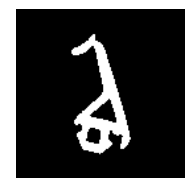

(e)

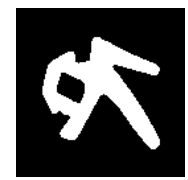

(k)

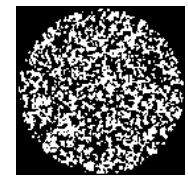

(q)

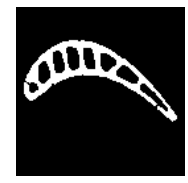

(v)

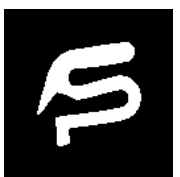

(f)

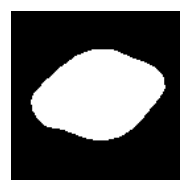

(1)

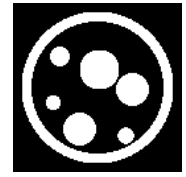

(r)

Figure 4.12: TomoPhantom images taken from [94].

To compare the three histogram variants introduced in Section 4.2, we took 22 binary images of size $128 \times 128$ from [94] (see Fig. 4.12) and computed their local $Q$-concavity histograms. Then, we calculated the Euclidean distances of the histogram vectors between all possible (distinct) image pairs. Table 4.3 collects the maximal, minimal, and mean distance between the image pairs, as well as the standard deviation (SD) of the distances for different window sizes and for all three histogram approaches. From the entries of the table, we deduce the following. The minimum and maximum values of the approach that only takes the background points into account (see Eq. 4.12, and columns $b g$ in the following tables) covers a wider interval than those of the other two approaches; however, with greater deviation. Furthermore, 
the histograms of Eqs. 4.13 and 4.14 (columns all and $n z$, respectively) cannot distinguish two locally $Q$-convex images (e.g. with window size $5 \times 5$ Figs. 4.12a, 4.12t, and Figs. 4.12b, 4.12c, 4.121, 4.12u), whereas that of Eq. 4.12 is still able to measure some difference based on the number of background points. Concerning this latter approach, we observe that, in general, larger window sizes provide greater difference between the minimum and maximum values, and thus also greater mean and deviance values.

Remark 4.6 Values in Tables 4.3-4.6 are rounded to integers.

\begin{tabular}{|cc|c|c|c|c|}
\hline & & Min & Max & Mean & SD \\
\hline $3 \times 3$ & $\boldsymbol{b g}$ & 16 & 8806 & 2401 & 1749 \\
\hline $3 \times 3$ & all & 0 & 919 & 112 & 265 \\
\hline $3 \times 3$ & $\boldsymbol{n z}$ & 0 & 280 & 37 & 81 \\
\hline $5 \times 5$ & $\boldsymbol{b g}$ & 15 & 8798 & 2647 & 1924 \\
\hline $5 \times 5$ & $\boldsymbol{a l l}$ & 0 & 3499 & 421 & 999 \\
\hline $5 \times 5$ & $\boldsymbol{n z}$ & 0 & 421 & 53 & 118 \\
\hline $7 \times 7$ & $\boldsymbol{b g}$ & 12 & 10635 & 2859 & 2210 \\
\hline $7 \times 7$ & $\boldsymbol{a l l}$ & 0 & 5533 & 700 & 1568 \\
\hline $7 \times 7$ & $\boldsymbol{n z}$ & 0 & 365 & 50 & 101 \\
\hline $9 \times 9$ & $\boldsymbol{b g}$ & 34 & 11251 & 2939 & 2318 \\
\hline $9 \times 9$ & $\boldsymbol{a l l}$ & 0 & 6209 & 840 & 1742 \\
\hline $9 \times 9$ & $\boldsymbol{n z}$ & 0 & 244 & 40 & 66 \\
\hline $11 \times 11$ & $\boldsymbol{b g}$ & 18 & 11181 & 2950 & 2304 \\
\hline $11 \times 11$ & $\boldsymbol{a l l}$ & 0 & 6268 & 921 & 1735 \\
\hline $11 \times 11$ & $\boldsymbol{n z}$ & 0 & 162 & 36 & 42 \\
\hline $13 \times 13$ & $\boldsymbol{b g}$ & 18 & 10925 & 2944 & 2258 \\
\hline $13 \times 13$ & $\boldsymbol{a l l}$ & 0 & 6242 & 990 & 1697 \\
\hline $13 \times 13$ & $\boldsymbol{n z}$ & 0 & 128 & 36 & 31 \\
\hline
\end{tabular}

Table 4.3: Statistics of Euclidean distances for images of Fig. 4.12.

In a second experiment, we investigated how different textures can be separated by their local $Q$-concavity histograms. We used two different datasets: 1) software phantom images (Fig. 4.13, Fig. D.2);2) and real images from the Brodatz texture database [18] (Fig. 4.14, Fig. D.3). The size of the original images varied between $256 \times 256$ and $1230 \times 1120$. To test the descriptive power of the LQH, we first cut 50-50 random patches of size $128 \times 128$ of each image class of both datasets and computed their LQHs. Then, we calculated the Euclidean distances of the histogram vectors between all possible (distinct) image pairs. 


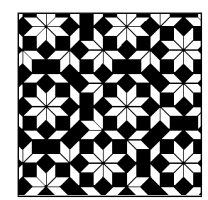

(a) Class 1

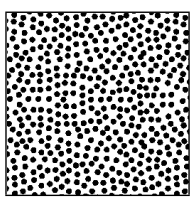

(b) Class 2

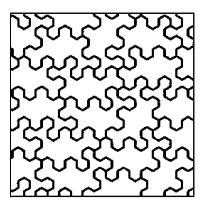

(c) Class 3

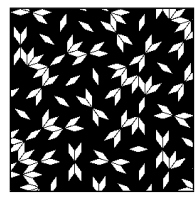

(d) Class 4

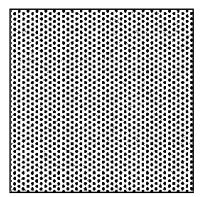

(e) Class 5

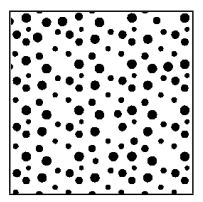

(f) Class 6

Figure 4.13: Software phantom image classes.

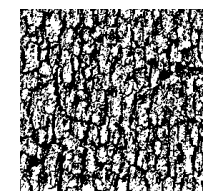

(a)

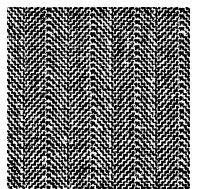

(g)

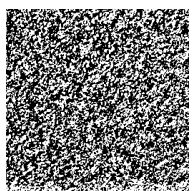

(b)

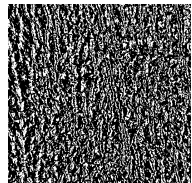

(h)

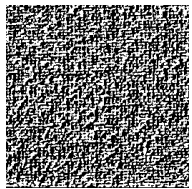

(c)

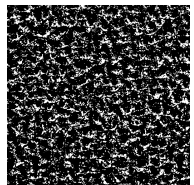

(i)

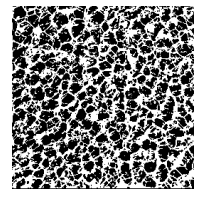

(d)

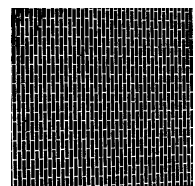

(j)

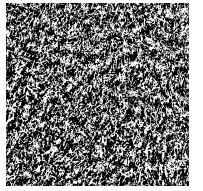

(e)

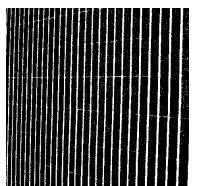

(k)

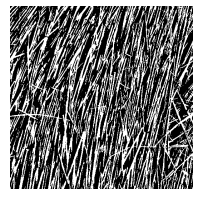

(f)

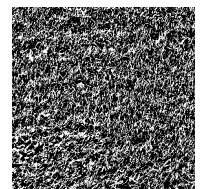

(1)

Figure 4.14: Real image classes I.[18].

Table 4.4 indicates the maximal, minimal, and mean distance between the image pairs, as well as the standard deviation (SD) of the distances for different window sizes for different approaches. Tables 4.5 and 4.6 provide the intraclass standard deviation of the various classes.

Remark 4.7 Tables E.1 and E.2 (in Appendix E) display the mean Euclidean distance between the representatives of different texture classes (in other words, the mean interclass distance) of Figs. 4.13 and 4.14, respectively.

Utilizing the background approach, the interclass Euclidean distances are typically greater than in the case of the other two histogram variants. We also observe that taking an arbitrary image pair from Tables E.1 and E.2 and checking their corresponding intraclass deviation in Tables 4.5 and 4.6, generally speaking, this latter value is relatively smaller (compared to the distance value, e.g. by taking the ratio of the two) for the background variant than for the other two methods. Based on these two experiments, in the sequel, we prefer to use the histogram based on the background points.

It can also be observed that the interclass Euclidean distances (see mean values in Table 4.4) are large enough, while the intraclass standard deviations are small enough to separate the different image classes. Therefore, we are able to deduce from the table entries that various image classes can be properly distinguished from each other. We also note that the appropriate window size cannot be globally defined in a straightforward manner based on these observations. This issue will be discussed later in the chapter. 


\begin{tabular}{|c|c|c|c|c|c|c|c|c|}
\hline & \multicolumn{4}{|c|}{ Fig. 4.13} & \multicolumn{4}{|c|}{ Fig. 4.14} \\
\hline & Min & Max & Mean & SD & Min & Max & Mean & SD \\
\hline $3 \times 3$ & 77 & 9182 & 4375 & 3119 & 180 & 4821 & 2007 & 1362 \\
\hline $3 \times 3$ & 1 & 375 & 222 & 120 & 38 & 1165 & 449 & 290 \\
\hline $3 \times 3$ & 1 & 269 & 138 & 79 & 21 & 351 & 152 & 82 \\
\hline $5 \times 5$ & 996 & 10781 & 5069 & 3123 & 158 & 8170 & 3172 & 2060 \\
\hline $5 \times 5$ & 134 & 2689 & 1112 & 972 & 39 & 4546 & 1769 & 1158 \\
\hline $5 \times 5$ & 60 & 766 & 374 & 272 & 24 & 555 & 236 & 140 \\
\hline $7 \times 7$ & 680 & 11410 & 5595 & 3359 & 137 & 10301 & 4040 & 2693 \\
\hline $7 \times 7$ & 112 & 3373 & 1654 & 1237 & 35 & 6851 & 2754 & 1787 \\
\hline $7 \times 7$ & 54 & 673 & 356 & 211 & 35 & 458 & 212 & 112 \\
\hline $9 \times 9$ & 278 & 10873 & 5242 & 3654 & 112 & 10835 & 4252 & 3070 \\
\hline $9 \times 9$ & 130 & 3021 & 1639 & 1088 & 120 & 7631 & 3008 & 2109 \\
\hline $9 \times 9$ & 58 & 462 & 261 & 125 & 42 & 332 & 167 & 73 \\
\hline $11 \times 11 \quad b g$ & 424 & 10442 & 5074 & 3897 & 90 & 10262 & 3761 & 3090 \\
\hline $11 \times 11$ all & 300 & 3987 & 1966 & 1196 & 89 & 7496 & 2577 & 2077 \\
\hline $11 \times 11$ & 53 & 443 & 226 & 148 & 57 & 422 & 170 & 104 \\
\hline $13 \times 13$ & 108 & 9957 & 4863 & 3947 & 74 & 9104 & 3062 & 2843 \\
\hline $13 \times 13$ & 345 & 4197 & 1945 & 1140 & 120 & 6984 & 2012 & 1839 \\
\hline $13 \times 13$ & 48 & 490 & 215 & 198 & 43 & 363 & 151 & 94 \\
\hline
\end{tabular}

Table 4.4: Statistics of mean interclass Euclidean distances for the two datasets.

\begin{tabular}{|c|c|c|c|c|c|c|c|c|c|}
\hline & $\begin{array}{c}3 \times 3 \\
b g\end{array}$ & $\begin{array}{c}3 \times 3 \\
\text { all }\end{array}$ & $\begin{array}{c}3 \times 3 \\
n z\end{array}$ & $\begin{array}{c}5 \times 5 \\
b g\end{array}$ & $\begin{array}{c}5 \times 5 \\
\text { all }\end{array}$ & $\begin{array}{c}5 \times 5 \\
n z\end{array}$ & $\begin{array}{c}7 \times 7 \\
b g\end{array}$ & $\begin{array}{c}7 \times 7 \\
\text { all }\end{array}$ & $\begin{array}{c}7 \times 7 \\
n z\end{array}$ \\
\hline $4.13 a$ & 363 & 81 & 52 & 267 & 98 & 82 & 363 & 63 & 46 \\
\hline $4.13 \mathrm{~b}$ & 74 & 6 & 4 & 58 & 20 & 12 & 61 & 19 & 17 \\
\hline $4.13 c$ & 124 & 5 & 3 & 121 & 86 & 19 & 74 & 109 & 24 \\
\hline $4.13 \mathrm{~d}$ & 301 & 46 & 26 & 253 & 41 & 19 & 342 & 62 & 12 \\
\hline $4.13 \mathrm{e}$ & 52 & 24 & 16 & 75 & 84 & 69 & 53 & 63 & 53 \\
\hline $4.13 \mathrm{f}$ & 125 & 3 & 2 & 123 & 6 & 4 & 130 & 12 & 4 \\
\hline
\end{tabular}

\begin{tabular}{|c|c|c|c|c|c|c|c|c|c|}
\hline & $\begin{array}{c}9 \times 9 \\
b g\end{array}$ & $\begin{array}{c}9 \times 9 \\
\text { all } \\
\end{array}$ & $\begin{array}{c}9 \times 9 \\
n z\end{array}$ & $\begin{array}{c}11 \times 11 \\
\text { bg }\end{array}$ & $\begin{array}{c}11 \times 11 \\
\text { all }\end{array}$ & $\begin{array}{c}11 \times 11 \\
n z\end{array}$ & $\begin{array}{c}13 \times 13 \\
b g\end{array}$ & $\begin{array}{c}13 \times 13 \\
\text { all }\end{array}$ & $\begin{array}{c}13 \times 13 \\
n z\end{array}$ \\
\hline $4.13 a$ & 394 & 59 & 37 & 321 & 70 & 21 & 252 & 56 & 24 \\
\hline $4.13 \mathrm{~b}$ & 48 & 36 & 30 & 26 & 49 & 25 & 20 & 57 & 20 \\
\hline $4.13 c$ & 17 & 99 & 17 & 11 & 107 & 11 & 7 & 93 & 7 \\
\hline $4.13 \mathrm{~d}$ & 294 & 58 & 4 & 347 & 91 & 4 & 353 & 112 & 4 \\
\hline $4.13 \mathrm{e}$ & 30 & 50 & 30 & 39 & 54 & 39 & 64 & 74 & 64 \\
\hline $4.13 \mathrm{f}$ & 140 & 36 & 7 & 161 & 52 & 9 & 95 & 68 & 11 \\
\hline
\end{tabular}

Table 4.5: Intraclass deviation of image classes of Fig. 4.13. 


\begin{tabular}{|c|c|c|c|c|c|c|c|c|c|}
\hline & $\begin{array}{c}3 \times 3 \\
b g\end{array}$ & $\begin{array}{c}3 \times 3 \\
\text { all }\end{array}$ & $\begin{array}{c}3 \times 3 \\
n z\end{array}$ & $\begin{array}{c}5 \times 5 \\
\text { bg }\end{array}$ & $\begin{array}{c}5 \times 5 \\
\text { all }\end{array}$ & $\begin{array}{c}5 \times 5 \\
n z\end{array}$ & $\begin{array}{c}7 \times 7 \\
b g\end{array}$ & $\begin{array}{c}7 \times 7 \\
\text { all }\end{array}$ & $\begin{array}{c}7 \times 7 \\
n z\end{array}$ \\
\hline $4.14 \mathrm{a}$ & 79 & 30 & 9 & 94 & 76 & 16 & 125 & 108 & 18 \\
\hline $4.14 \mathrm{~b}$ & 132 & 41 & 12 & 205 & 114 & 20 & 76 & 45 & 23 \\
\hline $4.14 c$ & 106 & 22 & 11 & 165 & 129 & 22 & 145 & 113 & 22 \\
\hline $4.14 d$ & 206 & 26 & 8 & 217 & 39 & 11 & 268 & 97 & 18 \\
\hline $4.14 \mathrm{e}$ & 201 & 47 & 13 & 316 & 175 & 13 & 324 & 240 & 14 \\
\hline $4.14 \mathrm{f}$ & 190 & 42 & 16 & 237 & 149 & 23 & 458 & 434 & 23 \\
\hline $4.14 \mathrm{~g}$ & 115 & 12 & 5 & 88 & 23 & 6 & 99 & 48 & 8 \\
\hline $4.14 \mathrm{~h}$ & 168 & 28 & 9 & 235 & 151 & 18 & 264 & 270 & 19 \\
\hline $4.14 \mathrm{i}$ & 143 & 20 & 7 & 189 & 62 & 8 & 279 & 154 & 11 \\
\hline $4.14 j$ & 101 & 12 & 9 & 104 & 19 & 7 & 101 & 29 & 5 \\
\hline $4.14 \mathrm{k}$ & 158 & 10 & 5 & 183 & 33 & 6 & 210 & 86 & 13 \\
\hline 4.141 & 174 & 23 & 13 & 205 & 186 & 28 & 267 & 267 & 24 \\
\hline
\end{tabular}

\begin{tabular}{|c|c|c|c|c|c|c|c|c|c|}
\hline & $\begin{array}{c}9 \times 9 \\
\text { bg }\end{array}$ & $\begin{array}{c}9 \times 9 \\
\text { all }\end{array}$ & $\begin{array}{c}9 \times 9 \\
n z\end{array}$ & $\begin{array}{c}11 \times 11 \\
\text { bg }\end{array}$ & $\begin{array}{c}11 \times 11 \\
\text { all }\end{array}$ & $\begin{array}{c}11 \times 11 \\
n z\end{array}$ & $\begin{array}{c}13 \times 13 \\
\text { bg }\end{array}$ & $\begin{array}{c}13 \times 13 \\
\text { all }\end{array}$ & $\begin{array}{c}13 \times 13 \\
n z\end{array}$ \\
\hline $4.14 \mathrm{a}$ & 141 & 120 & 20 & 126 & 118 & 21 & 92 & 73 & 22 \\
\hline $4.14 b$ & 31 & 68 & 23 & 23 & 85 & 23 & 23 & 88 & 23 \\
\hline $4.14 c$ & 47 & 35 & 25 & 25 & 69 & 25 & 23 & 72 & 23 \\
\hline $4.14 d$ & 319 & 179 & 19 & 282 & 144 & 21 & 183 & 122 & 22 \\
\hline $4.14 \mathrm{e}$ & 293 & 217 & 15 & 204 & 186 & 14 & 130 & 138 & 14 \\
\hline $4.14 \mathrm{f}$ & 537 & 557 & 18 & 464 & 475 & 14 & 433 & 473 & 14 \\
\hline $4.14 \mathrm{~g}$ & 206 & 138 & 12 & 160 & 130 & 14 & 50 & 73 & 14 \\
\hline $4.14 \mathrm{~h}$ & 420 & 471 & 21 & 368 & 393 & 16 & 350 & 410 & 14 \\
\hline $4.14 \mathrm{i}$ & 275 & 208 & 13 & 302 & 205 & 12 & 335 & 244 & 15 \\
\hline $4.14 j$ & 105 & 90 & 9 & 337 & 350 & 162 & 342 & 375 & 40 \\
\hline $4.14 \mathrm{k}$ & 274 & 188 & 19 & 444 & 351 & 29 & 564 & 524 & 78 \\
\hline 4.141 & 306 & 315 & 20 & 168 & 254 & 19 & 80 & 185 & 17 \\
\hline
\end{tabular}

Table 4.6: Intraclass deviation of image classes of Fig. 4.14.

\subsubsection{Experiment with the Retina Dataset}

As a case study, in order to investigate the classification power of the introduced shape descriptor, the previous experiment described in Section 4.1.3 was repeated with the same dataset, settings, and classifier (CHASEDB1 and DRIVE dataset, different types of added random noise, etc.). We previously concluded that the global $Q$-concavity measure (using just two directions) can ensure comparable - or in some cases, even better - results than that obtained by [30] employing many directions. Consequently, the question is whether the local $Q$-concavity histogram could outperform the global $Q$-concavity measure. We attempted to classify the images into two categories (CHASEDB1 and DRIVE) based on their local $Q$-concavity histograms using the background points (see Eq. 4.12) by the 5-nearest neighbor classifier with inverse Euclidean distance. To avoid overfitting, we used leave-one-out cross-validation.

As we attempted to develop a fully locally computable descriptor, we opted for the local normalization form of Eq. 4.8. To compare the performance of the local descriptor to the global $Q$-concavity measure, the formula of local $Q$-concavity contribution at point $(i, j)$ (provided in Eq. 4.11) was 
modified to

$$
\varphi_{F, n o r m}^{w}(i, j)=\frac{n_{0}^{w}(i, j) n_{1}^{w}(i, j) n_{2}^{w}(i, j) n_{3}^{w}(i, j)(1-f(i, j))}{\left(\alpha^{w}(i, j)+h^{w}(i, j)+v^{w}(i, j)\right)^{4}},
$$

where

$$
\alpha^{w}(i, j)=\sum_{l=i-w}^{i+w} \sum_{k=j-w}^{j+w} f(l, k)
$$

denotes the number of points belonging to $F$ in the current window,

$$
v^{w}(i, j)=\sum_{k=j-w}^{j+w} f(i, k)
$$

is the number of points of $F$ in the $i^{\text {th }}$ column, and

$$
h^{w}(i, j)=\sum_{l=i-w}^{i+w} f(l, j)
$$

is the number of points of $F$ in the $j^{\text {th }}$ row, restricted to the window, respectively. Finally, the local $Q$-concavity histogram $(L Q H)$ of $F$ is a mapping hist $_{F, w}: \mathbb{R} \rightarrow \mathbb{Z}$ with

$$
r \mapsto\left|(i, j) \in \mathcal{R} \backslash F: \varphi_{F, n o r m}^{w}(i, j)=r\right| .
$$

Remark 4.8 In Eq. 4.5, the normalizing denominator for the local Q-concavity contribution at point $(i, j)$ is $\left(\left(\alpha^{w}(i, j)+h^{w}(i, j)+v^{w}(i, j)\right) / 4\right)^{4}$. However, the constant factor $\frac{1}{4}$ can be omitted in the case of local $Q$-concavity histograms as only the relative values of the bins are significant.

Since $\varphi_{F, \text { norm }}^{w}(i, j)$ is not an integer anymore, the bins of the histogram are not straightforward to index. To overcome this issue, we carry out quantization. Let $q$ be the number of quantization levels, i.e. the number of bins to occur in the histogram. Then we obtain the bin indices by the following formula:

$$
\text { bin_index }=\left\lfloor\varphi_{F, n o r m}^{w}(i, j) / \frac{\max \varphi_{F, n o r m}^{w}}{q-1}\right\rfloor,
$$

where the theoretical maximum value of $\varphi_{F, \text { norm }}^{w}(i, j)$ is

$$
\max \varphi_{F, \text { norm }}^{w}=\frac{1}{4^{4}}=0.00390625
$$

regardless of window size (see also Remark 4.8).

Example 1. The contribution matrix for each pixel of Fig. 4.15a with window size $3 \times 3$ is shown in Fig. $4.15 \mathrm{~b}$. The pixels that are omitted - since they belong to the border of the image - are denoted by dots, while the pixels that are not observed - based on Eqs. 4.11 and 4.16 - are denoted by *. In 
the case of Eq. 4.11, we get $x=54$ and $y=12$. After normalization (see Eq. 4.16), it yields the same contribution matrix, but with $x=0.003688$ and $y=0.002929$. Finally, calculating the LQH with quantization level $q=10$ results in the vector $\left[\begin{array}{llllllllll}10 & 0 & 0 & 0 & 0 & 0 & 0 & 1 & 0 & 1\end{array}\right]$.

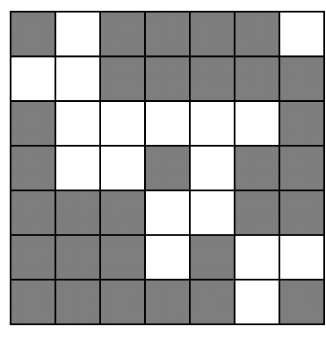

(a)

$$
\left[\begin{array}{ccccccc}
\cdot & \cdot & \cdot & \cdot & \cdot & \cdot & \cdot \\
\cdot & * & 0 & 0 & 0 & 0 & \cdot \\
\cdot & * & * & * & * & * & \cdot \\
\cdot & * & * & x & * & 0 & \cdot \\
\cdot & 0 & 0 & * & * & 0 & \cdot \\
\cdot & 0 & 0 & * & y & * & \cdot \\
\cdot & \cdot & \cdot & \cdot & \cdot & \cdot & \cdot
\end{array}\right]
$$

(b)

Figure 4.15: Sample image (a) and its contribution matrix (b).

Naturally, fewer quantization levels contain less information about the image. On the other hand, too many quantization levels - i.e. LQH with high dimensions - can lead to an unreasonably extensive processing time or even overfitting when LQH are used for image classification, for example. A strategy for finding the appropriate number of bins used for quantization will be presented later in this chapter. 


\begin{tabular}{|c|c|c|c|c|c|c|c|}
\hline Noise type & Noise level & SLBP & $3 \times 3$ & $5 \times 5$ & $7 \times 7$ & $9 \times 9$ & Global \\
\hline Gaussian & 0 & 100.0 & 90.0 & 90.0 & 72.5 & 72.5 & 90.0 \\
\hline Gaussian & 1 & 82.5 & 82.5 & 85.0 & 77.5 & 77.5 & 77.5 \\
\hline Gaussian & 2 & 82.5 & 90.0 & 80.0 & 87.5 & 85.0 & 70.0 \\
\hline Gaussian & 3 & 90.0 & 87.5 & 100.0 & 95.0 & 95.0 & 42.5 \\
\hline Gaussian & 4 & 77.5 & 70.0 & 75.0 & 72.5 & 87.5 & 45.0 \\
\hline Gaussian & 5 & 67.5 & 70.0 & 80.0 & 75.0 & 85.0 & 42.5 \\
\hline Gaussian & 6 & 72.5 & 75.0 & 82.5 & 80.0 & 72.5 & 65.0 \\
\hline Gaussian & 7 & 65.0 & 72.5 & 67.5 & 77.5 & 75.0 & 52.5 \\
\hline Gaussian & 8 & 65.0 & 70.0 & 70.0 & 57.5 & 62.5 & 52.5 \\
\hline Gaussian & 9 & 65.0 & 52.5 & 60.0 & 67.5 & 27.5 & 52.5 \\
\hline S \& P & 0 & 100.0 & 97.5 & 95.0 & 87.5 & 82.5 & 92.5 \\
\hline S \& P & 1 & 100.0 & 92.5 & 87.5 & 85.0 & 82.5 & 95.0 \\
\hline S \& P & 2 & 100.0 & 95.0 & 87.5 & 95.0 & 95.0 & 92.5 \\
\hline S \& P & 3 & 100.0 & 85.0 & 77.5 & 85.0 & 92.5 & 92.5 \\
\hline S \& P & 4 & 100.0 & 85.0 & 82.5 & 87.5 & 87.5 & 87.5 \\
\hline S \& P & 5 & 100.0 & 90.0 & 80.0 & 85.0 & 87.5 & 92.5 \\
\hline S \& P & 6 & 100.0 & 75.0 & 90.0 & 92.5 & 95.0 & 92.5 \\
\hline S \& P & 7 & 100.0 & 90.0 & 80.0 & 87.5 & 85.0 & 87.5 \\
\hline S \& P & 8 & 100.0 & 85.0 & 92.5 & 92.5 & 97.5 & 87.5 \\
\hline S \& P & 9 & 100.0 & 80.0 & 77.5 & 87.5 & 87.5 & 87.5 \\
\hline Speckle & 0 & 100.0 & 82.5 & 92.5 & 72.5 & 72.5 & 90.0 \\
\hline Speckle & 1 & 77.5 & 87.5 & 77.5 & 80.0 & 77.5 & 92.5 \\
\hline Speckle & 2 & 85.0 & 87.5 & 87.5 & 87.5 & 82.5 & 95.0 \\
\hline Speckle & 3 & 92.5 & 95.0 & 90.0 & 87.5 & 87.5 & 95.0 \\
\hline Speckle & 4 & 87.5 & 87.5 & 82.5 & 85.0 & 75.0 & 92.5 \\
\hline Speckle & 5 & 90.0 & 92.5 & 87.5 & 82.5 & 82.5 & 95.0 \\
\hline Speckle & 6 & 95.0 & 95.0 & 95.0 & 85.0 & 82.5 & 92.5 \\
\hline Speckle & 7 & 90.0 & 97.5 & 95.0 & 85.0 & 82.5 & 92.5 \\
\hline Speckle & 8 & 92.5 & 97.5 & 95.0 & 90.0 & 92.5 & 92.5 \\
\hline Speckle & 9 & 90.0 & 92.5 & 90.0 & 90.0 & 87.5 & 92.5 \\
\hline & & & & & & & \\
\hline
\end{tabular}

Table 4.7: Classification accuracy of retina images for $q=2$, in percentage.

Tables 4.7 and 4.8 represent the classification accuracy for different window sizes with quantization levels $q=2$ and $q=10$, respectively, together with the classification results of the global $Q$-concavity descriptor (see Eq. 4.8). For further reference, the accuracy achieved by Shift Local Binary Patterns (SLBP, Section 2.1.3) is also presented. We opted for this method as a reference, seeing as its approach is similar to that of our local $Q$-concavity histograms. In the aforementioned tables, the best results achieved by the $Q$-convexitybased approaches (i.e. not considering SLBP) are highlighted. 


\begin{tabular}{|c|c|c|c|c|c|c|c|}
\hline Noise type & Noise level & SLBP & $3 \times 3$ & $5 \times 5$ & $7 \times 7$ & $9 \times 9$ & Global \\
\hline Gaussian & 0 & 100.0 & 100.0 & 100.0 & 97.5 & 95.0 & 90.0 \\
\hline Gaussian & 1 & 82.5 & 80.0 & 70.0 & 77.5 & 97.5 & 77.5 \\
\hline Gaussian & 2 & 82.5 & 85.0 & 85.0 & 85.0 & 87.5 & 70.0 \\
\hline Gaussian & 3 & 90.0 & 85.0 & 95.0 & 87.5 & 87.5 & 42.5 \\
\hline Gaussian & 4 & 77.5 & 77.5 & 75.0 & 70.0 & 85.0 & 45.0 \\
\hline Gaussian & 5 & 67.5 & 70.0 & 75.0 & 80.0 & 80.0 & 42.5 \\
\hline Gaussian & 6 & 72.5 & 75.0 & 77.5 & 85.0 & 72.5 & 65.0 \\
\hline Gaussian & 7 & 65.0 & 70.0 & 55.0 & 70.0 & 77.5 & 52.5 \\
\hline Gaussian & 8 & 65.0 & 42.5 & 57.5 & 70.0 & 65.0 & 52.5 \\
\hline Gaussian & 9 & 65.0 & 62.5 & 60.0 & 72.5 & 45.0 & 52.5 \\
\hline S \& P & 0 & 100.0 & 100.0 & 100.0 & 87.5 & 90.0 & 92.5 \\
\hline S \& P & 1 & 100.0 & 95.0 & 97.5 & 87.5 & 95.0 & 95.0 \\
\hline S \& P & 2 & 100.0 & 90.0 & 97.5 & 95.0 & 95.0 & 92.5 \\
\hline S \& P & 3 & 100.0 & 87.5 & 95.0 & 97.5 & 95.0 & 92.5 \\
\hline S \& P & 4 & 100.0 & 92.5 & 92.5 & 95.0 & 95.0 & 87.5 \\
\hline S \& P & 5 & 100.0 & 90.0 & 97.5 & 97.5 & 97.5 & 92.5 \\
\hline S \& P & 6 & 100.0 & 95.0 & 97.5 & 100.0 & 97.5 & 92.5 \\
\hline S \& P & 7 & 100.0 & 97.5 & 97.5 & 95.0 & 97.5 & 87.5 \\
\hline S \& P & 8 & 100.0 & 92.5 & 95.0 & 95.0 & 95.0 & 87.5 \\
\hline S \& P & 9 & 100.0 & 95.0 & 97.5 & 97.5 & 97.5 & 87.5 \\
\hline Speckle & 0 & 100.0 & 100.0 & 100.0 & 97.5 & 92.5 & 90.0 \\
\hline Speckle & 1 & 77.5 & 90.0 & 62.5 & 70.0 & 92.5 & 92.5 \\
\hline Speckle & 2 & 85.0 & 75.0 & 85.0 & 72.5 & 87.5 & 95.0 \\
\hline Speckle & 3 & 92.5 & 95.0 & 92.5 & 87.5 & 82.5 & 95.0 \\
\hline Speckle & 4 & 87.5 & 85.0 & 72.5 & 70.0 & 77.5 & 92.5 \\
\hline Speckle & 5 & 90.0 & 92.5 & 85.0 & 82.5 & 67.5 & 95.0 \\
\hline Speckle & 6 & 95.0 & 92.5 & 90.0 & 82.5 & 70.0 & 92.5 \\
\hline Speckle & 7 & 90.0 & 90.0 & 87.5 & 92.5 & 85.0 & 92.5 \\
\hline Speckle & 8 & 92.5 & 95.0 & 95.0 & 82.5 & 82.5 & 92.5 \\
\hline Speckle & 9 & 90.0 & 90.0 & 87.5 & 77.5 & 82.5 & 92.5 \\
\hline
\end{tabular}

Table 4.8: Classification accuracy of retina images for $q=10$, in percentage.

We observe that in the presence of Gaussian noise, in nearly all instances, the local, histogram-based method performs significantly better than the one based on the global $Q$-concavity measure, even better than SLBP, both for $q=2$ and $q=10$. For Salt \& Pepper noise, SLBP is best; however, especially for $q=10$, the local method is almost as advantageous as SLBP. We stress that SLBP is a 256-dimensional descriptor, whereas the histogram-based method only uses 10-dimensional vectors (when $q=10$ ). In the case of Speckle noise, the global $Q$-concavity measure seems to be the best choice, although in some cases, and especially for smaller window sizes, the local approach as well as SLBP ensures comparable accuracy. 
As mentioned previously, that in the case of the global descriptor, Gaussian noise was a challenging issue (see Table 4.2), which is also reflected in the right column of Tables 4.7 and 4.8. Note that the local approach can at least partially solve this issue and improve the classification accuracy.

\subsubsection{Determining the Appropriate Window Size and Quantization Level}

Turning to the question of which parameter setting could ensure the highest classification accuracy, we introduce a strategy to determine the appropriate window size and quantization level to calculate LQH in the case of classification issues. We present an approach that relies on the technique published in [65], and modify it according to our needs.

Let us consider $p$ different image classes and let $r$ denote the number of patches (sample images) of each image class. First, the LQHs are calculated for all the $r$ patches; next the mean LQH is calculated for the $i^{\text {th }}$ class as follows.

$$
\text { meanLQH } H_{i}=\frac{1}{r} \cdot \sum_{j=1}^{r} L Q H_{i, j} \quad(i=1, \ldots, p),
$$

where $L Q H_{i, j}$ denotes the LQH of the $j^{\text {th }}$ patch from the $i^{\text {th }}$ class. Now, consider the Euclidean distances between the mean LQHs and the $r$ number of LQHs of the corresponding classes.

$$
\begin{aligned}
& D_{i, j}=\sqrt{\sum_{k=1}^{z} \mid L Q H_{i, j}(k)-\text { meanLQH }\left.H_{i}(k)\right|^{2}} \\
& (i=1, \ldots, p) \quad(j=1, \ldots, r),
\end{aligned}
$$

where $z$ is the number of bins of the LQHs. The standard deviation of the distances for the $i^{\text {th }}$ class is

$$
\sigma_{i}=\sqrt{\frac{1}{p-1} \cdot \sum_{j=1}^{p}\left|D_{i, j}-\mu_{i}\right|^{2}} \quad(i=1, \ldots, p),
$$

where

$$
\mu_{i}=\frac{1}{r} \cdot \sum_{j=1}^{r} D_{i, j}(i=1, \ldots, p) .
$$

The inner distance of the classes is defined as

$$
\text { Inner }=\frac{1}{p} \cdot \sum_{i=1}^{p} \sigma_{i} .
$$

Let us consider the mean $\mathrm{LQH}$ of the mean $L Q H_{i}$ vectors

$$
L Q H_{\text {mean }}=\frac{1}{p} \cdot \sum_{i=1}^{p} \text { mean } L Q H_{i}
$$


and then the Euclidean distance of each mean $L Q H_{i}$ vector to the $L Q H_{\text {mean }}$

$$
D_{i}=\sqrt{\sum_{k=1}^{z} \mid \text { meanLQH } H_{i}(k)-\left.L Q H_{\text {mean }}(k)\right|^{2}} \quad(i=1, \ldots, p),
$$

where $z$ is again the number of bins of the LQHs. The outer distance is defined as

$$
\text { Outer }=\sqrt{\frac{1}{p-1} \cdot \sum_{i=1}^{p}\left|D_{i}-\eta\right|^{2}}
$$

where

$$
\eta=\frac{1}{p} \cdot \sum_{i=1}^{p} D_{i}
$$

Finally, the classification power is determined by calculating

$$
P W=\frac{\text { Outer }}{\text { Inner }}
$$

for all possible window sizes and number of bins. It is clear that for the best result the intraclass distances (Inner) must be small and the interclass distances (Outer) must be large. Therefore, the highest PW defines the appropriate window size and quantization level.

Remark 4.9 Note that we do not state that either $L Q H_{\text {mean }}$ or mean $L Q H_{i}$ for any $i=1, \ldots, p$ encode a vector possibly corresponding to an image as its $L Q H$ vector. We simply use 'mean' as the mean of vectors from the same dimensional real vector space.

\begin{tabular}{|c|c|c|c|c|c|c|c|c|c|c|}
\hline & 2 & 4 & 8 & 10 & 16 & 32 & 64 & 128 & 256 & 512 \\
\hline $3 \times 3$ & 8.76 & 8.61 & 8.76 & 8.84 & 8.56 & 8.74 & 8.85 & 8.77 & 8.95 & 8.88 \\
\hline $5 \times 5$ & 10.08 & 10.76 & 10.36 & 10.75 & 10.99 & 10.90 & 11.05 & 10.73 & 10.74 & 10.49 \\
\hline $7 \times 7$ & 11.21 & 11.94 & 12.46 & 12.40 & 12.31 & 12.48 & 12.73 & 12.34 & 12.26 & 12.67 \\
\hline $9 \times 9$ & 12.49 & 11.75 & 12.46 & 12.68 & 13.28 & 12.80 & 12.99 & 13.60 & 13.05 & 13.21 \\
\hline $11 \times 11$ & 9.90 & 10.32 & 10.83 & 11.10 & 11.63 & 12.02 & 11.74 & 11.50 & 11.52 & 11.78 \\
\hline $13 \times 13$ & 8.91 & 8.92 & 9.74 & 10.39 & 11.13 & 11.49 & 12.00 & 12.02 & 12.32 & 11.99 \\
\hline
\end{tabular}

\begin{tabular}{|c|c|c|c|c|c|c|c|c|c|c|}
\hline & 2 & 4 & 8 & 10 & 16 & 32 & 64 & 128 & 256 & 512 \\
\hline $3 \times 3$ & 15.35 & 15.00 & 15.51 & 14.47 & 15.47 & 15.56 & 14.52 & 15.62 & 15.18 & 14.46 \\
\hline $5 \times 5$ & 13.75 & 16.88 & 17.75 & 17.40 & 16.61 & 17.01 & 17.48 & 17.88 & 17.91 & 17.70 \\
\hline $7 \times 7$ & 17.11 & 18.94 & 18.58 & 19.00 & 20.28 & 20.65 & 20.81 & 20.32 & 22.22 & 21.70 \\
\hline $9 \times 9$ & 17.40 & 18.85 & 17.58 & 16.92 & 17.20 & 18.27 & 19.04 & 18.04 & 19.51 & 19.73 \\
\hline $11 \times 11$ & 16.27 & 15.34 & 16.47 & 16.35 & 16.24 & 16.02 & 17.46 & 17.87 & 17.80 & 18.03 \\
\hline $13 \times 13$ & 14.65 & 15.86 & 15.67 & 15.84 & 15.79 & 15.85 & 17.01 & 17.46 & 18.43 & 17.14 \\
\hline
\end{tabular}

Table 4.9: $P W$ values for Fig. 4.13 with different quantization levels (horizontal) and window sizes (vertical).

Table 4.10: $P W$ values for Fig. 4.14 with different quantization levels (horizontal) and window sizes (vertical). 
Tables 4.9 and 4.10 represent the $P W$ values of Fig. $4.13(p=6 ; r=50)$ and Fig. $4.14(p=12 ; r=50)$, respectively, with different quantization levels and window sizes.

For both datasets, $7 \times 7$ is a suitable window size (based on the $P W$ values), although in the case of the dataset of Fig. 4.13, window size $5 \times 5$, while in the case of Fig. 4.14, window size $9 \times 9$ could also be a viable option. This is in accordance with the high mean values of Table 4.4 .

Regarding the quantization levels, note that even 10-16 bins can provide relatively satisfactory classification accuracy for these window sizes. Therefore, we opted to use 10 bins.

\subsection{Local $Q$-Concavity Histograms for Binary Image Reconstruction}

In Binary Tomography, the aim is to reconstruct binary images from their projections. The great challenge in BT is to provide trustful reconstructions form as few projections as possible. However, the low number of projections can cause the problem to be extremely ill-posed. A common way to reduce the search space of feasible solutions is to incorporate some prior information regarding the image to be reconstructed. In this section, the inherently insufficient amount of projection data is augmented by $\mathrm{LQH}$ priors.

This time, the regularization utilized in solving Eq. 1.14 is based on the concept of $Q$-convexity. Assuming the image to be reconstructed belongs to a certain class, representatives of this class can be selected and their LQH vectors can be calculated. In the reconstruction process, the $\mathrm{LQH}$ vectors are taken into account as prior information. In this section, we work with two projections: the horizontal $(H)$ and vertical $(V)$ ones. Hence, Eq. 1.14 becomes

$$
C(\mathbf{X})=\left\|H-H^{\prime}\right\|_{2}+\left\|V-V^{\prime}\right\|_{2}+\|+\gamma \cdot \Phi(\mathbf{X}) \rightarrow \min ,
$$

where $H$ and $V$ are input vectors (row and column sums of the image, respectively); and $H^{\prime}$ and $V^{\prime}$ are the corresponding vectors belonging to the current solution image $\mathbf{X} . \Phi(\mathbf{X})$ measures the Euclidean distance between the LQH vector of image $\mathbf{X}$ and all representative LQH vectors, and ultimately takes the minimum. Formally,

$$
\Phi(\mathbf{X})=\min _{t}\left\{\left\|L Q H(\mathbf{X})-L Q H\left(\mathbf{X}_{t}\right)\right\|_{2}\right\}
$$

where $\mathbf{X}_{1}, \mathbf{X}_{2}, \ldots, \mathbf{X}_{t}$ are the $t$ sample images from the same class as $\mathbf{X}$, known a priori.

For calculating LQH (with normalization and quantization), we used the implementation based on Eqs. 4.16 - 4.22. To optimize the cost function (see Eq. 4.33), we used SA (Alg. 1 in Section 1.4), again. 


\subsubsection{Fast LQH Calculation}

Calculating the $\mathrm{LQH}$ vectors from scratch in each iteration of SA is quite time-consuming. Furthermore, fast LQH calculation would also be beneficial when an abundance of such descriptors must be processed, e.g. in classification issues. Three approaches are presented below to speed up this process.

\section{Dynamic Programming}

First, we present an approach based on integral images and dynamic programming (DP). The idea is to decrease computational complexity by calculating LQH for one pixel only; whereas for the other pixels, only the differences are taken into consideration.

LQH is calculated and stored for the first observed pixel based on Eq. 4.11. Then, LQHs of the first observed pixel of each row (DP1 part) are calculated by

$$
\begin{array}{r}
n_{0}^{w}(i, j)=n_{0}^{w}(i, j-1)-\sum_{l=i-w}^{i} f(l, j-w-1)+\sum_{l=i-w}^{i} f(l, j) \\
n_{1}^{w}(i, j)=n_{1}^{w}(i, j-1)-\sum_{l=i}^{i+w} f(l, j-w-1)+\sum_{l=i}^{i+w} f(l, j) \\
n_{2}^{w}(i, j)=n_{2}^{w}(i, j-1)-\sum_{l=i}^{i+w} f(l, j-1)+\sum_{l=i}^{i+w} f(l, j+w) \\
n_{3}^{w}(i, j)=n_{3}^{w}(i, j-1)-\sum_{l=i-w}^{i} f(l, j-1)+\sum_{l=i-w}^{i} f(l, j+w) .
\end{array}
$$

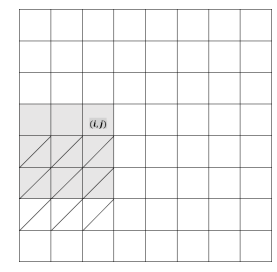

(a) $n_{0}^{w}(i, j)$

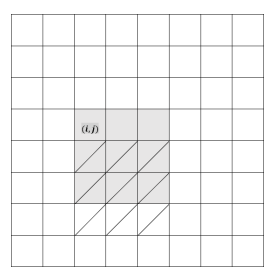

(b) $n_{1}^{w}(i, j)$

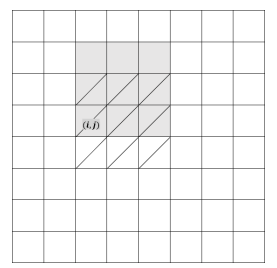

(c) $n_{2}^{w}(i, j)$

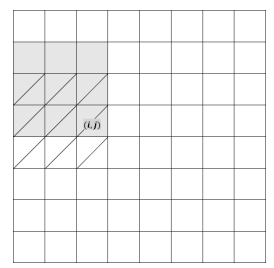

(d) $n_{3}^{w}(i, j)$

Figure 4.16: Illustration of calculating DP1 part $(w=2)$.

Fig. 4.16 illustrates how DP1 part is calculated for the different $n_{p}^{w}(i, j)$-s $(p=0,1,2,3)$. Pixels with a gray background belong to $n_{p}^{w}(i, j)$, while pixels filled with diagonal lines belong to $n_{p}^{w}(i, j-1)$. Therefore, the values of pixels filled with only diagonal lines are subtracted from $n_{p}^{w}(i, j-1)$, and the values of pixels with just a gray background are added to the result. Pixels with both properties can be omitted. 
LQHs for the other pixels in the same row (DP2 part) are calculated by

$$
\begin{gathered}
n_{0}^{w}(i, j)=n_{0}^{w}(i-1, j)-\sum_{k=j-w}^{j} f(i-w-1, k)+\sum_{k=j-w}^{j} f(i, k) \\
n_{1}^{w}(i, j)=n_{1}^{w}(i-1, j)-\sum_{k=j-w}^{j} f(i-1, k)+\sum_{k=j-w}^{j} f(i+w, k) \\
n_{2}^{w}(i, j)=n_{2}^{w}(i-1, j)-\sum_{k=j}^{j+w} f(i-1, k)+\sum_{k=j}^{j+w} f(i+w, k) \\
n_{3}^{w}(i, j)=n_{3}^{w}(i-1, j)-\sum_{k=j}^{j+w} f(i-w-1, k)+\sum_{k=j}^{j+w} f(i, k) .
\end{gathered}
$$

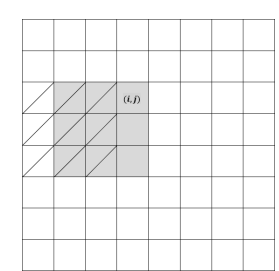

(a) $n_{0}^{w}(i, j)$

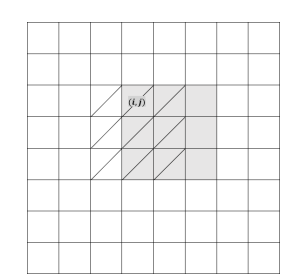

(b) $n_{1}^{w}(i, j)$

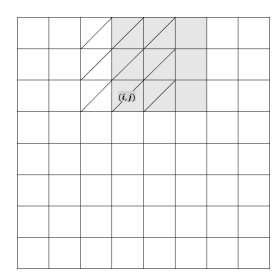

(c) $n_{2}^{w}(i, j)$

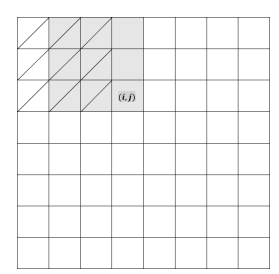

(d) $n_{3}^{w}(i, j)$

Figure 4.17: Illustration of calculating DP2 part $(w=2)$.

Fig. 4.17 illustrates the calculation of DP2 part, while Fig. 4.18 indicates the entire process of DP computation. In the latter, $\mathrm{LQH}$ for the pixel filled with black is explicitly determined. For the other pixels, only the differences are calculated in DP1 part (gray pixels) and DP2 part (white pixels).

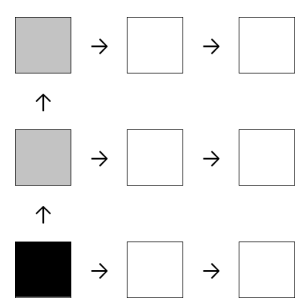

Figure 4.18: Illustration of the dynamic programming process when calculating $\mathrm{LQH}$ values.

In Fig. 4.19, an example is presented for image matrix size $5 \times 5$ and window size $3 \times 3$. In this case, only the highlighted pixels are examined as follows. The algorithm calculates and stores the LQH value of $x_{11}$. Only the differences of LQH are calculated for $x_{21}$ (see Eqs. 4.35-4.38) with the result stored. Based on this, LQH of $x_{31}$ is determined. The first observed pixel in the next row is $x_{12}$, of which LQH is defined based on the LQH of $x_{11}$ (see Eqs. 4.394.42). 


$$
\left[\begin{array}{lllll}
x_{04} & x_{14} & x_{24} & x_{34} & x_{44} \\
x_{03} & x_{13} & x_{23} & x_{33} & x_{43} \\
x_{02} & x_{12} & x_{22} & x_{32} & x_{42} \\
x_{01} & x_{11} & x_{21} & x_{31} & x_{41} \\
x_{00} & x_{10} & x_{20} & x_{30} & x_{40}
\end{array}\right]
$$

Figure 4.19: Sample for dynamic programming version.

To calculate the normalized LQH based on Eq. 4.16, $\alpha^{w}(i, j), h^{w}(i, j)$, and $v^{w}(i, j)$ must also be dynamically updated. In DP1 part, $h^{w}(i, j)$ needs to be calculated explicitly, and

$$
\begin{gathered}
\alpha^{w}(i, j)=\alpha^{w}(i, j-1)-\sum_{l=i-w}^{i+w} f(l, j-w-1)+\sum_{l=i-w}^{i+w} f(l, j+w), \\
\left.v^{w}(i, j)=v^{w}(i, j-1)-f(i, j-w-1)+f(i, j+w)\right) .
\end{gathered}
$$

In DP2 part, $v^{w}(i, j)$ needs to be calculated explicitly, and

$$
\begin{gathered}
\alpha^{w}(i, j)=\alpha^{w}(i-1, j)-\sum_{k=j-w}^{j+w} f(i-w-1, k)+\sum_{k=j-w}^{j+w} f(i+w, k), \\
h^{w}(i, j)=h^{w}(i-1, j)-f(i-w-1, j)+f(i+w, j) .
\end{gathered}
$$

We compared the DP approach to the one where each value is explicitly calculated. We used the image classes of Figs. 4.13 and 4.14, with a fixed image patch size of $256 \times 256$ but with different window sizes. Sample mean results of 10 tests of Fig. 4.14i are indicated in Fig. 4.20 (the trends are similar for the other images as well). The following can be deduced: for smaller window sizes, dynamic programming requires higher running time than the original method due to the fact that DP calculates and stores LQHs for all pixels, while the original method considers pixels with 0 values only. On the other hand, for larger window sizes, running time is significantly reduced. Therefore, this approach is useful if larger windows are required for practical reasons. 


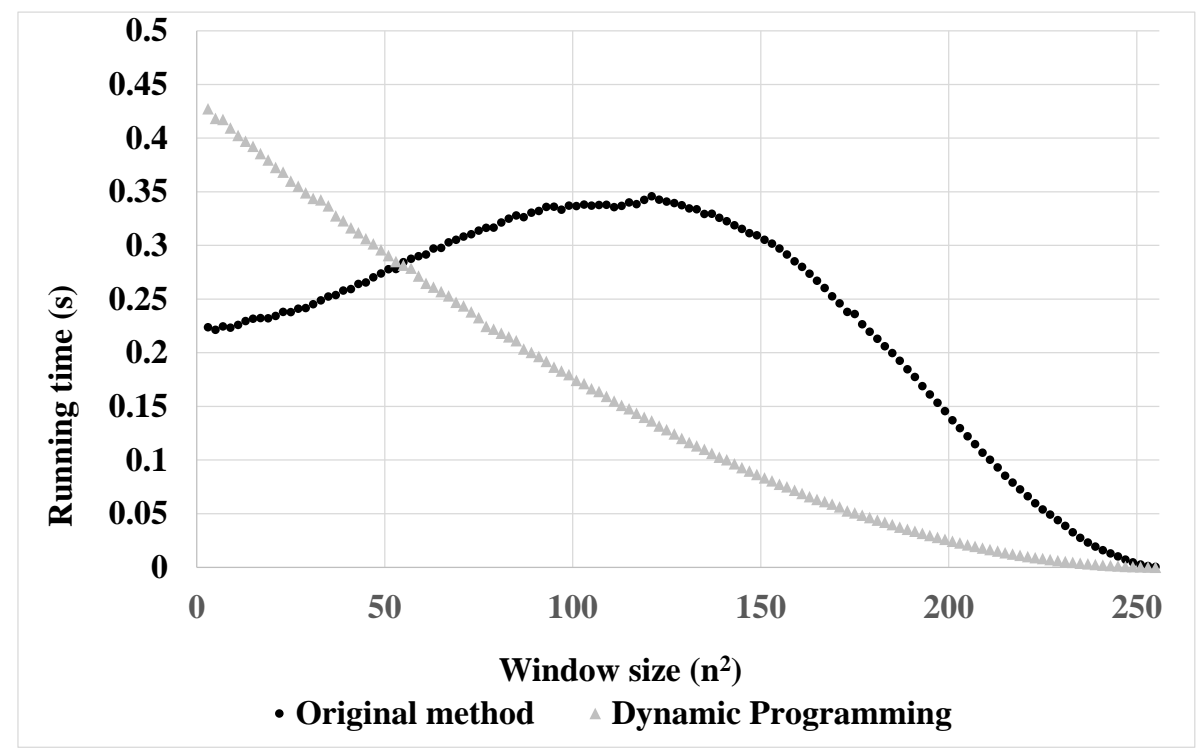

Figure 4.20: Running time (in seconds) of the original and the DP approaches for different windows sizes of Fig. 4.14i.

\section{Random Sampling}

The second idea is, instead of calculating the LQH for all image pixels, only a predefined amount (e.g. $10 \%, 20 \%$, etc.) is examined. Pixels are randomly selected. To investigate this method, again, we performed tests on the image classes of Figs. 4.13 and 4.14 for different window sizes. Here, for comparative purposes, we normalized Eq. 4.16 with the number of examined pixels. A representative example of Fig. $4.13 \mathrm{c}$ is displayed in Fig. 4.21. In other cases, the graphs were found to be similar.

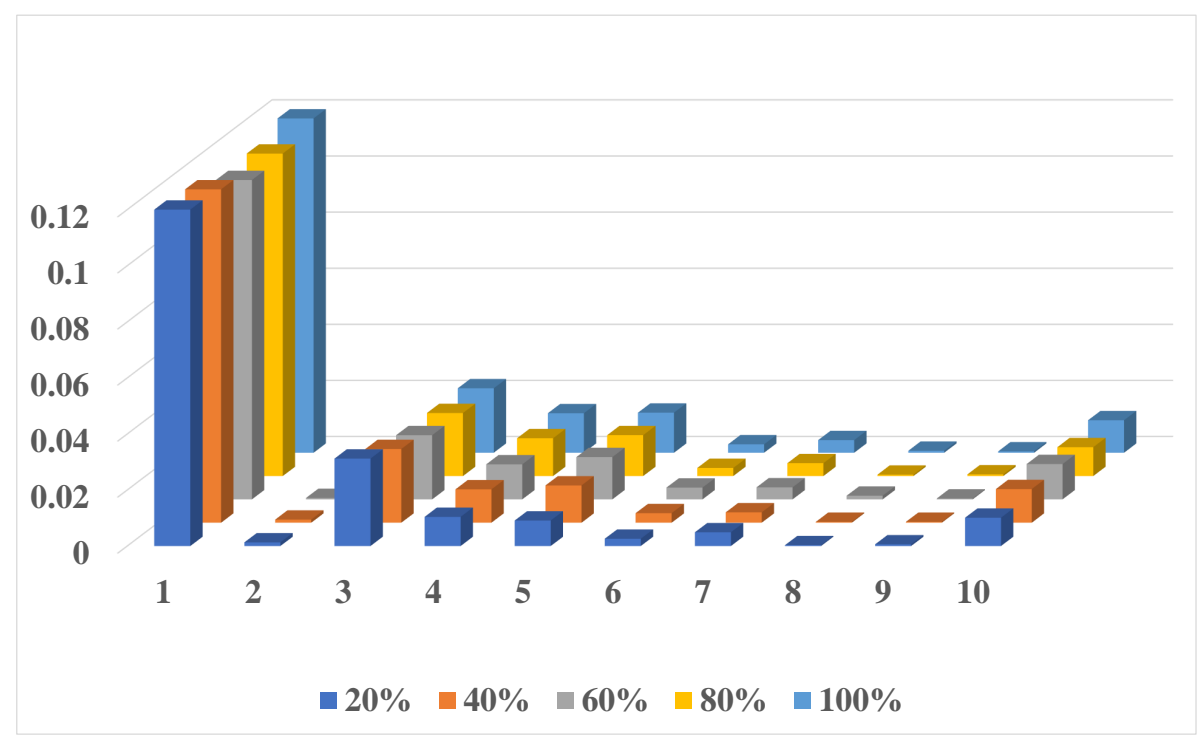

Figure 4.21: Contents of the LQH bins for $q=10$ and window size $5 \times 5$ of Fig. 4.13 c, with different amounts of pixels examined. 
The resulting LQH vectors gained by random sampling are similar to the fully evaluated ones, even when only $20 \%$ of the pixels are examined. With this strategy, running time can be reduced drastically. Due to the fact that this approach is largely random in itself, unfortunately, it is not applicable with the SA algorithm. Since the positions of the randomly selected pixels are not fixed, the method generates non-comparable results; namely, in all iterations, the positions of the randomly selected pixels may change, and the pixels to be inverted are also randomly selected. If the positions of the selected pixels are fixed at the beginning, the LQH vectors may remain unchanged in the SA iterations - since the pixels to be inverted are randomly selected -, which may lead to the objective function value being unable to decrease. Still, the advantage of this approach is indisputable. When a multitude of images need to be processed from the viewpoint of $Q$-convexity, this method may save a considerable amount of time.

\section{Local Update}

In the third approach, we take advantage of the observation that the LQH vector does not need to be entirely recalculated in each iteration of SA. Since only one pixel $(p)$ is modified in each iteration, we are able to update the $\mathrm{LQH}$ vector by focusing only on those parts of the image where the modified pixel has a potential impact. If the window size is $u \times u$, then the $(2 u+1) \times(2 u+$ 1) neighborhood of $p$ is examined as follows. In the first iteration, the entire $\mathrm{LQH}$ is calculated. After that, in each iteration, $p$ is randomly selected, and only the LQH for its neighborhood is calculated, while the resulting (partial) $\mathrm{LQH}$ is subtracted from the original one. Then, $p$ is inverted, and finally, the $\mathrm{LQH}$ for its neighborhood is recalculated and added to the previous $\mathrm{LQH}$. Using this method, running time can be reduced significantly. Furthermore, this strategy is fully in accordance with the concept of SA, which is why this method is selected to speed up reconstruction.

Example 2. Figure 4.22 provides an example, where the pixel $p=0$ is to be inverted, the image size is $16 \times 16, q=10$ and $u=3$. The highlighted image pixels are examined, the rest are unaffected. In this instance, the original $\mathrm{LQH}$ vector is

$$
L Q H_{\text {original }}=\left[\begin{array}{llllllllll}
42 & 0 & 0 & 0 & 0 & 0 & 10 & 18 & 12 & 13
\end{array}\right] .
$$

The LQH of the $(2 u+1) \times(2 u+1)$ neighborhood of $p$ is

$$
L Q H_{\text {before }}=\left[\begin{array}{llllllllll}
4 & 0 & 0 & 0 & 0 & 0 & 1 & 2 & 1 & 3
\end{array}\right]
$$

before the inversion, and

$$
L Q H_{\text {after }}=\left[\begin{array}{llllllllll}
4 & 0 & 0 & 0 & 0 & 0 & 1 & 4 & 1 & 2
\end{array}\right]
$$

after the inversion. 
The actual LQH of the full matrix is thus

$$
\begin{gathered}
L Q H_{\text {actual }}= \\
L Q H_{\text {original }}-L Q H_{\text {before }}+L Q H_{\text {after }}=\left[\begin{array}{llllllllll}
42 & 0 & 0 & 0 & 0 & 0 & 10 & 20 & 12 & 12
\end{array}\right] .
\end{gathered}
$$

\begin{tabular}{|l|l|l|l|l|l|l|l|l|l|l|l|l|l|l|l|}
\hline 0 & 0 & 1 & 1 & 1 & 1 & 0 & 1 & 0 & 1 & 1 & 1 & 0 & 0 & 1 & 0 \\
\hline 0 & 0 & 1 & 1 & 1 & 1 & 0 & 0 & 1 & 0 & 1 & 0 & 1 & 0 & 1 & 0 \\
\hline 1 & 0 & 1 & 0 & 0 & 0 & 0 & 0 & 0 & 0 & 0 & 1 & 1 & 1 & 0 & 1 \\
\hline 0 & 0 & 1 & 1 & 1 & 0 & 0 & 0 & 1 & 1 & 0 & 0 & 0 & 1 & 1 & 1 \\
\hline 1 & 1 & 0 & 0 & 0 & 1 & 0 & 1 & 1 & 1 & 0 & 0 & 0 & 1 & 1 & 1 \\
\hline 0 & 1 & 0 & 0 & 1 & 1 & 1 & 0 & 1 & 0 & 0 & 1 & 0 & 1 & 1 & 0 \\
\hline 1 & 0 & 0 & 1 & 0 & 0 & 0 & 1 & 0 & 1 & 1 & 0 & 0 & 1 & 1 & 0 \\
\hline 0 & 1 & 0 & 1 & 0 & 0 & 0 & 1 & 1 & 1 & 1 & 1 & 0 & 0 & 0 & 1 \\
\hline 1 & 0 & 0 & 0 & 0 & 1 & 1 & $p$ & 1 & 1 & 0 & 0 & 0 & 0 & 0 & 0 \\
\hline 1 & 1 & 1 & 1 & 0 & 0 & 1 & 1 & 0 & 0 & 1 & 1 & 0 & 0 & 1 & 1 \\
\hline 1 & 1 & 1 & 1 & 0 & 1 & 0 & 0 & 1 & 0 & 0 & 1 & 0 & 0 & 0 & 1 \\
\hline 1 & 0 & 0 & 1 & 1 & 0 & 0 & 0 & 1 & 1 & 1 & 1 & 0 & 1 & 1 & 0 \\
\hline 0 & 1 & 0 & 1 & 1 & 0 & 0 & 1 & 1 & 0 & 0 & 0 & 1 & 1 & 1 & 1 \\
\hline 1 & 0 & 1 & 1 & 1 & 1 & 0 & 1 & 0 & 0 & 1 & 1 & 0 & 1 & 1 & 1 \\
\hline 1 & 1 & 1 & 1 & 0 & 1 & 1 & 1 & 1 & 1 & 0 & 1 & 1 & 1 & 0 & 1 \\
\hline 1 & 1 & 1 & 0 & 1 & 1 & 1 & 1 & 0 & 1 & 1 & 0 & 0 & 0 & 0 & 1 \\
\hline
\end{tabular}

Figure 4.22: Sample local update $(u=3, q=10)$.

\subsubsection{Results}

We used two different datasets again: 1) software phantom images (Fig. 4.13); 2) and real images from the Brodatz texture database [18] (Fig. 4.14).

For the numerical evaluation of the of reconstructed image quality - apart from the differences of the terms of the cost function - we calculated pixel error (see Eq. 2.18 in Section 2.4.1). For further reference, we also used the Euclidean distances of the SLBP [54] vectors between the original and the reconstructed images ('SLBP distance')

$$
D_{S L B P}=\left\|S L B P_{0}-S L B P_{r}\right\|_{2},
$$

where $S L B P_{o}$ means the SLBP vector of the original image and $S L B P_{r}$ stands for the SLBP vector of the reconstructed image. We selected this method as a reference, since its approach is similar to that of ours (LQH).

All parameters of SA algorithm were set manually, in an empirical manner. Each time, the method started out with a random binary image. The stopping criteria of the algorithm were to reach 1000000 iterations or to perform a given number of iterations without improving the optimal result (parameter $\xi$ ). The initial temperature was set to $T_{1}=350$, while the cooling schedule was controlled by $\alpha=0.99$. The SA algorithm was allowed to remain the same temperature for some iterations; in our case, this was fine-tuned by $\beta=0.035$. Selecting a neighbor meant randomly selecting 
and inverting an image pixel. Based on empirical investigations, we found that a satisfactory parameter setting is $\gamma \in[0.4,0.7], \xi \in[3000,6000]$, and $u \times u \in\{3 \times 3,5 \times 5, \ldots, 13 \times 13\}$ (for the window size), depending on image class. The quantization level was $q=10$. We observed 150 random patches of size $128 \times 128$ as the prior dataset, meaning $t=150$ (see Eq. 4.34).

Remark 4.10 Setting the parameters of $S A$ is quite challenging. We also attempted another version of Eq. 4.33 using the mean value of differences instead of the minimal values (in the objective function). The $H$ and $V$ differences decreased substantially, but unfortunately, the LQH differences - as well as the visible differences - remained high despite the fact $\gamma$ was increased. We also attempted to increase parameters $\xi$ and $\alpha$, and to modify the initial image, but unfortunately, none of these attempts resulted in better solutions, and as another unwanted consequence, running time was usually higher.

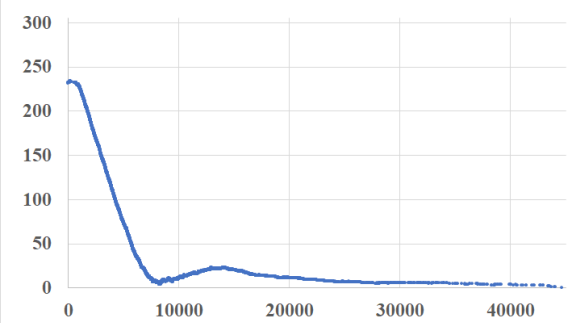

(a) $\left\|H-H^{\prime}\right\|_{2}$

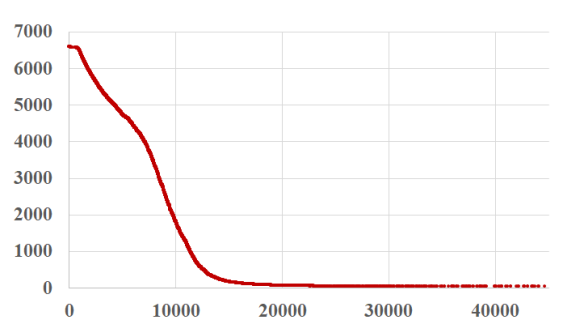

(c) $\Phi(\mathbf{X})$

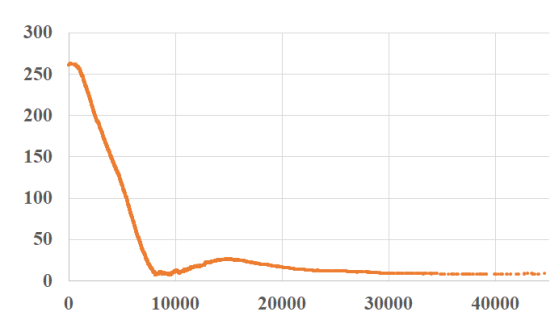

(b) $\left\|V-V^{\prime}\right\|_{2}$

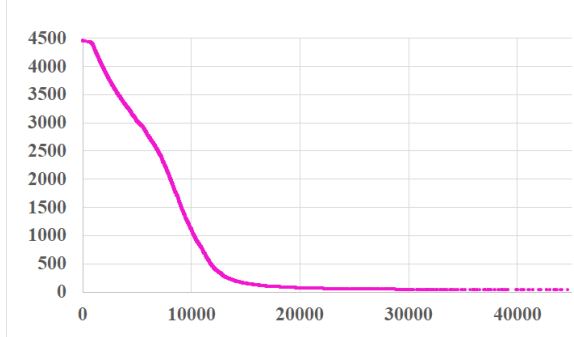

(d) $C(\mathbf{X})$

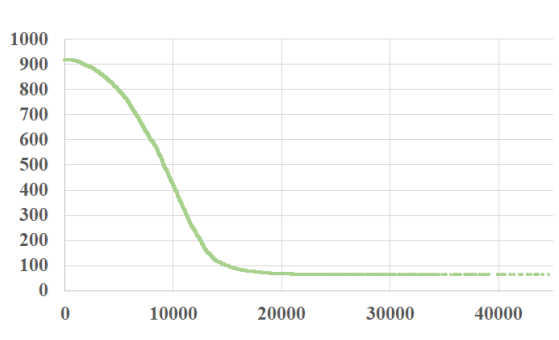

(e) $D_{S L B P}$

Figure 4.23: Terms of the cost function (vertical axis) in the case of Fig. 4.13b, with image size $128 \times 128$, window size $7 \times 7$, $\xi=5000$, and $\gamma=0.6$ regarding the number of iterations (horizontal axis). 
The tests were conducted on 5 patches of size $128 \times 128$ from each image class, and the mean value of the numerical results was taken. Figure 4.23 with Table 4.11 present an example of reconstructing an image from the class of Fig. $4.13 b$ with window size $7 \times 7, \gamma=0.6$, and $\xi=5000$. The various subfigures indicate the different terms of the cost function (see Eq. 4.33) and the SLBP distance. The algorithm terminated after performing 49647 iterations, since it was unable to improve the optimum. It is apparent that the algorithm started out with sizeable and ended with minor differences (also reaching 0 difference in term $\left\|H-H^{\prime}\right\|_{2}$ ). SLBP distances also showed a decrease, meaning the texture of the resulting image was more and more similar to the original in each iteration.

\begin{tabular}{|c|c|c|c|c|c|}
\hline & $C(\mathbf{X})$ & $\left\|H-H^{\prime}\right\|_{2}$ & $\left\|V-V^{\prime}\right\|_{2}$ & $\Phi(\mathbf{X})$ & $D_{S L B P}$ \\
\hline Initial value & 4453.84 & 231.94 & 260.75 & 6601.91 & 916.44 \\
\hline Final value & 33.06 & 0 & 8.25 & 41.35 & 63.14 \\
\hline
\end{tabular}

Table 4.11: Initial and final values corresponding to Fig. 4.23.

Fig. 4.24a presents the original, while Fig. $4.24 \mathrm{~b}$ reveals the resulting image of SA. Even though the reconstructed image does not fully resemble the structure of the original image, the low final values of the terms in the cost function specify that this phenomenon is caused by the inherent loss of information in the projections, not by the optimization process. Indeed, the reconstruction from the horizontal and vertical projections is an extremely ill-posed problem. In comparison, in Fig. 4.24c, we present the image reconstructed from two projections (with 0 projection error and 606.6 SLBP error) with Ryser's algorithm [74], which is unable to take any prior information into account. The pixel error is $43 \%$ in the case of SA, and $42 \%$ for Ryser's algorithm, meaning the relative amount of misclassified pixels is the same. In contrast, visual quality is much better with SA.

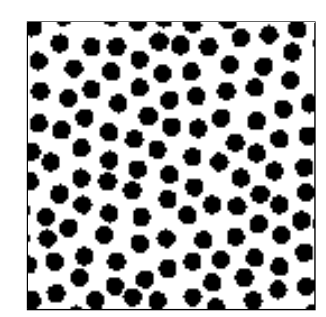

(a) Original image

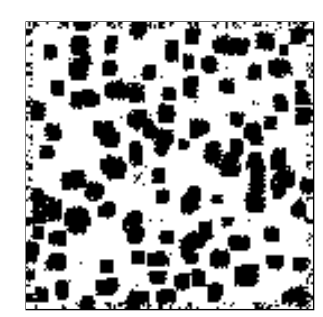

(b) Result of SA

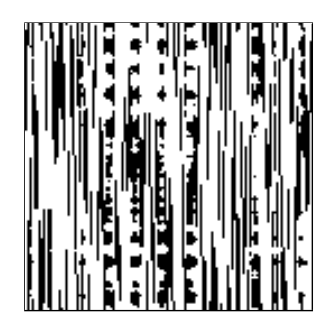

(c) Result of Ryser

Figure 4.24: Results of SA and Ryser's algorithm in the case of Fig. $4.13 \mathrm{~b}$ for image size $128 \times 128$, window size $7 \times 7$,

$$
\xi=5000 \text { and } \gamma=0.6 \text {. }
$$

Tables 4.12 and 4.13 show examples of the best results of the SA algorithm for image classes of Figs. 4.13 and 4.14, respectively. The differences of the horizontal and vertical projections of the original and reconstructed images can reach less value than 20 (even 0 in some cases). Moreover, the differences of the LQH vectors of the original and reconstructed images decreased substantially during the iterations (in the tables, $C(\mathbf{X})_{\text {start }}$ denotes the initial objective 
function value, $C(\mathbf{X})$ denotes the final objective function value and $u$ stands for the window size $u \times u$ ). The SLBP distances are also satisfactory, starting usually with high values (e.g. 916.44) and ending in much lower values (e.g. 63.14).

\begin{tabular}{|c|r|c|c|c|r|r|r|r|r|r|}
\hline Fig. & \multicolumn{1}{c|}{$u$} & $\gamma$ & $\zeta$ & $E_{p}$ & $C(\mathbf{X})_{\text {start }}$ & $C(\mathbf{X})$ & $\left\|H-H^{\prime}\right\|_{2}$ & $\left\|V-V^{\prime}\right\|_{2}$ & \multicolumn{1}{c}{$\Phi(\mathbf{X})$} & $D_{\text {SLBP }}$ \\
\hline $4.13 \mathrm{a}$ & 13 & 0.5 & 3000 & $34 \%$ & 4961.22 & 80.85 & 10.73 & 10.24 & 119.76 & 280.48 \\
\hline $4.13 \mathrm{~b}$ & 7 & 0.6 & 5000 & $43 \%$ & 4466.20 & 26.33 & 2.60 & 6.33 & 29.00 & 60.44 \\
\hline $4.13 \mathrm{c}$ & 5 & 0.4 & 3000 & $27 \%$ & 2538.76 & 40.90 & 15.02 & 17.05 & 22.07 & 264.14 \\
\hline $4.13 \mathrm{~d}$ & 13 & 0.6 & 4000 & $30 \%$ & 7494.82 & 75.56 & 16.02 & 15.40 & 73.56 & 278.70 \\
\hline $4.13 \mathrm{e}$ & 9 & 0.5 & 5000 & $26 \%$ & 2156.00 & 33.02 & 12.31 & 19.42 & 2.57 & 370.32 \\
\hline $4.13 \mathrm{f}$ & 9 & 0.5 & 3000 & $26 \%$ & 3916.62 & 53.25 & 14.00 & 15.24 & 48.02 & 103.22 \\
\hline
\end{tabular}

Table 4.12: Sample SA results of Fig. 4.13.

\begin{tabular}{|c|c|c|c|c|r|r|r|r|r|r|}
\hline Fig. & $u$ & $\gamma$ & $\zeta$ & $E_{p}$ & $C(\mathbf{X})_{\text {start }}$ & $C(\mathbf{X})$ & $\left\|H-H^{\prime}\right\|_{2}$ & $\left\|V-V^{\prime}\right\|_{2}$ & $\Phi(\mathbf{X})$ & $D_{\text {SLBP }}$ \\
\hline $4.14 \mathrm{a}$ & 5 & 0.7 & 3000 & $47 \%$ & 4591.04 & 25.41 & 11.66 & 13.05 & 1.00 & 190.34 \\
\hline $4.14 \mathrm{~b}$ & 5 & 0.7 & 3000 & $48 \%$ & 3359.12 & 38.21 & 18.46 & 18.77 & 1.40 & 101.06 \\
\hline $4.14 \mathrm{c}$ & 7 & 0.7 & 3000 & $46 \%$ & 3041.03 & 26.94 & 8.56 & 17.39 & 1.43 & 172.16 \\
\hline $4.14 \mathrm{~d}$ & 11 & 0.6 & 4000 & $47 \%$ & 4031.90 & 58.01 & 19.32 & 19.28 & 32.34 & 229.84 \\
\hline $4.14 \mathrm{e}$ & 7 & 0.7 & 3000 & $45 \%$ & 4299.90 & 36.55 & 18.44 & 16.79 & 1.90 & 199.72 \\
\hline $4.14 \mathrm{f}$ & 7 & 0.6 & 4000 & $44 \%$ & 4590.60 & 57.33 & 17.64 & 17.84 & 36.42 & 358.86 \\
\hline $4.14 \mathrm{~g}$ & 9 & 0.5 & 3000 & $38 \%$ & 4042.26 & 38.37 & 10.52 & 19.66 & 16.38 & 152.32 \\
\hline $4.14 \mathrm{~h}$ & 7 & 0.6 & 3000 & $40 \%$ & 5031.88 & 28.54 & 13.05 & 14.73 & 1.26 & 197.56 \\
\hline $4.14 \mathrm{i}$ & 9 & 0.7 & 4000 & $31 \%$ & 7440.58 & 30.82 & 15.93 & 14.49 & 0.57 & 184.45 \\
\hline $4.14 \mathrm{j}$ & 3 & 0.4 & 6000 & $15 \%$ & 4616.85 & 39.57 & 15.49 & 18.97 & 12.77 & 385.78 \\
\hline $4.14 \mathrm{k}$ & 11 & 0.4 & 5000 & $15 \%$ & 5723.39 & 44.35 & 9.07 & 18.17 & 42.77 & 201.37 \\
\hline 4.141 & 9 & 0.7 & 3000 & $43 \%$ & 3983.18 & 27.15 & 12.37 & 13.80 & 1.40 & 188.98 \\
\hline
\end{tabular}

Table 4.13: Sample SA results of Fig. 4.14.

Taking pixel error into account, we deduce that it is usually quite high, but this is somewhat misleading. We again emphasize that two projections hold very little information. Despite this, augmenting information with prior knowledge leads to improved visual quality in the reconstruction, which is reflected in the final value of the cost function and the final SLBP distance as well.

\subsection{Conclusions}

In this chapter, we first extended the Quadrant-concavity measure to describe spatial relations between objects and consider complex spatial relations like enlacement and interlacement. This approach permits easier modelling of these configurations as highlighted by the examples, and allowed us to define two interlacement descriptors which differ in normalization. In the experiments conducted for classification issues, we developed the idea to consider the foreground as one object and the background as the other. This method is similar to the one in [30], as the two methods aim at 
modelling the same idea. However, our method is based on a fully twodimensional approach, whereas the other is based on one-dimensional directional enlacement. We believe that the two-dimensional approach is more powerful, and indeed in the experiments, simply by using two directions (i.e. four quadrants), we reached comparable or even better results than that obtained by [30] employing many directions.

Secondly, we extended the global $Q$-concavity measure to histograms collecting $Q$-concavity values calculated under all possible positions of an image window of predefined size. We investigated three different variants: (1) focusing only on the background points; (2) examining all the points; and (3) omitting the zero bin. The properties of each were studied. We found that the histogram based on the background points is the most appropriate for classification. We conducted an illustrative experiment comparing the classification accuracy of the local $Q$-concavity histogram with SLBP and the global $Q$-concavity descriptor. We deduced that LQH ensures comparable accuracy. Furthermore, in many cases, it outperforms the others. Moreover, for related image classification issues, we also presented a way to determine the appropriate window size and quantization level for calculating LQH. Three different strategies were also proposed to decrease the processing time of LQH calculation.

Finally, we examined how local $Q$-concavity histogram information improves the quality of binary tomographic reconstruction using two projections. Integrating LQH into the reconstruction process, we solved the corresponding optimization problem with SA. We conducted tests on two different datasets, and as a final conclusion, we found that using $\mathrm{LQH}$ as prior information significantly improves the reconstruction quality from the visible point of view.

This chapter is based on papers $[23,88,87]$.

In this chapter, the author regards the following as her main contributions:

- Global Quadrant-Convexity

- testing and analyzing classification accuracy,

- Local Quadrant-Convexity

- suggesting three different approaches for the local $Q$-concavity histograms,

- suggesting and formalizing local update strategies to speed up the calculation of LQH,

- implementation of the suggested methods,

- testing and comparing them to already published algorithms,

- testing and analyzing classification accuracy,

- adaptation of LQH into the reconstruction process,

- solving the problem with SA and fine-tuning its parameters,

- evaluating results. 


\section{Chapter 5}

\section{Conclusions of the Thesis}

In this thesis, we examined how a variety of prior information improves the quality of binary image reconstruction using a limited number of projections. We reformulated the reconstruction process into an optimization problem (complemented by different priors), and attempted to solve it via Simulated Annealing. During the experiments, it turned out that in our case, the widely used RME is not appropriate for describing reconstruction quality. Therefore, we split different terms of the objective function and also defined pixel error $\left(E_{p}\right)$ for numerical analysis.

Initially, we delved into texture information using different versions of Local Binary Patterns (LBP, FLBP, SLBP, DRLBP), and found that, in our case, SLBP is the best choice. We used DART and Ryser's algorithm as references. We tested our idea on different datasets; first on synthetic images, then software phantom images, and finally, on real images. We found that SLBP as texture prior information significantly improves reconstruction quality, especially when only very few projections are available.

Next, inspired by Nonogram puzzles, we incorporated a structural prior, the number of strips per row and column, into the reconstruction process. We first suggested a deterministic integer programming approach to solve the reconstruction problem. Since it is seldom applicable in practice due to the high running time required, we also proposed a stochastic method based on SA with different initializing strategies (BasicSA, FixpixelSA, RyserSA, and CurveballSA). A local update of the number of strips in each iteration was also presented, which substantially reduced the running time of the above mentioned methods.

For evaluation, we used three different datasets: random images of various densities, real Nonogram puzzles, and so-called TomoPhantom images. We found that although FixpixelSA is the fastest, RyserSA, and CurveballSA outperform the other methods. We also found that pixel error is high even if the objective function value is relatively small. This is due to the presence of switching components, which yield lots of different solutions for the same input data.

Then, we extended the Quadrant-concavity measure to describe spatial relations between objects and consider complex spatial relations like enlacement and interlacement. The classification experiments yielded promising results.

Next, we defined the local $Q$-concavity histograms with three variants 
(background, all, nonzero) and found that the histogram based on the background points is the most suitable for classification. We conducted an illustrative experiment to compare classification accuracy of the local $Q$-concavity histogram to SLBP and the global Q-concavity descriptor. We deduced that LQH ensures comparable accuracy. Furthermore, in many cases, it outperforms the other methods. Moreover, regarding image classification issues, we also presented a way to find the appropriate window size and quantization level for calculating LQH. Three different strategies were also proposed to decrease the time needed to calculate $\mathrm{LQH}$.

Finally, we integrated LQH into the reconstruction process and found that using $\mathrm{LQH}$ as prior information significantly improves the reconstruction quality from the visible point of view.

In conclusion, we reached promising results using the above mentioned priors in Binary Tomography. Naturally, we cannot expect perfect reconstruction from just two projections. Still, the improvements in quality are indisputable.

We believe that the combination of priors presented here could lead to even better reconstructions, especially if these were to be combined with further priors that have already proved promising in two-projection Binary Tomography, such as shape orientation [56]. 


\section{Appendix A}

\section{Summary in English}

The basic aim of tomography is to reconstruct the description (or the model) of the source object from its slices. Slices are 2D cross-sectional images that are sectioned from the 3D object by a 2D plane. Due to the nondestructive restrictions, slices cannot be accessed directly, only secondary information is available about them. This information is usually the sum of the material densities in a given 2D slice along certain directions.

In this study, we worked with transmission tomography, meaning the radiation comes from outside of the examined object. During an experiment, the object to be examined stands between the source of the X-ray and the detectors, which measure the exiting intensity of radiation. When an X-ray beam passes through an object, its intensity decreases due to physical mechanisms, i.e. a part of it is absorbed. Passing through different materials, the degree of absorption is different and is always specific to the given material.

The image to be reconstructed can be created with several continuous techniques (e.g. analytical methods, algebraic reconstruction methods). Unfortunately, these techniques need several hundreds of equiangularly positioned projections to achieve reasonable image quality, meaning they are almost always useless when only few projections are available. A projection is a collection of line integrals of the image taken along predefined straight lines.

In some cases, one can assume that the object to be reconstructed consists of just a few known materials, i.e. only a few different grayscale intensity values - that are known in advance - can appear in the image representing the object. Discrete Tomography (DT) is concerned with exactly such issues, thus, fewer projections could potentially be enough for a satisfactory reconstruction.

Binary Tomography (BT) is a special case of DT, which can be utilized when the object to be reconstructed consists of a single material, yielding a corresponding image containing only $0 \mathrm{~s}$ and $1 \mathrm{~s}$. There are a lot of wellfunctioning algorithms in DT or BT (e.g. DART, Ryser's algorithm, etc.), but unfortunately, they are unable to use prior information. Tracing the binary reconstruction back to an optimization problem could lead to an approach where prior information can be incorporated into the reconstruction process.

This thesis is the summary of the author's research in the field of BT, where the goal is to improve reconstruction quality by using prior information about the image to be reconstructed. 


\section{A.1 Key Points of the Thesis}

The findings of this dissertation can be divided into three thesis groups. Table A.1 provides an overview of the results in relation to publications of the author.

In the first thesis group, I studied how texture information improves the quality of binary reconstruction using very few projections. These results were published in conference proceedings [85], and in a journal article [83].

I/1. I examined and integrated the basic LBP prior into the reconstruction process and solved the corresponding optimization problem by SA. I tested the algorithm on different datasets and evaluated the results.

I/2. I examined and compared the different LBP variants, and found that SLBP is the most useful in this case. I defined the proper objective function and integrated the SLBP prior into the reconstruction process and solved the corresponding optimization problem by SA. I tested the algorithm on different datasets and evaluated the results. I also defined alternative quality measurements for the results to be comparable.

In the second thesis group, I introduced a novel prior, based on Nonogram puzzles, to describe the expected structure of the reconstructed image: the number of strips (consecutive 1s of maximal length) in each row and column. These results were published in three conference proceedings $[8,84,86]$.

II/1. I first solved the reconstruction problem with a deterministic integer programming approach; then proposed the stochastic method based on SA to resolve the issue; and finally, compared the results.

II/2. I defined different strategies for the SA algorithm, implemented and compared them; tested the algorithm on different datasets, and evaluated the results. I also examined how switching components affect the reconstruction process.

The third thesis group is based on global and local Quadrant-convexity. These results were published in two conference proceedings $[23,87]$ and are currently under review to be published as a journal article [88].

III/1. I tested and analyzed the classification accuracy of the global $Q$-convexity-based method.

III/2. I suggested three different approaches for calculating local $Q$-concavity histogram (LQH), then formalized the novel proposals and their corresponding equations. I tested the classification accuracy of the suggested methods and evaluated the results. 
III/3. I adapted the appropriate LQH approach into the reconstruction process, implemented it, and tested on diverse datasets. I defined various approaches for speedy calculation of LQH. Finally, I evaluated the results.

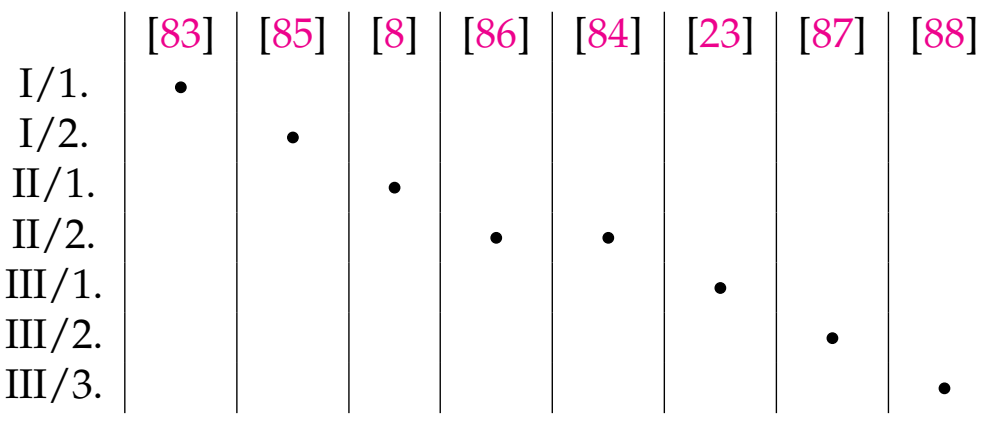

Table A.1: Overview of thesis points in relation to the author's publications. 



\section{Appendix B}

\section{Summary in Hungarian}

A tomográfia alapfeladata egy objektum belső szerkezetének rekonstruálása annak szeleteiből, ahol a szeleten olyan 2D keresztmetszeti képet értünk, amelyet úgy kapunk, hogy a 3D objektumot metsszük egy 2D síkkal. Mivel az objektumot a vizsgálat során nem akarjuk roncsolni, így a szeletekhez nem tudunk közvetlenül hozzáférni, csak másodlagos információval rendelkezünk róluk, mely általában egy adott 2D szelet anyagsûrû́ségének összege bizonyos irányok mentén.

Jelen kutatás során transzmissziós tomográfiát alkalmaztunk (ebben az esetben a sugárzás az objektumon kívülről származik), melynek során a vizsgálandó tárgy a röntgensugár forrása és a detektorok között áll (amelyek a sugárzás kilépő intenzitását mérik). Amikor egy röntgensugár áthalad egy tárgyon, annak intenzitása a fizikai hatások miatt csökken, vagyis a sugárzás egy része elnyelődik. Különböző anyagokon áthaladva az abszorpció mértéke más és más, és mindig az adott anyagra jellemző.

A rekonstruálandó kép többféle folytonos technikával (pl. analitikai módszerekkel, algebrai rekonstrukciós módszerekkel) előállítható, de a jó rekonstrukcióhoz általában több száz vetületre van szükség. Vetületnek nevezzük az előre meghatározott egyenesek mentén vett vonalmenti integrálok halmazát. Számos gyakorlati alkalmazásban azonban nem áll rendelkezésünkre a megfelelő mennyiségú vetület. Bizonyos esetekben ugyanakkor feltételezhetô, hogy a rekonstruálandó objektum csak néhány ismert anyagból áll, vagyis csak néhány, előre ismert szürkeárnyalatos intenzitásérték jelenhet meg az objektumot ábrázoló képen. A diszkrét tomográfia (DT) ilyen problémákkal foglalkozik, így kevesebb vetületből is megfelelő minőségú rekonstrukció állítható elő.

A bináris tomográfia (BT) a DT azon speciális esete, amely akkor alkalmazható, ha a rekonstruálandó objektum egyetlen anyagból áll. Ennek következménye, hogy a hozzá tartozó kép csak 0 és 1 értékeket tartalmazhat. Számos algoritmus ismert mind a DT mind a BT területén (pl. DART, Ryser algoritmus), de ezek sokszor nem tudnak prior információval dolgozni. A bináris rekonstrukció optimalizálási problémára való visszavezetése olyan megközelítést nyújt, ahol a prior információk beépíthetők a rekonstrukciós folyamatba.

Jelen értekezés a szerző BT területén történt kutatásainak összefoglalása, melynek során cél volt a rekonstrukció minőségének javítása különféle prior információ felhasználásával. 


\section{B.1 Az eredmények tézisszerú összefoglalása}

Az értekezés eredményei három csoportba sorolhatók. Az eredmények és a kapcsolódó publikációk viszonyát a B.1 táblázat foglalja össze.

Az első téziscsoportban azt vizsgáltam, hogy kevés vetület használata esetén a textúra információ hogyan javíthatja a bináris rekonstrukció minőségét. Az eredményeket egy konferencia kiadványban [85] és egy folyóiratban [83] publikáltam.

I/1. Megvizsgáltam és beépítettem az alap LBP-t a rekonstrukciós folyamatba, majd a megfelelő optimalizálási problémát SA-val oldottam meg. Különböző adathalmazokon teszteltem az algoritmust, végül kiértékeltem az eredményeket.

I/2. Megvizsgáltam és összehasonlítottam a különböző LBP variánsokat, melynek során megállapítottam, hogy esetünkben az SLBP a legjobban alkalmazható változat. Definiáltam a megfelelő célfüggvényt, és integráltam az SLBP-t a rekonstrukciós folyamatba, majd a megfelelő optimalizálási problémát SA-val oldottam meg. Különböző adathalmazokon teszteltem az algoritmust és értékeltem ki az eredményeket. Az eredmények összehasonlíthatósága érdekében az RME mellett egyéb minőség-mérőszámokat is definiáltam.

A második téziscsoportban a Nonogram játék ötlete alapján újfajta priort határoztam meg, amely a rekonstruált kép szerkezetét írja le: a futamok (maximális számú egymást követő fekete pixelek) számát az egyes sorokban és oszlopokban. Az eredményeket három konferencia kiadványban [8, 84, 86] publikáltam.

II/1. A rekonstrukciós feladatot először egész értékú programozási feladattal oldottam meg. Javasoltam továbbá egy szimulált hútésen (Simulated Annealing, SA) alapuló, sztochasztikus módszert is. Az algoritmusok eredményeit összehasonlítottam.

II/2. Különböző stratégiákat határoztam meg az SA algoritmushoz, implementáltam és összehasonlítottam őket. Többféle adathalmazon végeztem tesztelést és értékeltem ki az eredményeket. Megvizsgáltam, hogy a kapcsoló komponensek jelenléte hogyan befolyásolhatja a rekonstrukciós folyamatot.

A harmadik téziscsoport a globális és lokális kvadráns-konvexitáson (Quadrant-convexity, Q-konvexitás) alapszik. Az eredményeket két konferencia kiadványban [23, 87] publikáltam, továbbá benyújtottam egy folyóirat cikket is [88].

III/1. Teszteltem és elemeztem a globális Q-konvexitáson alapuló módszer osztályozási pontosságát. 
III/2. Különböző megközelítéseket dolgoztam ki a lokális Q-konkávsági hisztogram (LQH) kiszámításához. A javaslatok formalizálása után teszteltem a módszerek osztályozási pontosságát és kiértékeltem az eredményeket.

III/3. A megfelelő LQH változatot adaptáltam a rekonstrukciós folyamatba, és különböző adathalmazokon teszteltem. Kidolgoztam az LQH gyors kiszámítására vonatkozó variánsokat. Végül kiértékeltem az eredményeket.

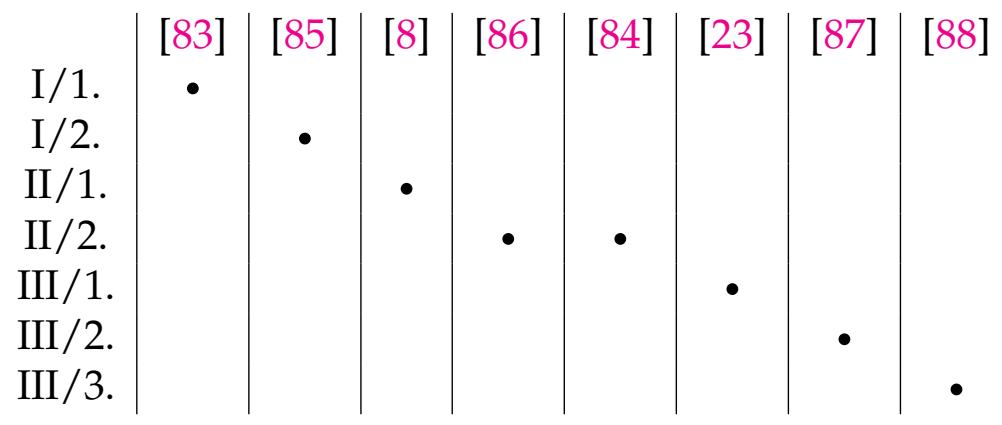

Table B.1: A tézispontok és a szerző publikációinak kapcsolata. 



\title{
Appendix C
}

\section{Publications of the Author}

\author{
Journal publications
}

- Judit Szúcs, Péter Balázs: Binary Image Reconstruction Using Local Binary Pattern Priors; In: International Journal of Circuits, Systems and Signal Processing (NAUN) 11, pp. 296-299. (2017). ISSN: 1998-4464. SJR: Q4

- Judit Szúcs, Péter Balázs: Local Q-Concavity Histograms for Binary Image Classification and Reconstruction; In: Submitted to The Visual Computer SJR: Q2

\section{Full papers in conference proceedings}

- Péter Balázs, Judit Szúcs: Reconstruction of Binary Images with Fixed Number of Strips; In: Image Analysis and Recognition. Ed. by Aurélio Campilho, Fakhri Karray, and Bart ter Haar Romeny. Vol. 10882. Cham: Springer International Publishing, 2018, pp. 11-19.

(ISBN: 978-3-319-93000-8)

DOI: 10.1007/978-3-319-93000-8_2 CORE: C

- Judit Szúcs, Péter Balázs: Variants of Simulated Annealing for Strip Constrained Binary Tomography; In: Computational Modeling of Objects Presented in Images. Fundamentals, Methods, and Applications. Ed. by Reneta P. Barneva et al. Vol. 10986. Cham: Springer International Publishing, 2019, pp. 82-92.

(ISBN: 978-3-030-20805-9)

DOI: $10.1007 / 978-3-030-20805-9 \_8$

- Sara Brunetti, Péter Balázs, Péter Bodnár, Judit Szúcs: A Spatial Convexity Descriptor for Object Enlacement; In: Proceedings of International Conference on Discrete Geometry for Computer Imagery. Ed. by Michel Couprie et al. Vol. 11414. Cham: Springer International Publishing, 2019, pp. 330-342.

(ISBN: 978-3-030-20805-9)

DOI: 10.1007/978-3-030-14085-4_26 CORE: C 
- Judit Szúcs, Péter Balázs: An Improved Simulated Annealing Approach for Reconstructing Binary Images with Fixed Number of Strips; In: Image Analysis and Recognition. Ed. by Fakhri Karray, Aurélio Campilho, and Alfred Yu. Vol. 11662. Cham: Springer International Publishing, 2019, pp. 174-185.

(ISBN: 978-3-030-27202-9)

DOI: 10.1007/978-3-030-27202-9_15 CORE: C

- Judit Szúcs, Péter Balázs: Binary Tomography Using Variants of Local Binary Patterns as Texture Priors; In: Computer Analysis of Images and Patterns. Ed. by Mario Vento and Gennaro Percannella. Vol. 11678. Cham: Springer International Publishing, 2019, pp. 141-154.

(ISBN: 978-3-030-29891-3)

DOI: 10.1007/978-3-030-29888-3_12 CORE: B

- Judit Szúcs, Péter Balázs: Local Q-Convexity Histograms for Shape Analysis; In: Combinatorial Image Analysis. Ed. by Tibor Lukić et al. Vol. 12148. Cham: Springer International Publishing, 2020, pp. 245-257.

(ISBN: 978-3-030-51002-2)

DOI: 10.1007/978-3-030-51002-2_18 CORE: C

\section{Other publications}

- Balázs Péter, Lékó Gábor, Ozsvár Zoltán, Petrovszki Gábor, Szúcs Judit, Varga László: 3D ipari CT szkenner informatikai rendszerének tervezése és fejlesztése; In: Képfeldolgozók és Alakfelismerők Társaságának 11. konferenciája, Szováta, Romania, 24-27 January, 2017, Paper Nr. 58.

- Judit Szúcs, Péter Balázs: Binary Image Reconstruction based on Structural Information; In: 4th Winter School of PhD Students in Informatics and Mathematics, Pécs, Hungary, 24-26 February, 2017, pp. 33-34. (ISBN: 978-615-5586-12-5)

- Szúcs Judit: Képrekonstrukció tanult strukturális információval; In: XXXIII. Országos Tudományos Diákköri Konferencia, Informatika Tudományi Szekció, Számítógépes jelfeldolgozás, alakfelismerés tagozat, Veszprém, Hungary, 22 April, 2017.

- Judit Szúcs, Péter Balázs: Binary Image Reconstruction with Strip Constraints; In: 5th Winter School of PhD Students in Informatics and Mathematics, Debrecen, Hungary, 2-4 March, 2018, pp. 42-43.

(ISBN: 978-615-5586-23-1)

- Judit Szúcs: Image Reconstruction from Picross-based Vectors; In: Tavaszi Szél Konferencia 2018 absztrakt kötet, pp. 324.

(ISBN: 978-615-5586-26-2) 
- Judit Szúcs and Péter Balázs: Strip Constrained Binary Tomography; In: Volume of Short Papers of the 11th Conference of PhD Students in Computer Science, Szeged, Hungary, 25-27 June, 2018, pp. 96.

- Szúcs Judit, Balázs Péter: Bináris rekonstrukció nonogramszerú priorral; In: Képfeldolgozók és Alakfelismerők Társaságának 12. Konferenciája, Debrecen, Hungary, 28-31 January, 2019, Paper Nr. 13.

- Judit Szúcs, Péter Balázs: Binary Image Reconstruction Based on Texture Priors; In: 6th Winter School of PhD Students in Informatics and Mathematics; Szeged, Hungary, 22-24 February, 2019, pp. 30. (ISBN: 978-615-5586-37-8)

- Judit Szúcs, Péter Balázs: A Q-Convexity Based Local Shape Descriptor; In: 7th Winter School of PhD Students in Informatics and Mathematics; Veszprém, Hungary, 24-26 January, 2020, pp. 34.

(ISBN: 978-615-5586-54-5)

- Szúcs Judit: Q-konvexitáson alapuló alakleíró; In: XXIII. Tavaszi Szél Konferencia 2020 absztrakt kötet I., pp. 365.

(ISBN: 978-615-5586-70-5) 



\section{Appendix D}

\section{Images}

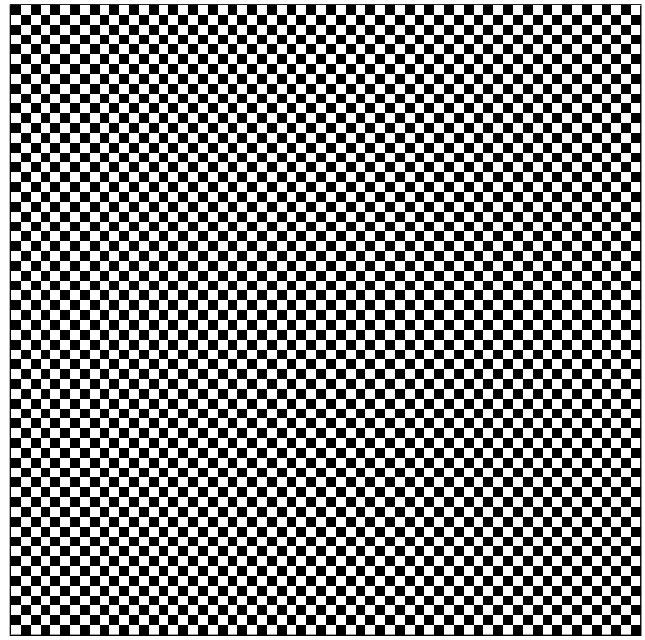

(a) Chessboard

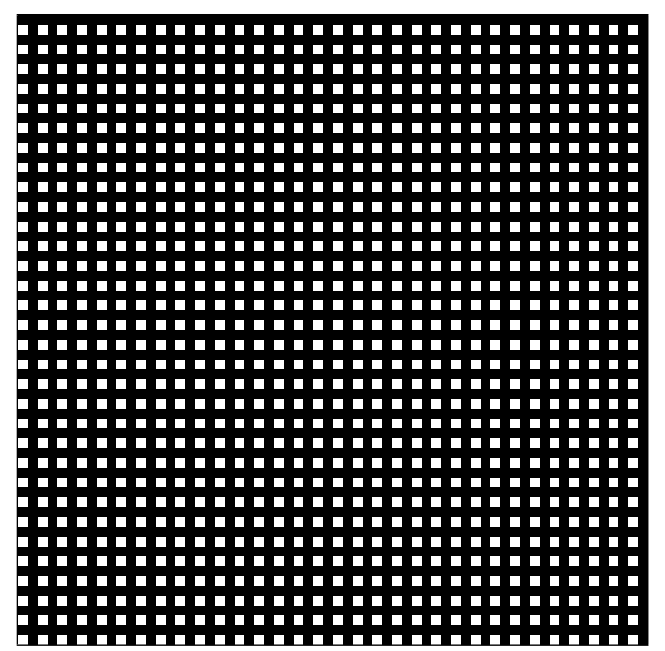

(c) Grid

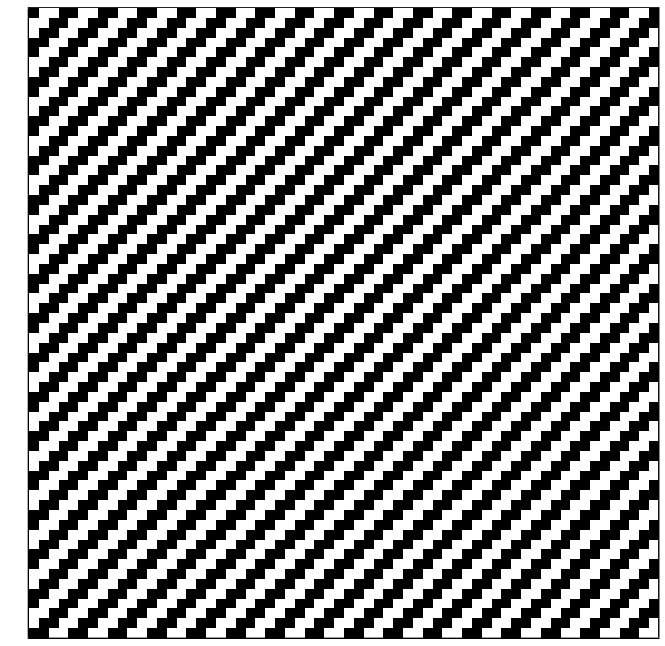

(b) Diagonal

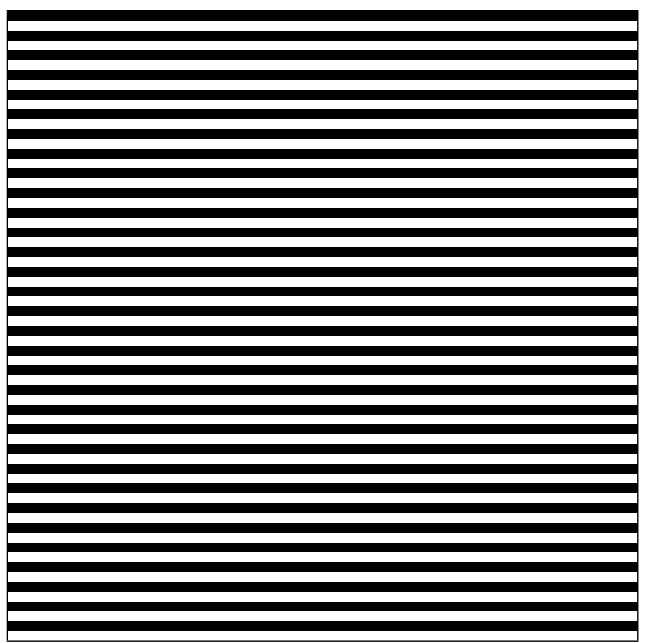

(d) Line

Figure D.1: Synthetic image classes. 


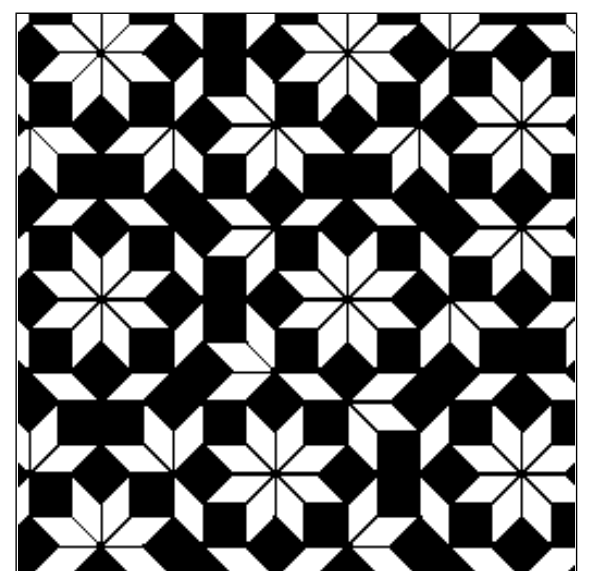

(a) Class 1

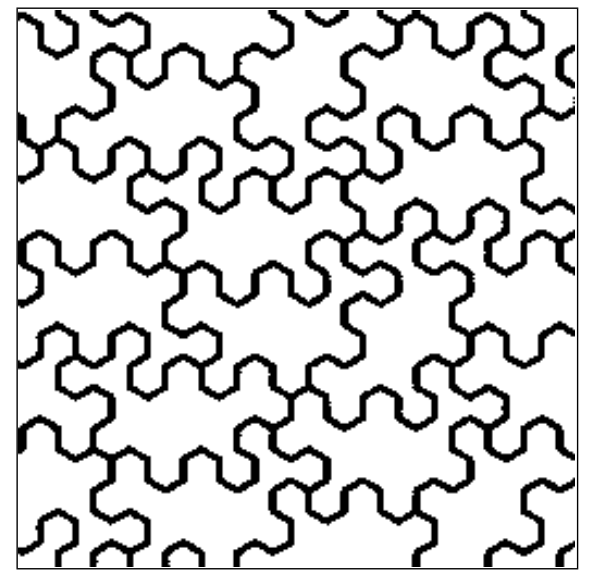

(c) Class 3

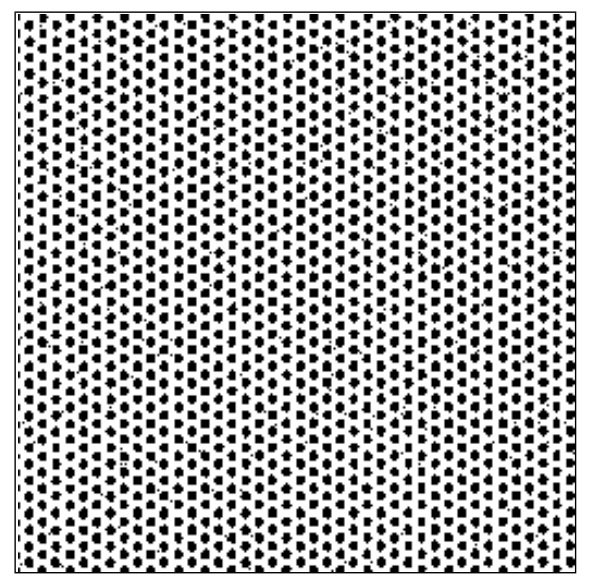

(e) Class 5

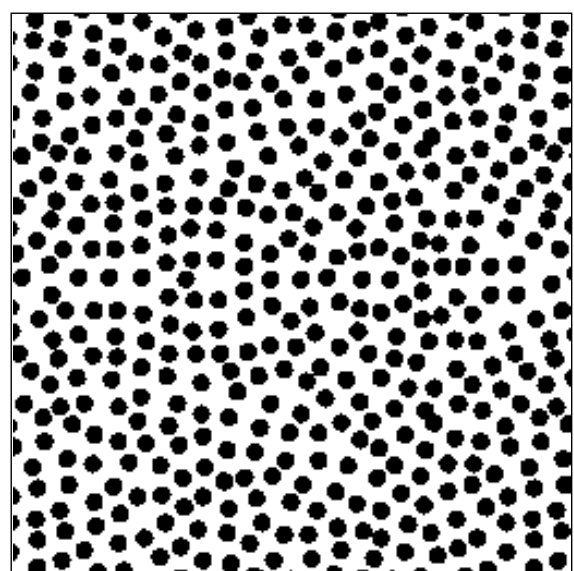

(b) Class 2

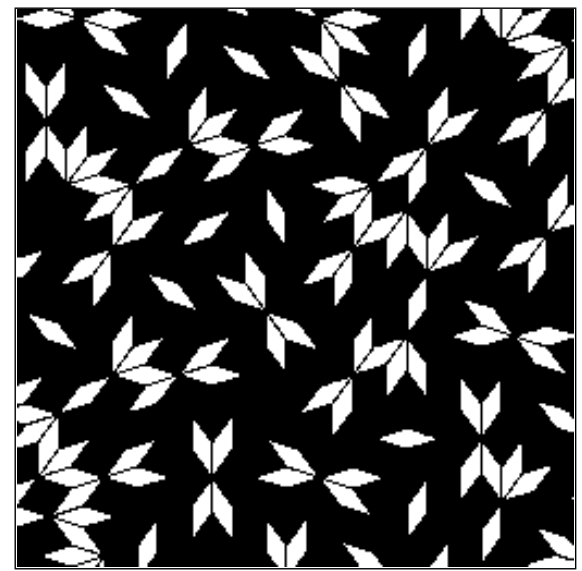

(d) Class 4

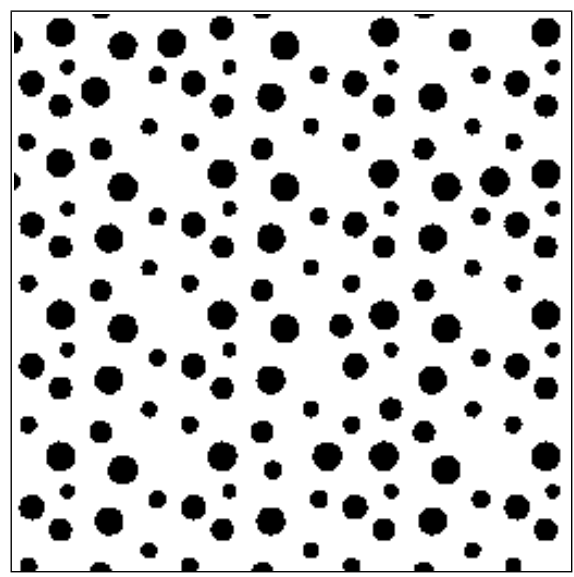

(f) Class 6

Figure D.2: Software phantom image classes. 


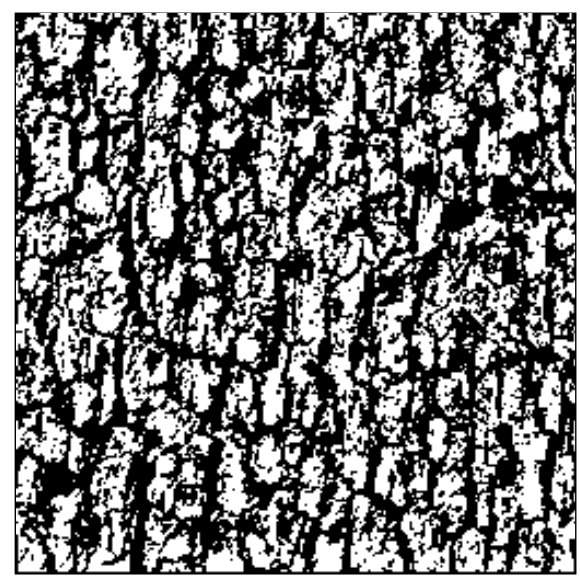

(a)

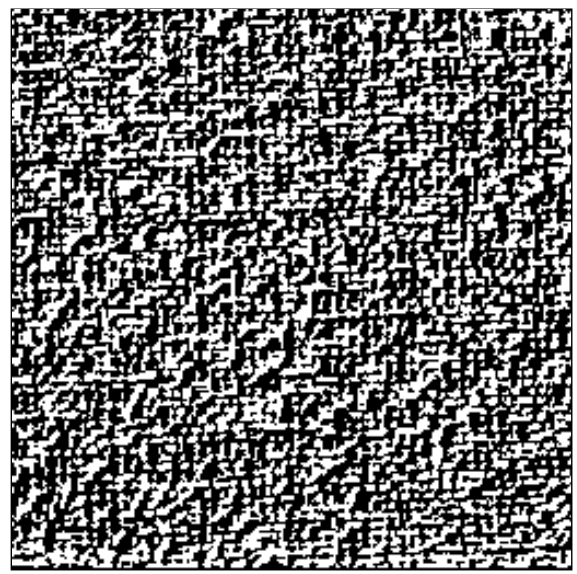

(c)

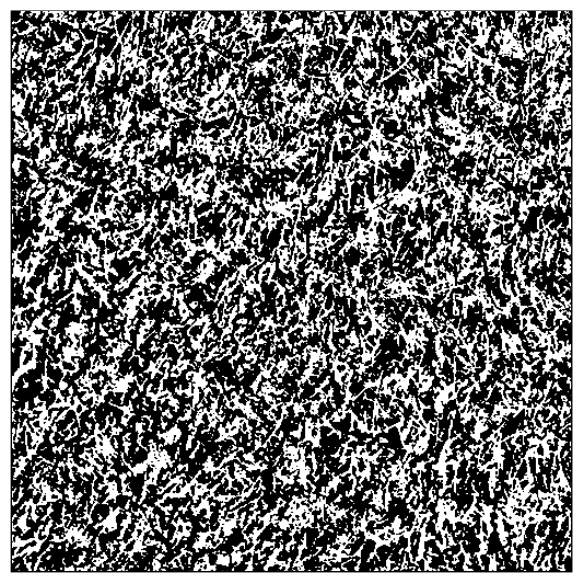

(e)

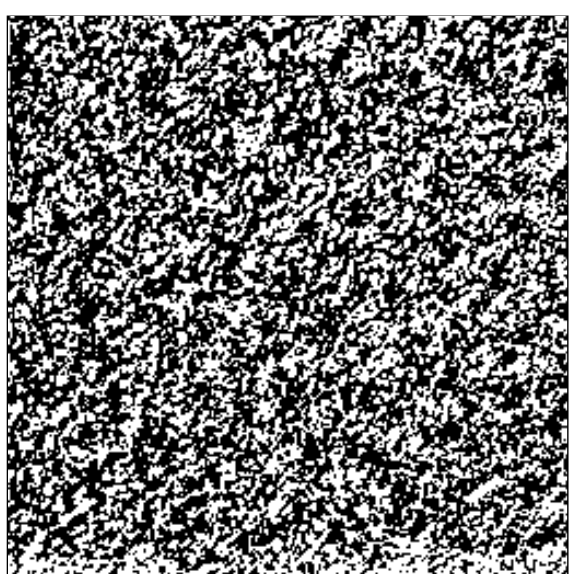

(b)

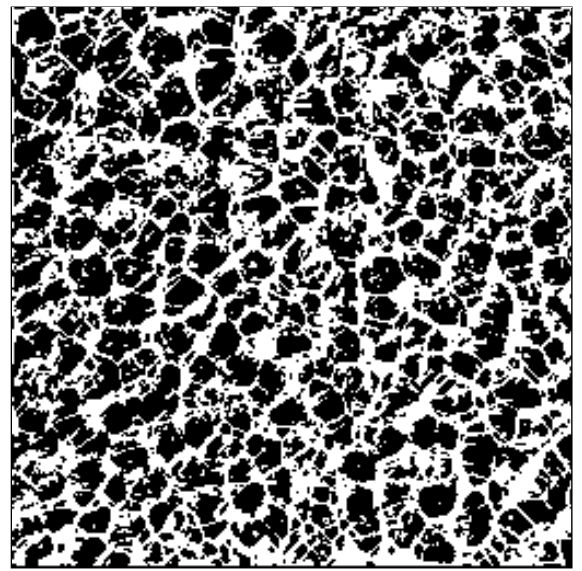

(d)

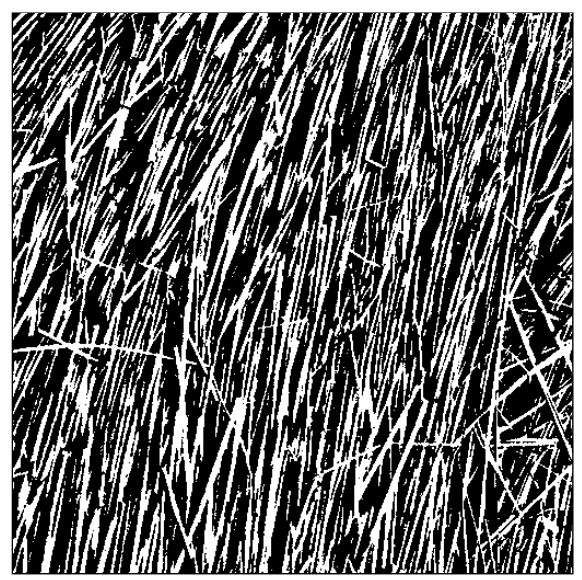

(f)

Figure D.3: Real image classes I. [18]. 


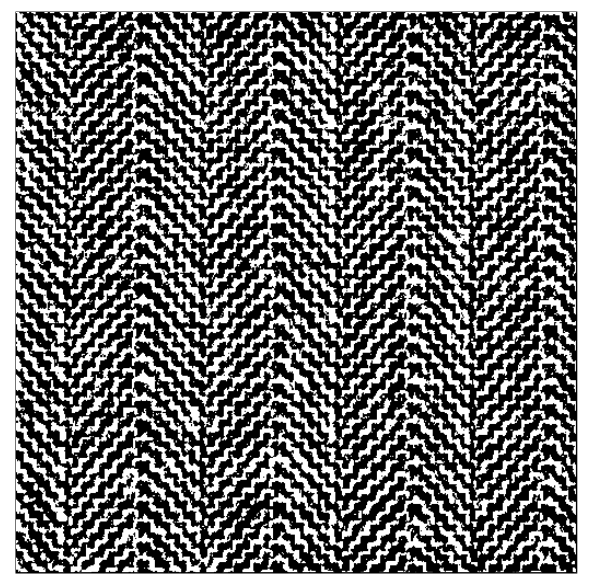

(g)

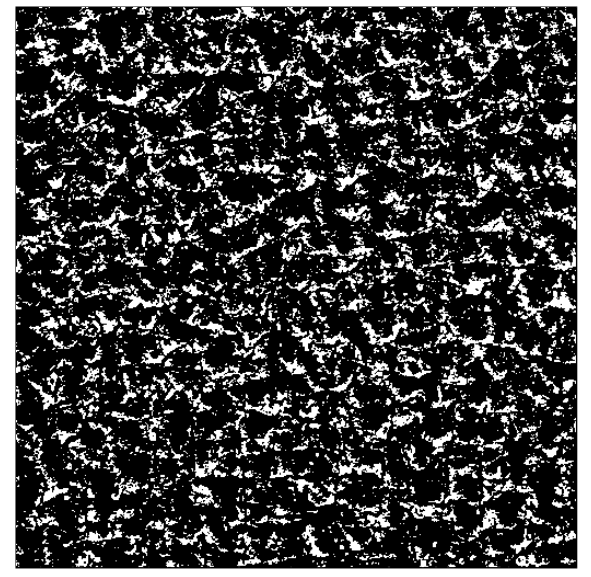

(i)

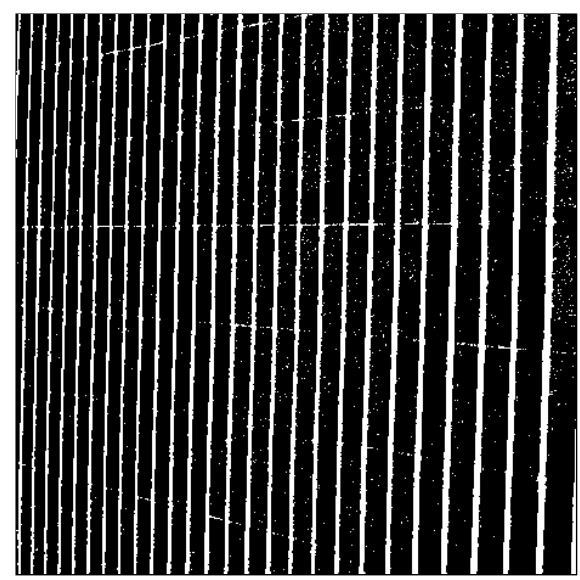

(k)

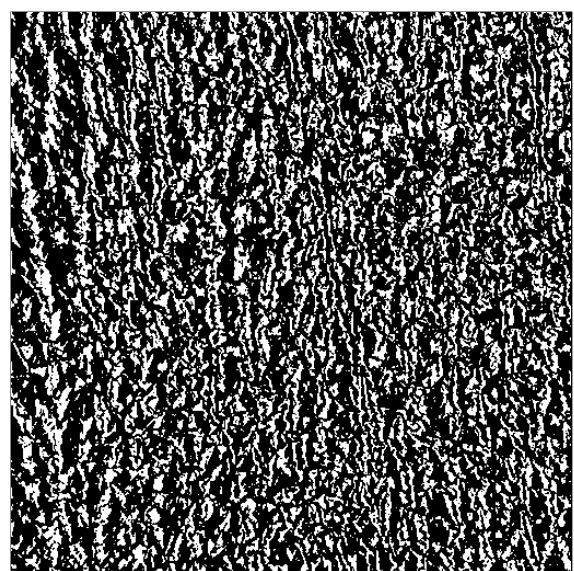

(h)

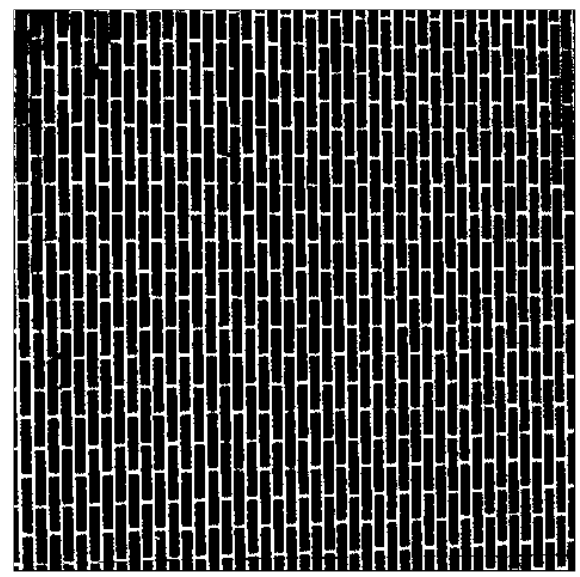

(j)

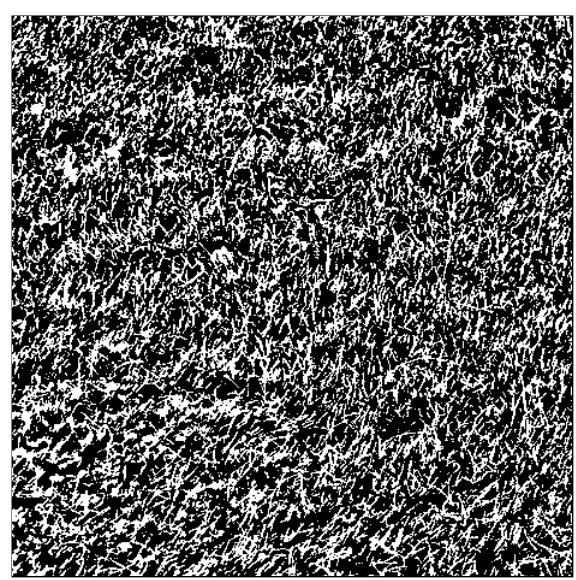

(1)

Figure D.3: Real image classes I. [18]. 


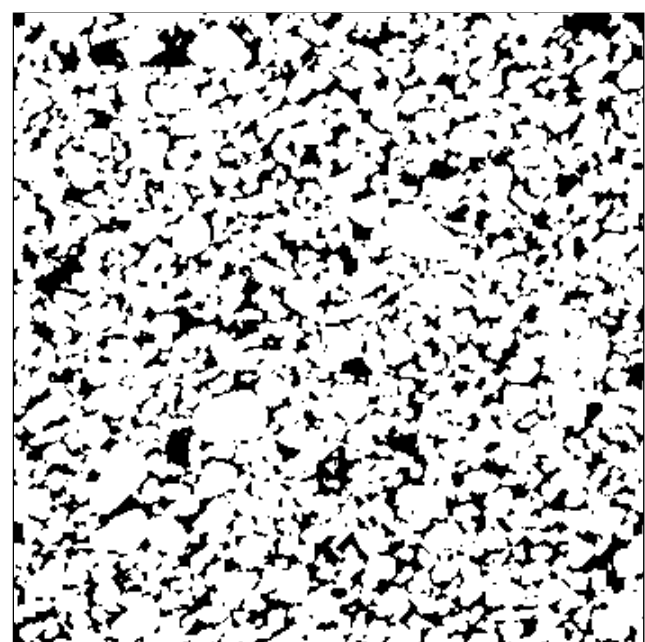

(a) Sandstone [63]

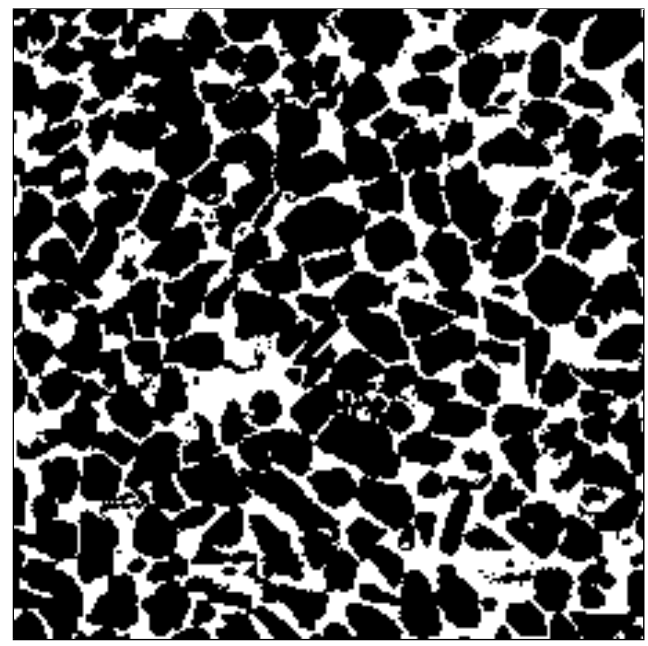

(c) Belgian fieldstone [24]

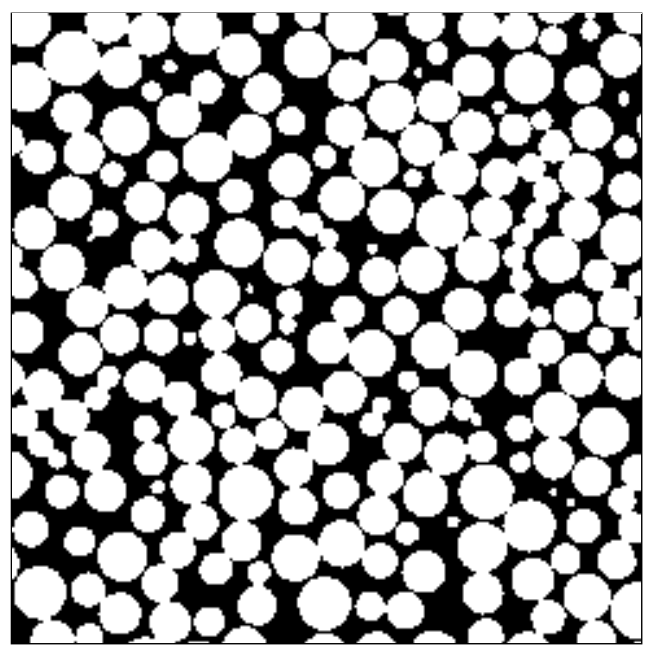

(b) Glass beads [49]

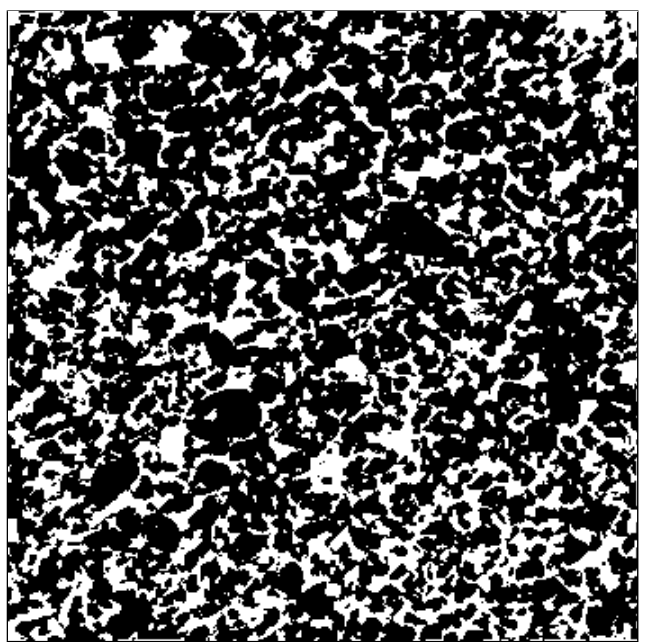

(d) Bentheimer networks [62]

Figure D.4: Real image classes II. [35]. 


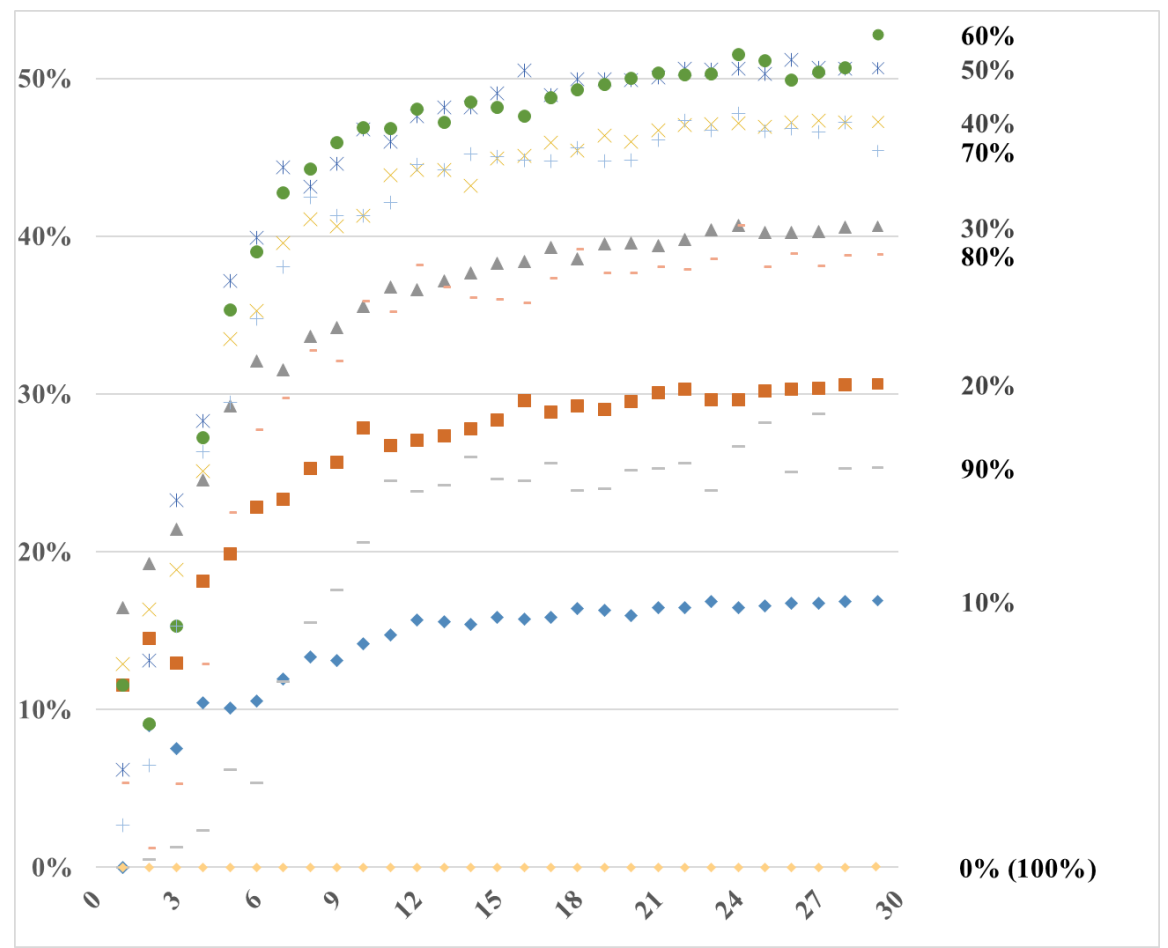

(a)

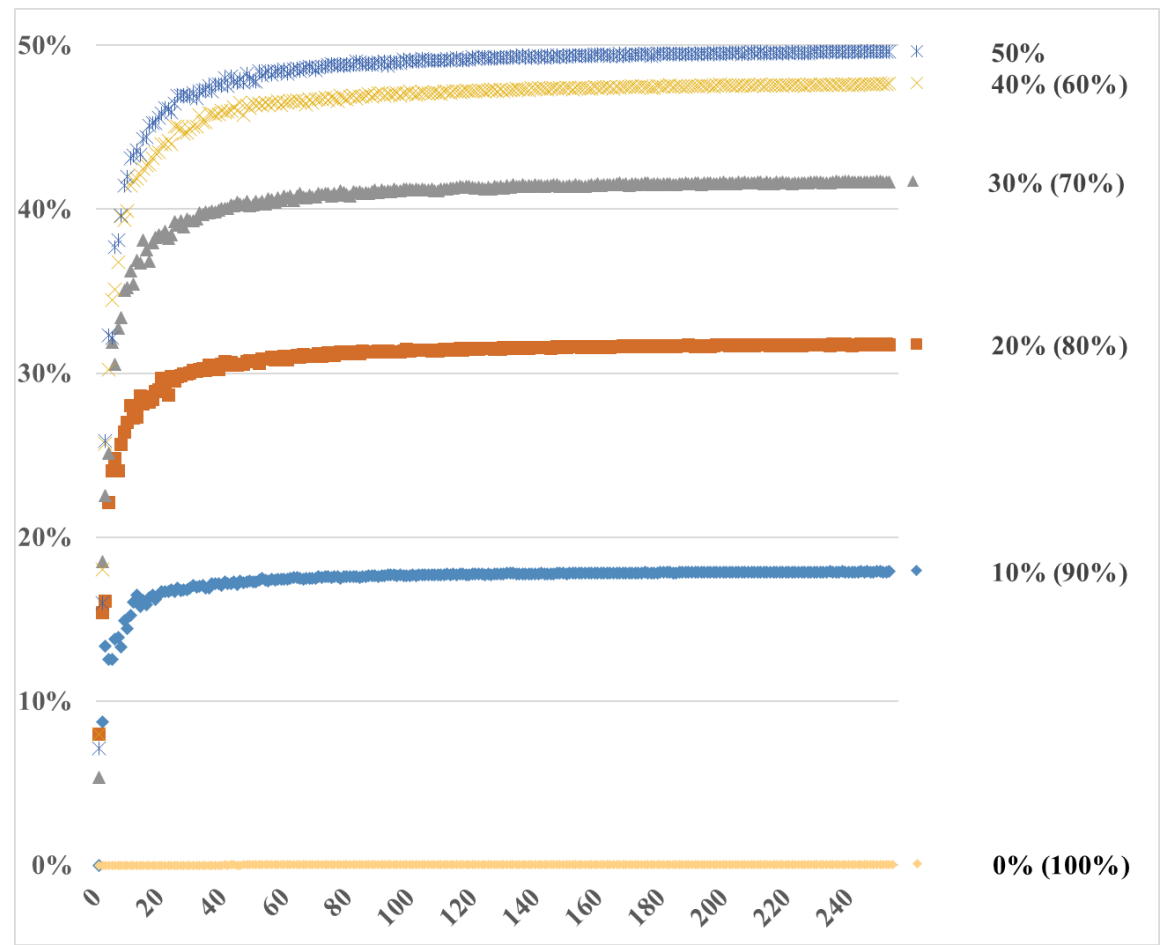

(b)

Figure D.5: Mean pixel error (vertical axis) of the intlinprog (a) and the SA (b) methods for different image sizes (horizontal axis). 


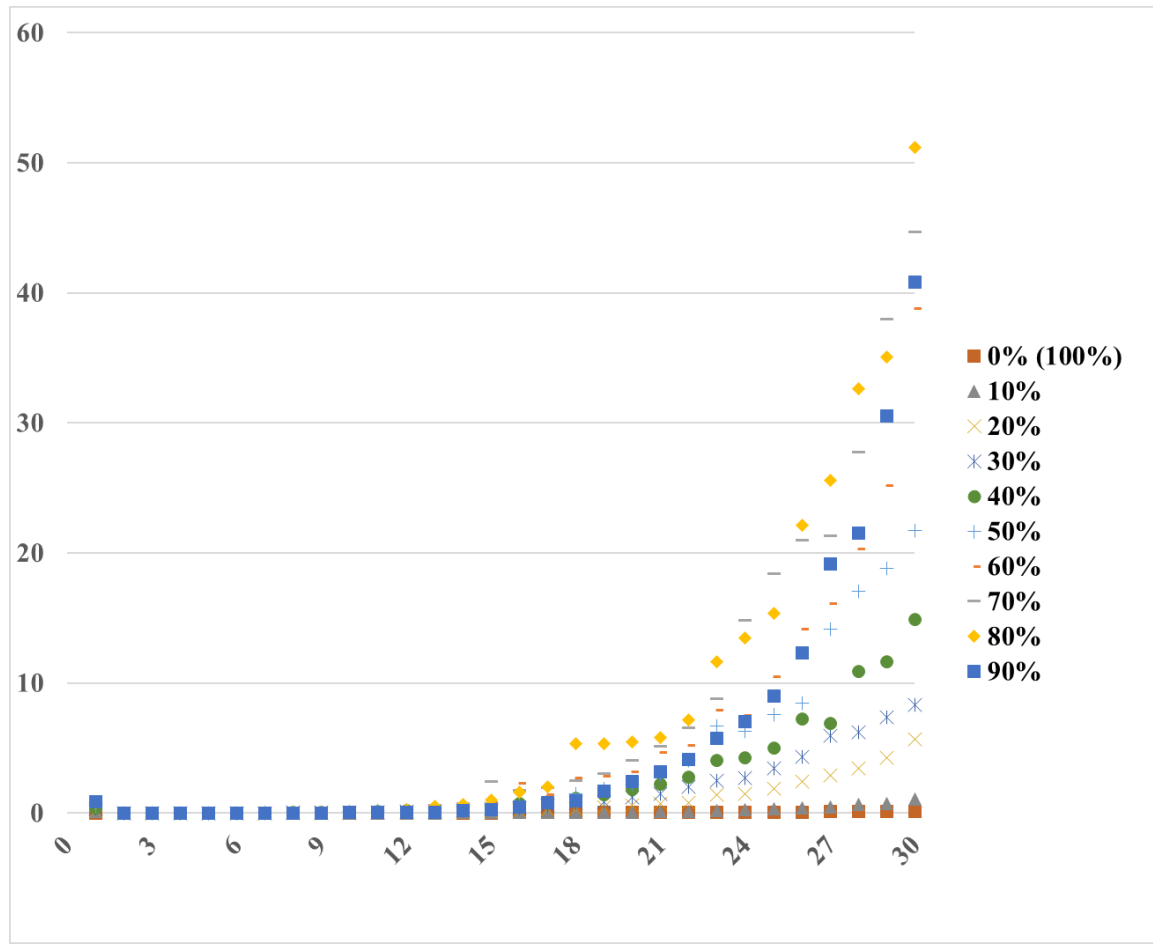

(a)

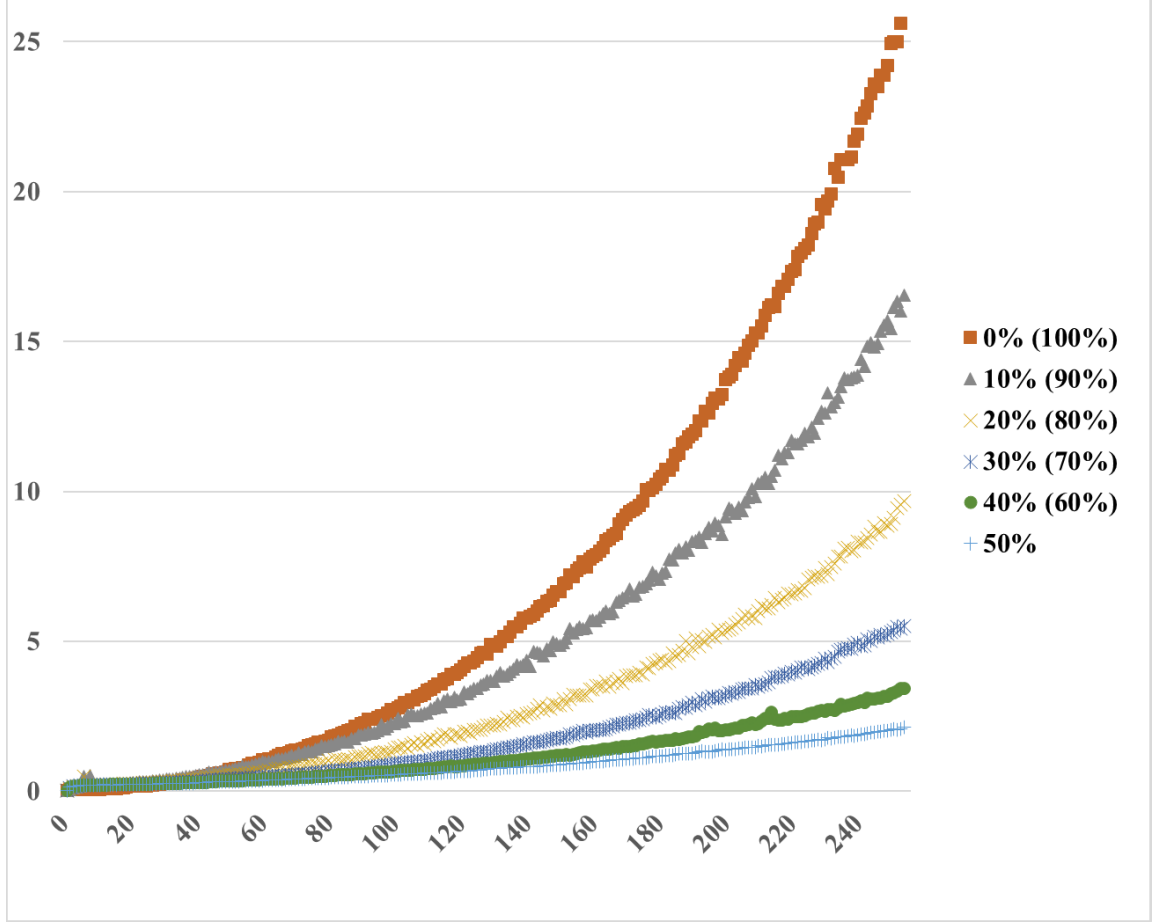

(b)

Figure D.6: Mean running time in seconds (vertical axis) of the intlinprog (a) and BasicSA (b) methods for different image sizes (horizontal axis). 


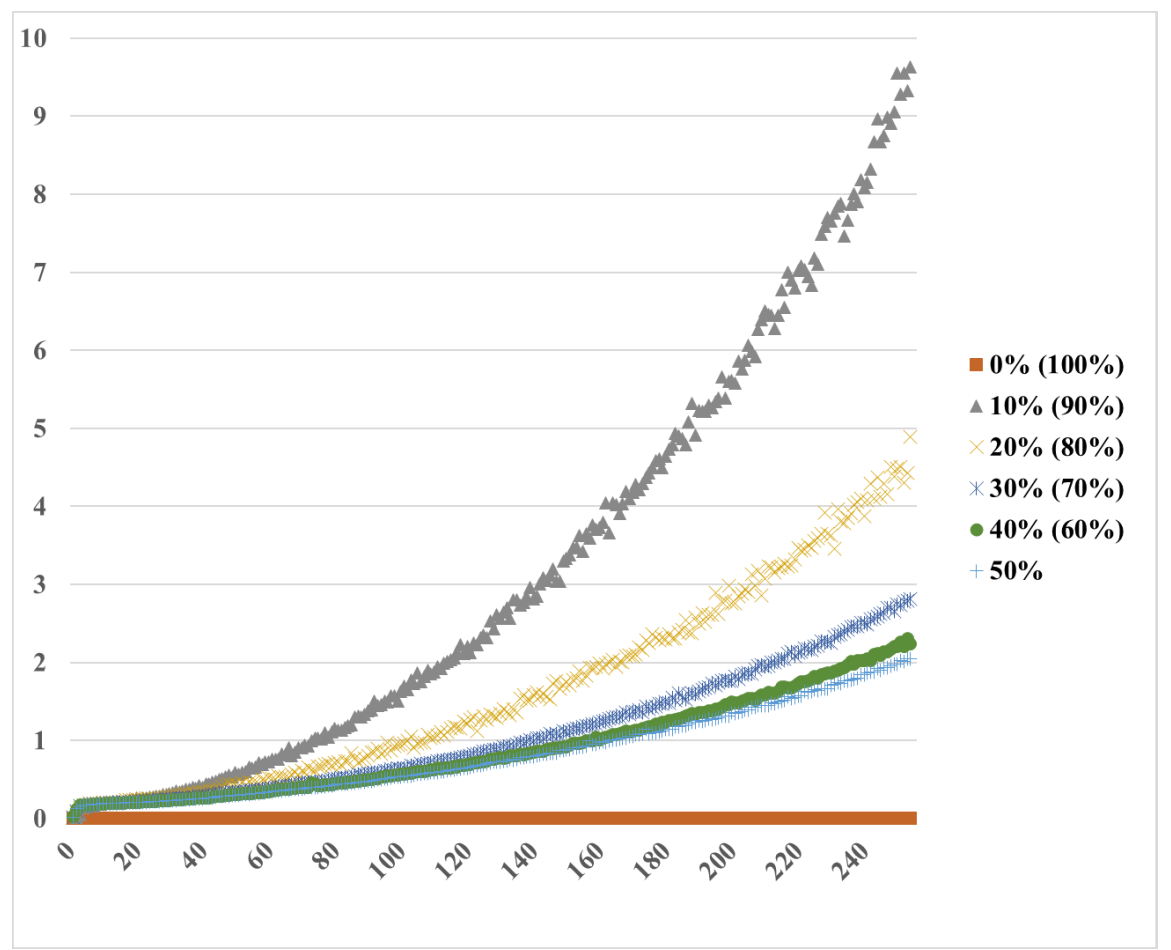

(c)

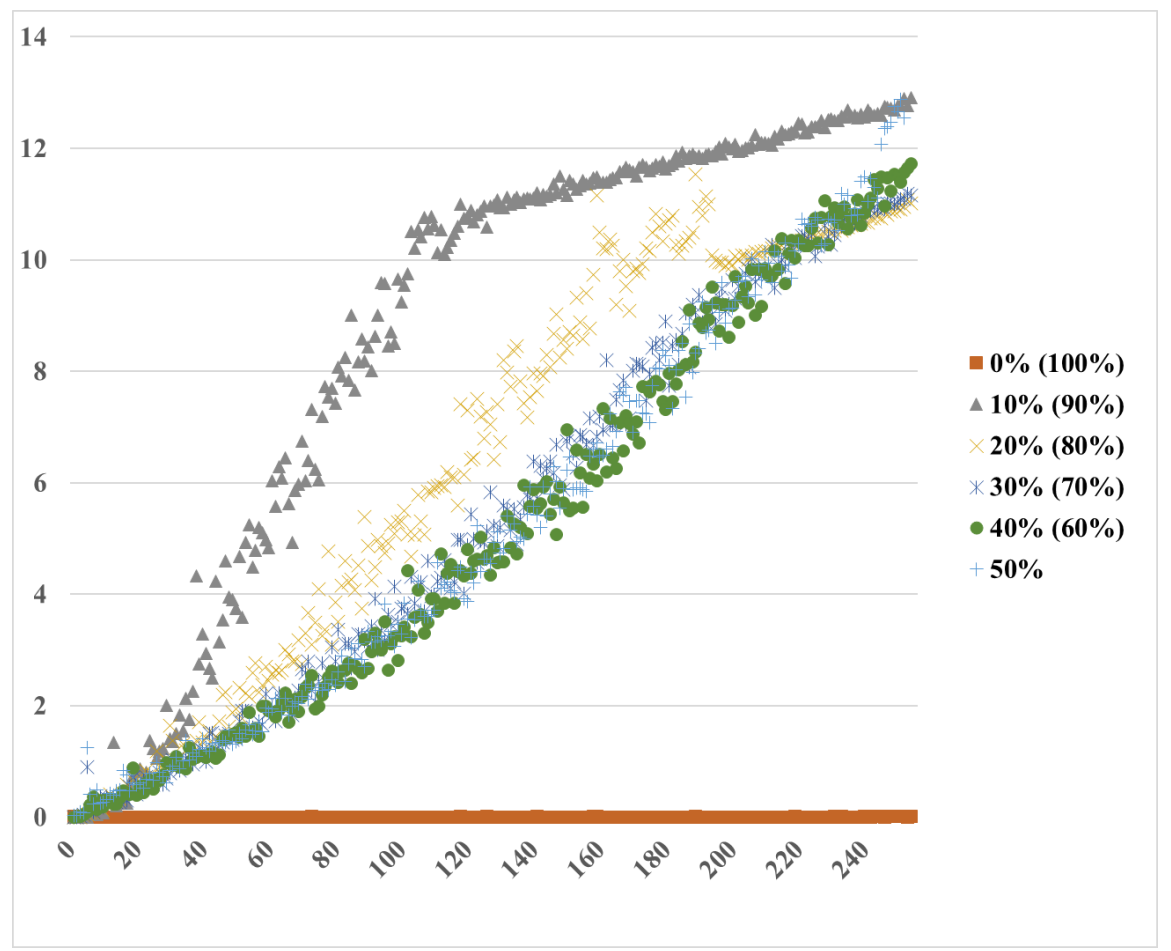

(d)

Figure D.6: Mean running time in seconds (vertical axis) of the FixpixelSA (c) and RyserSA (d) methods for different image sizes (horizontal axis). 


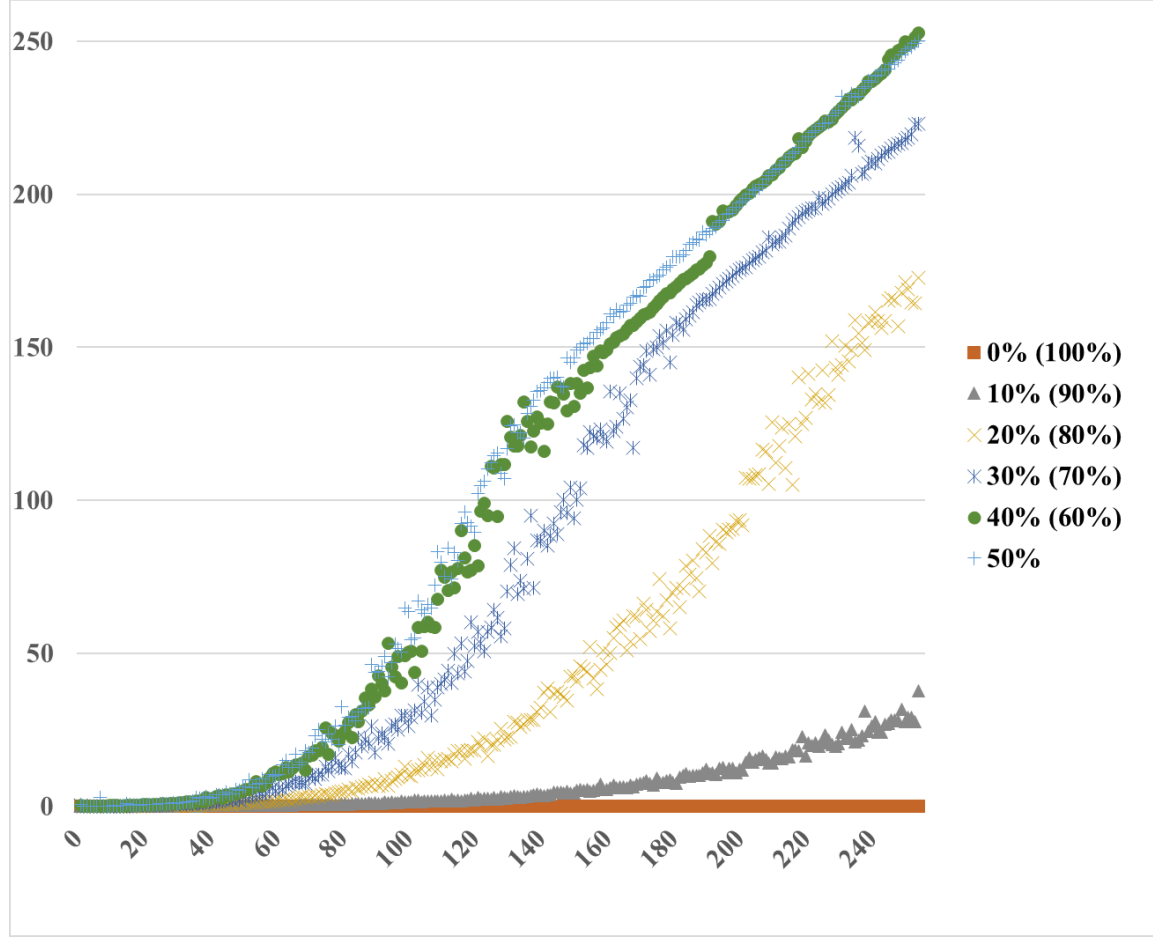

(e)

Figure D.6: Mean running time in seconds (vertical axis) of the CurveballSA (e) method for different image sizes (horizontal axis). 


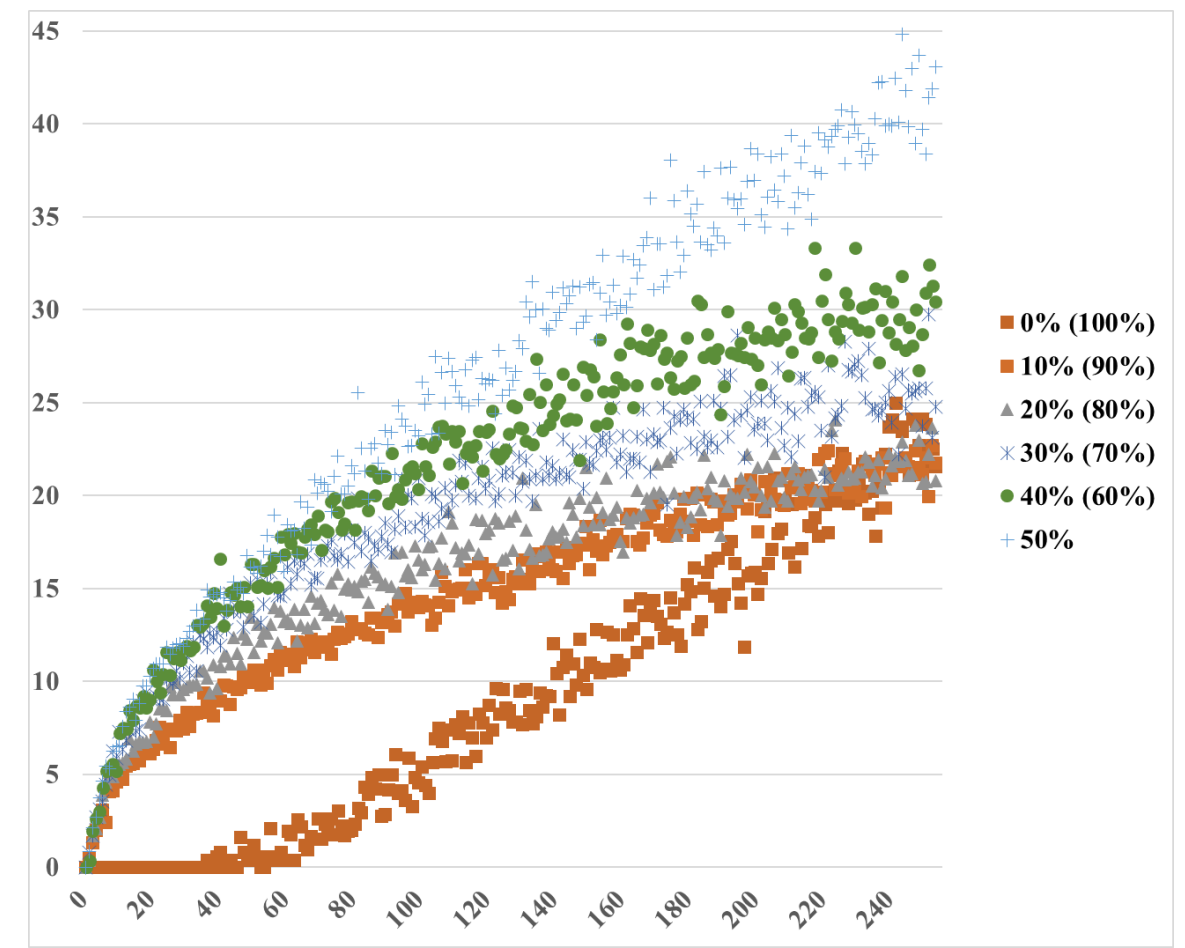

(a)

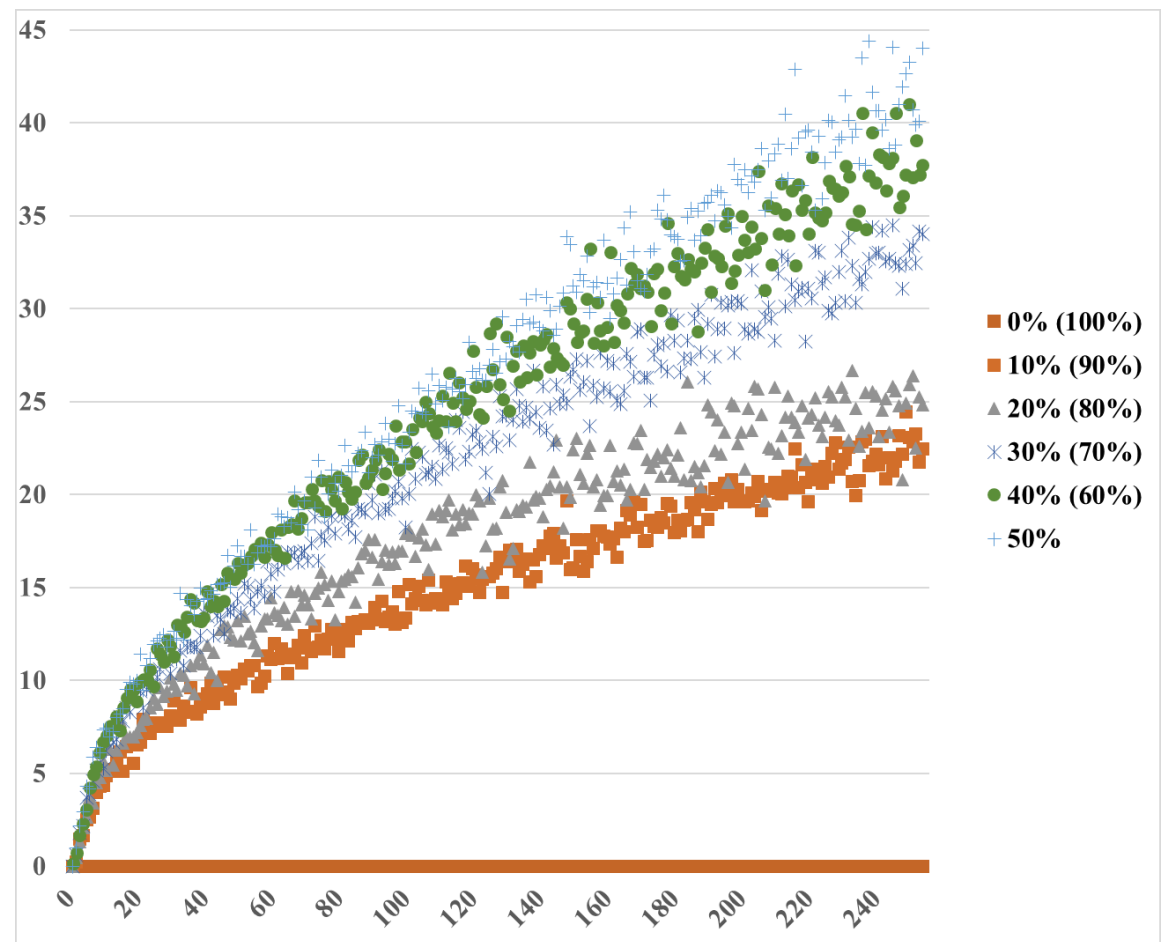

(b)

Figure D.7: Mean final objective value (vertical axis) of the BasicSA (a) and FixpixelSA (b) methods for different image sizes (horizontal axis) 


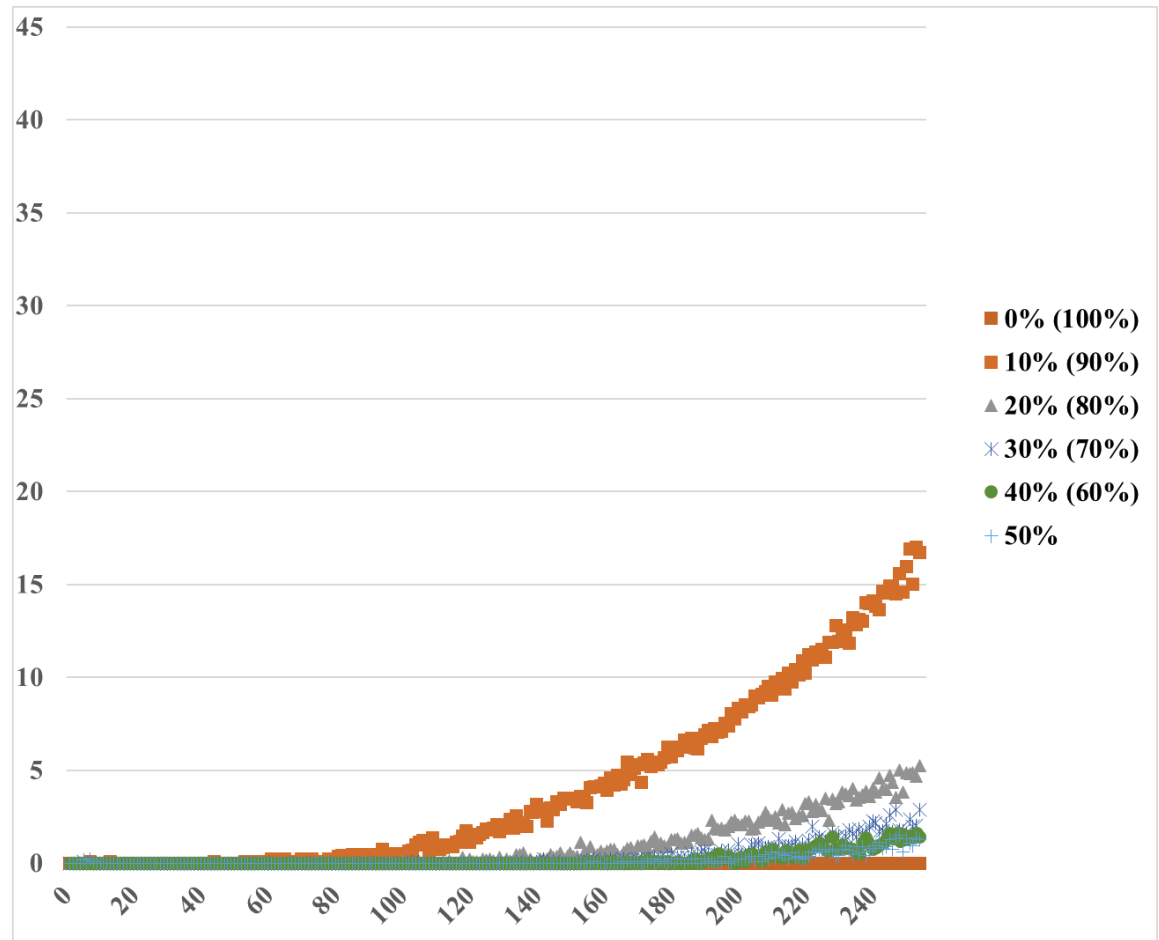

(c)

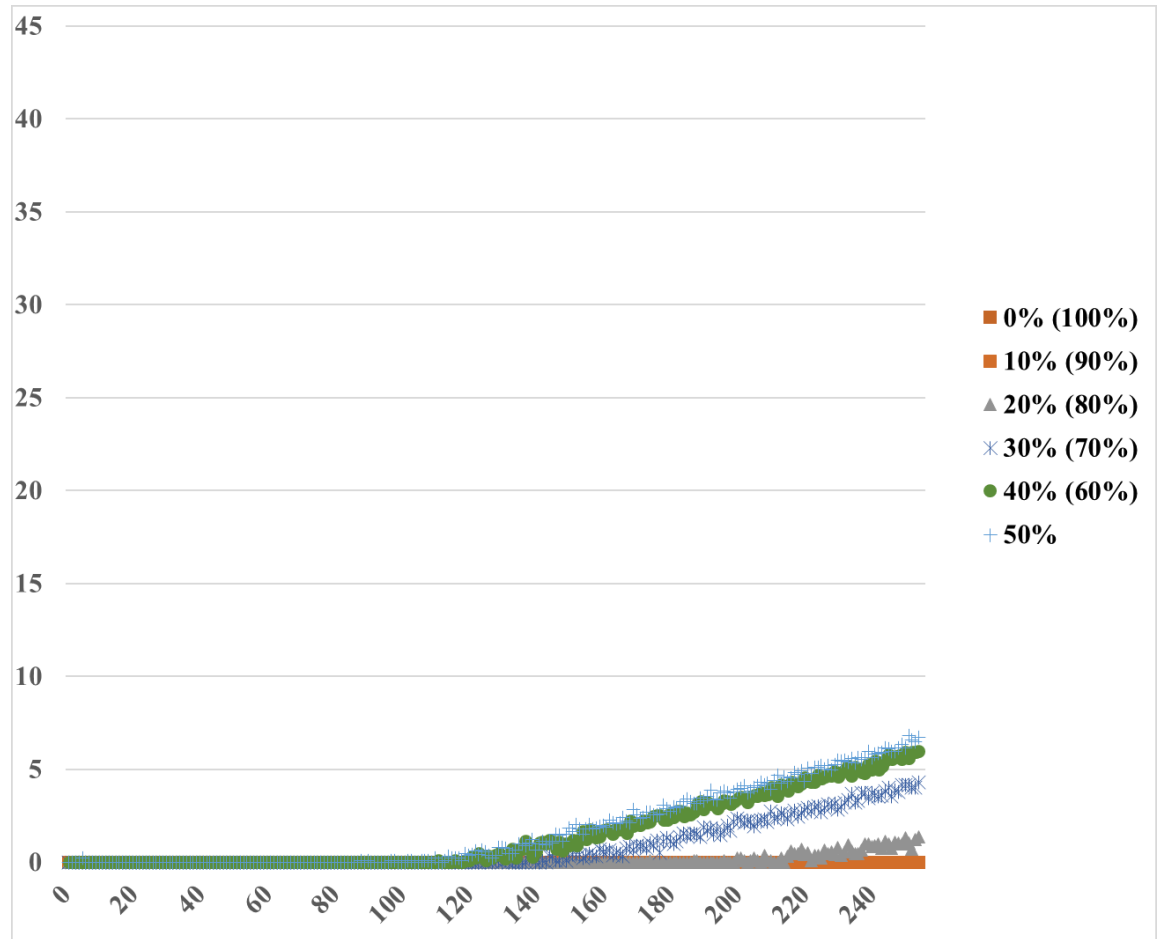

(d)

Figure D.7: Mean final objective value (vertical axis) of the RyserSA (c) and CurveballSA (d) methods for different image sizes (horizontal axis) 


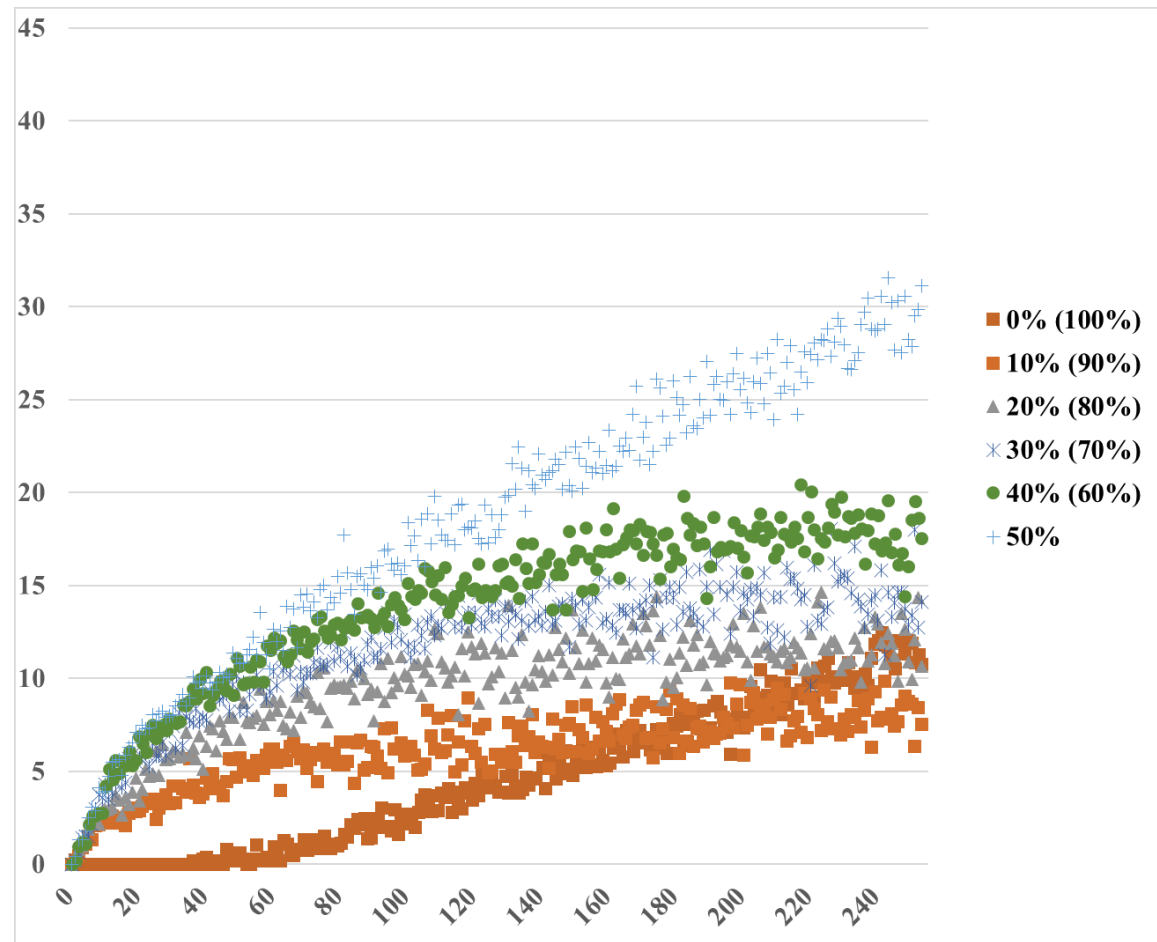

(a)

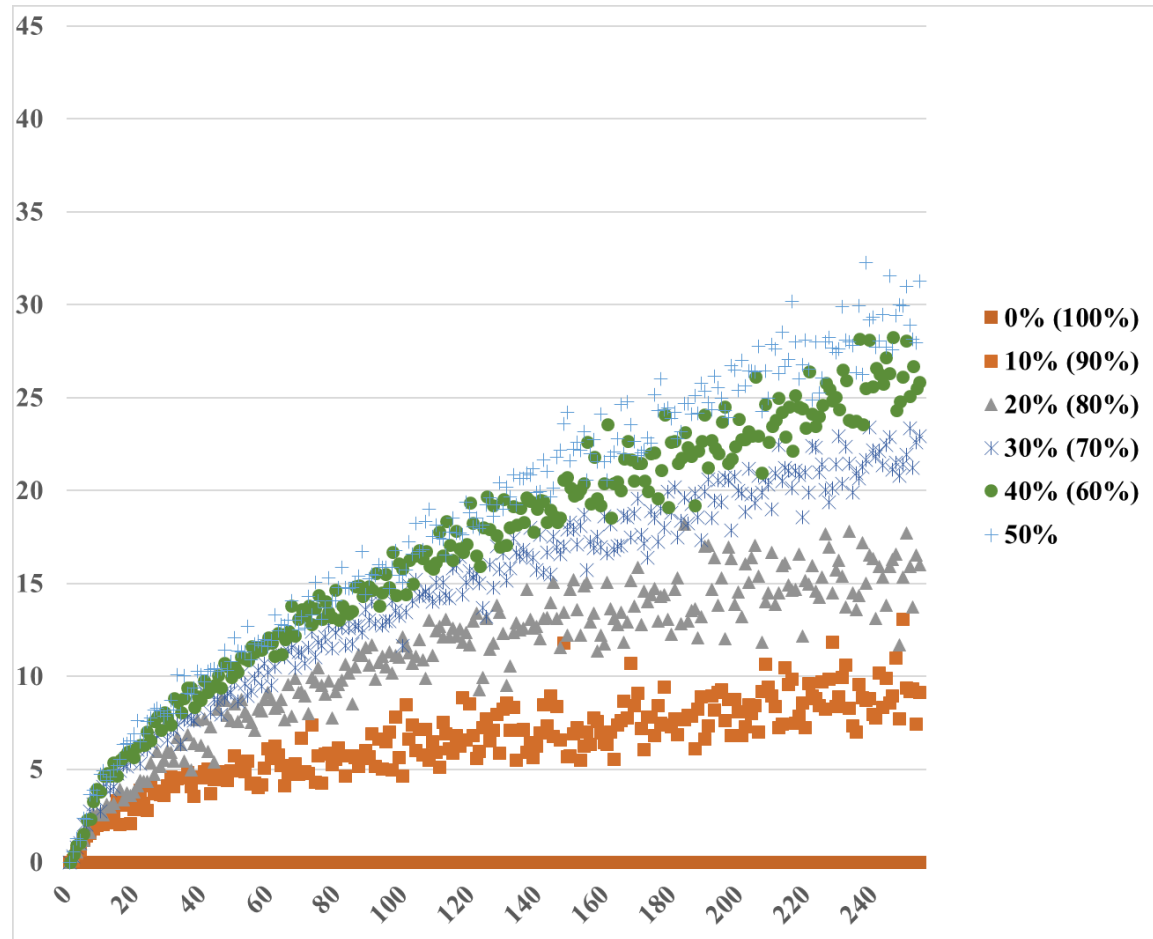

(b)

Figure D.8: Mean strip difference (vertical axis) of the BasicSA

(a) and FixpixelSA (b) methods for different image sizes (horizontal axis). 


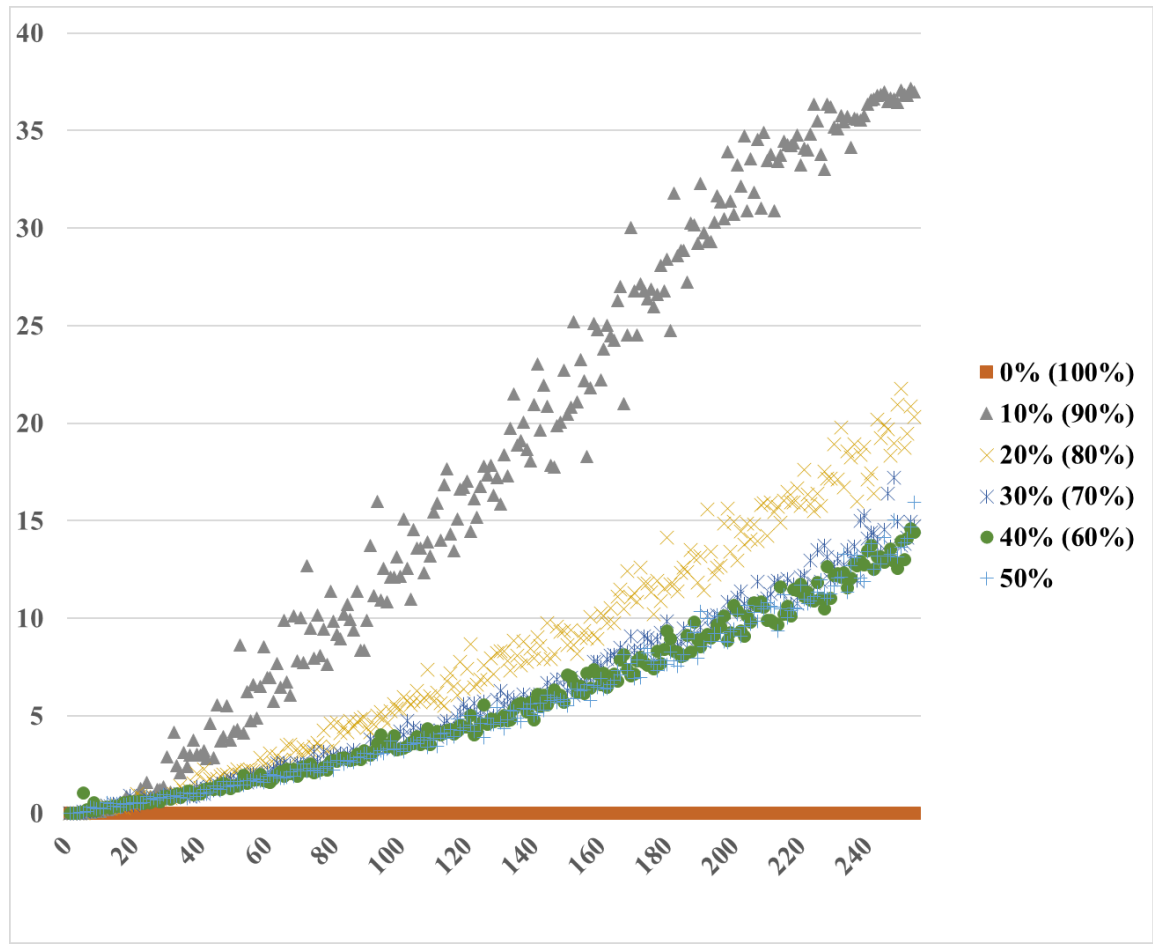

(a)

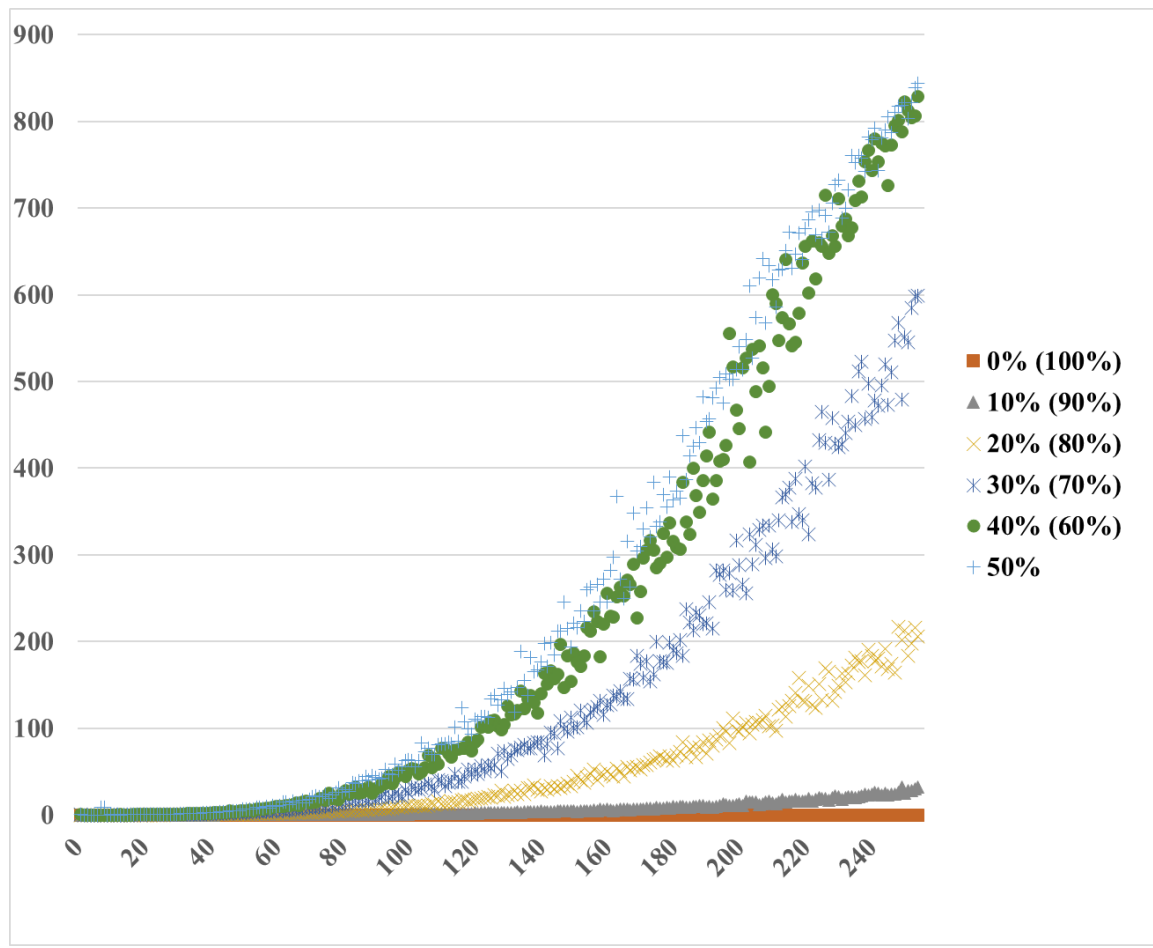

(b)

Figure D.9: Mean running time in seconds RyserSA (a) and CurveballSA (b) methods for different image sizes (horizontal axis). 


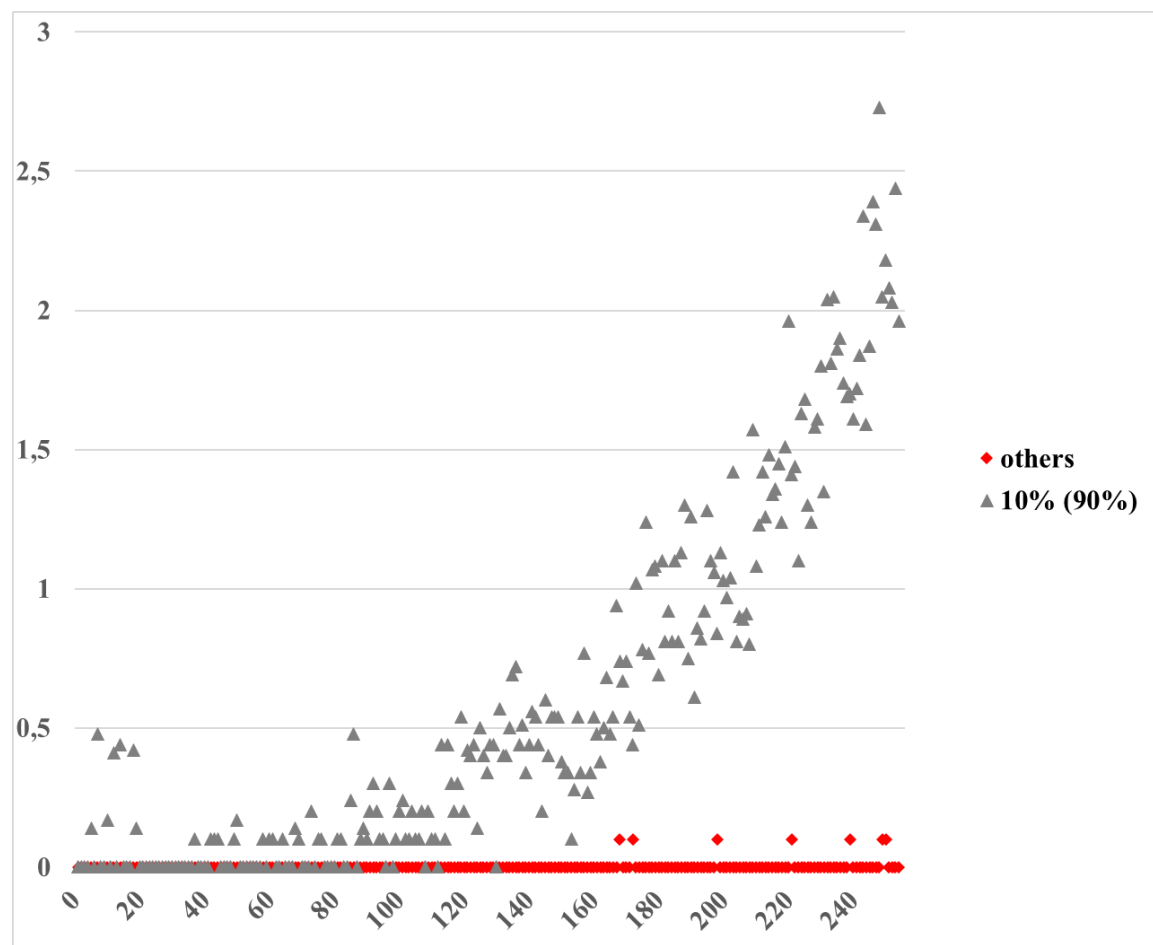

(a)

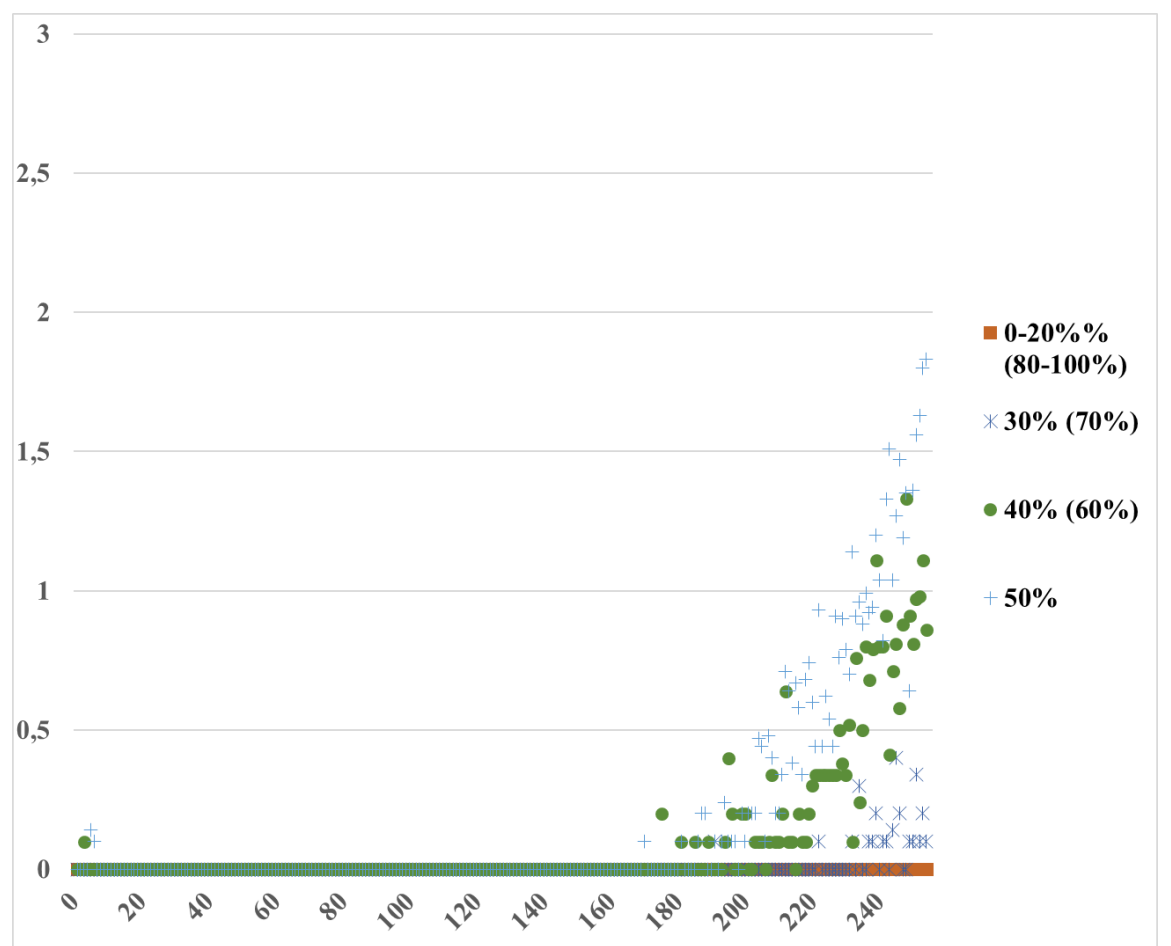

(b)

Figure D.10: Mean final objective value (vertical axis) of the RyserSA (a) and CurveballSA (b) methods for different image sizes (horizontal axis). 
Appendix E

Tables 


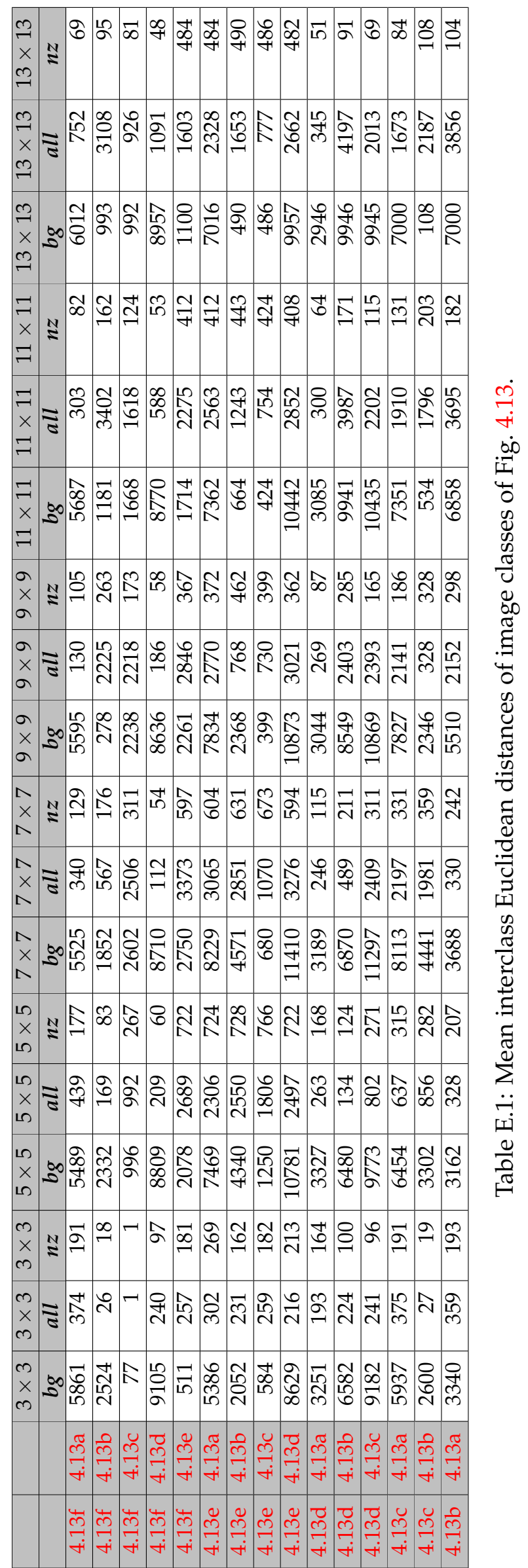




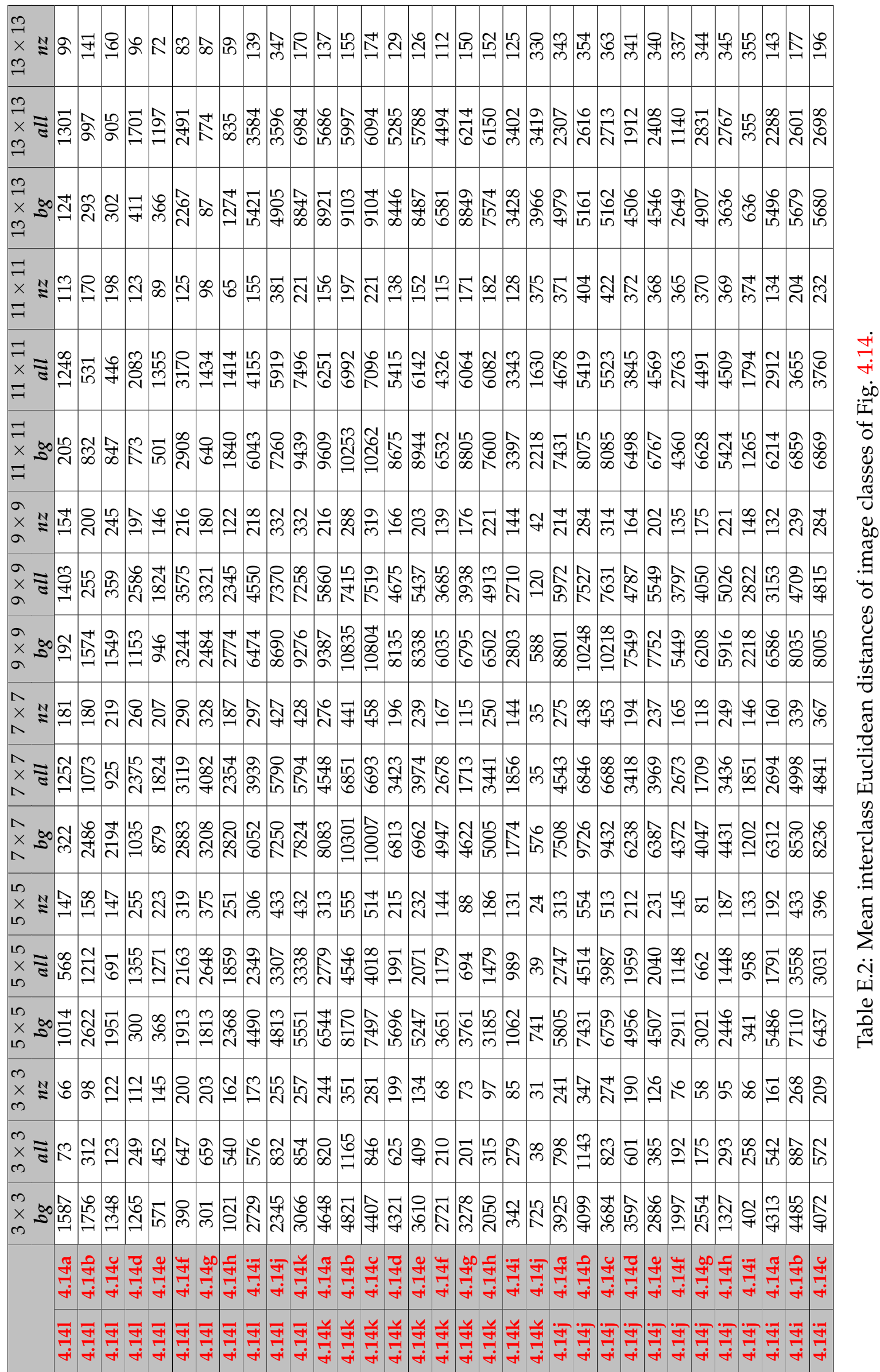




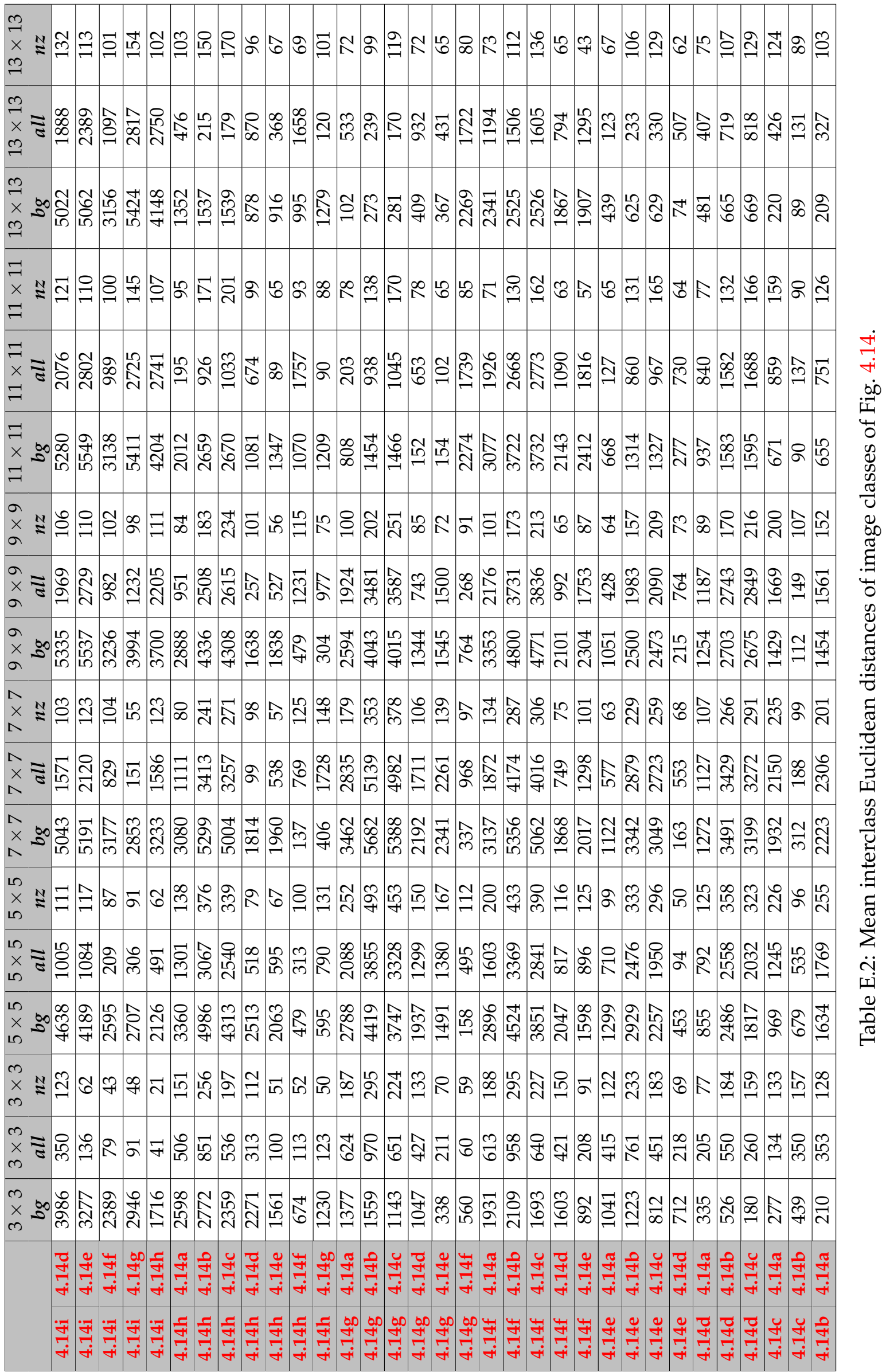




\section{Bibliography}

[1] Timo Ahonen and Matti Pietikäinen. "Soft histograms for local binary patterns". In: Proceedings of the Finnish signal processing symposium, FINSIG. Vol. 5. 9. 2007, pp. 1-4.

[2] Sakari Alenius, Ulla Ruotsalainen, and Jaakko Astola. “Using local median as the location of the prior distribution in iterative emission tomography image reconstruction". In: IEEE Transactions on Nuclear Science 45.6 (1998), pp. 3097-3104.

[3] Francisco J. A. Artacho, Jonathan M. Borwein, and Matthew K. Tam. "Recent results on Douglas-Rachford methods for combinatorial optimization problems". In: Journal of Optimization Theory and Applications 163.1 (2014), pp. 1-30.

[4] Norbert Babcsan et al. "Characterisation of ALUHAB aluminium foams with micro-CT". In: Procedia Mater. Sci 4 (2014), pp. 67-72.

[5] Perrine Babin et al. "In situ fast X-ray tomography study of the evolution of cellular structure in bread dough during proving and baking". In: Bubbles in Food 2. Elsevier, 2008, pp. 265-272.

[6] Péter Balázs and Sara Brunetti. "A measure of Q-convexity". In: International Conference on Discrete Geometry for Computer Imagery. Springer. 2016, pp. 219-230.

[7] Péter Balázs and Sara Brunetti. "A new shape descriptor based on a q-convexity measure". In: International Conference on Discrete Geometry for Computer Imagery. Springer. 2017, pp. 267-278.

[8] Péter Balázs and Judit Szúcs. "Reconstruction of Binary Images with Fixed Number of Strips". In: International Conference Image Analysis and Recognition. Springer. 2018, pp. 11-19.

[9] Péter Balázs et al. "A measure of directional convexity inspired by binary tomography". In: Fundamenta Informaticae 141.2-3 (2015), pp. 151167.

[10] Kees J. Batenburg and Walter A. Kosters. "Solving Nonograms by combining relaxations". In: Pattern Recognition 42.8 (2009), pp. 16721683.

[11] Kees J. Batenburg and Walter A. Kosters. “On the difficulty of Nonograms". In: ICGA Journal 35.4 (2012), pp. 195-205.

[12] Kees J. Batenburg and Jan Sijbers. "DART: a practical reconstruction algorithm for discrete tomography". In: IEEE Transactions on Image Processing 20.9 (2011), pp. 2542-2553. 
[13] Herbert Bay, Tinne Tuytelaars, and Luc Van Gool. "Surf: Speeded up robust features". In: European conference on computer vision. Springer. 2006, pp. 404-417.

[14] Daniel Berend et al. "Nonograms: Combinatorial questions and algorithms". In: Discrete Applied Mathematics 169 (2014), pp. 30-42.

[15] Isabelle Bloch. "Fuzzy sets for image processing and understanding". In: Fuzzy Sets and Systems 281 (2015), pp. 280-291.

[16] Isabelle Bloch, Olivier Colliot, and Roberto M. Cesar. "On the ternary spatial relation" Between"'. In: IEEE Transactions on Systems, Man, and Cybernetics, Part B (Cybernetics) 36.2 (2006), pp. 312-327.

[17] Laurence Boxer. "Computing deviations from convexity in polygons". In: Pattern Recognition Letters 14.3 (1993), pp. 163-167.

[18] Phil Brodatz. Textures: a photographic album for artists and designers. Dover Pubns, 1966.

[19] Sara Brunetti, Péter Balázs, and Péter Bodnár. "Extension of a onedimensional convexity measure to two dimensions". In: International Conference on Discrete Geometry for Computer Imagery. Springer. 2017, pp. 219-230.

[20] Sara Brunetti and Alain Daurat. "An algorithm reconstructing convex lattice sets". In: Theoretical Computer Science 304.1-3 (2003), pp. 35-57.

[21] Sara Brunetti and Alain Daurat. "Reconstruction of convex lattice sets from tomographic projections in quartic time". In: Theoretical Computer Science 406.1-2 (2008), pp. 55-62.

[22] Sara Brunetti et al. "Reconstruction of 4-and 8-connected convex discrete sets from row and column projections". In: Linear Algebra and its Applications 339.1-3 (2001), pp. 37-57.

[23] Sara Brunetti et al. "A Spatial Convexity Descriptor for Object Enlacement". In: International Conference on Discrete Geometry for Computer Imagery. Springer. 2019, pp. 330-342.

[24] Tom Bultreys and Wesley De Boever. Belgian Fieldstone. http: / /www . digitalrocksportal .org/projects/297. 2020.

[25] Corrie J. Carstens. "Proof of uniform sampling of binary matrices with fixed row sums and column sums for the fast curveball algorithm". In: Physical Review E 91.4: 042812 (2015).

[26] Corrie J. Carstens, Annabell Berger, and Giovanni Strona. "A unifying framework for fast randomization of ecological networks with fixed (node) degrees". In: MethodsX 5 (2018), pp. 773-780.

[27] Chung Chan et al. "Regularized image reconstruction with an anatomically adaptive prior for positron emission tomography". In: Physics in Medicine E Biology 54.24: 7379 (2009).

[28] Abraham Chawanji et al. "Use of X-ray micro tomography to study the microstructure of loose-packed and compacted milk powders". In: Journal of microscopy 248 (Aug. 2012), pp. 49-57. 
[29] Michaël Clément, Camille Kurtz, and Laurent Wendling. "Fuzzy directional enlacement landscapes". In: International Conference on Discrete Geometry for Computer Imagery. Springer. 2017, pp. 171-182.

[30] Michaël Clément et al. "Directional Enlacement Histograms for the Description of Complex Spatial Configurations between Objects". In: IEEE Transactions on Pattern Analysis and Machine Intelligence 39.12 (2017), pp. 2366-2380.

[31] Geir Dahl and Truls Flatberg. "Optimization and reconstruction of hvconvex (0,1)-matrices". In: Discrete applied mathematics 151.1-3 (2005), pp. 93-105.

[32] Navneet Dalal and Bill Triggs. "Histograms of oriented gradients for human detection". In: 2005 IEEE computer society conference on computer vision and pattern recognition (CVPR'05). Vol. 1. IEEE. 2005, pp. 886893.

[33] Alain Daurat. "Salient points of Q-convex sets". In: International journal of pattern recognition and artificial intelligence 15.07 (2001), pp. 10231030.

[34] Alain Daurat and Maurice Nivat. "Salient and reentrant points of discrete sets". In: Electronic Notes in Discrete Mathematics 12 (2003), pp. 208219.

[35] Digital Rocks Portal. https://www.digitalrocksportal.org.

[36] Frank Eibe, Mark A. Hall, and Ian H. Witten. "The WEKA workbench. Online appendix for data mining: practical machine learning tools and techniques". In: Morgan Kaufmann. 2016.

[37] Muhammad M. Fraz et al. "An ensemble classification-based approach applied to retinal blood vessel segmentation". In: IEEE Transactions on Biomedical Engineering 59.9 (2012), pp. 2538-2548.

[38] Kuang Gong et al. "PET image reconstruction using deep image prior". In: IEEE transactions on medical imaging 38.7 (2018), pp. 1655-1665.

[39] Richard Gordon, Robert Bender, and Gabor T. Herman. "Algebraic reconstruction techniques (ART) for three-dimensional electron microscopy and X-ray photography". In: Journal of theoretical Biology 29.3 (1970), pp. 471-481.

[40] Lena Gorelick et al. "Convexity shape prior for segmentation”. In: European Conference on Computer Vision. Springer. 2014, pp. 675-690.

[41] Lena Gorelick et al. "Convexity shape prior for binary segmentation". In: IEEE transactions on pattern analysis and machine intelligence 39.2 (2016), pp. 258-271.

[42] Enyu Guo et al. "Synchrotron X-ray tomographic quantification of microstructural evolution in ice cream-a multi-phase soft solid". In: Rsc Advances 7.25 (2017), pp. 15561-15573.

[43] Gabor T. Herman. Fundamentals of computerized tomography: image reconstruction from projections. Springer Science \& Business Media, 2009. 
[44] Gabor T. Herman and Attila Kuba. Discrete Tomography: Foundations, Algorithms, and Applications. Springer Science \& Business Media, 1999.

[45] Gabor T. Herman and Attila Kuba. Advances in discrete tomography and its applications. Springer Science \& Business Media, 2008.

[46] Changwu Huang, Yuanxiang Li, and Xin Yao. "A survey of automatic parameter tuning methods for metaheuristics". In: IEEE Transactions on Evolutionary Computation 24.2 (2019), pp. 201-216.

[47] Dimitris Iakovidis, Eystratios Keramidas, and Dimitris Maroulis. "Fuzzy local binary patterns for ultrasound texture characterization". In: Image Analysis and Recognition (2008), pp. 750-759.

[48] Avinash C. Kak and Malcolm Slaney. "Principles of computerized tomographic imaging. 1988". In: IEEE, New York (1988).

[49] Hasan Khan, Masa Prodanovic, and David Dicarlo. Particulate straining in simple porous media. http : / / www . digitalrocksportal . org / projects/51. 2016.

[50] Scott Kirkpatrick, C. Daniel Gelatt, and Mario P. Vecchi. “Optimization by simulated annealing”. In: Science 220.4598 (1983), pp. 671-680.

[51] Zoltán Kiss et al. "Reconstruction of pixel-based and geometric objects by discrete tomography. Simulation and physical experiments". In: Electronic Notes in Discrete Mathematics 20 (2005), pp. 475-491.

[52] Attila Kuba et al. "Medical applications of discrete tomography". In: Discrete Mathematical Problems with Medical Applications, DIMACS Series in Discrete Mathematics and Theoretical Computer Science, AMS 55 (2000), pp. 195-208.

[53] Gustaf Kylberg. FLBP and SLBP implementations for MATLAB. http: //www.cb.uu.se/ gustaf/textureDescriptors/.

[54] Gustaf Kylberg and Ida-Maria Sintorn. "Evaluation of noise robustness for local binary pattern descriptors in texture classification". In: EURASIP Journal on Image and Video Processing 2013.1: 17 (2013).

[55] Longin J. Latecki and Rolf Lakämper. "Convexity rule for shape decomposition based on discrete contour evolution". In: Computer Vision and Image Understanding 73.3 (1999), pp. 441-454.

[56] Tibor Lukić and Péter Balázs. "Binary tomography reconstruction based on shape orientation". In: Pattern Recognition Letters 79 (2016), pp. 1824.

[57] Tibor Lukić and Anikó Lukity. "A spectral projected gradient optimization for binary tomography". In: Computational Intelligence in Engineering. Springer, 2010, pp. 263-272.

[58] Tibor Lukić, Anikó Lukity, and László Gogolák. “Binary tomography reconstruction method with perimeter preserving regularization". In: Proceedings of the 8th Conference of the Hungarian Association for Image Processing and Pattern Recognition. 2011, pp. 83-91. 
[59] Jianhua Ma et al. "Iterative image reconstruction for cerebral perfusion CT using a pre-contrast scan induced edge-preserving prior". In: Physics in Medicine \& Biology 57.22 (2012), pp. 7519-7542.

[60] Pascal Matsakis, Laurent Wendling, and JingBo Ni. "A general approach to the fuzzy modeling of spatial relationships". In: Methods for handling imperfect spatial information. Springer, 2010, pp. 49-74.

[61] Rakesh Mehta and Karen Egiazarian. "Dominant rotated local binary patterns (DRLBP) for texture classification". In: Pattern Recognition Letters 71 (2016), pp. 16-22.

[62] Chul Moon and Matthew Andrew. Bentheimer networks. http://www. digitalrocksportal.org/projects/223. 2019.

[63] Chul Moon and Matthew Andrew. Intergranular Pore Structures in Sandstones. http://www. digitalrocksportal. org/projects/222. 2019.

[64] Loris Nanni, Alessandra Lumini, and Sheryl Brahnam. "Survey on LBP based texture descriptors for image classification". In: Expert Systems with Applications 39.3 (2012), pp. 3634-3641.

[65] Thanh P. Nguyen et al. "A Projection-Based Method for Shape Measurement". In: Journal of Mathematical Imaging and Vision (2020), pp. 116.

[66] Jan Odstrcilik et al. "Retinal vessel segmentation by improved matched filtering: evaluation on a new high-resolution fundus image database". In: IET Image Processing 7.4 (2013), pp. 373-383.

[67] Timo Ojala, Matti Pietikäinen, and David Harwood. "A comparative study of texture measures with classification based on featured distributions". In: Pattern Recognition 29.1 (1996), pp. 51-59.

[68] Timo Ojala, Matti Pietikäinen, and Topi Maenpaa. "Multiresolution gray-scale and rotation invariant texture classification with local binary patterns". In: IEEE Transactions on pattern analysis and machine intelligence 24.7 (2002), pp. 971-987.

[69] Emilio G. Ortiz-García et al. "Automated generation and visualization of picture-logic puzzles". In: Computers \& Graphics 31.5 (2007), pp. 750-760.

[70] Moon-Won Park and Yeong-Dae Kim. "A systematic procedure for setting parameters in simulated annealing algorithms". In: Computers E Operations Research 25.3 (1998), pp. 207-217.

[71] Shuai-jun Peng and Zhi-fang Wu. "Research on the CT image reconstruction of steel tube section from few projections". In: NDT E E International 42.5 (2009), pp. 435-440.

[72] Esa Rahtu, Mikko Salo, and Janne Heikkila. "A new convexity measure based on a probabilistic interpretation of images". In: IEEE Transactions on Pattern Analysis and Machine Intelligence 28.9 (2006), pp. 15011512. 
[73] Paul L. Rosin and Joviša Žunić. "Probabilistic convexity measure". In: IET image processing 1.2 (2007), pp. 182-188.

[74] Herbert J. Ryser. "Combinatorial properties of matrices of zeros and ones". In: Canadian Journal of Mathematics 9 (1957), pp. 371-377.

[75] Burkhard Schillinger. "Proposed combination of CAD data and discrete tomography for the detection of coking and lubricants in turbine blades or engines". In: Electronic Notes in Discrete Mathematics 20 (2005), pp. 493-499.

[76] Thomas Schüle et al. "Discrete tomography by convex-concave regularization and DC programming". In: Discrete Applied Mathematics 151.1-3 (2005), pp. 229-243.

[77] E. S. Skakov and V. N. Malysh. "Parameter meta-optimization of metaheuristics of solving specific NP-hard facility location problem". In: J. Phys. Conf. Series. Vol. 973. 012063. 2018.

[78] Milan Šonka, Václav Hlaváč, and Roger Boyle. Image Processing, Analysis, and Machine Vision, International Student Edition. 2008.

[79] Milan Šonka, Vaclav Hlavac, and Roger Boyle. Image processing, analysis, and machine vision. Cengage Learning, 2014.

[80] Joes Staal et al. "Ridge-based vessel segmentation in color images of the retina". In: IEEE transactions on medical imaging 23.4 (2004), pp. 501509.

[81] Helman I. Stern. "Polygonal entropy: a convexity measure". In: Pattern Recognition Letters 10.4 (1989), pp. 229-235.

[82] Giovanni Strona et al. "A fast and unbiased procedure to randomize ecological binary matrices with fixed row and column totals". In: $\mathrm{Na}$ ture communications 5.1 (2014), pp. 1-9.

[83] Judit Szúcs and Péter Balázs. “Binary Image Reconstruction Using Local Binary Pattern Priors". In: International Journal of Circuits, Systems and Signal Processing 11 (2017), pp. 296-299.

[84] Judit Szúcs and Péter Balázs. "An Improved Simulated Annealing Approach for Reconstructing Binary Images with Fixed Number of Strips". In: International Conference on Image Analysis and Recognition. Springer. 2019, pp. 174-185.

[85] Judit Szúcs and Péter Balázs. "Binary Tomography Using Variants of Local Binary Patterns as Texture Priors". In: International Conference on Computer Analysis of Images and Patterns. Springer. 2019, pp. 141-154.

[86] Judit Szúcs and Péter Balázs. "Variants of Simulated Annealing for Strip Constrained Binary Tomography". In: Lecture Notes in Computer Science 10986. 2019, pp. 1-11.

[87] Judit Szúcs and Péter Balázs. "Local Q-Convexity Histograms for Shape Analysis". In: International Workshop on Combinatorial Image Analysis. Springer. 2020, pp. 245-257. 
[88] Judit Szúcs and Péter Balázs. "Local Q-Concavity Histograms for Binary Image Classification and Reconstruction". In: Submitted to The Visual Computer (2021).

[89] Tamás S. Tasi, László G. Nyúl, and Péter Balázs. "Directional convexity measure for binary tomography". In: Iberoamerican Congress on Pattern Recognition. Springer. 2013, pp. 9-16.

[90] Nobuhisa Ueda and Tadaaki Nagao. "NP-completeness results for NONOGRAM via parsimonious reductions". In: preprint (1996).

[91] Wim Van Aarle et al. "A 3-dimensional discrete tomography approach for superresolution micro-CT images: application to foams". In: The first international conference on image formation in X-ray computed tomography. Citeseer. 2010, pp. 45-48.

[92] Wim Van Aarle et al. "The ASTRA Toolbox: A platform for advanced algorithm development in electron tomography". In: Ultramicroscopy 157 (2015), pp. 35-47.

[93] Wim Van Aarle et al. "Fast and flexible X-ray tomography using the ASTRA toolbox". In: Optics express 24.22 (2016), pp. 25129-25147.

[94] László G. Varga et al. "Local and global uncertainty in binary tomographic reconstruction". In: Computer Vision and Image Understanding 129 (2014). Special section: Advances in Discrete Geometry for Computer Imagery, pp. 52-62.

[95] Ben M. Waller, Mark S. Nixon, and John N. Carter. "Image reconstruction from local binary patterns". In: 2013 International Conference on Signal-Image Technology \& Internet-Based Systems. IEEE. 2013, pp. 118123.

[96] Jing Wang, Tianfang $\mathrm{Li}$, and Lei Xing. "Iterative image reconstruction for CBCT using edge-preserving prior". In: Medical physics 36.1 (2009), pp. 252-260.

[97] Wen-Li Wang and Mei-Huei Tang. "Simulated annealing approach to solve nonogram puzzles with multiple solutions". In: Procedia Computer Science 36 (2014), pp. 541-548.

[98] Gerhard J. Woeginger. "The reconstruction of polyominoes from their orthogonal projections". In: Information Processing Letters 77.5-6 (2001), pp. 225-229.

[99] Jan Wolter. Survey of paint-by-numbers puzzle solvers. http://webpbn . $\mathrm{com} /$ survey/index.html.

[100] Jan Wolter. Web Paint-by-Number. https://webpbn.com/.

[101] I-Chen $\mathrm{Wu}$ et al. "An Efficient Approach to Solving Nonograms". In: IEEE Transactions on Computational Intelligence and AI in Games 5.3 (2013), pp. 251-264. 
[102] Ni Yang et al. "Impact of flavour solvent on biscuit micro-structure as measured by $\mathrm{X}$-ray micro-computed tomography and the distribution of vanillin and HMF (HPLC)". In: European Food Research and Technology 235.6 (2012), pp. 1083-1091.

[103] Guoying Zhao. LBP implementation for MATLAB. http : / / www . cse . oulu.fi/CMV/Downloads/LBPMatlab.

[104] Jovisa Zunic and Paul L. Rosin. "A new convexity measure for polygons". In: IEEE Transactions on Pattern Analysis and Machine Intelligence 26.7 (2004), pp. 923-934. 